\title{
Dependence of soil microbial community structure and function on land use types and management regimes
}

\author{
Dis sertation \\ for the award of the degree \\ "Doctor rerum naturalium" \\ of the Georg-August-Universität Göttingen
}

within the doctoral program Microbiology \& Biochemistry

of the Georg-August University School of Science (GAUSS)

\author{
submitted by \\ Kristin Kaiser
}

from

Melsungen

Göttingen, 2016 


\section{Thesis Committee / Members of the Examination Board}

Prof. Dr. Rolf Daniel, Genomic and Applied Microbiology, Institute for Microbiology and Genetics, Georg-August-Universität Göttingen

PD Dr. Michael Hoppert, General Microbiology, Institute for Microbiology and Genetics, GeorgAugust-Universität Göttingen

Prof. Dr. Scheu, Animal Ecology, J.F. Blumenbach Institute for Zoology and Anthropology, Georg-August-Universität Göttingen

\section{Further members of the Examination Board}

Prof. Dr. Kai Heimel, Microbial Cell Biology, Institute for Microbiology and Genetics, Georg-August-Universität Göttingen

Prof. Dr. Stefan Vidal, Agricultural Entomology, Department for Cropsciences, GeorgAugust-Universität Göttingen

Prof. Dr. Stefanie Pöggeler, Genetics of Eucaryotic Microorganisms, Institute for Microbiology and Genetics, Georg-August-Universität Göttingen

Date of oral examination: 07.07.2016 
To my Mom, one of the strongest and most inspiring persons I know, and my Dad, for always believing in me. 


\section{TABLE OF CONTENTS}

I. SUMMARY ..............................................................................................................................9

II. GENERAL INTRODUCTION .................................................................................................. 13

II.1. THE SOIL HABITAT AND ITS MICROBIAL COMMUNITIES ..................................... 14

II.2. PLANT-ASSOCIATED MICROBIAL COMMUNITIES ........................................................ 15

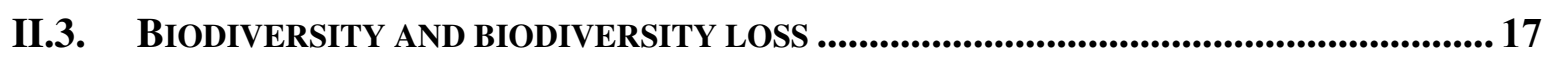

II.4. STUDY REGIONS AND FRAMEWORKS .................................................................. 19

II.4.1. The German Biodiversity Exploratories ........................................................ 19

II.4.2. The Grassland Management Experiment (GrassMan) ...................................... 23

II.4.3. The Vicia faba L. and Triticum aestivum L. Intercropping Experiment

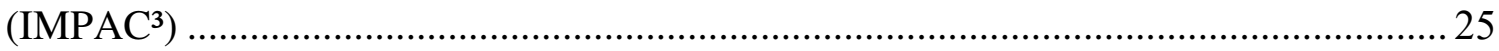

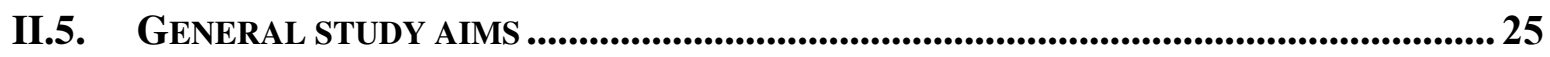

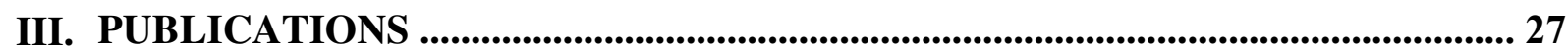

III.1. EFFECTS OF NUCLEIC EXTRACTION METHODS....................................... 29

Abstract........................................................ 31

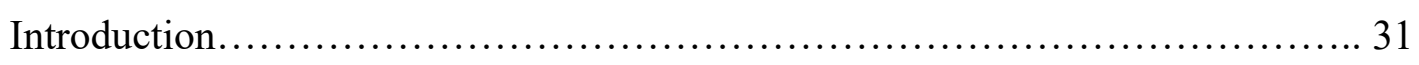

Materials and Methods................................................ 31

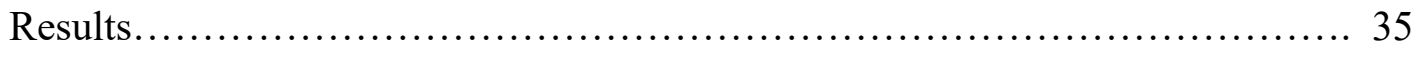

Discussion............................................................. 40

Acknowledgements.................................................. 41

References............................................................ 41

III.2. DRIVERS OF SOIL BACTERIA ....................................................................... 44

Abstract.......................................................... 46

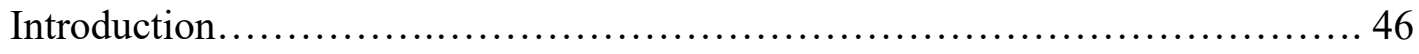

Results and Discussion................................................. 47

Conclusion.............................................................. 53

Materials and Methods............................................... 54

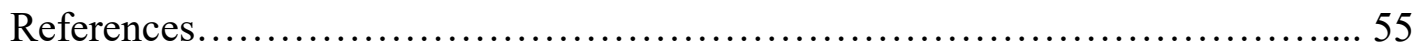

Acknowledgements............................................... 57 
III.3. TREE SPECIES EFFECTS ON SOIL MICROBIAL COMMUNITIES.............. 58

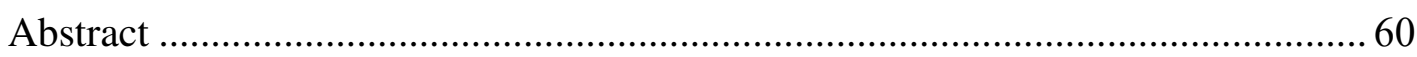

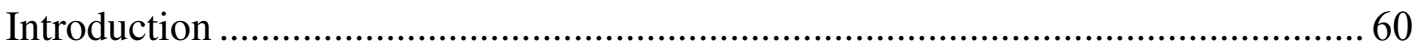

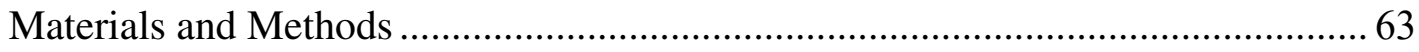

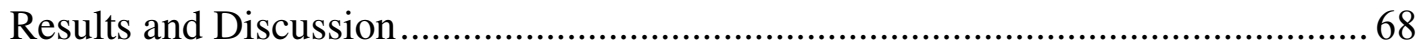

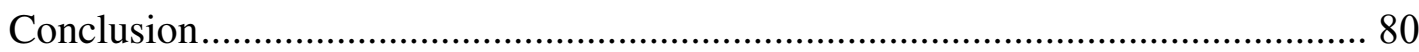

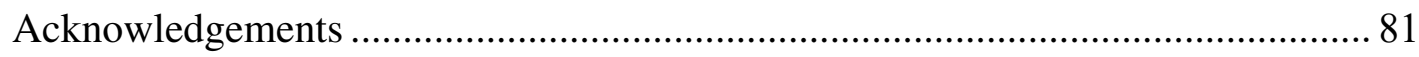

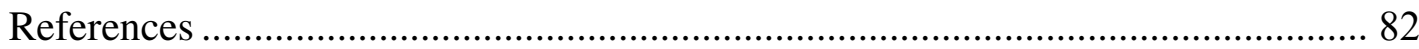

III.4. GROUP-SPECIFIC EFFECTS OF GRASSLAND LAND USE ON SADS ......... 94

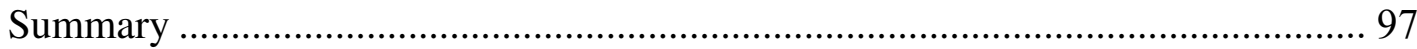

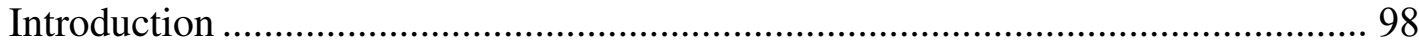

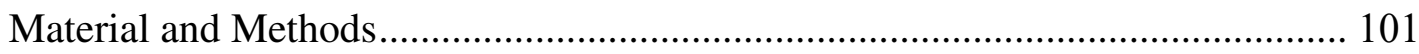

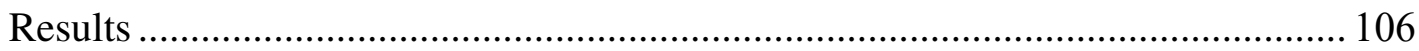

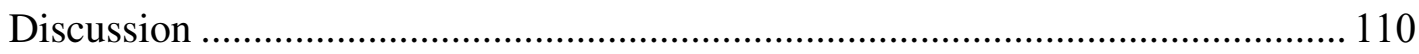

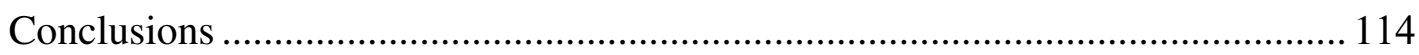

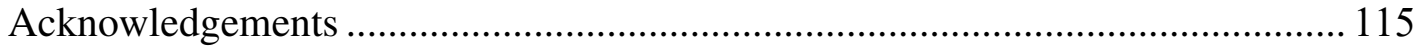

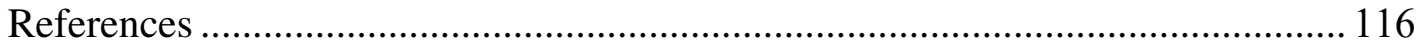

III.5. FOREST MANAGEMENT AND BIODIVERSITY ....................................... 122

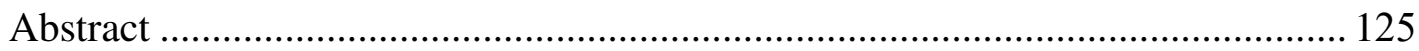

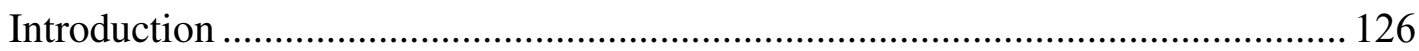

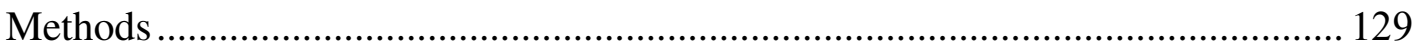

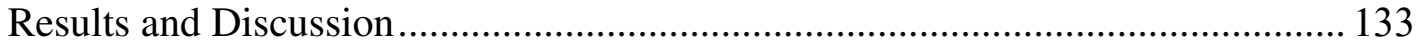

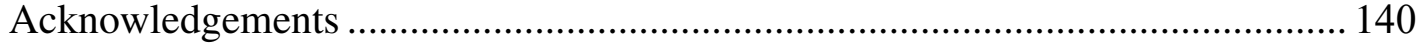

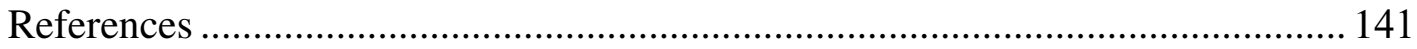

III.6. BACTERIAL ENDOPHYTES IN IMPORTANT GRASS SPECIES................. 146

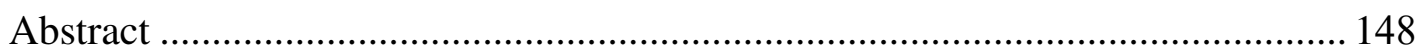

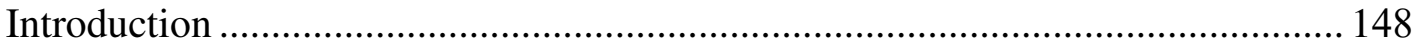

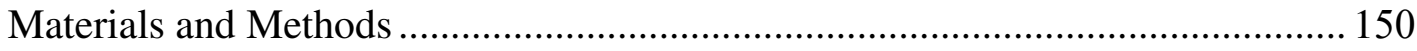

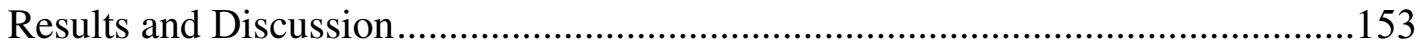


Conclusion 167

References 168

\section{III.7. SOIL ARCHAEAL COMMUNITIES UNDER DIFFERENT CROPPING}

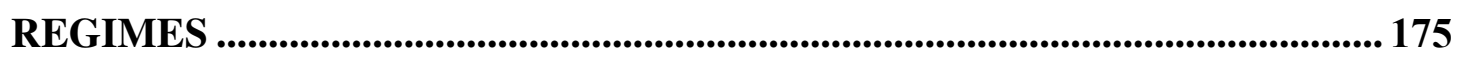

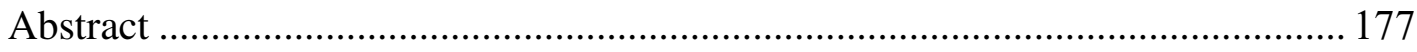

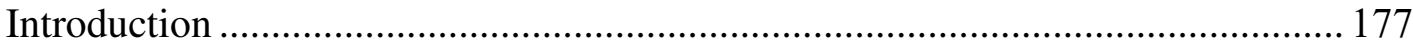

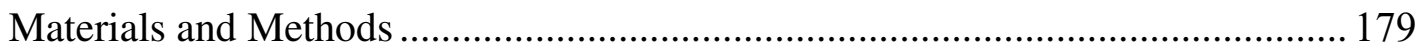

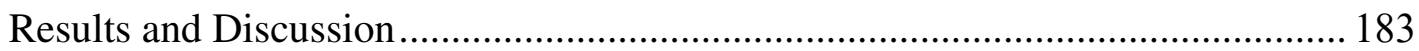

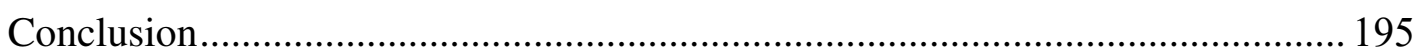

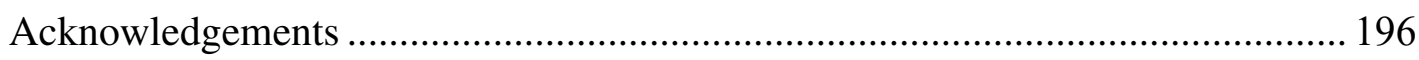

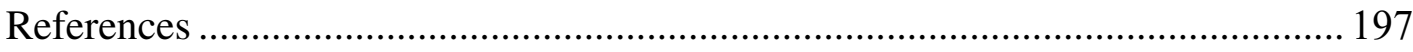

III.8. MICROBIAL COMMUNITIES UNDER CROPPING REGIMES.................. 204

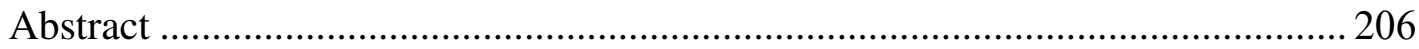

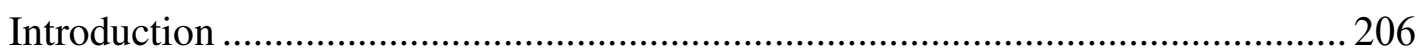

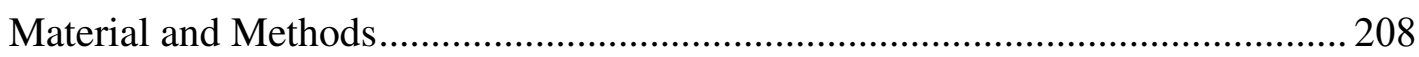

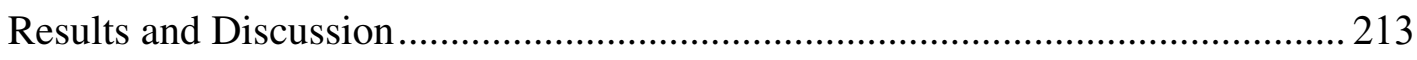

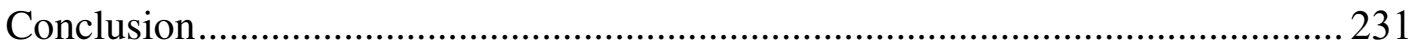

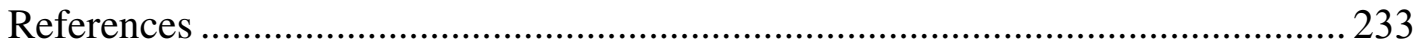

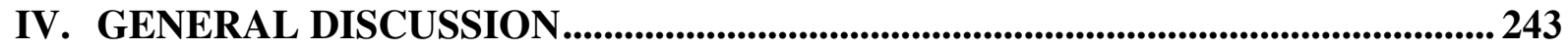

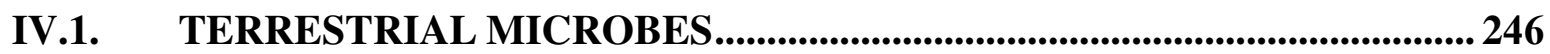

IV.1.1. Soil bacterial communities and their response to land use intensity .............. 246

IV.1.2. Soil bacterial communities in response to environmental parameters ........... 251

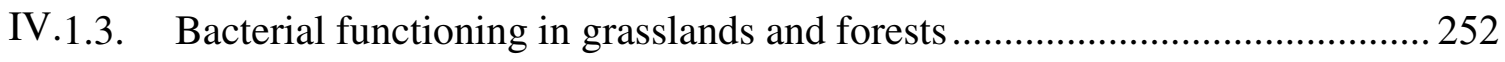

IV.2. PLANT-ASSOCIATED MICROBIAL COMMUNITIES ............................. 254

IV.3. CONCLUDING REMARKS AND OUTLOOK................................................................. 256

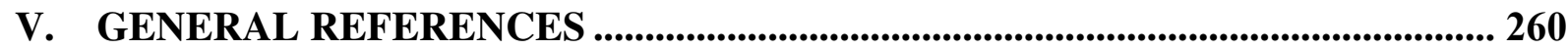

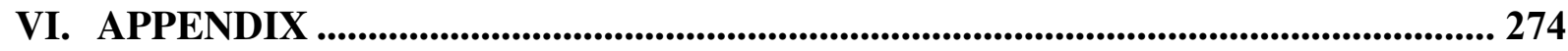

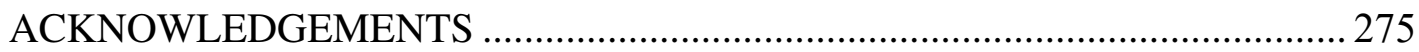

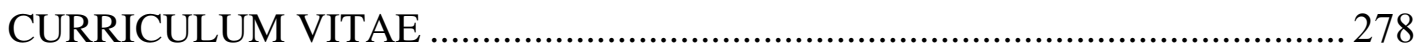




\section{TABLE OF CONTENTS}

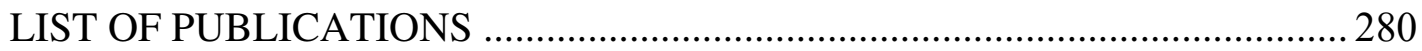

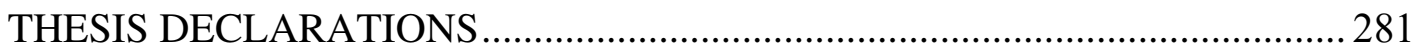


'Everything is a process. Always. Otherwise there wouldn't be science.'

Max Erhard 


\section{CHAPTER I}

SUMMARY 


\section{SUMMARY}

Soil microbial communities are the most diverse assemblages of organisms on earth. They play key roles in nutrient cycling and help prevent soil erosion. Soil microbial communities also harbor many potentially plant-associaed microorganisms. Plant-associated microbes inhabit the rhizosphere or phyllosphere, or live endophytic within plants. Despite the increasing number of studies on both soil and plant-associated microbial communities, the response of microbial communities towards land use intensification is still not fully understood. The aim of this thesis was to provide insights into the structure, diversity and function of soil and plant-associated microbial communities by amplicon-based analyses with regard to potential abiotic, biotic and anthropogenic drivers.

The first study investigated the effect of different nucleic acid extraction methods on the abundance and diversity of 16S rRNA genes and transcripts derived from different soils. Quality and yields of nucleic acids varied considerably between the different extraction methods applied, as well as between the different soils. Furthermore, abundances of dominant soil taxa varied by a factor up to ten by applying different extraction methods. Therefore, it is of high importance to choose an extraction method that is able to reproduce diversity and composition of the soil microbial community over a range of differing soils. This is crucial when soils from the entire study area should be compared, as they might differ in their properties.

The second study presented a large-scale analysis of soil bacterial communities in temperate grasslands and forests. Therefore, 300 samples were taken in May 2011 in a joint sampling campaign of the German Biodiversity Exploratory project. Metagenomic DNA was extracted and the V3-V5 regions of the bacterial 16S rRNA gene were amplified and pyrosequenced, to assess bacterial community structure and diversity. Additionally, a functional profile was predicted based on the taxonomic profile. The bacterial community structure was driven by edaphic properties with $\mathrm{pH}$ as the major driver while land use intensification represented by different management regimes exhibited only minor effects. However, tree species notably affected soil bacterial community structure, with distinct bacterial communities in soils beneath broadleaved and coniferous trees. Edaphic properties were significantly different between grassland and forest soils, resulting in distinct bacterial community structures. Biogeographic variation of edaphic properties also resulted in regional patterns of bacterial community structure. Bacterial diversity was additionally strongly dependent on soil $\mathrm{pH}$. Furthermore, the functional profile of the bacterial communities was 


\section{SUMMARY}

shaped by the same drivers as community structure and diversity. Because of the strong impact of soil $\mathrm{pH}$, genes involved in the acid tolerance response (ATR) were in the focus of the analyses of the functional profiles. Genes involved in alkali production, biofilm formation and attributed to two component systems were more abundant in profiles from low $\mathrm{pH}$ soils. The functional profiles of grassland and forests soils were significantly different. The investigation of different key enzyme-encoding genes involved in nutrient cycling revealed that certain functions are either more abundant in grassland (e.g. PAH degradation, alkaline phosphatase, urease, chitinase) or forests soils (e.g. acid phosphatase, methane oxidation, nitrous oxide-reductase, nitrogenase).

The third study investigated soil bacterial and fungal communities beneath beech and spruce trees, and their changes with increasing distance to the tree trunks, soil depth and season. Community structure was driven by edaphic properties ( $\mathrm{pH}$, clay content) and the tree species. Seasonal changes as well as depth-related changes were observed for community structure of both bacteria and fungi. Additionally, bacterial community structure and diversity was affected by the distance from the trunk beneath spruce trees.

The following two studies synthesized the effects of land use intensification on different taxonomic groups. The fourth study investigated species abundance distributions (SADs) of 10 aboveground and belowground taxonomic groups in grasslands under different management regimes. SADs are a powerful tool to investigate community changes, as they not only capture overall changes in community structure, but also indicate whether these changes are driven by abundant or rare species. Species richness was largely unaltered by increasing land use intensification. In addition, belowground organisms (bacteria and arbuscular mycorrhizal fungi) were not significantly affected by land use intensity. The fifth study analyzed the effects on biodiversity by management regimes (even-aged or uneven-aged forests) in European beech forests. Gamma-, beta-, and alpha-diversity of 15 taxonomic groups were analyzed. Gamma diversity of bacteria and fungi as well as of plant and animals was higher in even-aged forests than in uneven-aged forests. These differences were driven by a higher beta-diversity in even-aged forests.

The last three studies focused on plant-associated microbial communities. In the sixth study bacterial endophyte communities in three agriculturally important grasses (Lolium perenne, Festuca rubra and Dactylis glomerta) in response to fertilization and mowing in two subsequent years (2010 and 2011) were analyzed. Diversity was highest in D. glomerta, and community structure was significantly shaped by the host plants. Fertilization only affected 
endophytic community structure and diversity in 2010, while mowing had no effect in both years.

In studies seven and eight, a wheat/faba bean intercropping experiment investigated soil archaeal and soil and plant-associated bacterial and fungal communities, respectively. Soil archaeal but not bacterial or fungal community structure was affected by plant species and cropping regime. Bacterial and fungal community structure was similar in bulk soil and rhizosphere, and bacterial communities were distinct in the endosphere of roots and leaves. Fungal communities did not follow this trend.

In conclusion, soil microbial communities in soils are affected by edaphic properties. These effects most likely overrule effects of land use intensification. Plant-associated microbial assemblages are mainly shaped by the host plant and plant compartment. Nevertheless, agricultural management such as intercropping, alters archaeal community structure and therefore potentially affects microbial community structure on long-term basis. 
CHAPTER II

GENERAL INTRODUCTION 


\section{GENERAL INTRODUCTION}

Global ecology is currently challenged by the Anthropocene, the current, human-dominated time period (Corlett, 2015). Human influence on ecology is exhibited mainly by global warming, elevated $\mathrm{CO}_{2}$ from fossil fuel burning and massive agriculture, or land use intensification (Sikorski, 2015). While global warming and elevated $\mathrm{CO}_{2}$ may have positive effects on soil bacterial activity (Heimann and Reichstein, 2008; Karhu et al., 2014), and carbon and nitrogen fixation (He et al., 2014), the effects of land use intensification by means of fertilization have been shown to negatively affect soil microbial community structure and biomass (Ramirez et al., 2010, 2012). However, it has also been shown that neither plant invasion, vegetation clipping and nitrogen fertilization alter soil microbial community structure (Carey et al., 2015), while conventional versus organic farming results in distinct patterns of microbial communities (Hartmann et al., 2015). Therefore, anthropogenic effects on soil microbes are not yet completely unraveled. They have the potential to alter microbial community structure, diversity and function, and subsequently impact soil functioning and processes. A better understanding of microbial ecology in different systems with regard to land use intensification is essential to develop new strategies for sustainable land use and agricultural management in the future.

\section{II.1. The soil habitat and its microbial communities}

Soil as an ecosystem provides a wide range of important ecosystem services such as nutrient cycling, plant nutrition, bioremediation of pollutants, pest control and the regulation of greenhouse gases emission (Dominati et al., 2010). It is also a highly diverse habitat, physically as well as chemically. The soil matrix consists of mineral particles and organic matter, stabilized by the formation of aggregates with clay, silt and sand particles, the respective microbiota (Daniel, 2005) and air- and water-filled pores (Figure 1). The amount of clay, organic matter and soil moisture influences soil $\mathrm{pH}$. Basic cations from humic soil substances are eventually washed out and replaced by $\mathrm{H}^{+}$under humid conditions, resulting in acidification. This effect can be retarded by the presence of clay minerals. Additionally, the redox potential of a soil (presence and absence of electron acceptors such as $\mathrm{O}_{2}, \mathrm{NO}_{3}{ }^{-}$or $\mathrm{Mn}$ and $\mathrm{Fe}$ ) can vary strongly and affect metabolic pathways such as nitrogen fixation, denitrification and methanogenesis considerably (Paul, 2014). Therefore, it also impacts microorganisms, which are dependent on these pathways for growth. Soil-inhabiting microbial communities play an important role in the global nutrient cycles. They can 


\section{GENERAL INTRODUCTION}

contribute to the release of greenhouse gases, mineralization processes and decomposition, but can also promote plant growth. Soil conditions can change rapidly. A range of properties such as pH (Fierer and Jackson, 2006; Lauber et al., 2009), carbon and nitrogen concentrations (De Vries et al., 2012), and moisture (Brockett et al., 2012; Cruz-Martinez et al., 2009) are known to induce shifts in composition of soil microbial communities. Soil is by far the most diverse habitat with the largest community sizes of microorganisms (Daniel, 2005), with an estimate of $10^{8}$ cells per gram (Torsvik et al., 1990) and up to $8 \times 10^{6}$ species (Gans et al., 2005). This can be attributed to the extreme heterogeneity of soils (reviewed by Sikorski, 2015). Microorganisms from all three kingdoms of life - Bacteria, Archaea and Eucarya- are common and frequently found in soil (Goldmann et al., 2015; Herzog et al., 2015; Schneider et al., 2015). The structure of certain groups of microorganisms has been shown to directly control the rate of processes in soils (Bodelier et al., 2013; Strickland et al., 2009). Thus, they are of high ecological and economical importance.

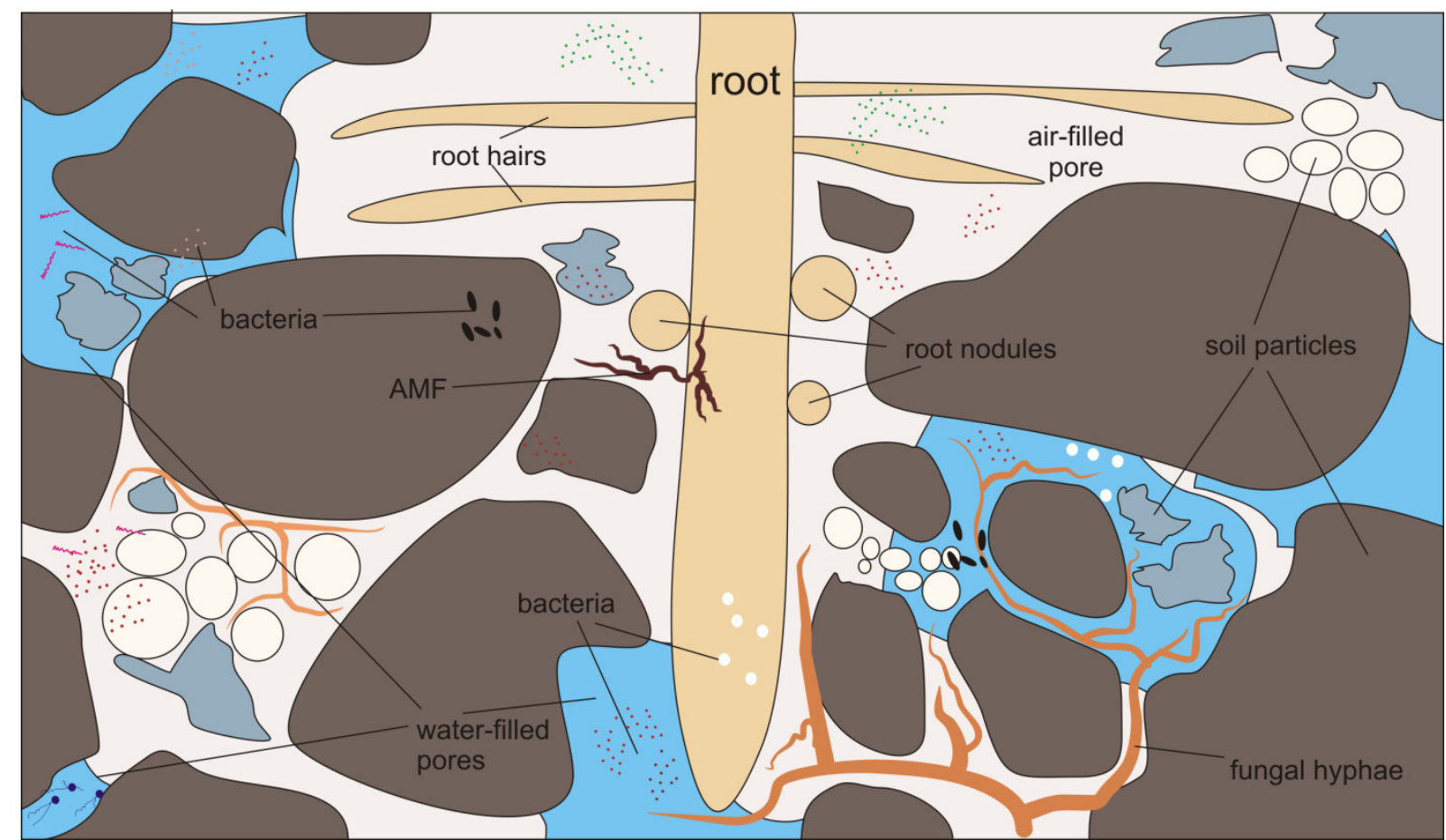

Figure 1. Generalized overview of the soil matrix with microbial habitats. The soil matrix forms by soil particles, air- and water filled pores and the respective microbiota (here bacteria and fungi; AMF: arbuscular mycorrhizal fungus). Microorganisms attach to soil particles, form biofilms on particle surfaces, or live freely in the available water films in pores and between and on the surface of soil particles. Plant roots provide additional habitats, as they can eventually be colonized by fungi and also bacteria.

\section{II.2. Plant-associated microbial communities}

Several members of the plant microbiota are known to be beneficial for their host by providing a variety of services. Bacteria promote plant growth by nitrogen fixation, phosphorus solubilization, and siderophore, phytohormone and auxin production. 
Additionally, bacteria are able to produce a variety of antimicrobial compounds and thereby contribute to biological pest control and protection against pathogens (reviewed in Bulgarelli et al., 2013).

Plants offer different habitats for microorganisms such as the phyllosphere, rhizosphere and endosphere. The phyllosphere summarizes the aboveground plant surfaces. Microorganisms inhabiting the phyllosphere are called epiphytes (Lindow and Brandl, 2003; Vorholt, 2012). The rhizosphere was defined as the zone around the roots influenced by plants (Hiltner, 1904). Since then, the definition of the rhizosphere has been modified and includes the rhizoplane or root surface (McNear Jr, 2013). Lastly, microorganisms are able to live within the plants. This habitat is known as the endosphere and its inhabitants are called endophytes. Some endophytes are symbionts, such as nitrogen-fixing bacteria, that live in root nodules and provide nitrogen comounds to their hosts (Figure 2).

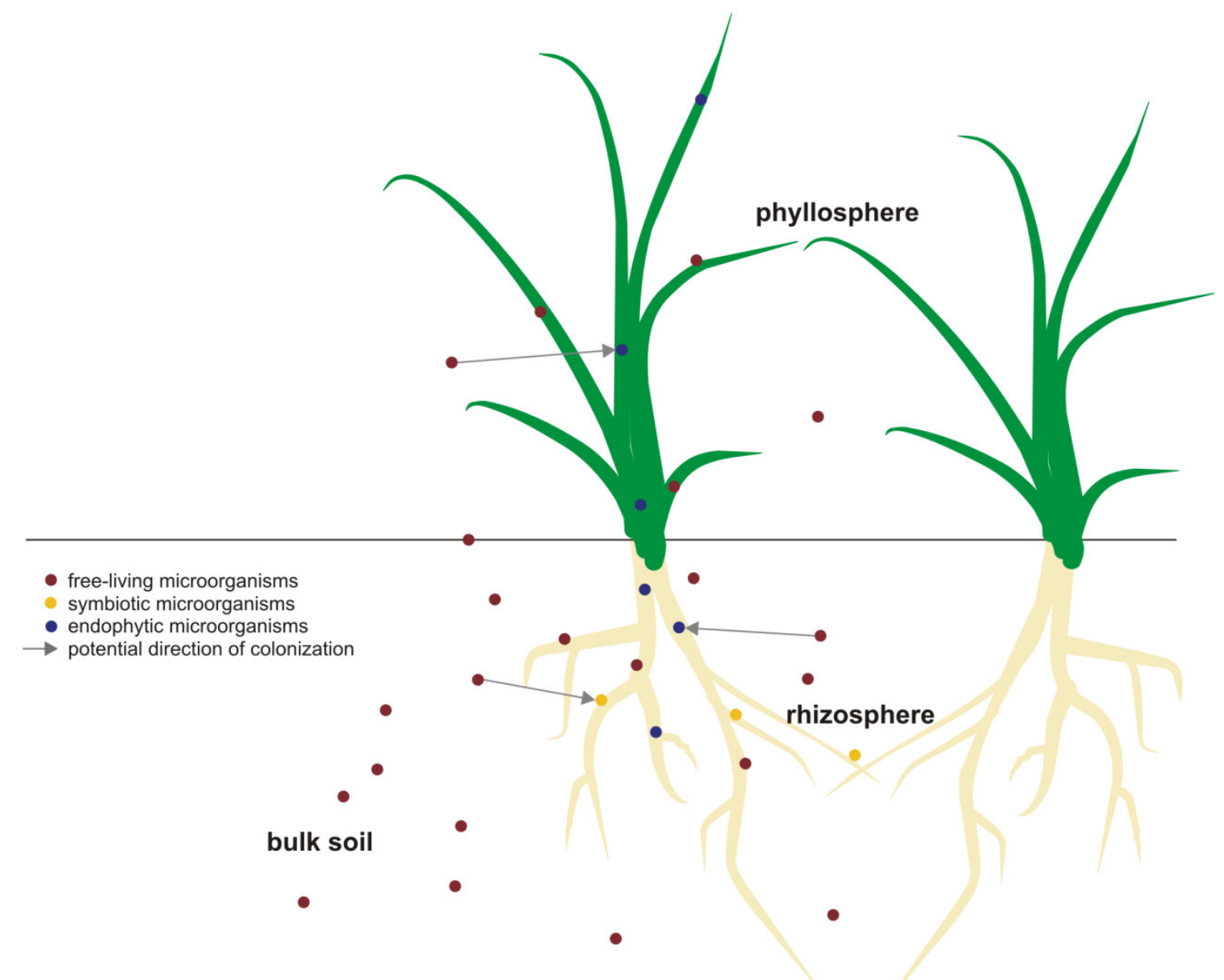

Figure 2. Microbial habitats provided by plants and different livestyles of plant-associated microorganisms. Grey arrows indicate potential directions of plant colonization by microorganisms, e.g. vio recreuitmeht from bulk soil and rhizosphere, or by plant wounding. 


\section{GENERAL INTRODUCTION}

Endophytes are by definition microorganisms that colonize the host tissue internally without damaging the host or causing symptoms of a disease (Hallmann et al., 1997). Plants are suitable habitats for microorganisms as they provide nutrients and offer protection from abiotic and biotic stresses (Kowalchuk et al., 2010). So far, endophytic microorganisms were found in all plants that have been investigated, including grasses (Wemheuer et al., 2016), pine tree roots (Marupakula et al., 2016), oilseed rape or tomato (Nejad and Johnson, 2000). Endophytes can also colonize all plant parts including fruits, seeds, leaves, stems, tubers and roots (Hallmann et al., 1997; Sturz et al., 1997). Many endophytic bacteria are able to penetrate and colonize root tissues (Quadt-Hallmann et al., 1997; Reinhold-Hurek and Hurek, 1998). Additionally, plant wounding by tillage, mowing or herbivores can result in microbes entering the plant (reviewed inSiddiqui and Shaukat, 2003; Figure 2).

Endophytic communities vary among plant genotypes, between stressed and unstressed plants (Sessitsch et al., 2002) as well as between developmental stages. They are dependent on the nutritional supply offered by their host plant (Hallmann et al., 1997). Abiotic factors such as soil parameters (altered by fertilizer and herbicide application) or crop rotation may also influence endophytic community composition (Fuentes-Ramírez et al., 1999; Seghers et al., 2004) by altering the physiological status of the plant.

Rhizospheric microbial communities are influenced by plant species and soil type (Berg and Smalla, 2009). Microorganisms in the rhizosphere benefit from root exudates, which include organic acids, amino acids and carbohydrates (Somers et al., 2004) and have the potential to acidify the soil in their immediate surroundings. Several bacteria are adapted to acidic soil conditions and evolved different mechanisms to cope with low $\mathrm{pH}$ (Cotter and Hill, 2003; Dilworth et al., 2001). Root exudates may also contain secondary metabolites such as salicylic acids, jasmonic acids and chitosans (Walker et al., 2003), which stimulate a defense response and thereby inhibit bacterial and fungal growth. The number of bacterial cells in the rhizosphere is also reported to be higher than in bulk soil (Gamalero et al., 2004; Watt et al., 2006). Additionally, bacterial communities in the rhizosphere differ from those in the corresponding bulk soil (Marilley et al., 1998). The factors that directly or indirectly influence plant-associated microbial communities are numerous. However, studies analyzing the whole microbial community present in the endosphere and soil comprising different agrosystems, management regimes or land use intensities are still missing.

\section{II.3. Biodiversity and biodiversity loss}

Biodiversity loss is a problem due to its direct and indirect links to ecosystem functioning. For example, an ecosystem function in which microorganisms play important key roles is nutrient 
cycling. Nutrient cycling is important for the ecosystem service of provisioning. We rely on provisioning, which can come from a variety of ecosystems, e.g. fish from fishery in aquatic and marine ecosystems and crops in agrosystems such as food, wood production systems in forests or fodder production systems in grasslands (Cardinale et al., 2012). Changes in ecosystem functioning can alter ecosystem services, which can have severe consequences for the world's population. This underlines the importance of biodiversity on human well-being. In their review on the impact of biodiversity loss on humanity, Cardinale et al. (2012) defined several ways how biodiversity loss may affect ecosystem functioning. They state that a high biodiversity supports biomass production, decomposition and recycling of nutrients as well as ecosystem stability, productiveness and multi-functionality.

The need for a thorough understanding of possible links between biodiversity, ecosystem functioning and services is evident. Human activity is known to negatively affect global biodiversity by means of different actions such as habitat conversion (forest to plantation), degradation (rainforest clear cutting) and fragmentation (highways), climate change, harvesting, and pollution (Tittensor et al., 2014). However, a major driver of biodiversity loss discussed in the past years is land use intensification (Newbold et al., 2015).

The most important land use systems in temperate zones, including Central Europe, are grasslands and forests. Both land use types occur under different management regimes along a gradient of land use intensification. In grasslands intensification occurs through fertilization, mowing and grazing in all possible combinations. In forest, the management mostly depends on the mode and interval of harvesting. In Europe, two management types are currently employed: (1) even-aged and (2) uneven-aged forests, opposed to the unmanaged forests protected as National Parks. Even-aged forests are generated by the traditional shelterwood system (Altersklassenwald). Here, a cohort of even-aged trees is replaced by a new cohort through repeated cutting over decades. The uneven-aged forests are a result of the alternative single tree selection system (Plenterwald), which is considered to be more 'close-to-nature' (Schall et al., Chapter III.5).

Newbold et al. (2015) presented a study on the effects of land use intensification on biodiversity. However, their datasets did not well represent the microbial biodiversity. Microorganisms are key players in many nutrient cycles and other ecosystem functions, and knowledge on their responses and possible adaptations towards increasing land use intensity would be important. To date, the mechanisms and extent of land use intensification influence on microbial communities and their diversity is rather limited. Since the arrival of the new millennium, several studies have focused possible effects of land use intensity on soil 


\section{GENERAL INTRODUCTION}

microbial communities in grasslands (e.g. Carey et al., 2015; Tardy et al., 2015) and forests (e.g. Hartmann et al., 2014; Urbanová et al., 2015). In the past few years, microbial ecologists began to explore the mechanisms of land use intensification on soil microbes by employing next-generation sequencing (NGS) techniques. These technologies allow the direct sequencing of metagenomic DNA and RNA (cDNA), and 16S/18S rRNA gene or other marker gene amplicons, to gain insights into microbial community composition, diversity and function. They have been employed successfully to analyze the structure of microbial communities of various environments such as water (Wemheuer et al., 2014), extreme habitats (e.g. Röske et al., 2014; Schneider et al., 2013; Simon et al., 2009), and soil (e.g. Nacke et al., 2011; Uroz et al., 2011; Will et al., 2010). Still, large comparative studies employing state-of-the-art technology are lacking. Such studies would be important to understand whether land use intensification in temperate systems as shown for organisms at higher taxonomic levels is a threat to soil microbial biodiversity or not.

\section{II.4. Study regions and frameworks}

\section{II.4.1. The German Biodiversity Exploratories}

The German Biodiversity Exploratories initiative is a large-scale, long-term project to study the feedback between land use, biodiversity, and ecosystem processes in real-world ecosystems (Fischer et al., 2010). They comprise a set of standardized field plots in three different regions of Germany covering different management types and intensities in grasslands and forests. The Exploratories serve as a joint research platform with over 300 researchers from 68 groups of 38 different institutions involved, who study various aspects of the relationships through monitoring, comparative observation and experiments (Fischer et al. 2010). To gain an understanding of the interactions between land use, biodiversity and ecosystem functioning, comparative and experimental studies are required at an appropriate spatial scale (Fischer et al. 2010). To allow general conclusions, studies also have to cover several regions, as different regions also differ in their landscape, resources, conditions, and soil properties. All these requirements are fulfilled by the structure of the German Biodiversity Exploratories. They are situated in three different regions of Germany: (1) the UNESCO Biosphere Reserve Schorfheide-Chorin in the lowlands of Northeast Germany (Figure 1A), a young glacial landscape with many wetlands, (2) the National Park Hainich and its surrounding area, the Dün region, situated in the hilly lands of Central Germany (Figure 1B), and (3) the UNESCO Biosphere Reserve Schwäbische Alb (Figure 1C), which is 
situated in the low mountain ranges of Southwest Germany (Fischer et al. 2010). The Exploratories not only feature a set of varying management regimes, but also cover different geographic and climatic conditions on a north-south gradient (Table 1). Land use intensity in the Exploratories ranges from low to high in both grasslands (meadows $<$ pastures $<$ mown pastures) and forests (unmanaged $<$ age class $<$ selection), which are either fertilized or nonfertilized in grasslands, and comprised of different tree species in forests (Table 1). In the past two years, the project reached the point where most initial data collections and data analyses from the first sampling campaign (2008) and also from the second campaign (2011) are finished. Now, data from the different contributing groups are available. These data enables syntheses approaches, which could provide information on how land-use intensity influences biodiversity on different trophic levels. This has been facilitated by the implementation of the land use intensity index (LUI), which is a measure for land use intensity in grasslands (Blüthgen et al., 2012) and the silvicultural management index (SMI), which describes land use intensity in forests (Schall and Ammer, 2013). In 2014, Allan and colleagues found that multidiversity is negatively related with land use intensity in grasslands.

However, the authors also found that interannual variation of land use intensity enhances multidiversity. Multidiversity integrated the species richness of 49 different organism groups ranging from bacteria to birds. Manning et al. (Manning et al., 2015) showed that management intensification in grasslands weakens associations between plant and animal taxa. Additionally, (Allan et al., 2015) analyzed the effects of land use intensification on ecosystem functionality. They found that biodiversity loss and changes in functional composition of communities altered several ecosystem services in grasslands. So far, comparable studies regarding forests are still missing. Furthermore, soil bacterial communities and diversity have so far only been analyzed on a limited number of plots. The general impact of land use intensity on soil bacterial communities at a large scale in different regions and different systems (grasslands and forests) is still largely unknown. 


\section{GENERAL INTRODUCTION}

Table 1: Geological features and number of plots per land use type for each of the three exploratories. Adapted from Fischer et al. (2010).

\begin{tabular}{|c|c|c|c|c|}
\hline & & \multicolumn{3}{|c|}{ Exploratory } \\
\hline & & Schorfheide-Chorin & Hainich-Dün & Schwäbische Alb \\
\hline Location & & north-eastern Germany & central germany & south-western Germany \\
\hline Size & & $\sim 1300 \mathrm{~km}^{2}$ & $\sim 1300 \mathrm{~km}^{2}$ & $\sim 422 \mathrm{~km}^{2}$ \\
\hline & & young glacial & calcareous & calcareous bedrock \\
\hline & & landscape & bedrock & with karst phenomena \\
\hline $\begin{array}{l}\text { Human population } \\
\text { density }\end{array}$ & & $23 \mathrm{~km}-1$ & 116 km-1 & $285 \mathrm{~km}-1$ \\
\hline Altitude a.s.l. & & $3-140 \mathrm{~m}$ & $285-550 \mathrm{~m}$ & $460-860 \mathrm{~m}$ \\
\hline $\begin{array}{l}\text { Annual mean } \\
\text { temperature }\end{array}$ & & $8-8.5^{\circ} \mathrm{C}$ & $6.5-8^{\circ} \mathrm{C}$ & $6-7^{\circ} \mathrm{C}$ \\
\hline \multirow{2}{*}{$\begin{array}{l}\text { Annual } \\
\text { precipitation }\end{array}$} & & $500-600 \mathrm{~mm}$ & $500-800 \mathrm{~mm}$ & $700-1000 \mathrm{~mm}$ \\
\hline & & \multicolumn{3}{|c|}{ Number of plots per land use type } \\
\hline grasslands & & 50 & 50 & 50 \\
\hline \multirow{2}{*}{ Meadows } & fertilized & 7 & 7 & 18 \\
\hline & non-fertilized & 11 & - & 4 \\
\hline \multirow{2}{*}{ Pastures } & fertilized & - & 2 & 2 \\
\hline & non-fertilized & 22 & 18 & 17 \\
\hline \multirow{2}{*}{ Mown pastures } & fertilized & 3 & 15 & 9 \\
\hline & non-fertilized & 7 & 8 & - \\
\hline forests & & 50 & 50 & 50 \\
\hline Unmanaged forest & & 5 & 13 & 5 \\
\hline \multirow{4}{*}{ Age-class forest } & beech & 16 & 24 & 33 \\
\hline & oak & 7 & - & - \\
\hline & spruce & - & 4 & 12 \\
\hline & pine & 22 & - & - \\
\hline Selection forest & & - & 9 & - \\
\hline
\end{tabular}




\section{GENERAL INTRODUCTION}

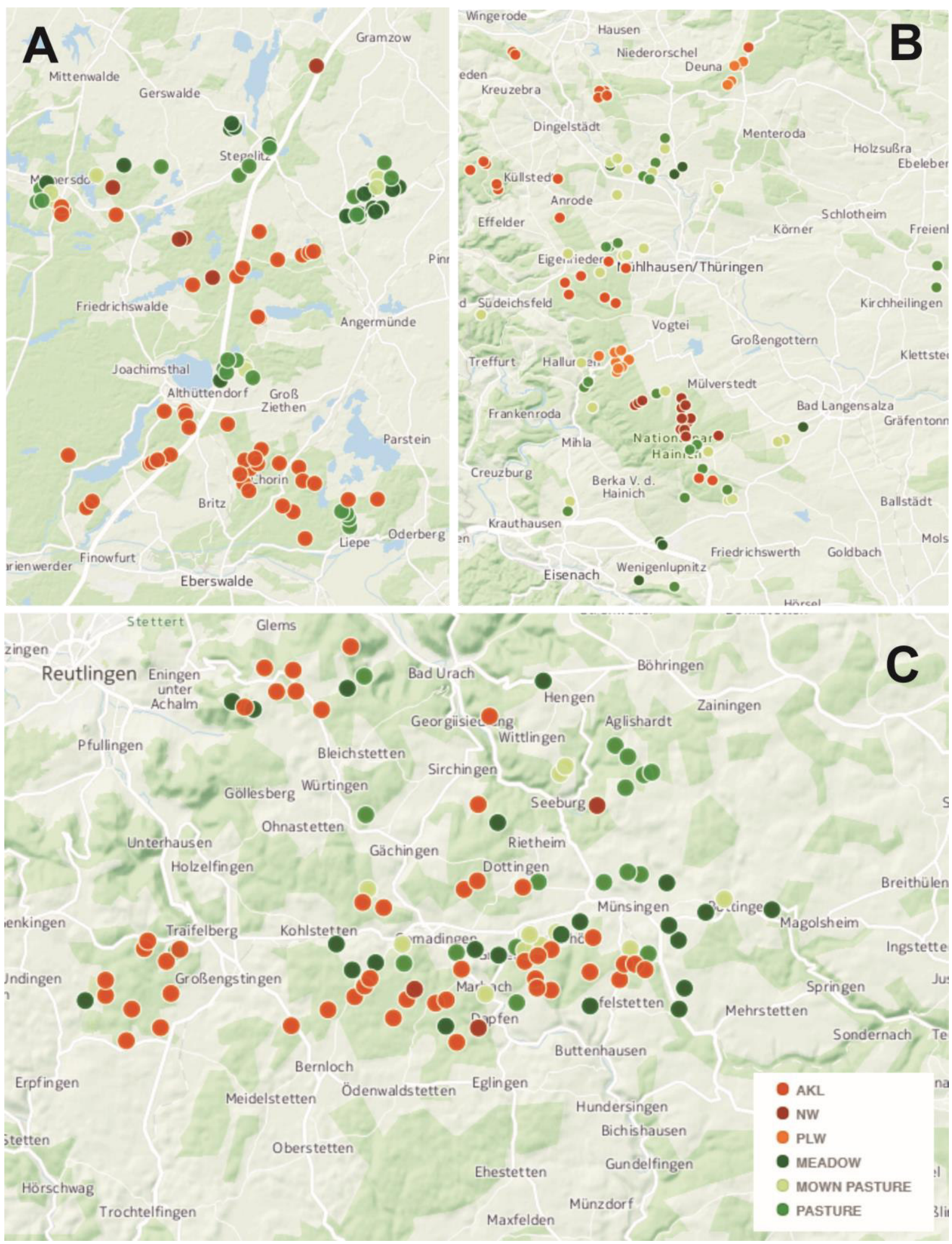

Figure 1: Maps of the three German Biodiversity Exploratories. (A) The Schorfheide-Chorin exploratory north of Eberswalde, Brandenburg, including the Biosphärenreservat. (B) The Hainich-Dün exploratory around Mühlhausen, Thuringia, including the Nationalpark Hainich. (C) The Schwäbische Alb exploratory, south-east of Reutlingen in Baden-Württemberg. Each dot is color coded by land use system (grasslands: green, forests: brown) and land use intensity (dark: low land use intensity, light: high land use intensity). The management regimes in forests are abbreviated as follows: AKL - age class forest, $\mathrm{NW}$ - unmanaged forest, PLW - selection forest. Complete map accessible at https://goo.gl/Ygmr04 


\section{GENERAL INTRODUCTION}

\section{II.4.2. The Grassland Management Experiment (GrassMan)}

The Grassland Management Experiment (GrassMan) has been established as a long-term field experiment with different management intensity treatments. Initiated in 2008 , it is a semi-natural, moderately species-rich grassland site in the Solling mountains in Lower Saxony, central Germany (5144'53" N, 9³2'43" E, $490 \mathrm{~m}$ a. s. 1.). This site has been traditionally used as an extensive pasture and meadow since the end of the 19th century (Petersen et al., 2012). According to Petersen et al. (2012), the number of plant species ranged from 13 to 17 in $9 \mathrm{~m}^{2}$ phytosociological relevés. The vegetation consists of a nutrient poor, moderately wet Lolio-Cynosuretum with high abundances of Agrostis capillaris L. and Festuca rubra L. (Petersen et al., 2012). The dominating soil type of the experimental area is a shallow (40-60 cm), stony Haplic Cambisol (Keuter et al., 2013) with a $\mathrm{pH}_{\mathrm{KCl}}$ ranging from 4.18 to 5.47 .

The full-factorial design of GrassMan includes two mowing frequencies (once per year in July vs. three cuttings in May, July, and September) and two fertilization treatments (none vs. NPK fertilization). The third factor aimed at varying plant diversity in the GrassMan plots. The three sward compositions (monocot-reduced, dicot-reduced, species-rich as control) were manipulated by selective herbicide applications targeting either dicots or monocots. One third of the plots remained untreated and was used as controls (speciesrich). Each treatment was replicated six times resulting in 72 plots of 15 x 15 m size. The experimental layout was a Latin rectangle design, arranged in 6 rows and 12 columns, two columns forming one block (Figure 2). The distance between rows and columns was $5 \mathrm{~m}$ and the distance within columns $3 \mathrm{~m}$. 


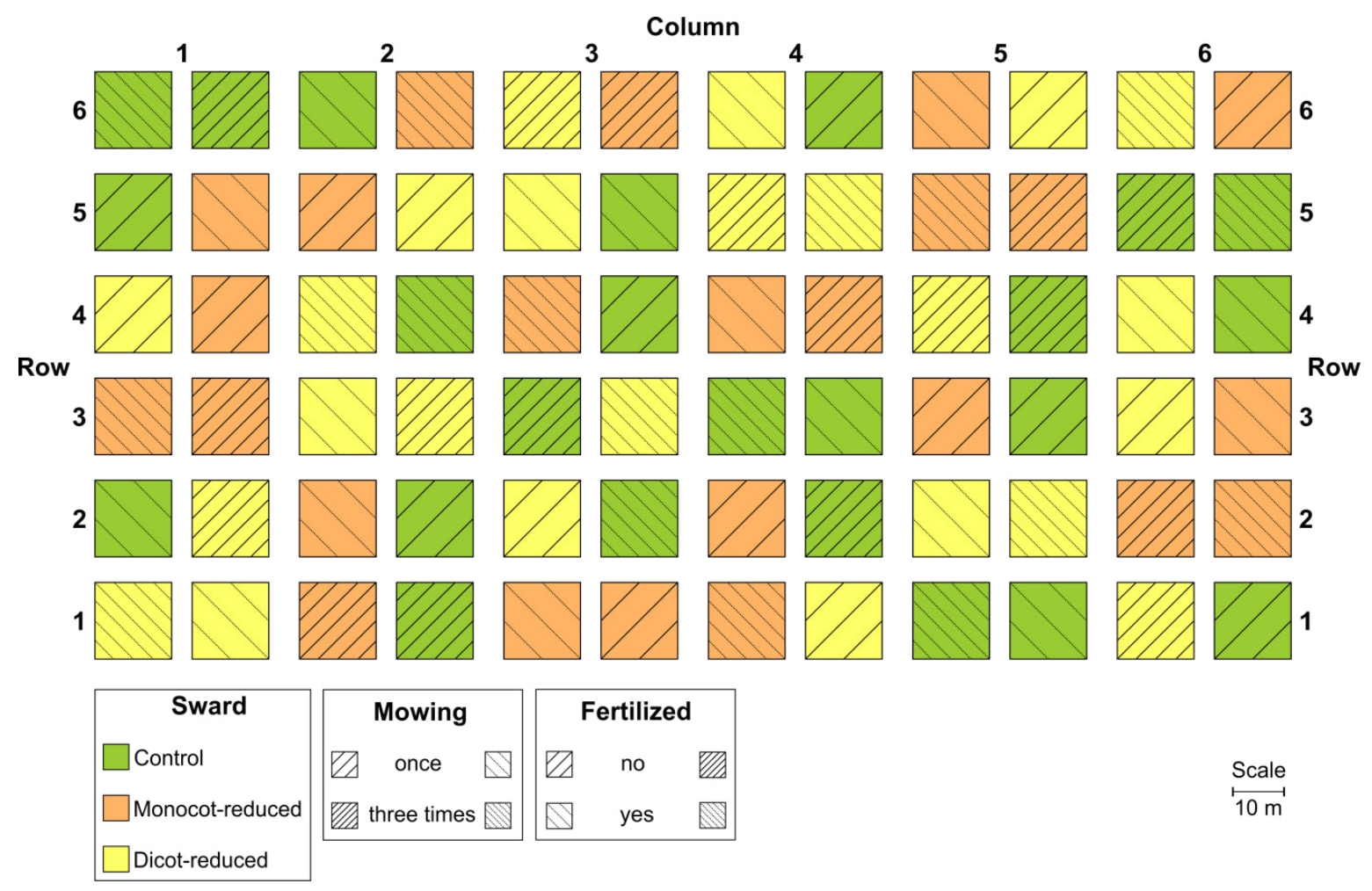

Figure 2: Experimental design of the GrassMan experimental field in the Solling Mountains in Lower Saxony, central Germany (51 $44^{\prime} 53^{\prime \prime}$ N, $9^{\circ} 32^{\prime} 43^{\prime \prime}$ E, $490 \mathrm{~m}$ a. s. 1.). The full-factorial design of this study included two mowing frequencies (mown once per year in July vs. three cuttings in May, July, and September), two fertilization treatments (no vs. NPK fertilization), and three different plant diversity levels (monocot-reduced, dicot-reduced, species-rich as control). The figure was taken from Wemheuer et al. (2016), after authorization from the author. 


\section{GENERAL INTRODUCTION}

\section{II.4.3. The Vicia faba L. and Triticum aestivum L. Intercropping Experiment (IMPAC ${ }^{3}$ )}

The IMPAC ${ }^{3}$ project investigates novel genotypes for mixed cropping in improved sustainable land use in arable land, grassland and forest. The overall aim is to combine agronomic, genetic, ecologic and social-economic research to gain a better understanding of the ecological functioning and societal acceptance of diversified farming systems. In 2003, Hof and Rauber found that of 344 intercropping cases $60 \%$ showed favorable mixing effects.

It is important that the intercrop components do not compete for identical ecological niches (Ofori and Stern, 1987). There is evidence that barley in intercropping mixtures has beneficial effects on the intercropping partners, or even outcompete monocultures with respect to biomass and grain yield (Rauber et al., 2000). An intercropping experiment was established for wheat and faba bean. Both species were grown in monocultures and in intercropping mixtures. The aim was to identify whether intercropping is beneficial for both plant species or not. Furthermore, the plant-associated microbial communities should be investigated for a detailed insight into the genotype versus environment interactions of the crop plants. Therefore, prokaryotic (Archaea and Bacteria) and eukaryotic (Fungi) microorganisms were analyzed belowground and aboveground.

\section{II.5. General study aims}

Nowadays, it is widely acknowledged that microbial communities play an essential role in global nutrient cycling and support ecosystem functioning. It is important to understand the factors that impact and control microbial community structure and function. Many studies have investigated the effects of environmental conditions such as $\mathrm{pH}$, water and nutrient content or soil texture on microbial community composition. Anthropogenic factors, such as land use and management have been studied to a lesser extent. There are also very few large-scale comparative studies investigating the drivers of microbial community composition.

To ensure comparability between the different studies, the first part of this thesis focused on identification of a nucleic acid extraction method that is applicable to a wide range of different soils and provides in addition a high quality of nucleic acids and a recovered diversity without biasing the community composition significantly (Chapter III.1). 
The main focus of this thesis was on anthropogenic effects on soil bacterial communities in grassland and forest systems under different managements in three different regions of Germany. The major aims were:

1. To investigate the influence of increasing land use intensity in grassland and forest systems on bacterial community composition, diversity and function. Therefore, 300 soil samples were taken in 2011 within the framework of the German Biodiversity Exploratories, comprising 150 grassland and 150 forest soil samples. The results are discussed in chapter III.2, III.4 and III.5.

2. To analyze changes in bacterial and fungal community composition with respect to tree species, samples were taken in 2013 and derived from spruce or beech forest plots. Four different distances to each tree were sampled in spring and autumn (Chapter III.3).

Additionally, this thesis investigated anthropogenic effects on plant-associated microbial communities. The aims of these analyses were:

3. To unravel the effect of three different perennial grasses (Dactylis glomerata L., Festuca rubra L. and Lolium perenne L.), fertilization and mowing on endophytic bacterial communities, discussed in Chapter III.6.

4. To elucidate how intercropping of faba bean (Vicia faba L.) and wheat (Triticum aestivum L.) changes the microbial community composition in soil and endosphere. The results are discussed in Chapter III.7. and III.8. 


\section{CHAPTER III}

PUBLICATIONS 
'One should look for what is, and not for what one thinks should be.'

Albert Einstein 
Chapter III.1.

EfFects of Nucleic Acid Extraction Methods 
III.1.

\section{Estimates of the bacterial ribosome content and diversity in soils are significantly affected by different nucleic acid extraction methods}

Running title: Effects of Nucleic Acid Extraction Methods

Pia K. Wüst ${ }^{1}$, Heiko Nacke ${ }^{2}$, Kristin Kaiser ${ }^{2}$, Sven Marhan ${ }^{3}$, Johannes Sikorski ${ }^{1}$, Ellen Kandeler ${ }^{3}$, Rolf Daniel ${ }^{2,4}$ and Jörg Overmann ${ }^{1}$

${ }^{1}$ Department of Microbial Ecology and Diversity Research, Leibniz-Institute DSMZ German Collection of Microorganisms and Cell Cultures, Braunschweig, Germany

${ }^{2}$ Department of Genomic and Applied Microbiology, Institute of Microbiology and Genetics, Georg-August University Göttingen, Göttingen, Germany

${ }^{3}$ Institute of Soil Science and Land Evaluation, Soil Biology Section, University of Hohenheim, Stuttgart, Germany

${ }^{4}$ Göttingen Genomics Laboratory, Institute of Microbiology and Genetics, GeorgAugust University Göttingen, Göttingen, Germany

Author's contribution:

I am a coauthor of this manuscript and conducted the DNA experiments and preliminary data analyses. I also commented on and discussed the manuscript with the other authors. 


\title{
Estimates of Soil Bacterial Ribosome Content and Diversity Are Significantly Affected by the Nucleic Acid Extraction Method Employed
}

\author{
Pia K. Wüst, ${ }^{a}$ Heiko Nacke, ${ }^{\mathbf{b}}$ Kristin Kaiser, ${ }^{\mathbf{b}}$ Sven Marhan, ${ }^{\mathrm{c}}$ Johannes Sikorski, ${ }^{\text {a }}$ Ellen Kandeler, ${ }^{\mathbf{c}}$ Rolf Daniel, ${ }^{\mathbf{b}, \mathbf{d}}$ Jörg Overmann ${ }^{\mathrm{a}}$ \\ Department of Microbial Ecology and Diversity Research, Leibniz Institute DSMZ-German Collection of Microorganisms and Cell Cultures, Braunschweig, Germanya; \\ Department of Genomic and Applied Microbiology, Institute of Microbiology and Genetics, Georg-August University Göttingen, Göttingen, Germany ${ }^{b}$; Institute of Soil \\ Science and Land Evaluation, Soil Biology Section, University of Hohenheim, Stuttgart, Germany; Göttingen Genomics Laboratory, Institute of Microbiology and Genetics, \\ Georg-August University Göttingen, Göttingen, Germany ${ }^{d}$
}

Modern sequencing technologies allow high-resolution analyses of total and potentially active soil microbial communities based on their DNA and RNA, respectively. In the present study, quantitative PCR and 454 pyrosequencing were used to evaluate the effects of different extraction methods on the abundance and diversity of $16 \mathrm{~S}$ rRNA genes and transcripts recovered from three different types of soils (leptosol, stagnosol, and gleysol). The quality and yield of nucleic acids varied considerably with respect to both the applied extraction method and the analyzed type of soil. The bacterial ribosome content (calculated as the ratio of $16 \mathrm{~S}$ rRNA transcripts to $16 \mathrm{~S}$ rRNA genes) can serve as an indicator of the potential activity of bacterial cells and differed by 2 orders of magnitude between nucleic acid extracts obtained by the various extraction methods. Depending on the extraction method, the relative abundances of dominant soil taxa, in particular Actinobacteria and Proteobacteria, varied by a factor of up to 10. Through this systematic approach, the present study allows guidelines to be deduced for the selection of the appropriate extraction protocol according to the specific soil properties, the nucleic acid of interest, and the target organisms.

oil is one of the most complex and diverse microbial habitats, with $1 \mathrm{~g}$ containing up to $10^{10}$ cells and $10^{4}$ bacterial species $(1$, 2). While DNA sequences provide information about the total microbial community, RNA can be used to analyze the fraction of microorganisms that has the capacity to actively synthesize proteins (3-5). The ratio of bacterial $16 \mathrm{~S}$ rRNA transcripts to $16 \mathrm{~S}$ rRNA gene copies has been used as an indicator of the potential specific activity since it reflects the cellular ribosome content (6, 7). However, nucleic acid extraction from soils is affected by insufficient cell lysis or losses during extraction, variable reproducibility, and various effects of soil $\mathrm{pH}$, clay content, and organic carbon content (8-13), and coextracted organic compounds can inhibit DNA polymerase and reverse transcriptase employed in downstream molecular analyses (14).

Direct nucleic acid extraction methods are based on the lysis of cells inside the soil matrix, whereas indirect methods commence with the isolation of bacterial cells from soil prior to nucleic acid extraction (8). Indirect methods typically yield longer nucleic acid fragments which are useful for metagenomic studies $(10,15)$ but often result in a significantly lower yield and diversity of nucleic acid molecules $(10,16)$. Existing protocols for the direct extraction of DNA and RNA from soils $(13,17-25)$ have partly been evaluated $(19,21,24,26-30)$, but only a few studies have compared extraction efficiencies of methods recovering both DNA and RNA $(21,24)$. In particular, these methods have so far not been compared with extraction protocols optimized for either DNA or RNA alone. Information about the effects of different extraction methods on the phylogenetic analysis is scant $(31,32)$. As a result, the implications of different extraction methods for estimates of potential bacterial activity or diversity in soils have remained largely unclear, but they are particularly relevant for studies of the interdependence of bacterial diversity, activity, and environmental parameters across physicochemically diverse soils $(33,34)$.

The present study employed quantitative PCR and pyrosequencing to evaluate the effects of different methods on the abundance and diversity of $16 \mathrm{~S}$ rRNA genes and transcripts extracted from three contrasting soils and to determine essential factors for a reliable extraction of nucleic acids. The soils selected are representative for humid temperate regions worldwide and differ with respect to soil development, grain size composition, and quantity and quality of organic matter, as well as nutrient budgets.

\section{MATERIALS AND METHODS}

Study sites. Samples were collected in April 2011 from the $A_{h}$ horizon (thickness between 5 and $10 \mathrm{~cm}$ ) of representative grassland plots (AEG31, HEG4, and SEG8) of the German Biodiversity Exploratories (35; http://www.biodiversity-exploratories.de) (Table 1). The three exploratories are located in the biosphere reserve Schorfheide-Chorin (Brandenburg, northeastern Germany), the national park Hainich and its surroundings in Thuringia (central Germany), and the biosphere reserve Swabian Alb in Baden-Wuerttemberg (southwestern Germany). Plant debris, coarse roots, and pebbles were removed and the soil was passed

Received 4 January 2016 Accepted 13 February 2016

Accepted manuscript posted online 19 February 2016

Citation Wüst PK, Nacke H, Kaiser K, Marhan S, Sikorski J, Kandeler E, Daniel R,

Overmann J. 2016. Estimates of soil bacterial ribosome content and diversity are significantly affected by the nucleic acid extraction method employed. Appl

Environ Microbiol 82:2595-2607. doi:10.1128/AEM.00019-16.

Editor: F. E. Löffer, University of Tennessee and Oak Ridge National Laboratory

Address correspondence to Jörg Overmann, joerg.overmann@dsmz.de.

Supplemental material for this article may be found at http://dx.doi.org/10.1128 /AEM.00019-16.

Copyright $\odot$ 2016, American Society for Microbiology. All Rights Reserved. 
TABLE 1 Origin and characteristics of topsoils sampled for nucleic acid analyses ${ }^{a}$

\begin{tabular}{|c|c|c|c|}
\hline Characteristic & AEG31 & HEG4 & SEG8 \\
\hline Location & $\begin{array}{l}\text { Swabian Alb, Baden-Wuerttemberg, } \\
\text { Germany }\end{array}$ & $\begin{array}{l}\text { Hainich, Thuringia, } \\
\text { Germany }\end{array}$ & $\begin{array}{l}\text { Schorfheide-Chorin, Brandenburg, } \\
\text { Germany }\end{array}$ \\
\hline Coordinates & $48^{\circ} 25^{\prime} 0.0^{\prime \prime} \mathrm{N}, 9^{\circ} 30^{\prime} 0.0^{\prime \prime} \mathrm{E}$ & $51^{\circ} 6^{\prime} 47.5^{\prime \prime} \mathrm{N}, 10^{\circ} 26^{\prime} 10.3^{\prime \prime} \mathrm{E}$ & $53^{\circ} 6^{\prime} 50.0^{\prime \prime} \mathrm{N}, 14^{\circ} 1^{\prime} 0.5^{\prime \prime} \mathrm{E}$ \\
\hline $\mathrm{pH}\left(\mathrm{H}_{2} \mathrm{O}\right)$ & 7.7 & 7.6 & 7.7 \\
\hline $\mathrm{pH}\left(10 \mathrm{mM} \mathrm{CaCl}_{2}\right)$ & 7.2 & 7.1 & 7.3 \\
\hline Water content $(\%, w t / w t)$ & 45.6 & 44.6 & 31.2 \\
\hline Soil type & Leptosol & Stagnosol & Gleysol \\
\hline Land use type & Mown pasture (sheep), unfertilized & $\begin{array}{l}\text { Mown pasture (cattle), } \\
\text { fertilized }\end{array}$ & Pasture, unfertilized \\
\hline Sand $(\%)$ & 2.4 & 6.7 & 13.8 \\
\hline Silt (\%) & 38.1 & 51.4 & 62.3 \\
\hline Clay $(\%)$ & 59.5 & 41.9 & 23.9 \\
\hline Total carbon $\left(\mathrm{g} \mathrm{kg}^{-1}\right)$ & 70.2 & 66.9 & 153.1 \\
\hline Total organic carbon $\left(\mathrm{g} \mathrm{kg}^{-1}\right)$ & 69.6 & 66.9 & 73.2 \\
\hline Total nitrogen $\left(\mathrm{g} \mathrm{kg}^{-1}\right)$ & 6.8 & 6.0 & 7.1 \\
\hline Soluble ammonium ( $\left.\mathrm{mg} \mathrm{kg}^{-1}\right)$ & 17.4 & 7.6 & 20.3 \\
\hline Soluble nitrate $\left(\mathrm{mg} \mathrm{kg}^{-1}\right)$ & 12.0 & 17.6 & 10.2 \\
\hline Total bacterial cells (g, wet wt ${ }^{-1}$ ) & $9.9 \times 10^{9}$ & $2.5 \times 10^{10}$ & $3.9 \times 10^{9}$ \\
\hline
\end{tabular}

${ }^{a}$ Values are the means from duplicate analyses. Data on soil texture, total carbon, total organic carbon, and total nitrogen are from reference 6 ; all other data were determined in the present study.

through a $2-\mathrm{mm}$ mesh sieve. Afterwards, samples were stored at $-80^{\circ} \mathrm{C}$. Total soil carbon, organic carbon, total nitrogen, soluble nitrate and ammonium, and bacterial cell numbers were determined as described previously (6). The three soils selected differed with respect to soil type, texture, and carbon and nutrient contents (Table 1). SEG8 exhibited a significantly darker color than the other soils due to a high content of organic substances. All soils had near neutral and comparable pHs (Table 1).

Extraction and purification of nucleic acids. The extraction methods comprised a similar number of commercial kits (methods 1, 2, 3a, and 3b; i.e., MoBio a, MoBio b, MP, and MP) and custom protocols (methods 4, $5,6,7,8$; i.e., Lueders, Persoh, Petric $a$, Petric $b$, and Töwe) to assess under which conditions the more time-saving commercial kits can be applied. Also, the methods differed with respect to cell lysis conditions and subsequent purification steps in order to cover the major types of chemical treatments (Table 2). All selected extraction methods include a bead beating step for mechanical cell lysis, since this procedure represents the most efficient lysis method for soils $(10,36)$. In contrast to the other methods tested, the method Persoh (no. 5) includes three consecutive bead beating steps and precipitation of organic compounds by $\mathrm{Al}_{2}\left(\mathrm{SO}_{4}\right)_{3}$ and $\mathrm{NaOH}$ before lysis. Four of the protocols (methods 2, 4, 5, and 8; i.e., MoBio $b$, Lueders, Persoh, and Töwe) have been developed for the coextraction of DNA and RNA using phenol-chloroform-isoamyl alcohol (PCI). International Organization for Standardization (ISO) standard 11063 is based on the method published by Martin-Laurent et al. (27), was approved by the ISO, and was tested without (method Petric $a$, no. 6) or with (method Petric $b$, no. 7) subsequent purification steps (22). Each extraction protocol was tested in three technical replicates for each soil sample.

Coextracted DNA and RNA were subsequently separated using either a commercially available kit or enzymatic digestion (Fig. 1). In one approach, $50 \%$ of the volume of each individual coextract was used to separate DNA and RNA by the AllPrep DNA/RNA minikit (Qiagen, Hilden, Germany) using a modified protocol. After addition of 3.5 volumes of buffer RLT Plus (Qiagen) to the coextract, we proceeded with step 4 of the protocol (transfer of the diluted coextract to the DNA spin column). In an alternative and parallel approach, $25 \%$ of the volume of the coextract was used to obtain DNA by digestion of coextracted RNA with RNase A (DNase free; Fermentas, St. Leon-Rot, Germany) and subsequent precipitation with 0.1 volume of $3 \mathrm{M}$ sodium acetate $(\mathrm{pH} 6.8)$ plus 2 volumes of isopropanol. The remaining $25 \%$ of the coextract was treated with DNase
I (RNase free; Fermentas), and RNA was precipitated with 0.1 volume of 3 $\mathrm{M}$ sodium acetate ( $\mathrm{pH}$ 5.2) and 2 volumes of isopropanol.

Quantification of DNA and RNA. Concentrations of DNA and RNA were determined in duplicate using the Quant-iT PicoGreen doublestranded DNA (dsDNA) assay kit and the Quant-iT RiboGreen RNA assay kit (Life Technologies, Darmstadt, Germany), respectively, and a microtiter plate reader (Tecan Infinite M200; Männedorf, Switzerland). Values were corrected for background fluorescence. The quality of nucleic acids was checked via UV-visible (UV-Vis) spectroscopy (NanoDrop ND1000; Peqlab Biotechnologie, Erlangen, Germany) based on the $A_{260} / A_{280}$ and $A_{260} / A_{230}$ ratios and the absorbance at $320 \mathrm{~nm}$ (65). Nucleic acid extracts from environmental samples with an $A_{260} / A_{280}$ ratio above 1.75 and an $A_{260} / A_{230}$ value above 1.65 were considered pure (21).

Reverse transcription-PCR. RNA extracts were treated with Ribo-

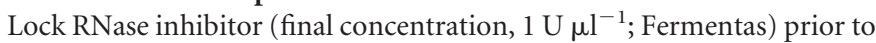
reverse transcription-PCR. For synthesis of cDNA from extracted RNA, the GoScript reverse transcription system was employed according to the protocol of the manufacturer (Promega, Madison, WI) using random hexamers.

qPCRs. Quantitative PCRs (qPCRs) were run in three (Acidobacteriaspecific assay) or four (Bacteria-specific assay) replicates employing a LightCycler 480 II real-time PCR instrument (Roche, Mannheim, Germany). Bacterial and acidobacterial 16S rRNA genes and transcripts were determined using primer sets $341 \mathrm{f}$ and $515 \mathrm{r}$ (Bacteria-specific assay) and Acido31f and 341r (Acidobacteria-specific assay), respectively (see Table $\mathrm{S} 14$ in the supplemental material). The PCR mixture $(20 \mu \mathrm{l})$ contained 10 $\mu \mathrm{l}$ of LightCycler 480 SYBR green I Mastermix (Roche), $0.4 \mathrm{mg} \mathrm{ml}^{-1}$ of bovine serum albumin (BSA; Roche), $0.3 \mu \mathrm{M}$ each primer, and genomic DNA and cDNA, respectively, as the template. For calibration, almost full-length 16S rRNA gene fragments of Edaphobacter modestus DSM $18101^{\mathrm{T}}$ were employed at concentrations between 10 and $10^{9}$ copies per reaction. Sample DNA and cDNA were diluted to concentrations that yielded values in the linear range of the standard curves (6). Melting curve analysis was conducted after each run to verify product specificity. Copy numbers were calculated according to reference 37 . The absence of residual DNA in RNA extracts was checked employing RNA extracts directly as the template in parallel qPCR runs. Inhibition of qPCR by coextracted inhibitory compounds was quantified by spiking DNA extracts with a defined copy number of $16 \mathrm{~S}$ rRNA gene fragments of E. modestus DSM 


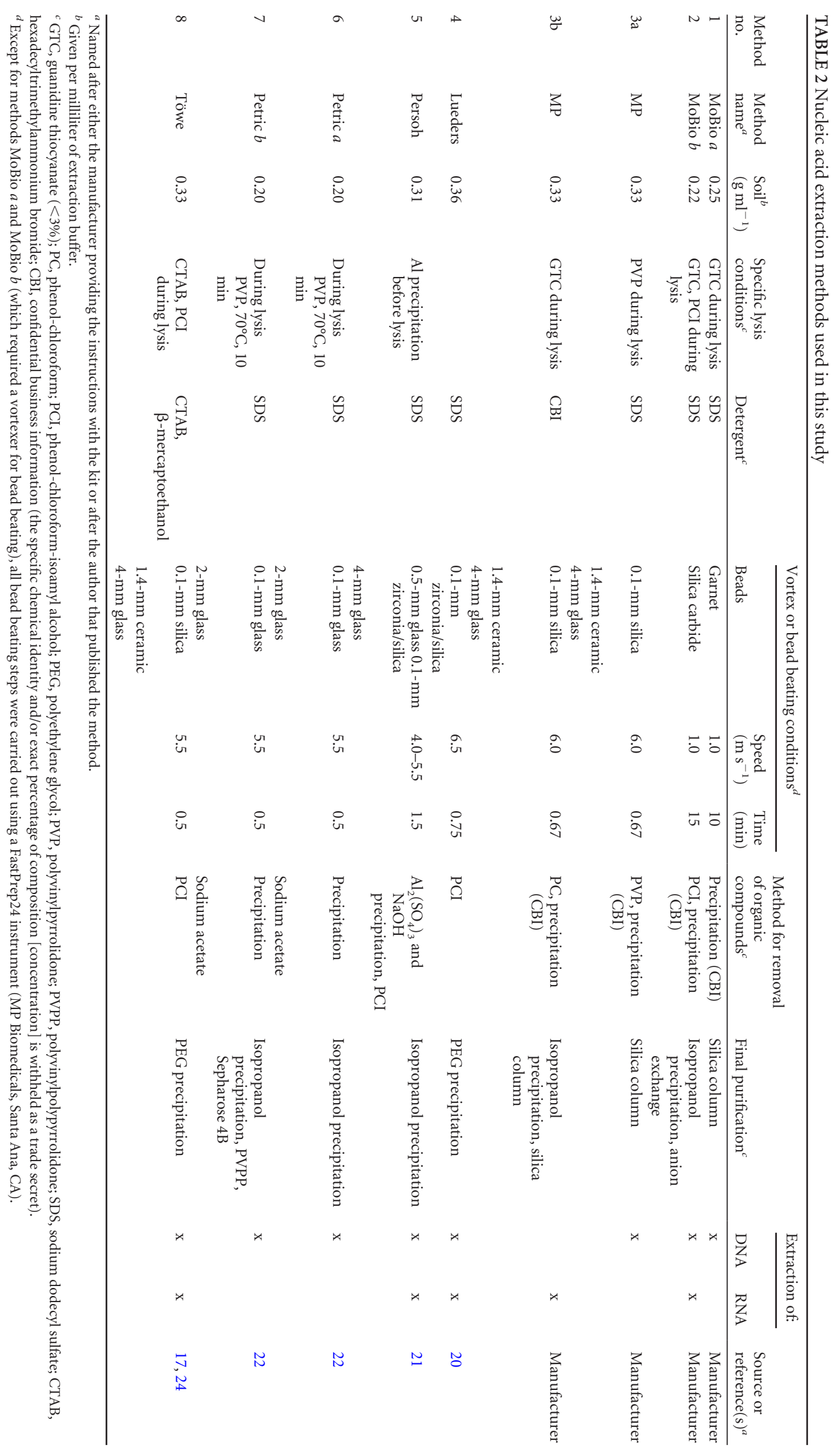




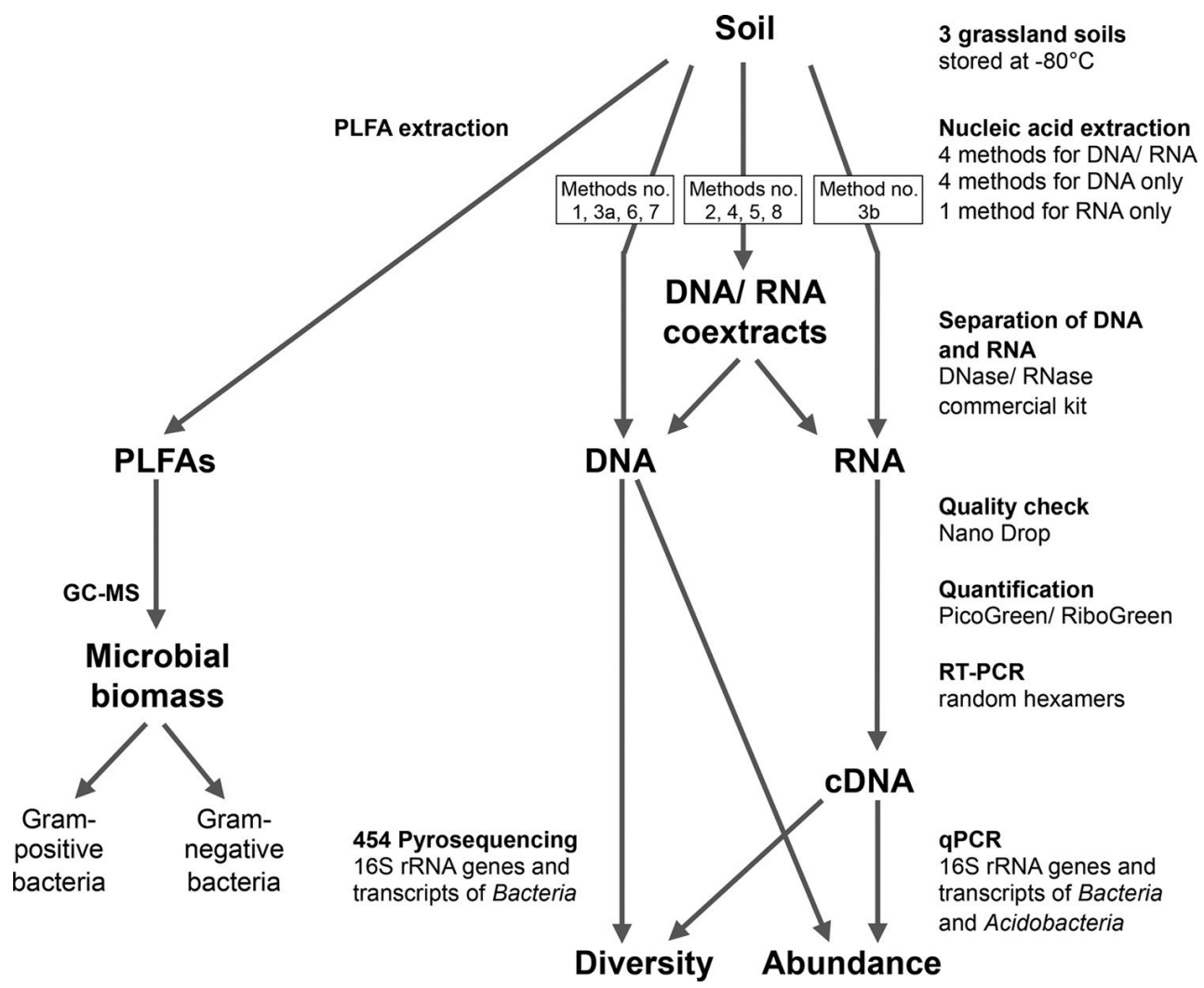

FIG 1 Methodological approach. Detailed information about the individual extraction methods is provided in Table 2.

$18101^{\mathrm{T}}$. Inhibition factors were calculated by determining the ratio of the expected to the measured copy number.

Amplification of partial 16S rRNA genes and transcripts for pyrosequencing. DNA extracts from replicate extractions were pooled at equal amounts. Likewise, RNA extracts were pooled and used for cDNA synthesis. The V2-V3 region of $16 \mathrm{~S}$ rRNA genes and transcript cDNA was amplified by PCR using genomic DNA and cDNA, respectively (Fig. 1). The PCR mixture $(50 \mu \mathrm{l})$ contained $10 \mu \mathrm{l}$ of 5 -fold reaction buffer (Phusion HF buffer, Finnzymes, Espoo, Finland), $200 \mu \mathrm{M}$ each of the four deoxynucleoside triphosphates, $5 \%$ (vol/ $/ \mathrm{vol}$ ) dimethyl sulfoxide (DMSO), 0.5 $\mathrm{U}$ of Phusion Hot Start high-fidelity DNA polymerase (Finnzymes), 10 to $200 \mathrm{ng}$ of DNA as the template, and $4 \mu \mathrm{M}$ each primer. Primer $101 \mathrm{f}$ containing Roche 454 pyrosequencing adaptor B and primer 530r containing a sample-specific MID (extended multiplex identifier; size, 10 nucleotides) together with Roche 454 pyrosequencing adaptor A were used for amplification (see Table S14). All samples were amplified in triplicate (PTC-200 cycler; MJ Research Inc., Watertown, MA), purified using the peqGold gel extraction kit (Peqlab Biotechnologie GmbH) as recommended by the manufacturer, and pooled at equal amounts. Quantification of PCR products was performed using the Quant-iT dsDNA BR assay kit and a Qubit fluorometer (Life Technologies). Sequences of the partial $16 \mathrm{~S}$ rRNA genes and transcript cDNA were determined with a GS-FLX 454 pyrosequencer (Roche) and titanium chemistry as recommended by the manufacturer.

Analysis of the pyrosequencing-derived data set. The generated sequences were reassigned to single samples based on the unique MIDs. The QIIME (38) script split_libraries.py was applied to remove sequences shorter than $200 \mathrm{bp}$ and sequences containing long homopolymers $(>8$ $\mathrm{bp}$ ) or more than two primer mismatches. Subsequently, denoising was performed by applying the scripts denoise_wrapper.py and inflate_denoiser.py. Primer sequences remaining after running the script split_libraries.py were truncated via the program cutadapt (39). Removal of chi- meras was performed by using the UCHIME program (40) and the Greengenes gold database (41) as references.

For the determination of operational taxonomic units (OTUs), we defined species and phylum level at 3 and 20\% genetic distances, respectively (42). Determination of OTUs, taxonomic classification of OTUs, and the calculations of rarefaction curves, the Shannon index (43) and the Chaol index (44) for each preprocessed data set, were performed using the QIIME 1.4 software package. Employing the QIIME script assign_taxonomy.py, preprocessed sequences were compared to the SILVA rRNA database (release 108) (45) using BLASTN. After termination of the QIIME script make_otu_table.py, a customized script was used to remove all OTUs from the OTU table that had been classified as chloroplasts. For subsequent comparative diversity analyses, the sizes of all data sets were adjusted to the same size of 6,300 sequences per DNA and RNA extract (i.e., the minimum number of available sequences that was obtained in the DNA extract of method Persoh for sample HEG4; see Table S3). These subsets of sequences were generated randomly, employing the QIIME script multiple_rarefactions.py (http://qiime.org/scripts/multiple _rarefactions.html).

Statistical analysis and graphic presentation. Statistical analysis was conducted in $\mathrm{R}$ (version 3.2.2 [http://www.R-project.org]). The twosided sign test was performed using the binom.test() function with default parameters in order to assess the systematic deviation between different DNA or RNA removal methods. The two-sample $t$ test was performed using the t.test $($ ) function with default parameters in order to test whether the variance among replicates obtained with commercial kits differed significantly from those of noncommercial methods. The multcomp analysis $(46,47)$ identified significant differences of means between any pairs of data within a multiple-group comparison (all-against-all), is suited for unequal group variances, and simultaneously controls the familywise error rate. The package vegan (48) was employed for multivariate statistical analyses. A detrended correspondence analysis of abundance data re- 
vealed gradient lengths of $<2$, indicating that methods optimal for linear environmental gradients (such as principal-component analyses [PCA]) are suitable for the data set (49). The effects of different extraction methods and different soil samples on nucleic acid quality parameters and on phylogenetic composition were analyzed separately for DNA and RNA extractions using PCA. Data were subjected to z-transformation ( $[x-$ mean] [standard deviation] ${ }^{-1}$ ). To analyze the effect of extraction methods on different phyla, the values obtained with all extraction methods were scaled separately by z-score transformation for each (sub)phylumsoil combination $($ mean $=0$; standard deviation $=1$ ). Thereby, the large differences in the order of magnitude of quality parameters or of abundances of different (sub)phyla were removed. As the z-score transformation was done separately for each soil, inherent differences in relative abundances of phyla across soils were also removed. In sum, only differences due to the different nucleic acid extraction methods were retained and subjected to PCA analysis. The envfit() function was used to fit soil parameters post hoc to the first two axes of the unconstrained PCA analysis. The $\mathrm{R}$ code used for statistical analysis is provided in the supplemental material. The ggplot2 package (50) was used for creation of figures.

PLFA analysis. For analysis of phospholipid fatty acids (PLFAs) (Fig. 1), 2 to $4 \mathrm{~g}$ of fresh soil samples was extracted following the procedure described by Frostegård et al. (51). Lipids were extracted with the Bligh and Dyer method (chloroform, methanol, and citrate buffer, 1:2:0.8 [ vol/ $\mathrm{vol} / \mathrm{vol}] ; \mathrm{pH} 4$ ) and fractionated via silica acid columns. The PLFA fraction was then subjected to alkaline methanolysis, using methylnondecanoate (19:0) as an internal standard. The generated fatty acid methyl esters (FAMEs) were identified based on their retention times employing a gas chromatography (GC) Auto System XL (PerkinElmer Corporation, St. Louis, Norwalk, CT) equipped with an HP- 5 capillary column ( $50 \mathrm{~m}$ by $0.2-\mathrm{mm}$ inner diameter; film thickness, $0.33 \mu \mathrm{m}$ ). To verify correct identification of FAMEs, standardized soil samples were analyzed by GC-mass spectrometry (GC-MS) with an HP 5890 series II coupled with a 5972 mass selective detector and equipped with a DB-5MS capillary column (30 $\mathrm{m}$ by $0.25-\mathrm{mm}$ inner diameter; film thickness, $0.2 \mu \mathrm{m}$ ) (52). Bacterial biomass was estimated from the sum of i15:0, a15:0, 15:0, i16:0, 16:1 $1 \omega 7$, i17:0, cy17:0, and cy19:0 (51, 53). The PLFAs i15:0, a15:0, i16:0, and i17:0 are indicative of Gram-positive bacteria, whereas cy17:0 and cy19:0 are characteristic of Gram-negative bacteria. The PLFA 18:2 $\omega 6,9$ was used as a marker for fungal biomass.

Nucleotide sequence accession number. The sequences obtained in this study are available from the National Center for Biotechnology Information (NCBI) Sequence Read Archive under accession number SRA058915.

\section{RESULTS}

Yield and purity of extracted nucleic acids. DNA was extracted by eight and RNA by five different extraction methods (Table 2). All methods were successful for the extraction of DNA and RNA from soils HEG4 and SEG8. However, method Töwe (no. 8) reproducibly failed to extract DNA from the clay-rich soil AEG31 (Fig. 2). For the methods that extracted DNA and RNA simultaneously (methods 4, 5, and 8), we tested two different approaches for the subsequent separation of RNA and DNA (treatments with DNase and RNase or the commercial AllPrep DNA/RNA minikit; Fig. 1). Eighteen different combinations of type of nucleic acid, extraction method, and type of soil were tested (see Table S1 in the supplemental material), but none of the two methods resulted in systematically higher yields of DNA or RNA (sign test; $P>0.05$ ). Therefore, DNA and RNA derived from enzymatic digestion of coextracts were selected for the following comparative analyses.

Yields of DNA and RNA differed by up to 2 and 3 orders of magnitude, respectively, depending on both the applied extraction method and the analyzed soil (Fig. 2). DNA yields ranged between 0.3 and $38.1 \mu \mathrm{g}$ of DNA (g [wet weight ${ }^{-1}$ ) (Fig. 2A) and differed for the same soil sample by factors of 33, 65, and 107 (AEG31, HEG4, and SEG8, respectively) between the eight methods. The largest amounts of DNA were detected using the methods published by Lueders et al. (20) (no. 4) and Persoh et al. (21) (no. 5) (Fig. 2A). The variation between replicates of noncommercial methods was significantly higher than that of commercial kits (mean variances approximated 0.10 for published protocols and 0.01 for commercial kits; $t$ test, $P<0.05$ ) (Fig. 2A). Methods MoBio $a$ (no. 1) and MP (no. 3a) were equally efficient for the extraction of DNA from AEG31 and HEG4, but method MoBio $a$ proved to be more efficient for isolating DNA from the carbonrich soil SEG8. Most notably, consistently small amounts of DNA were recovered after extraction following ISO standard extraction protocols (Petric $a$ and Petric $b$; no. 6 and 7 ) or the PCI protocol by Töwe et al. (no. 8).

The five methods for the extraction of RNA yielded mean recoveries between 0.03 and $64.9 \mu \mathrm{g}$ (g [wet weight] ${ }^{-1}$ ) and differed by up to 3 orders of magnitude for the same soil (factors of 1,033 , 67, and 21 for samples AEG31, HEG4, and SEG8, respectively) (Fig. 2B). The average amounts of extracted RNA from AEG31 and HEG4 were largest when method MoBio $b$ (no. 2) was employed. In the case of SEG8, the largest amounts of RNA were recovered with method MP (no. $3 \mathrm{~b}$ ), but the variation among replicates was high. The smallest amounts of RNA were recovered from all soils when applying method Töwe.

The different extraction methods also produced various qualities of DNA and RNA (see Fig. S1 in the supplemental material). The DNA extracts obtained with method MoBio $a$ (no. 1) exhibited high $A_{260} / A_{280}$ and $A_{260} / A_{230}$ ratios and low $A_{320}$ values for all soils, indicating that this commercial kit produces high-quality DNA irrespective of the specific properties of the soil. The ISO standard extraction protocol produced measurable DNA extracts of medium quality only after purification using polyvinylpyrrolidone and Sepharose 4B columns (method Petric $b$; no. 7). The protocol by Lueders et al. (no. 4) resulted in RNA extracts with low contamination. The commercial kit MoBio $b$ (no. 2) produced high-purity RNA for soils AEG31 and HEG4 but contaminated RNA for soil SEG8, which is characterized by a high organic matter content. The commercial kits from MP (no. $3 \mathrm{a}$ and $3 \mathrm{~b}$ ) produced very low $A_{260} / A_{230}$ values for all soils.

Abundance of 16S rRNA genes and transcripts. Due to the dilution of DNA and RNA for qPCR and reverse transcription, respectively, inhibition of qPCR was negligible (inhibition factors ranged between 0.94 and 1.00). However, the different extraction procedures left different amounts of residual DNA in the RNA extracts as determined by direct qPCR of bacterial 16S rRNA genes in the RNA extracts (see Table S2 in the supplemental material). Thus, an additional DNase treatment of RNA extracts obtained with commercial kits is mandatory.

The mean copy numbers of bacterial $16 \mathrm{~S}$ rRNA genes recovered from the soils ranged between $5.8 \times 10^{7}$ and $3.8 \times 10^{10}$ copies (g [wet weight $]^{-1}$ ) (Fig. 2A). Mean acidobacterial gene copy numbers ranged between $5.6 \times 10^{5}$ and $2.8 \times 10^{8}$ copies (g [wet weight $\left.]^{-1}\right)$. The multcomp test demonstrated that the extraction methods produce significantly different results. The highest bacterial copy numbers for AEG31 and HEG4 and second highest values for SEG8 were detected in DNA isolated with method MP. The protocol by Persoh et al. also yielded high gene copy numbers 

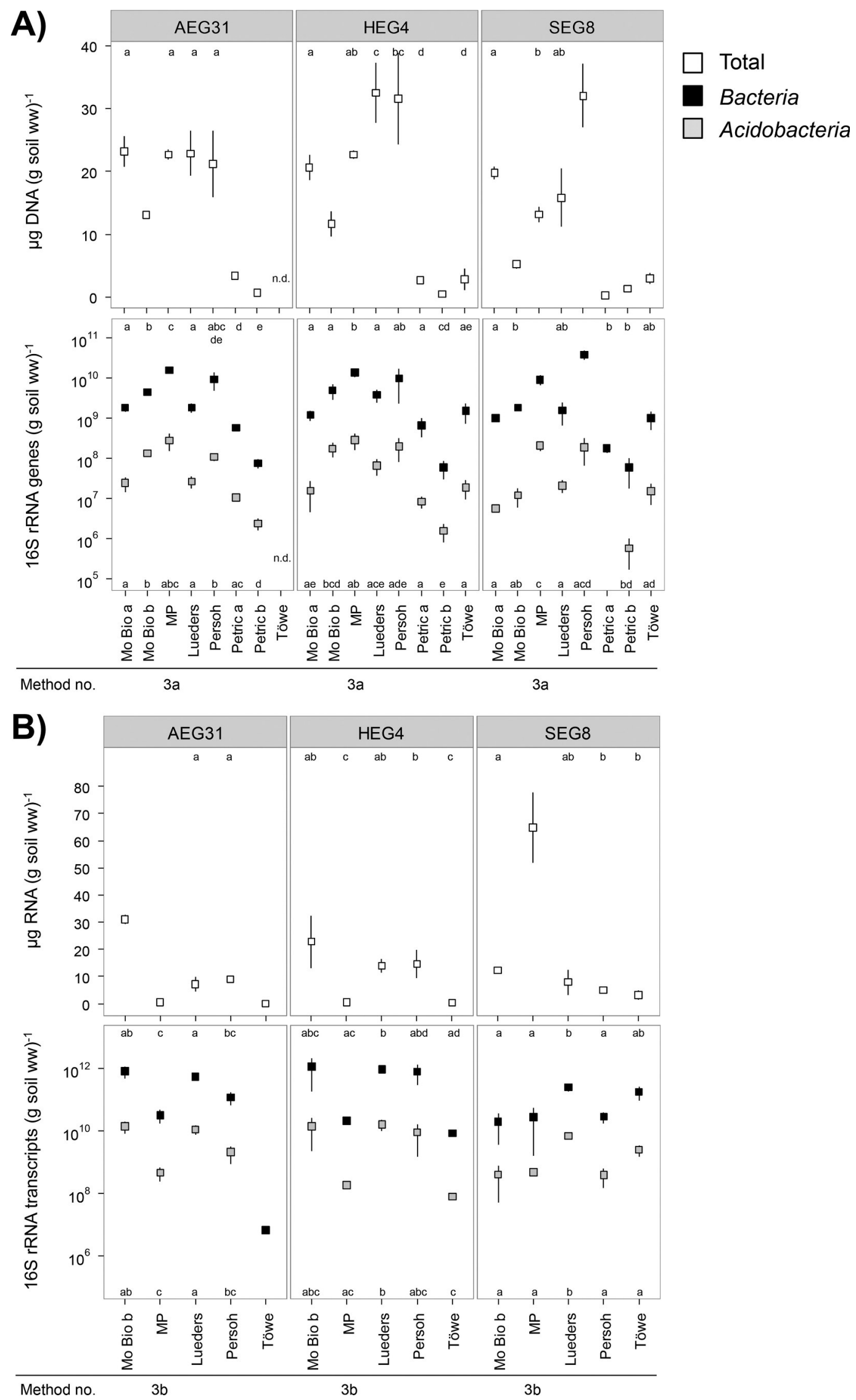

FIG 2 Yield of total DNA and copies of 16S rRNA genes (A) and yield of total RNA and copies of 16S rRNA transcripts (B). The squares (total DNA or total RNA, white squares; Bacteria, black squares; Acidobacteria, gray squares) represent mean values for the three extracts per soil sample ( \pm standard deviations). All values are means from replicate qPCR analyses (Bacteria, $n=4$; Acidobacteria, $n=3$ ). Methods that do not share a letter are significantly different (multcomp, $P<0.05$ ). Concentrations of DNA and RNA were determined in duplicates, using PicoGreen and RiboGreen, respectively. No results are shown for AEG31 using method Töwe (no. 8) since extraction of DNA from this soil failed with this method. Other missing values were under the detection limit of the qPCR assay. 


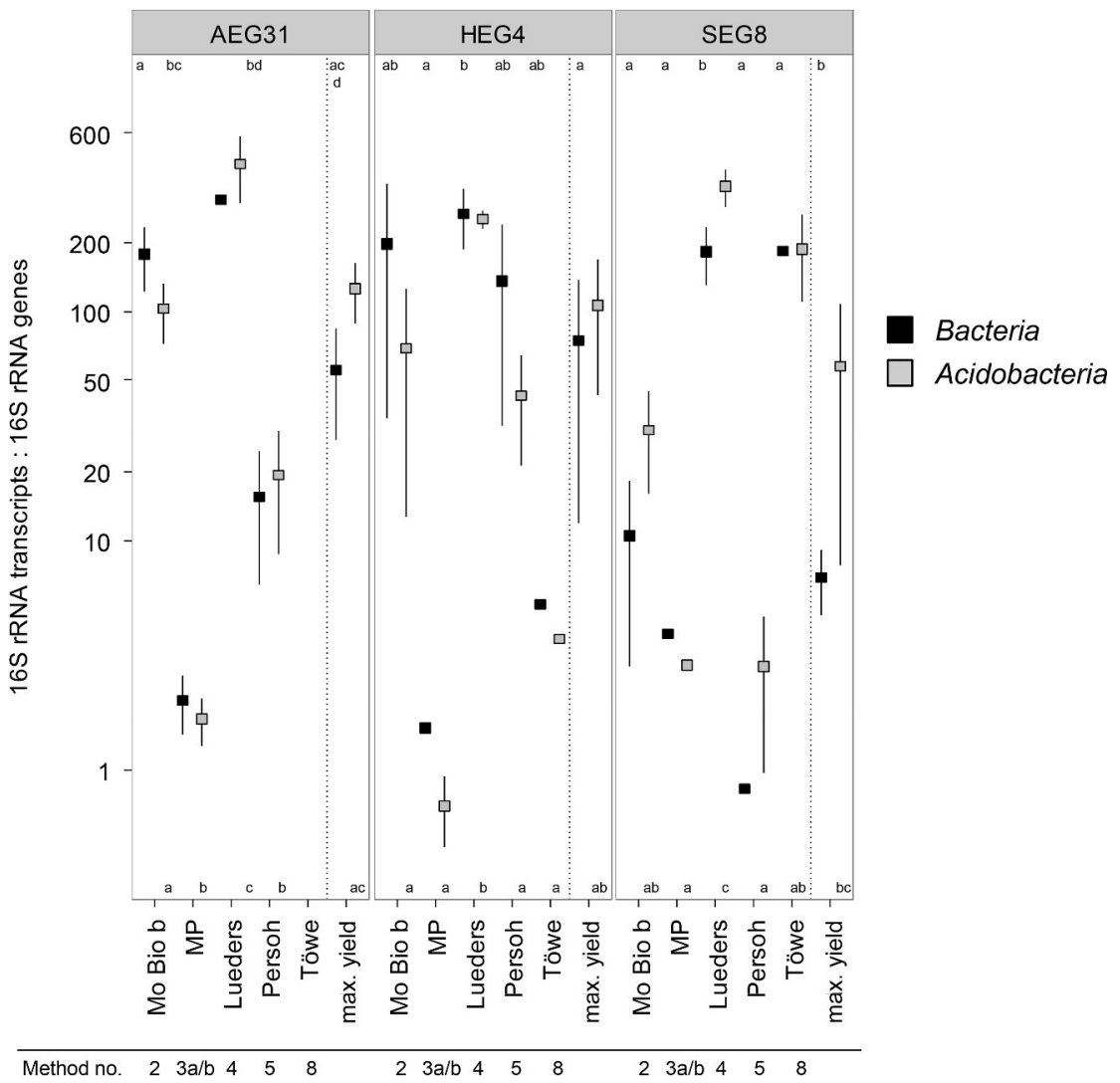

FIG 3 Ratio of 16S rRNA transcripts to 16S rRNA genes as an indicator of specific activity for Bacteria (black squares) and Acidobacteria (gray squares). The squares represent mean values for the three extracts per soil sample ( \pm standard deviations). Values are means from replicate qPCR analyses (Bacteria, $n=4$; Acidobacteria, $n=3$ ). Ratios calculated from methods yielding the maximum transcript or gene copies (denoted "max. yield") were calculated based on the methods that yielded the highest copy numbers per soil, nucleic acid, and taxon. The $y$ axis is logarithmic but shows absolute values. Methods that do not share a letter are significantly different (multcomp, $P<0.05$ ). No results are shown for AEG31 using method Töwe (no. 8) since extraction of DNA from this soil failed with this method.

for all three soils. The lowest gene copy numbers were obtained with the ISO standard extraction protocol (Petric $a$ and Petric $b$ ).

Mean values for bacterial transcript numbers ranged between $6.6 \times 10^{6}$ and $1.1 \times 10^{12}$ copies (g [wet weight] ${ }^{-1}$ ) (Fig. $\left.2 B\right)$. For acidobacterial transcripts, mean values ranged between $7.8 \times 10^{4}$ and $1.6 \times 10^{10}$ copies ( $\mathrm{g}$ [wet weight ${ }^{-1}$ ). Method MoBio $b$ (no. 2 ) yielded the highest bacterial transcript numbers for AEG31 and HEG4, but the transcript numbers for SEG8 were the lowest. In contrast, method Lueders et al. (20) yielded the highest bacterial transcript numbers for SEG8 and the second highest results for AEG31 and HEG4.

For the three soils investigated in the present study, the ratio of $16 \mathrm{~S}$ rRNA transcripts to $16 \mathrm{~S}$ rRNA genes ranged between 0.5 and 353.3 for Bacteria and between 0.5 and 595.5 for Acidobacteria and was strongly affected by the particular extraction method used (Fig. 3). The mean bacterial and acidobacterial ratios for the same soil sample differed by more than 2 orders of magnitude between the extraction methods. Most extraction methods produced high variations within extraction replicates (higher than factor 10). In contrast, ratios were reproducible for all three soils using method Lueders (no. 4) (Fig. 3).

Based on the methods that yielded highest copy numbers per soil, nucleic acid, and taxon, we calculated maximum yield ratios from values generated with the optimum extraction methods for DNA and RNA, respectively ("max. yield" in Fig. 3). Maximum ratios ranged between 3.5 and 121.0 for Bacteria and between 18.4 and 175.5 for Acidobacteria.

Bacterial diversity detected in different extracts. No PCR product for the V2-V3 region was obtained from two of the 23 DNA extracts, namely, those obtained from soil sample SEG8 with the ISO standard extraction 11063 (Petric $a$, no. 6) and the ISO standard extraction 11063 with purification (Petric $b$, no. 7), probably due to their low quality (see Fig. S1). Amplification of cDNA derived from RNA extracts was successful for all 15 samples. A total of 801,118 reads was generated. After preprocessing, including quality filtering and denoising, 481,572 sequences with an average length of $380 \mathrm{bp}$ were analyzed further (see Tables S3 and S4).

Rarefaction curves, richness, and diversity were calculated for OTUs defined at sequence divergence levels of 3 and 20\% (see Fig. S2 and S3 and Tables S5 and S6). Comparison of the rarefaction analyses with the number of OTUs determined by the Chao 1 richness estimator revealed that 56 to $94 \%$ (at a genetic distance of $20 \%$ ) and 22 to $69 \%$ (at a genetic distance of $3 \%$ ) of the estimated richness were covered by our survey. At 20\% sequence divergence, the number of DNA-based OTUs obtained from rarefaction analysis ranged between 89 and 244 (see Table S5) and varied by factors of 1.3 (AEG31), 2.5 (HEG4), and 1.4 (SEG8) between extraction methods. In order to focus on extraction method-dependent variations, richness estimates (no. of OTUs determined by rar- 


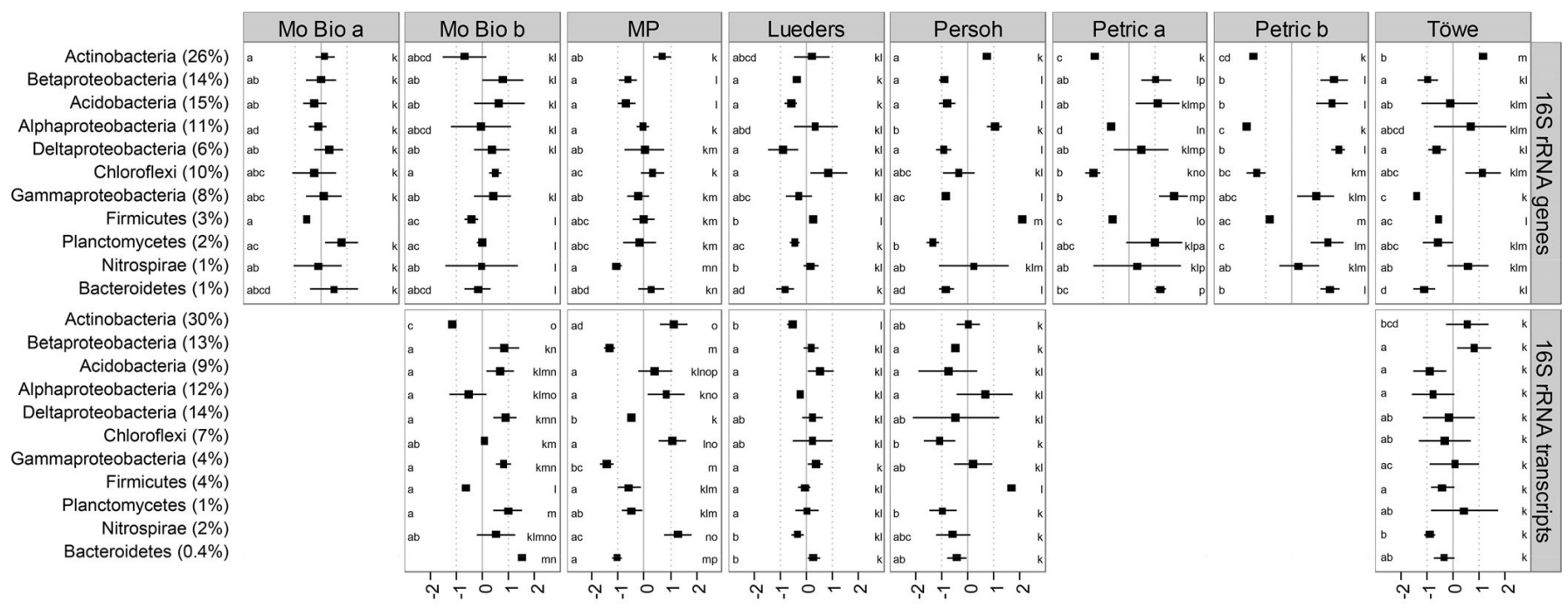

\section{z-transformed relative abundance}

FIG 4 z-transformed relative abundances of abundant phyla and proteobacterial classes detected in DNA and RNA extracts. Data were subjected to z-transformation $\left.([\mathrm{x}-\mathrm{mean}] \text { [standard deviation }]^{-1}\right)$. After $\mathrm{z}$-transformation, values around 0 approximate the mean value of all extraction methods and the standard deviation between all methods equals 1 . Negative values are indicative of a lower fraction of a taxonomic group, and positive values are indicative of a higher fraction, compared to the means of all eight (DNA) and five (RNA) methods, respectively. The squares represent mean values of the three soil samples ( \pm standard deviations). Mean relative abundances over all samples are provided after the taxon name. Horizontally spread letters from a to $\mathrm{d}$ shown in the left-hand side of each block denote statistically significant differences between the extraction methods for a given phylum. Methods that do not share a letter from a to d, per phylum, are significantly different (multcomp, $P<0.05$ ). Vertically spread letters ranging from $\mathrm{k}$ to $\mathrm{p}$ shown in the right-hand side of each block denote statistically significant differences between phyla, per extraction method. Phyla that do not share a letter from $\mathrm{k}$ to $\mathrm{p}$, per soil, are significantly different (multcomp, $P<0.05$ ).

efaction and by Chaol and Shannon index $\mathrm{H}^{\prime}$ ) were subjected to z-transformation (see Fig. S3). At 3\% and 20\% genetic distances, method Petric a (no. 6) yielded the lowest Shannon indices. The number of detected OTUs obtained from the RNA-based sequence analysis ranged between 135 and 282 at a genetic distance of 20\% (see Table S6) and differed by factors of 1.5, 1.4, and 1.6 for the soils AEG31, HEG4, and SEG8, respectively. Methods MoBio $b$ (no. 2) and Lueders (no. 4) consistently yielded higher values for all diversity estimates (see Fig. S3B and Table S6).

Bacterial $16 \mathrm{~S}$ rRNA sequences were affiliated with 24 bacterial phyla and 17 candidate divisions (see Tables S7 to S12). The relative abundances of individual bacterial phyla were strongly affected by the nucleic acid extraction method used. For example, the relative abundance of Actinobacteria and Betaproteobacteria in HEG4 ranged between 4.5 and $43.5 \%$ and 7.1 and $33.9 \%$, respectively (see Table S8). Some methods (e.g., methods MoBio $a$ [no. 1] and MP [no. 3a] for DNA and method Lueders [no. 4] for RNA) revealed abundances that are very similar to the mean abundances of any abundant taxonomic group, while other methods resulted in significantly higher or lower fractions of distinct taxonomic groups (Fig. 4). Many abundant taxonomic groups occurred less frequently in DNA and RNA extracted with method Persoh (no. 5) than with other methods, whereas Firmicutes were more abundant (Fig. 4). Abundance values obtained with methods Petric $a$, Petric $b$, and Töwe (no. 6, 7, and 8) deviated strongly from the mean abundances of all methods.

From the extraction methods that yielded the highest copy numbers per soil and nucleic acid, we determined optimized ratios of RNA-based relative abundances to DNA-based relative abundances for the 11 most abundant phyla and proteobacterial groups (Table 3). The highest ratios (up to 3.8) were obtained for
Deltaproteobacteria, Betaproteobacteria, and Planctomycetes, and low ratios (0.3 to 0.8) were obtained for Firmicutes and Bacteroidetes.

The analysis of soil phospholipid fatty acids is a nucleic acidindependent method to determine the microbial biomass in soils (54) and was therefore used for an independent assessment of the soil microbial community in the studied soils. Based on the analysis of phospholipid fatty acids (see Table S13 in the supplemental

TABLE 3 Optimized relative abundance ratios (RNA-based relative abundance to DNA-based relative abundance) for the 11 most abundant phyla and proteobacterial classes ${ }^{a}$

\begin{tabular}{|c|c|c|c|}
\hline \multirow[b]{2}{*}{ Phylum } & \multicolumn{3}{|c|}{ Ratio in soil sample } \\
\hline & $\begin{array}{l}\text { AEG31, } \\
\text { leptosol } \\
(\text { Swabian Alb })^{b}\end{array}$ & $\begin{array}{l}\text { HEG4, } \\
\text { stagnosol } \\
\text { (Hainich) }^{b}\end{array}$ & $\begin{array}{l}\text { SEG8, gleysol } \\
\text { (Schorfheide-Chorin })^{c}\end{array}$ \\
\hline Actinobacteria & 0.6 & 0.6 & 0.8 \\
\hline Betaproteobacteria & 1.8 & 1.6 & 1.4 \\
\hline Acidobacteria & 1.1 & 0.8 & 0.9 \\
\hline Alphaproteobacteria & 1.2 & 1.0 & 0.7 \\
\hline Deltaproteobacteria & 3.2 & 3.8 & 2.5 \\
\hline Chloroflexi & 0.7 & 0.7 & 0.7 \\
\hline Gammaproteobacteria & 1.1 & 0.6 & 1.1 \\
\hline Firmicutes & 0.3 & 0.7 & 0.6 \\
\hline Planctomycetes & 1.9 & 1.4 & 2.2 \\
\hline Nitrospirae & 1.5 & 1.7 & 1.5 \\
\hline Bacteroidetes & 0.5 & 0.4 & 0.8 \\
\hline
\end{tabular}

${ }^{a}$ Ratios were calculated based on extraction methods that yielded highest bacterial copy numbers per soil and nucleic acid.

${ }^{b}$ Based on methods MP (no. 3a) for DNA and MoBio $b$ (no. 2) for RNA.

${ }^{c}$ Based on methods Lueders (no. 4) for DNA and Persoh (no. 5) for RNA. 

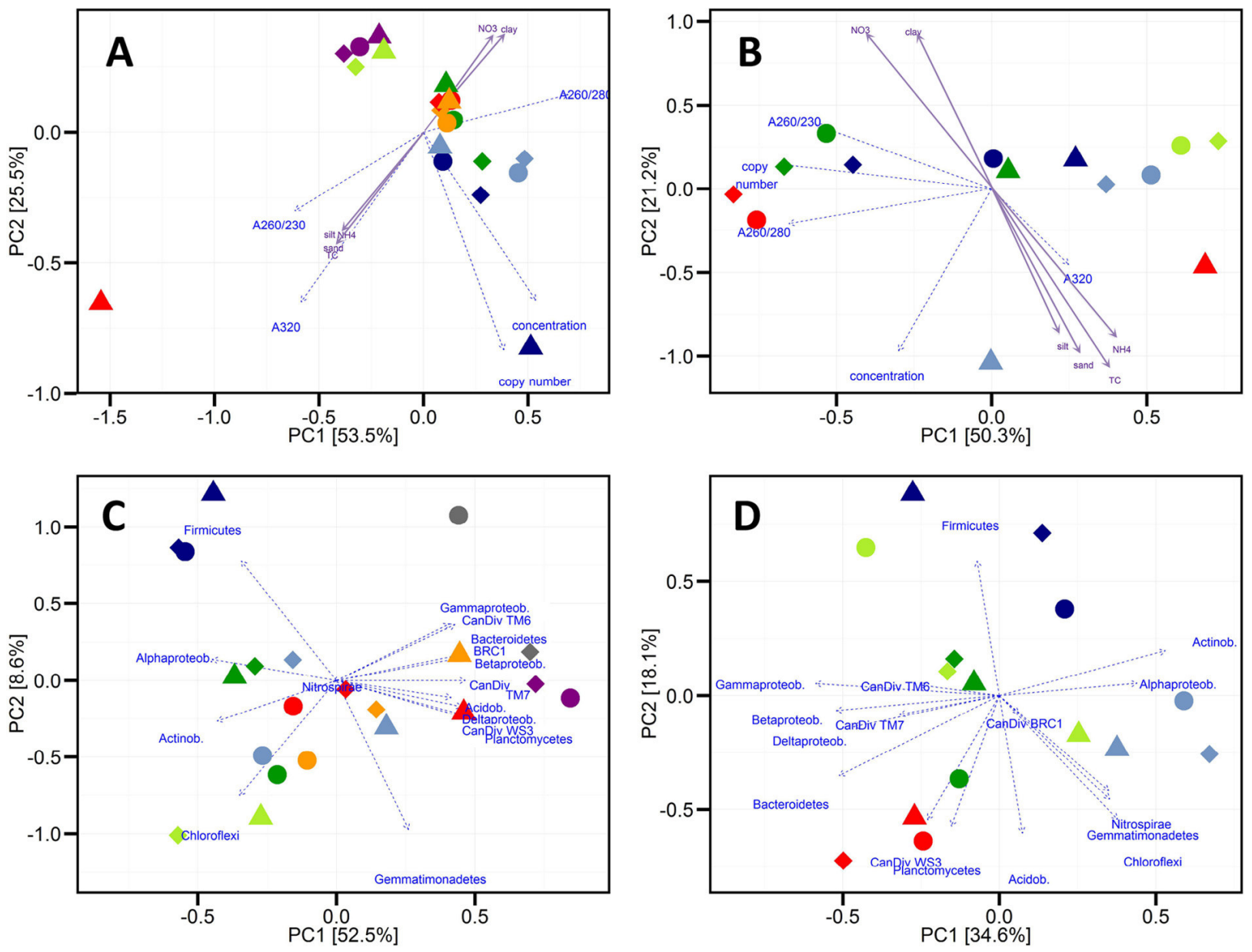

FIG 5 Unconstrained principal-component analysis of z-transformed concentration, copy number, and quality values of DNA extracts (A), of RNA extracts (B), and of relative abundances of 16 abundant phyla and proteobacterial classes detected in DNA extracts (C) and RNA extracts (D). Blue labels and dashed lines give scores of the dependent variables. Numerical variables of the soils were fitted post hoc onto the principal components of quality parameters of nucleic acid extracts in panels A and B and are shown as purple and straight arrows. Data for method Petric $a$ (no. 6) are not included in panel A since measurements of quality parameters failed for undiluted extracts from HEG4 and SEG8 due to the large amounts of contaminants (see Fig. S1 in the supplemental material); method Petric a yielded low concentrations and 16S rRNA gene copy numbers, similar to method Töwe, and method Töwe did not yield detecable amounts of DNA from the clay-rich soil AEG31 (Fig. 2A). Data on the phylogenetic composition in panels C and D were z-transformed for each (sub)phylum-soil combination and hence are independent of the a priori differences in the composition of soil bacterial communities in the different soil types. Only (sub)phyla with relative abundances of $>0.5 \%$ in more than half of the extracts were included in this analysis.

material), the ratio of Gram-positive to Gram-negative bacterial biomass approximated 3 for all three soils. Due to the different numbers of signature molecules for Gram-positive and Gramnegative organisms, this ratio is a rough estimate and is mainly used for comparison between different soil samples (55). Based on the analysis of $16 \mathrm{~S}$ rRNA genes, the ratios of most abundant Gram-positive taxa (i.e., Actinobacteria and Firmicutes) to most abundant Gram-negative taxa (i.e., Acidobacteria, Bacteroidetes, Chloroflexi, Planctomycetes, and Proteobacteria) were highly variable and depended on the extraction method (see Tables S7 to S12). The highest ratios were detected with method Persoh (no. 5; ratio, 0.5 to 1.1 ), whereas the lowest ratios were obtained with the ISO standard extraction protocol (no. 6 and 7; ratio, 0.1). The ISO standard extraction protocol was particularly less efficient in extracting DNA from Gram-positive bacteria than other extraction methods.

Multivariate statistical analysis. $\mathrm{z}$-transformed values of concentration, copy number, and the three quality parameters $\left(A_{260} /\right.$
$A_{230}, A_{260} / A_{280}$, and $\left.A_{320}\right)$ were used to assess the effects of extraction methods and soil parameters on the quality and quantity of nucleic acids recovered. A large fraction of variation was explained by the first and second principal components (in Fig. 5A and B, 79 and $71.5 \%$, respectively). Methods Petric $b$ and Töwe (no. 7 and 8 ) were distinct from all other methods in that they consistently recovered the smallest amount of DNA and amplifiable 16S rRNA genes from all soils. The results of the remaining 5 extraction methods were more similar in most cases, with the notable exception of MoBio $b$ extracts from soil SEG8, which had distinctly high $A_{320}$ and low $A_{260} / A_{280}$ values, and the Persoh extracts from SEG8, which were characterized by a combination of high values of $A_{320}$, DNA concentration, and amplifiable 16S rRNA genes (Fig. 5A). Standard parameters that differed significantly between the three soils (Table 1) were fitted post hoc onto the principal components, but none of the numerical variables of the soils showed a significant correlation with the two principal components (all $P$ values were $>0.06)$. 
Most RNA extracts differed with respect to principal component 1 (PC1), which was largely determined by $A_{260} / A_{230}, A_{260} /$ $A_{280}$, and $16 \mathrm{~S}$ rRNA copy numbers. The most unfavorable combination of these quality parameters was found for the Töwe extraction method (Fig. 5B). A pronounced influence of the soil type was apparent for the three methods MoBio $b$, Lueders, and Persoh (no. 2, 4, and 5), which consistently yielded the most unfavorable values for the three quality parameters in extracts generated from soil SEG8. However, this effect of soil type could not be related to any of the standard soil parameters tested, similar to the DNA extracts.

Unconstrained PCA of the scaled abundances of 16 (sub)phyla revealed inherent differences in the microbial community composition in DNA and RNA extracts from different soils (see Fig. S4A and B). The community composition of the soils as determined in DNA extracts separated according to PC2 and due to the relative abundances of Alphaproteobacteria, Gemmatimonadetes, and Nitrospirae (see Fig. S4A). Of the soil parameters tested, nitrate and ammonia concentrations were significantly correlated with PC1 and PC2 ( $P \leq 0.01$, envfit function in vegan). In unconstrained PCA, the bacterial community composition determined in RNA extracts did not show clear patterns for the different extraction protocols but yielded significant correlations $(0.017<P<0.047)$ of community composition with the soil parameters total carbon, nitrate concentration, and sand content (see Fig. S4B).

After removing the effects of the inherently different bacterial community compositions of the different soils by appropriate scaling, PCA still revealed a clear effect of the different extraction methods on the community composition determined (Fig. 5C and D). Notably, method Persoh (no. 5) recovered a higher fraction of Firmicutes in DNA and RNA extracts than the other methods. While methods Lueders (no. 4) and Töwe (no. 8) recovered larger fractions of Alphaproteobacteria, Actinobacteria, and Chloroflexi in DNA extracts, method Petric $b$ (no. 7) had distinctly higher fractions of Beta-, Gamma-, and Deltaproteobacteria, Bacteroidetes, Acidobacteria, and Planctomycetes (Fig. 5C). With the exception of method Töwe, the phylogenetic compositions were most similar in RNA extracts obtained by the same method (Fig. 5D). Method MP (no. 3b) selected for Alphaproteobacteria, Actinobacteria, $\mathrm{Ni}$ trospirae, Gemmatimonadetes, and Chloroflexi, whereas method MoBio $b$ (no. 2) yielded higher abundances of Planctomycetes and candidate division WS3.

\section{DISCUSSION}

Though certain parameters of the different protocols cannot be compared on a quantitative basis or are simply kept confidential by commercial suppliers (Table 2), several factors affecting nucleic acid extraction were identified.

Factors determining the extraction and amplification efficiency of nucleic acids. Considering the bacterial numbers in the soils $\left\{1.2 \times 10^{9}\right.$ to $2.5 \times 10^{10}$ cells $\left(\mathrm{g}\right.$ [wet weight ${ }^{-1}$ ) $\}$ (Table 1 ) and the average genome size of soil bacteria (4.7 Mb [56]), $1 \mathrm{~g}$ of soil is expected to contain up to $127 \mu \mathrm{g}$ of bacterial DNA, while the actual amount obtained in our study ranged between 0.3 and 38.1 $\mu \mathrm{g}$ of DNA (g [wet weight] ${ }^{-1}$ ), suggesting that some extraction protocols clearly fail to recover DNA from the majority of bacterial cells present in the soils even if coextracted eukaryotic DNA is not accounted for. Slow-growing cells of the soil bacterium Streptomyces coelicolor A3 (15) and Escherichia coli B/r contain 31 and
20 fg of RNA cell ${ }^{-1}$, respectively (57). Whereas the RNA content of soil bacteria in situ has not been determined, marine and estuarine bacteria contain, on average, $9.4 \mathrm{fg}$ of RNA cell ${ }^{-1}$ (7). Accordingly, the amount of extracted bacterial RNA in the three exploratory soils would be expected to exceed 11.3 to $235 \mu \mathrm{g}$ (g [wet weight $]^{-1}$ ), whereas the actual recovery of RNA ranged between 0.03 and $64.9 \mu \mathrm{g}$ (g [wet weight] ${ }^{-1}$ ).

Systematically low yields of DNA and 16S rRNA gene copy numbers were obtained with methods Petric $a$, Petric $b$, and Töwe (no. 6, 7, and 8). In particular, method Töwe failed to extract detectable amounts of DNA from the clay-rich soil AEG31. This method was the only one employing hexadecyltrimethylammonium bromide (CTAB) as a detergent. At $\mathrm{pH}$ values above 5, low extraction efficiencies for clay-rich soils $(9,13)$ are caused by the strong binding of the polyvalent anion DNA to negatively charged clay minerals via divalent cations (58). Our results corroborate those of a previous study showing that SDS and Tris- $\mathrm{HCl}$ yielded larger DNA and RNA amounts than lysis buffers containing CTAB (21). In contrast, the low performance of method Petric $a$ can be attributed to the liberation of loosely bound organic matter (indicated by the high $A_{320}$ ), most likely through high-temperature lysis and the lack of an efficient subsequent purification. Method Petric $b$ comprises two additional final purification steps which, however, did not improve the DNA yield. Obviously, the strong contamination of extracts by organic compounds interfered with purification and hence resulted in a low recovery of DNA. Thus, the two ISO standard extraction protocols are not suitable for recovering DNA at high yields, at least from the three types of soils investigated in the present study.

Methods Persoh and MoBio $b$ differed pronouncedly from all others by the high $A_{320}$ values that were specifically observed in DNA extracts from soil SEG8. MoBio $b$ extracts from this soil also exhibited lower $A_{260} / A_{280}$ values, whereas method Persoh recovered significantly larger amounts of DNA and amplifiable 16S rRNA genes. Soil SEG8 had the lowest clay and highest total organic carbon (TOC) contents. The larger amount of organic compounds liberated by extraction may be due to a much lower binding strength of organic compounds to the sand and silt fractions prevailing in SEG8. Method MoBio $b$ differed from all other methods in employing a combination of guanidine thiocyanate, a strong chaotropic agent, and phenol-chloroform-isoamyl alcohol. Apparently, this combination resulted in the undesired extraction of organic compounds. In contrast, method Persoh encompasses a unique precipitation step that is highly efficient in removing the liberated organic compounds. Method Persoh (no. 5 ) is thus clearly superior with respect to yield and purity and hence should be chosen when extracting DNA from soils that contain loosely bound organic compounds. According to our analysis, method MP (no. 3a) represents the second most robust method for PCR-based analysis of DNA from soil.

The available commercial kits for RNA extraction do not offer a higher reproducibility than noncommercial protocols. Based on our multivariate analysis, organic compounds coextracted from soil SEG8 systematically interfered with the isolation of RNA for the three methods Lueders, Persoh, and MoBio $b$. Similar to the case with DNA, method MoBio $b$ yielded the largest amounts of organic compounds and hence should not be applied to soils containing large amounts of loosely bound organic compounds. Based on their generally low performance, methods Töwe and MP cannot be recommended for the extraction of RNA from soils. 
Factors affecting diversity analyses. Some of the extraction methods tested have been reported to extract bacterial, archaeal, and fungal DNA with different efficiencies (23). Our results demonstrate that the 9 different protocols actually result in a distinct phylogenetic composition of the nucleic acids recovered. This substantiates previous findings that were based on low-resolution fingerprint analyses $(24,26,27)$.

A comparison with the results of the independent assessment of the soil microbial community through the analysis of the phospholipid fatty acid composition indicates that the different protocols differ with respect to extraction efficiency of Gram-positive bacteria, which are known to be more resistant to cell lysis than Gram-negative bacteria (9). The consistently higher fraction of Firmicutes recovered in DNA as well as RNA extracts obtained with the Persoh method suggests that a significantly higher efficiency of cell disruption of Firmicutes is achieved by the extended bead beating of this method. The ISO standard extraction protocol (methods Petric $a$ and $b$ ) had a lower efficiency of extracting DNA from Gram-positive bacteria than did all other extraction methods. Notably, methods Lueders, Persoh, and Töwe, and partially also MP, recovered higher percentages of Alphaproteobacteria, Actinobacteria, and Chloroflexi in the DNA extracts. All 4 methods employ a phenol-chloroform step that might affect the efficiency of cell lysis for these groups.

Effects of extraction protocols on the determination of the cellular ribosome content. The cellular ribosome content is proportional to the specific growth rate in various bacteria $(4,59,60)$ and has been employed as an indicator of the potential activity of bacterial cells $(6,7)$. Although the cellular ribosome content is affected by nutrient limitation (4), dormancy (3), or species-specific differences in rrn operon and genome numbers (59), it still provides valuable information on the status of bacterial cells in situ. Based on our results, conclusions about the ribosome content of bacterial taxa critically depend on the extraction method used. For example, application of method MP (no. 3a and 3b) would lead to the conclusion that the complete bacterial community is inactive (ratios approximate a value of 1) in all three soils, while a high ribosome content (ratios between 200 and 300) was determined using method Lueders (no. 4).

During exponential growth of Escherichia coli, the maximum ratio of rRNA transcripts to genes is 2,006, as calculated from published ribosome numbers per cell, the rrn operon copy number, and ploidy (number of genomes) per cell (61). The much lower values determined for the three exploratory soils by the optimum combination of extraction method data could be caused by a large fraction of physiologically inactive soil bacteria (62) and/or a low average physiological activity of the bacterial cells. The highest ratios (up to 3.8) were obtained for Deltaproteobacteria, Betaproteobacteria, and Planctomycetes, suggesting that these taxonomic groups harbor many species which are potentially active in the soil. In contrast, low ratios (0.3 to 0.8) for Firmicutes and Bacteroidetes suggest that only a small fraction of these taxa is potentially active in the studied soil. Interestingly, mean maximum-yield ratios for Acidobacteria were always higher than those for Bacteria as a whole in all three soils, indicating that Acidobacteria on average and as a group have a higher ribosome content than the average of soil bacteria in these three soils. These differences in the ribosome content between Acidobacteria and total Bacteria become even more pronounced when considering the low average $r r n$ operon number of Acidobacteria (1.5) compared to that of total Bacteria (4.6) (63).

Conclusions. Our comparative analysis demonstrates that the choice of extraction protocols specifically affects the quality and quantity as well as the phylogenetic composition of the resulting DNA and RNA extracts. Notably, and despite the advantages of method standardization in general (64), a single standardized protocol for nucleic acid extraction that would be equally efficient for different soil types, target organisms, and nucleic acid types does not exist. However, several guidelines for the selection of appropriate extraction protocols can be deduced (1). CTAB is inferior to SDS to overcome the quantitative adsorption of DNA to clay minerals (2). The extraction from soils containing large amounts of loosely bound organic matter requires phenol-chloroform-isoamyl alcohol or ion-exchange columns for efficient purification steps that cannot compensated for by the addition of PVP (3). Guanidine thiocyanate should be avoided when large amounts of organic matter would be coextracted; instead, organic contaminants should be precipitated in an initial step (4). Extending the bead beating beyond the period usually employed improves cell lysis of Gram-positive soil bacteria.

\section{ACKNOWLEDGMENTS}

This work was funded through DFG Priority Program 1374 (Infrastructure-Biodiversity-Exploratories [grants OV 20/18-1 and OV 20/18-2]) and the DSMZ. Field work permits were given by the responsible state environmental offices of Baden-Wuerttemberg, Thuringia, and Brandenburg (according to section $72 \mathrm{BbgNatSchG).}$

We thank the managers of the three exploratories, Swen Renner, Katrin Hartwich, Sonja Gockel, Kerstin Wiesner, and Martin Gorke, for their work in maintaining the plot and project infrastructure; Simone Pfeiffer and Christiane Fischer for giving support through the central office; Michael Owonibi for managing the central database; and Markus Fischer, Eduard Linsenmair, Dominik Hessenmöller, Jens Nieschulze, Daniel Prati, Ingo Schöning, François Buscot, Ernst-Detlef Schulze, Wolfgang W. Weisser, and the late Elisabeth Kalko for their role in setting up the Biodiversity Exploratories project. Special thanks go to Ingo Schöning (Max-Planck-Institut für Biogeochemie, Jena, Germany), Nadine Herold (Max-Planck-Institut für Biogeochemie), and Vanessa Baumgartner (Leibniz Institute DSMZ, Braunschweig, Germany) for providing soil data and to Bärbel Foesel for helpful discussions. We thank Alicia Geppert and Anja Stieler for skilled technical assistance.

\section{FUNDING INFORMATION}

This work, including the efforts of Joerg Overmann, was funded by Deutsche Forschungsgemeinschaft (DFG) (OV 20/18-1 and OV 20/18-2).

\section{REFERENCES}

1. Roesch LFW, Fulthorpe RR, Riva A, Casella G, Hadwin AKM, Kent AD, Daroub SH, Camargo FAO, Farmerie WG, Triplett EW. 2007. Pyrosequencing enumerates and contrasts soil microbial diversity. ISME J $1: 283-290$.

2. Torsvik V, Ovreas L. 2002. Microbial diversity and function in soil: from genes to ecosystems. Curr Opin Microbiol 5:240-245. http://dx.doi.org /10.1016/S1369-5274(02)00324-7.

3. Blazewicz SJ, Barnard RL, Daly RA, Firestone MK. 2013. Evaluating rRNA as an indicator of microbial activity in environmental communities: limitations and uses. ISME J 11:2061-2068.

4. Molin S, Givskov M. 1999. Application of molecular tools for in situ monitoring of bacterial growth activity. Environ Microbiol 1:383-391. http://dx.doi.org/10.1046/j.1462-2920.1999.00056.x.

5. Moran MA, Torsvik VL, Torsvik T, Hodson RE. 1993. Direct extraction and purification of rRNA for ecological studies. Appl Environ Microbiol 59:915-918.

6. Foesel BU, Nägele V, Naether A, Wüst PK, Weinert J, Bonkowski M, 
Lohaus G, Polle A, Alt F, Oelmann Y, Fischer M, Friedrich MW, Overmann J. 2014. Determinants of Acidobacteria activity inferred from the relative abundances of 16S rRNA transcripts in German grassland and forest soils. Environ Microbiol 16:658-675.

7. Jeffrey WH, Von Haven R, Hoch MP, Coffin RB. 1996. Bacterioplankton RNA, DNA, protein content and relationships to rates of thymidine and leucine incorporation. Aquat Microb Ecol 10:87-95. http://dx.doi.org /10.3354/ame010087.

8. Bakken LR, Frostegård A. 2006. Nucleic acid extraction from soil, p 49-73. In Nannipieri P, Smalla K (ed), Nucleic acids and proteins in soil. Springer, Berlin, Germany.

9. Frostegård A, Courtois S, Ramisse V, Clerc S, Bernillon D, Le Gall F, Jeannin P, Nesme X, Simonet P. 1999. Quantification of bias related to the extraction of DNA directly from soils. Appl Environ Microbiol 65 : $5409-5420$

10. Lombard N, Prestat E, van Elsas JD, Simonet P. 2011. Soil-specific limitations for access and analysis of soil microbial communities by metagenomics. FEMS Microbiol Ecol 78:31-49. http://dx.doi.org/10.1111/j .1574-6941.2011.01140.x.

11. Novinscak A, Filion M. 2011. Effect of soil clay content on RNA isolation and on detection and quantification of bacterial gene transcripts in soil by quantitative reverse transcription-PCR. Appl Environ Microbiol 77: 6249-6252. http://dx.doi.org/10.1128/AEM.00055-11.

12. Sagova-Mareckova M, Cermak L, Novotna J, Plhackova K, Forstova J, Kopecky J. 2008. Innovative methods for soil DNA purification tested in soils with widely differing characteristics. Appl Environ Microbiol 74: 2902-2907. http://dx.doi.org/10.1128/AEM.02161-07.

13. Zhou J, Bruns MA, Tiedje JM. 1996. DNA recovery from soils of diverse composition. Appl Environ Microbiol 62:316-322.

14. Tebbe CC, Vahjen W. 1993. Interference of humic acids and DNA extracted directly from soil in detection and transformation of recombinant DNA from bacteria and a yeast. Appl Environ Microbiol 59:2657-2665.

15. Bertrand H, Poly F, Van VT, Lombard N, Nalin R, Vogel TM, Simonet P. 2005. High molecular weight DNA recovery from soils prerequisite for biotechnological metagenomic library construction. J Microbiol Methods 62:1-11. http://dx.doi.org/10.1016/j.mimet.2005.01.003.

16. Luna GM, Dell'Anno A, Danovaro R. 2006. DNA extraction procedure: a critical issue for bacterial diversity assessment in marine sediments. Environ Microbiol 8:308-320. http://dx.doi.org/10.1111/j.1462-2920.2005 .00896.x.

17. Griffiths RI, Whiteley AS, O’Donnell AG, Bailey MJ. 2000. Rapid method for coextraction of DNA and RNA from natural environments for analysis of ribosomal DNA- and rRNA-based microbial community composition. Appl Environ Microbiol 66:5488-5491. http://dx.doi.org/10 .1128/AEM.66.12.5488-5491.2000.

18. Hurt RA, Qiu X, Wu L, Roh Y, Palumbo AV, Tiedje JM, Zhou J. 2001. Simultaneous recovery of RNA and DNA from soils and sediments. Appl Environ Microbiol 67:4495-4503. http://dx.doi.org/10.1128/AEM.67.10 .4495-4503.2001.

19. İnceoğlu Ö, Hoogwout EF, Hill P, van Elsas JD. 2010. Effect of DNA extraction method on the apparent microbial diversity of soil. Appl Environ Microbiol 76:3378-3382. http://dx.doi.org/10.1128/AEM.02715-09.

20. Lueders T, Manefield M, Friedrich MW. 2004. Enhanced sensitivity of DNA- and rRNA-based stable isotope probing by fractionation and quantitative analysis of isopycnic centrifugation gradients. Environ Microbiol 6:73-78.

21. Persoh D, Theuerl S, Buscot F, Rambold G. 2008. Towards a universally adaptable method for quantitative extraction of high-purity nucleic acids from soil. J Microbiol Methods 75:19-24. http://dx.doi.org/10.1016/j .mimet.2008.04.009.

22. Petric I, Philippot L, Abbate C, Bispo A, Chesnot T, Hallin S, Laval K, Lebeau T, Lemanceau P, Leyval C, KLindström Pandard P, Romero E, Sarr A, Schloter M, Simonet P, Smalla K, Wilke BM, Martin-Laurent F. 2011. Inter-laboratory evaluation of the ISO standard 11063 "Soil quality-method to directly extract DNA from soil samples." J Microbiol Methods 84:454-460.

23. Plassart P, Terrat S, Thomson B, Griffiths R, Dequiedt S, Lelievre M, Regnier T, Nowak V, Bailey M, Lemanceau P, Bispo A, Chabbi A, Maron P-A, Mougel C, Ranjard L. 2012. Evaluation of the ISO standard 11063 DNA extraction procedure for assessing soil microbial abundance and community structure. PLoS One 7(9):e44279. http://dx.doi.org/10 .1371/journal.pone.0044279.

24. Töwe S, Wallisch S, Bannert A, Fischer D, Hai B, Haesler F, Kleineidam
K, Schloter M. 2011. Improved protocol for the simultaneous extraction and column-based separation of DNA and RNA from different soils. J Microbiol Methods 84:406-412. http://dx.doi.org/10.1016/j.mimet.2010 .12 .028 .

25. Wang Y, Morimoto S, Ogawa N, Oomori T, Fujii T. 2009. An improved method to extract RNA from soil with efficient removal of humic acids. J Appl Microbiol 107:1168-1177. http://dx.doi.org/10.1111/j.1365-2672 2009.04298.x.

26. Carrigg C, Rice O, Kavanagh S, Collins G, O’Flaherty V. 2007. DNA extraction method affects microbial community profiles from soils and sediment. Appl Microbiol Biotechnol 77:955-964. http://dx.doi.org/10 .1007/s00253-007-1219-y.

27. Martin-Laurent F, Philippot L, Hallet S, Chaussod R, Germon JC, Soulas G, Catroux G. 2001. DNA extraction from soils: old bias for new microbial diversity analysis methods. Appl Environ Microbiol 67:23542359. http://dx.doi.org/10.1128/AEM.67.5.2354-2359.2001.

28. Niemi MR, Heiskanen I, Wallenius K, Lindström K. 2001. Extraction and purification of DNA in rhizosphere soil samples for PCR-DGGE analysis of bacterial consortia. J Microbiol Methods 45:155-165. http://dx.doi .org/10.1016/S0167-7012(01)00253-6.

29. Ning J, Liebich J, Kästner M, Zhou J, Schäffer A, Burauel P. 2009. Different influences of DNA purity indices and quantity on PCR-based DGGE and functional gene microarray in soil microbial community study. Appl Microbiol Biotechnol 82:983-993. http://dx.doi.org/10.1007 /s00253-009-1912-0.

30. Sessitsch A, Gyamfi S, Stralis-Pavese N, Weilharter A, Pfeifer U. 2002. RNA isolation from soil for bacterial community and functional analysis: evaluation of different extraction and soil conservation protocols. J Microbiol Methods 51:171-179. http://dx.doi.org/10.1016/S0167-7012(02) 00065-9.

31. Feinstein LM, Sul WJ, Blackwood CB. 2009. Assessment of bias associated with incomplete extraction of microbial DNA from soil. Appl Environ Microbiol 75:5428-5433. http://dx.doi.org/10.1128/AEM.00120-09.

32. Terrat S, Christen R, Dequiedt S, Lelievre M, Nowak V, Regnier T, Bachar D, Plassart P, Wincker P, Jolivet C, Bispo A, Lemanceau P, Maron PA, Mougel C, Ranjard L. 2012. Molecular biomass and MetaTaxogenomic assessment of soil microbial communities as influenced by soil DNA extraction procedure. Microb Biotechnol 5:135-141. http://dx.doi.org/10.1111/j.1751-7915.2011.00307.x.

33. Nacke H, Thürmer A, Wollherr A, Will C, Hodac L, Herold N, Schöning I, Schrumpf M, Daniel R. 2011. Pyrosequencing-based assessment of bacterial community structure along different management types in German forest and grassland soils. PLoS One 6(2):e17000. http://dx.doi.org /10.1371/journal.pone.0017000.

34. Shange RS, Ankumah RO, Ibekwe AM, Zabawa R, Dowd SE. 2012 Distinct soil bacterial communities revealed under a diversely managed agroecosystem. PLoS One 7(7):e40338. http://dx.doi.org/10.1371/journal .pone.0040338.

35. Fischer M, Bossdorf O, Gockel S, Hänsel F, Hemp A, Hessenmöller D, Korte G, Nieschulze J, Pfeiffer S, Prati D, Renner S, Schöning I, Schumacher U, Wells K, Buscot F, Kalko EKV, Linsenmair KE, Schulze ED, Weisser WW. 2010. Implementing large-scale and long-term functional biodiversity research: The Biodiversity Exploratories. Basic Appl Ecol 11:473-485. http://dx.doi.org/10.1016/j.baae.2010.07.009.

36. Bürgmann H, Pesaro M, Widmer F, Zeyer J. 2001. A strategy for optimizing quality and quantity of DNA extracted from soil. J Microbiol Methods 45:7-20. http://dx.doi.org/10.1016/S0167-7012(01)00213-5.

37. Ritalahti KM, Amos BK, Sung Y, Wu Q, Koenigsberg SS, Loffler FE. 2006. Quantitative PCR targeting 16S rRNA and reductive dehalogenase genes simultaneously monitors multiple Dehalococcoides strains. Appl Environ Microbiol 72:2765-2774. http://dx.doi.org/10.1128/AEM.72.4.2765 $-2774.2006$.

38. Caporaso JG, Kuczynski J, Stombaugh J, Bittinger K, Bushman FD, Costello EK, Fierer N, Pena AG, Goodrich JK, Gordon JI, Huttley GA, Kelley ST, Knights D, Koenig JE, Ley RE, Lozupone CA, McDonald D, Muegge BD, Pirrung M, Reeder J, Sevinsky JR, Turnbaugh PJ, Walters WA, Widmann J, Yatsunenko T, Zaneveld J, Knight R. 2010. QIIME allows analysis of high-throughput community sequencing data. Nat Methods 7:335-336. http://dx.doi.org/10.1038/nmeth.f.303.

39. Martin M. 2011. Cutadapt removes adapter sequences from highthroughput sequencing reads. EMBnet J 17:10-12.

40. Edgar RC, Haas BJ, Clemente JC, Quince C, Knight R. 2011. UCHIME 
improves sensitivity and speed of chimera detection. Bioinformatics 27: 2194-2200. http://dx.doi.org/10.1093/bioinformatics/btr381.

41. DeSantis TZ, Hugenholtz P, Larsen N, Rojas M, Brodie EL, Keller K, Huber T, Dalevi D, Hu P, Andersen GL. 2006. Greengenes, a chimerachecked 16S rRNA gene database and workbench compatible with ARB. Appl Environ Microbiol 72:5069-5072. http://dx.doi.org/10.1128/AEM .03006-05.

42. Schloss PD, Handelsman J. 2005. Introducing DOTUR, a computer program for defining operational taxonomic units and estimating species richness. Appl Environ Microbiol 71:1501-1506. http://dx.doi.org/10 .1128/AEM.71.3.1501-1506.2005.

43. Shannon CE. 1948. A mathematical theory of communication. Bell Syst Tech J 27:379-423. http://dx.doi.org/10.1002/j.1538-7305.1948 .tb01338.x.

44. Chao A, Bunge J. 2002. Estimating the number of species in a stochastic abundance model. Biometrics 58:531-539. http://dx.doi.org/10.1111/j .0006-341X.2002.00531.x.

45. Pruesse E, Quast C, Knittel K, Fuchs BM, Ludwig W, Peplies J, Glöckner FO. 2007. SILVA: a comprehensive online resource for quality checked and aligned ribosomal RNA sequence data compatible with ARB. Nucleic Acids Res 35:7188-7196. http://dx.doi.org/10.1093/nar/gkm864.

46. Herberich E, Sikorski J, Hothorn T. 2010. A robust procedure for comparing multiple means under heteroscedasticity in unbalanced designs. PLoS One 5(3):e9788. http://dx.doi.org/10.1371/journal.pone.0009788.

47. Hothorn T, Bretz F, Westfall P. 2008. Simultaneous inference in general parametric models. Biom J 50:346-363. http://dx.doi.org/10.1002/bimj .200810425 .

48. Oksanen J, Blanchet FG, Kindt R, Legendre P, Minchin PR, O'Hara RB, Simpson GL, Solymos P, Stevens MHH, Wagner H. 2015. vegan: Community Ecology Package. R package version 2.3-1. http://CRAN.R-project .org/package $=$ vegan.

49. ter Braak CJF, Smilauer P. 2002. CANOCO reference manual and CanoDraw for Windows user's guide: software for canonical community ordination (version 4.5). Microcomputer Power, Ithaca, NY.

50. Wickham H. 2009. ggplot2: elegant graphics for data analysis. Springer, New York, NY.

51. Frostegård A, Bååth E, Tunlio A. 1993. Shifts in the structure of soil microbial communities in limed forests as revealed by phospholipid fatty acid analysis. Soil Biol Biochem 25:723-730. http://dx.doi.org/10.1016 /0038-0717(93)90113-P.

52. Poll J, Marhan S, Haase S, Hallmann J, Kandeler E, Ruess L. 2007. Low amounts of herbivory by root-knot nematodes affect microbial community dynamics and carbon allocation in the rhizosphere. FEMS Microbio Ecol 62:268-279. http://dx.doi.org/10.1111/j.1574-6941.2007.00383.x.

53. Zelles L. 1999. Fatty acid patterns of phospholipids and lipopolysaccharides in the characterisation of microbial communities in soil: a review. Biol Fertil Soils 29:111-129. http://dx.doi.org/10.1007/s003740050533.

54. Frostegård A, Bååth E. 1996. The use of phospholipid fatty acid analysis to estimate bacterial and fungal biomass in soil. Biol Fertil Soils 22:59-65. http://dx.doi.org/10.1007/BF00384433.

55. Kramer S, Marhan S, Ruess L, Armbruster W, Butenschoen O, Haslwimmer H, Kuzyakov Y, Pausch J, Scheunemann N, Schoene J, Schmalwasser A, Totsche KU, Walker F, Scheu S, Kandeler E. 2012 Carbon flow into microbial and fungal biomass as a basis for the belowground food web of agroecosystems. Pedobiologia 55:111-119. http://dx .doi.org/10.1016/j.pedobi.2011.12.001.

56. Raes J, Korbel JO, Lercher MJ, von Mering C, Bork P. 2007. Prediction of effective genome size in metagenomic samples. Genome Biol 8:R10. http://dx.doi.org/10.1186/gb-2007-8-1-r10.

57. Cox RA. 2004. Quantitative relationships for specific growth rates and macromolecular compositions of Mycobacterium tuberculosis, Streptomyces coelicolor A3(2) and Escherichia coli B/r: an integrative theoretical approach. Microbiology 150:1413-1426. http://dx.doi.org/10.1099/mic.0 .26560-0.

58. Pietramellara G, Ascher J, Borgogni F, Ceccherini MT, Guerri G Nannipieri P. 2009. Extracellular DNA in soil and sediment: fate and ecological relevance. Biol Fertil Soils 45:219-235. http://dx.doi.org/10 .1007/s00374-008-0345-8.

59. Fegatella F, Lim J, Kjelleberg S, Cavicchioli R. 1998. Implications of rRNA operon copy number and ribosome content in the marine oligotrophic ultramicrobacterium Sphingomonas sp. strain RB2256. Appl Environ Microbiol 64:4433-4438.

60. Keener J, Nomura M. 1996. Regulation of ribosome synthesis, p 14171431. In Neidhart FC, Curtiss R, III, Ingraham JL, Lin ECC, Low KB, Magasanik B, Reznikoff WS, Riley M, Schaechter M, Umbarger HE (ed), Escherichia coli and Salmonella: cellular and molecular biology, 2nd ed. ASM Press, Washington, DC.

61. Bremer H, Dennis PP. 1996. Modulation of chemical composition and other parameters of the cell by growth rate, $\mathrm{p}$ 1553-1569. In Neidhardt FC, Curtiss R, III, Ingraham JL, Lin ECC, Low KB, Magasanik B, Reznikoff WS, Riley M, Schaechter M, Umbarger HE (ed), Escherichia coli and Salmonella: cellular and molecular biology, 2nd ed. ASM Press, Washington, DC.

62. Norton JM, Firestone MK. 1991. Metabolic status of bacteria and fungi in the rhizosphere of ponderosa pine seedlings. Appl Environ Microbiol 57: 1161-1167.

63. Lee ZM, Bussema C, III, Schmidt TM. 2009. rrnDB: documenting the number of rRNA and tRNA genes in bacteria and archaea. Nucleic Acids Res 37:D489-D493. http://dx.doi.org/10.1093/nar/gkn689.

64. Philippot L, Ritz K, Pandard P, Hallin S, Martin-Laurent F. 2012. Standardisation of methods in soil microbiology: progress and challenges. FEMS Microbiol Ecol 82:1-10. http://dx.doi.org/10.1111/j.1574-6941 .2012.01436.x.

65. Miller DN. 2001. Evaluation of gel filtration resins for the removal of PCR-inhibitory substances from soils and sediments. J Microbiol Methods 44:49-58. http://dx.doi.org/10.1016/S0167-7012(00)00228-1. 
Chapter III.2.

DRIVERS OF SOIL B ACTERIA 
III.2.

\title{
Driving forces of soil bacterial community structure, diversity, and function in temperate grasslands and forests
}

\author{
Running title: Drivers of Soil Bacteria
}

Kristin Kaiser $^{1}$, Bernd Wemheuer ${ }^{1}$, Vera Korolkow ${ }^{1}$, Franziska Wemheuer ${ }^{2}$, Heiko Nacke ${ }^{1, \dagger}$, Ingo Schöning ${ }^{3}$, Marion Schrumpf ${ }^{3}$ and Rolf Daniel ${ }^{1, *}$

${ }^{1}$ Department of Genomic and Applied Microbiology, Institute of Microbiology and Genetics, Georg-August-University Göttingen, Grisebachstr. 8, D-37077 Göttingen, Germany

${ }^{2}$ Department of Crop Sciences, Georg-August-University Göttingen, Grisebachstr. 6, D-37077

Göttingen, Germany

${ }^{3}$ Max Planck Institute for Biogeochemistry, Hans-Knoell-Str. 10, D-07745 Jena, Germany

${ }^{\dagger}$ Present address: Institute of Biological and Environmental Sciences, University of Aberdeen, Aberdeen, United Kingdom

Author's contribution:

Designed the experiments: KK, HN, RD

Performed research: KK, VK

Contributed data: IS, MS

Analyzed data: KK, BW, FW

Wrote the paper: KK, BW, FW, RD 


\section{SCIENTIFIC REP

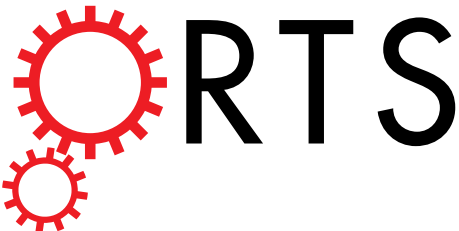

OPEN Driving forces of soil bacterial community structure, diversity, and function in temperate grasslands

Received: 18 May 2016

Accepted: 31 August 2016

Published: 21 September 2016 and forests

\author{
Kristin Kaiser ${ }^{1}$, Bernd Wemheuer ${ }^{1}$, Vera Korolkow ${ }^{1}$, Franziska Wemheuer ${ }^{2}$, Heiko Nacke ${ }^{1}$, \\ Ingo Schöning ${ }^{3}$, Marion Schrumpf ${ }^{3} \&$ Rolf Daniel $^{1}$
}

Soil bacteria provide a large range of ecosystem services such as nutrient cycling. Despite their important role in soil systems, compositional and functional responses of bacterial communities to different land use and management regimes are not fully understood. Here, we assessed soil bacterial communities in 150 forest and 150 grassland soils derived from three German regions by pyrotag sequencing of $16 \mathrm{~S}$ rRNA genes. Land use type (forest and grassland) and soil edaphic properties strongly affected bacterial community structure and function, whereas management regime had a minor effect. In addition, a separation of soil bacterial communities by sampling region was encountered. Soil pH was the best predictor for bacterial community structure, diversity and function. The application of multinomial log-linear models revealed distinct responses of abundant bacterial groups towards $\mathrm{pH}$. Predicted functional profiles revealed that differences in land use not only select for distinct bacterial populations but also for specific functional traits. The combination of $16 \mathrm{~S}$ rRNA data and corresponding functional profiles provided comprehensive insights into compositional and functional adaptations to changing environmental conditions associated with differences in land use and management.

Soil bacteria play an important role in biogeochemical cycles ${ }^{1,2}$. They control soil processes such as decomposition $^{3}$ and mineralization, including the associated release of greenhouse gases such as carbon dioxide $\left(\mathrm{CO}_{2}\right)$, nitrous oxide $\left(\mathrm{N}_{2} \mathrm{O}\right)$, and methane $\left(\mathrm{CH}_{4}\right)^{4,5}$ into the atmosphere. Moreover, several soil bacteria promote plant growth and productivity ${ }^{2,6}$. As soil represents a highly dynamic and complex environment, bacterial communities living in this ecosystem are influenced by a multitude of different biotic and abiotic factors. Previous studies showed that soil $\mathrm{pH}$ is a major driver of these communities ${ }^{7-9}$. Lauber and colleagues ${ }^{8}$ observed that the overall bacterial community composition in different soils from across South and North America was significantly correlated with soil pH. This was confirmed by a study of bacterial communities in German grassland and forest soils ${ }^{9}$. Other studies investigating the effect of edaphic parameters on soil bacteria found that these communities were influenced by the availability of nutrients such as carbon, nitrogen ${ }^{10,11}$, and soil moisture in grasslands ${ }^{12}$ and forests ${ }^{13}$

In recent years, the impact of land use intensification on bacterial community diversity and composition, e.g. by fertilization in grasslands, has been frequently investigated ${ }^{14-17}$. In a study by Herzog et al. ${ }^{15}$, composition and diversity of entire and active bacterial communities were altered by fertilizer application. Lauber et al. ${ }^{16}$ analyzed soil bacterial communities across different land use types such as grasslands and forests. For soil bacteria in forest systems, soil disturbance and organic matter removal ${ }^{18,19}$ as well as the dominant tree species ${ }^{20}$ have been shown to influence community composition. This provides evidence that land use intensification can alter soil bacterial community composition. However, most studies have focused on a limited number of soil samples in one region. Therefore, the response of bacterial communities in grasslands and forests to land use intensification and

${ }^{1}$ Department of Genomic and Applied Microbiology, Institute of Microbiology and Genetics, Georg-AugustUniversity Göttingen, Grisebachstr. 8, D-37077 Göttingen, Germany. ${ }^{2}$ Department of Crop Sciences, Georg-AugustUniversity Göttingen, Grisebachstr. 6, D-37077 Göttingen, Germany. ${ }^{3}$ Max Planck Institute for Biogeochemistry, Hans-Knoell-Str. 10, D-07745 Jena, Germany. Correspondence and requests for materials should be addressed to R.D. (email: rdaniel@gwdg.de) 


\begin{tabular}{|c|c|c|c|c|c|c|c|c|}
\hline Land use & Exploratory & $\mathbf{n}$ & pH & $\mathrm{C}: \mathrm{N}$ ratio & $\begin{array}{c}\text { Gravimetric } \\
\text { water content }(\%)\end{array}$ & Clay $\left(\mathrm{g} \mathrm{kg}^{-1}\right)$ & Silt $\left(\mathrm{g} \mathrm{kg}^{-1}\right)$ & Sand $\left(\mathrm{g} \mathrm{kg}^{-1}\right)$ \\
\hline \multirow{4}{*}{ Forest } & All plots & 150 & $4.5 \pm 1.1^{\mathrm{A}}$ & $13.8 \pm 3.2^{\mathrm{A}}$ & $33.5 \pm 18.1$ & $289.0 \pm 203.3^{\mathrm{A}}$ & $440.5 \pm 247.1$ & $67.5 \pm 386.7$ \\
\hline & Schorfheide-Chorin & 50 & $3.4 \pm 0.1^{\mathrm{a}}$ & $18.1 \pm 2.8^{\mathrm{a}}$ & $12.0 \pm 4.3^{\mathrm{a}}$ & $48.5 \pm 18.9^{\mathrm{a}}$ & $74.0 \pm 49.2^{\mathrm{a}}$ & $875.0 \pm 60.6^{\mathrm{a}}$ \\
\hline & Hainich-Dün & 50 & $4.6 \pm 0.9^{\mathrm{b}}$ & $12.8 \pm 1.1^{\mathrm{b}}$ & $33.5 \pm 6.4^{\mathrm{b}}$ & $307.0 \pm 99.3^{b}$ & $634.5 \pm 95.6^{\mathrm{b}}$ & $54.5 \pm 17.5^{\mathrm{b}}$ \\
\hline & Schwäbische Alb & 50 & $5.2 \pm 0.8^{\mathrm{b}}$ & $12.9 \pm 0.9^{\mathrm{b}}$ & $52.5 \pm 10.0^{c}$ & $501.0 \pm 104.8^{\mathrm{c}}$ & $445.0 \pm 107.6^{c}$ & $42.5 \pm 46.0^{\mathrm{b}}$ \\
\hline \multirow{4}{*}{ Grassland } & All plots & 150 & $6.7 \pm 0.7^{\mathrm{B}}$ & $10.3 \pm 0.9^{\mathrm{B}}$ & $31.5 \pm 39.4$ & $425.0 \pm 192.4^{\mathrm{B}}$ & $418.0 \pm 159.3$ & $74.5 \pm 228.2$ \\
\hline & Schorfheide-Chorin & 50 & $6.4 \pm 0.9^{\mathrm{a}}$ & $10.4 \pm 1.1^{\mathrm{a}}$ & $54.5 \pm 60.5^{\mathrm{a}}$ & $159.5 \pm 87.0^{\mathrm{a}}$ & $317.0 \pm 191.7^{\mathrm{a}}$ & $489.5 \pm 220.8^{\mathrm{a}}$ \\
\hline & Hainich-Dün & 50 & $7.1 \pm 0.9^{\mathrm{b}}$ & $10.1 \pm 0.5^{\mathrm{b}}$ & $22.0 \pm 5.4^{\mathrm{b}}$ & $452.0 \pm 130.3^{\mathrm{b}}$ & $489.5 \pm 122.7^{b}$ & $53.5 \pm 23.1^{\mathrm{b}}$ \\
\hline & Schwäbische Alb & 50 & $6.2 \pm 0.5^{\mathrm{a}}$ & $10.2 \pm 0.7^{\mathrm{b}}$ & $41.0 \pm 11.1^{\mathrm{a}}$ & $571.0 \pm 134.0^{c}$ & $386.0114 .6^{\mathrm{a}}$ & $41.0 \pm 45.0^{\mathrm{b}}$ \\
\hline
\end{tabular}

Table 1. Edaphic properties among different land uses and exploratories (median \pm SD). Significant differences between study regions are indicated by lowercase letters and between forest and grassland by capital letters according to Dunn's test $(\mathrm{P}<0.05)$.

environmental changes is not yet fully understood. Large comparative studies are required to unravel the diverse interactions between bacteria and their environments, and how changes in community composition might reflect changes in bacterial functioning.

The aim of the present study was to identify key drivers of bacterial community composition, diversity, and functions in forest and grassland soils. In addition, we aimed at clarifying in which way soil bacterial communities respond to management regime, and if changes are merely a product of the edaphic properties. In this study, 300 soil samples were taken from the three German Biodiversity Exploratories Schorfheide-Chorin, Hainich-Dün and the Schwäbische Alb ${ }^{21}$. Two previous studies focusing on subsets of samples taken in the Biodiversity Exploratories showed that bacterial diversity was influenced by land use intensity ${ }^{22}$ and land use type ${ }^{9}$. Bacterial communities were assessed by pyrotag sequencing targeting the bacterial 16S rRNA gene. Additionally, functional profiles were calculated from obtained $16 \mathrm{~S}$ rRNA gene data ${ }^{23}$. We focused on three main hypotheses: (1) soil bacterial communities exhibit distinct biogeographic patterns, (2) respond differently to soil conditions and land use intensification, and (3) bacterial community composition, diversity and functioning are shaped in a similar way within the same land use system.

\section{Results and Discussion}

General characteristics of the soil samples. Soil samples showed significant differences with respect to soil texture and edaphic properties (Table 1, Supplementary Material Tables S1 and S2). Forest soils were more acidic, had a higher $\mathrm{C}: \mathrm{N}$ ratio and smaller clay amount than grassland soils. Forest soil samples derived from the different exploratories exhibited significant differences in all measured edaphic properties. The SchorfheideChorin forest soils were more acid and had higher C:N ratios compared to the Hainich-Dün and Schwäbische Alb soils, which did not differ significantly. In addition, Schorfheide-Chorin forest soils also exhibited the lowest gravimetric water content, clay and silt amount of all exploratories.

Grassland soil samples derived from the different exploratories also exhibited significant differences between all measured edaphic properties. The Hainich-Dün grasslands soil had the highest $\mathrm{pH}$ values, lowest gravimetric water content and highest silt amount compared to the Schorfheide-Chorin and Schwäbische Alb soil, which did not differ significantly. The Schorfheide-Chorin grassland soils exhibited the highest C:N ratio and sand amount compared to the other two exploratories. Clay amount was lowest in the Schorfheide-Chorin grassland soils, followed by the Hainich-Dün soils. The highest clay amounts were determined for the Schwäbische Alb grassland soils. Significant differences in soil parameters between the different management regimes were not recorded (ANOVA, $\mathrm{P}>0.5$ in all cases).

Soil bacterial communities. Composition and diversity of soil bacterial communities were assessed by pyrotag sequencing of $16 \mathrm{~S}$ rRNA genes. After quality filtering, denoising, and removal of potential chimeras and non-bacterial sequences, approximately 2,700,000 high quality sequences with an average read length of $525 \mathrm{bp}$ were obtained for further analyses. All sequences were classified below phylum level. Based on richness estimator data (Michaelis-Menten fit; Supplementary Material Table S3) $78-88 \%$ of the operational taxonomic units (OTUs) at $80 \%$ identity (phylum level) and $27-55 \%$ of the OTUs at $97 \%$ identity (species level) were covered by the surveying effort (for rarefaction curves, see Supplementary Material Figs S1 and S2).

Obtained sequences clustered into 203,530 OTUs (97\% identity) and were assigned to 51 bacterial phyla, 574 orders and 1,215 families. The dominant phyla and proteobacterial classes ( $>1 \%$ of all sequences across all samples) were Actinobacteria $(23.75 \% \pm 8.55 \%)$, Alphaproteobacteria $(20.43 \% \pm 5.21 \%)$, Acidobacteria $(18.39 \% \% \pm 9.19 \%)$, Deltaproteobacteria $(7.22 \% \pm 2.84 \%)$. Bacteroidetes $(5.15 \% \pm 2.60 \%)$, Chloroflexi $(5.09 \% \pm 2.10 \%)$, Betaproteobacteria $(4.64 \% \pm 2.38 \%)$, Gammaproteobacteria $(4.32 \% \pm 1.23 \%)$, Gemmatimonadetes $(1.88 \% \pm 0.92 \%)$, Firmicutes $(1.18 \% \pm 3.20 \%)$, and Nitrospirae $(1.14 \% \pm 1.10 \%)$. These phylogenetic groups were present in all samples and accounted for more than $95 \%$ of all sequences analyzed in this study (Fig. 1). These results are consistent with previous studies on grassland $\mathrm{s}^{24}$ and temperate beech forest ${ }^{25}$. The most abundant phylotype $(3.99 \% \pm 2.44)$ is an uncultured member of the Subgroup 6 of the Acidobacteria. The five most abundant phylotypes that could be assigned to a genus are Bradyrhizobium ( $2.66 \% \pm 1.45 \%)$, Candidatus Solibacter $(2.00 \% \pm 1.86 \%)$, Haliangium $(1.39 \% \pm 0.74 \%)$, Variibacter $(1.36 \% \pm 0.58 \%)$ and Gaiella $(1.34 \% \pm 1.31 \%)$ of all sequences, respectively. 

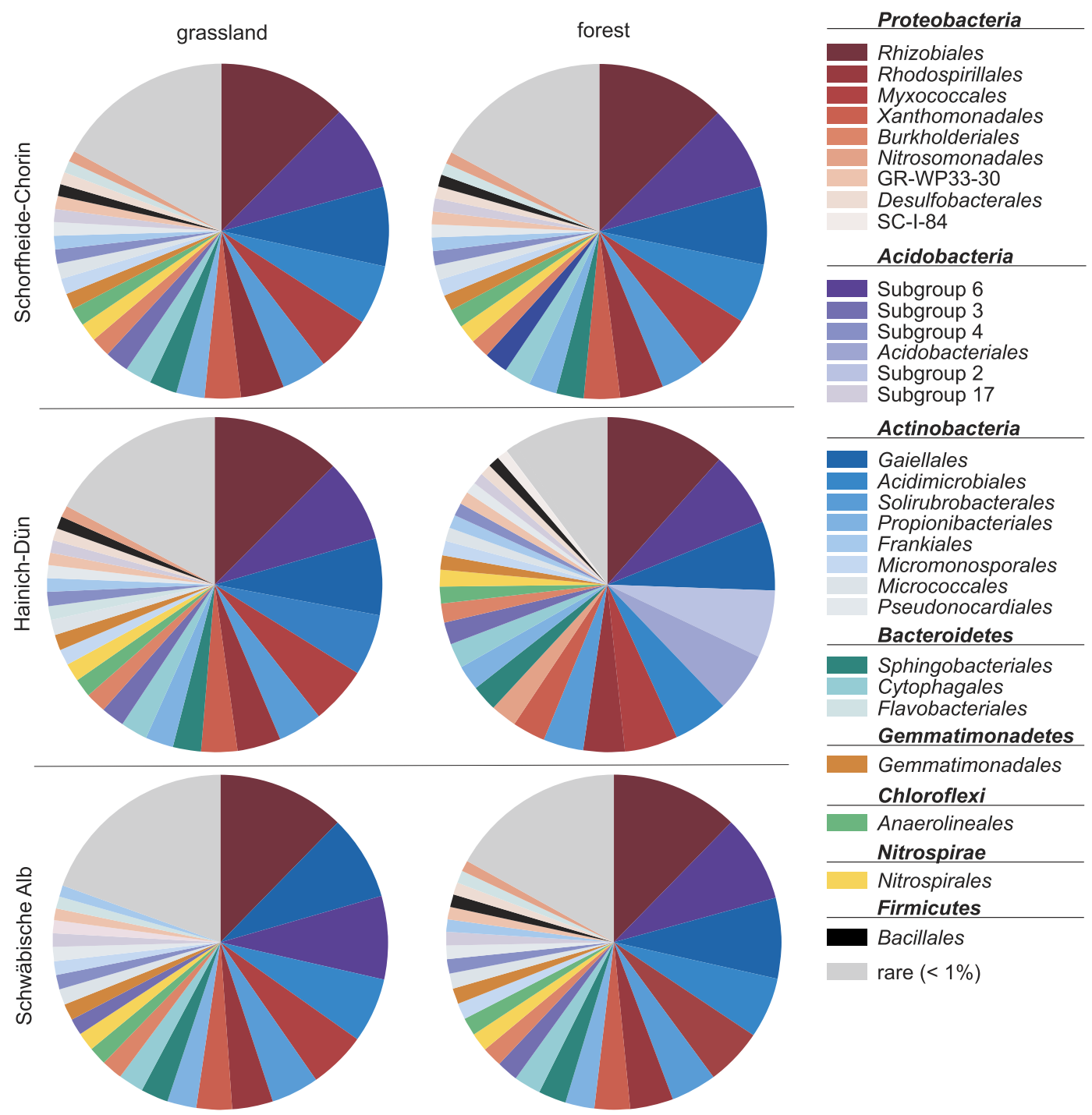

Figure 1. Abundances of bacterial orders in Schorfheide-Chorin, Hainich-Dün and Schwäbische Alb grassland and forest soils. Mean abundances of the most abundant bacterial orders $(>1 \%$ of the total bacterial community) for each exploratory and land use are given. Rare: sum of bacterial orders contributing $<1 \%$ to the total bacterial community per exploratory.

Biogeographic variations of soil bacterial diversity and community composition. Diversity (represented by the Shannon index $\mathrm{H}^{\prime}$ ) and community structure of soil bacteria (PERMANOVA, $\mathrm{P}<0.001$ ) differed between the three Biodiversity Exploratories. The Hainich-Dün exploratory harbored the most diverse bacterial community $\left(\mathrm{H}^{\prime}=10.22\right)$ compared to Schorfheide-Chorin $\left(\mathrm{H}^{\prime}=9.72\right)$ and the Schwäbische Alb $\left(\mathrm{H}^{\prime}=9.92\right)$. Furthermore, grassland soils are significantly more diverse than forest soils $\left(H^{\prime}=10.12\right.$ and $H^{\prime}=9.48$, respectively, with $\mathrm{P}<0.001$ ), which supports previous findings of Nacke and colleagues ${ }^{9}$, who reported that bacterial communities were more diverse in grasslands at phylum level. As samples derived from forests soils were more acidic than grassland soil samples $(\mathrm{P}<0.001)$, the difference in $\mathrm{pH}$ might explain the difference in diversity (Table 1 ).

The most dominant bacterial orders of the complete dataset differed in their distribution across the three exploratories. These differences most likely arose from differrences in edaphic properties in the exploratories. Therefore, we tested for correlation of environmental factors by NMDS analysis based on Bray-Curtis dissimilarities. Fitting the edaphic properties to the ordination revealed the $\mathrm{pH}$ as the strongest driver of the community. Additional canonical correspondence analysis (CCA) using $\mathrm{pH}$ as constrain showed that $\mathrm{pH}$ explains $26 \%$ of the variation in community structure $(\mathrm{P}<0.001$, Supplementary Figure $\mathrm{S} 3)$. We additionally found a separation of soil bacterial communities by sampling region (PERMANOVA, $\mathrm{P}<0.001$ ) and the two land use types grassland and forest (PERMANOVA, $\mathrm{P}<0.001$ ) (Supplementary Figure S4). Therefore, we were interested in a detailed analysis of the factors driving the changes in the structure of bacterial communities in each exploratory. We further split the data between grasslands and forests due to the strong separation between the community structure of both land use types. 
Key drivers of bacterial communities. To identify the key drivers of soil bacterial community structure for each land use type in each exploratory, we performed NMDS analysis for the six subsets. The soil pH was the only property, which affected the community structure in each subset (Fig. 2). Another property influencing the community structure in grasslands and forests was soil texture (amount of clay, sand and/or silt), which represents pore size, water and gas fluxes, and nutrient availability ${ }^{26,27}$. Moreover, soil texture is important for niche separation and protection from predation ${ }^{28}$.

In grassland soils, the C:N ratio influenced bacterial community structure in the Schwäbische Alb and Schorfheide-Chorin, but not in the Hainich-Dün. This is supported by a PFLA-based study on soil bacterial communities, in which edaphic properties such as soil texture, $\mathrm{pH}$, and $\mathrm{C}$ and $\mathrm{N}$ concentration were involved in structuring soil bacterial communities ${ }^{10}$. The land use intensity index (LUI) was only correlated with the Schwäbische Alb grassland community. However, the LUI only accounts for the amount and not for the source of fertilization. In the Schwäbische Alb grasslands, most plots received organic fertilizer (manure, dung), whereas fertilization in the Hainich-Dün and Schorfheide-Chorin was predominated by mineral fertilizer application. These findings support a recent study, in which soil microbial communities of farming systems receiving organic fertilizer were different compared to those of conventional, minerally fertilized systems and control soils ${ }^{29}$. In agreement with Geisseler and $\mathrm{Scow}^{30}$, clear trends suggesting bacterial community structural shifts due to long-term mineral fertilizer application, were not found in our survey.

In forest soils, the tree species was correlated with bacterial community structure in all exploratories, while the silvicultural management index (SMI) only significantly influenced the community structure in the Schorfheide-Chorin (Fig. 2). Soil bacterial communities under broadleaved (Fagus and Quercus) and coniferous (Pinus and Picea) trees formed distinct patterns. This is in accordance with results of previous studies ${ }^{9,20}$. Nacke et al. ${ }^{9}$ analyzed a subset of soil samples derived from the Schwäbische Alb and found that the bacterial community structure was different under beech (Fagus) and spruce (Picea). This is consistent with a study comparing bacterial communities under coniferous and broadleaved $\operatorname{trees}^{20}$. We did not observe a difference between the two broadleaved tree species, although differences in soil community structure between broadleaved trees have been described for Fagus versus Tilia and Acer ${ }^{31}$. These effects might be partly due to the reduced soil acidification and higher turnover rates of the leaf litter of Tilia and Acer ${ }^{32}$. Coniferous tree species such as spruce (Picea abies) and pine (Pinus sylvestris) are known to significantly decrease the soil $\mathrm{pH}$ (reviewed in ref. 33) due to the special chemical structure of evergreen litter or capture of atmospheric acidic compounds $s^{34}$. This would result in an indirect $\mathrm{pH}$ effect on soil bacteria. Additionally, this might be one of the reasons why tree species play an important role in the structuring of bacterial communities in all forest samples analyzed.

According to our hypothesis that bacterial community structure and diversity would be affected in similar ways under the same land use, we compared the bacterial diversity, represented by the Shannon index (H'), between the different management regimes (Supplementary Material Table S4). Differences in diversity were detected for the tree species in the Schwäbische Alb and Schorfheide-Chorin.

Interestingly, the management regimes in grasslands (meadow, pasture, mown pasture) and forests (unmanaged forest, age-lass forest, selection forest) exhibited no significant effect on bacterial diversity (PERMANOVA, $\mathrm{P}<0.05)$. This is in contrast to a previous study by Will et al. ${ }^{22}$, who found a higher bacterial diversity in grassland soils of low land use intensity in the Hainich-Dün. In contrast, Tardy et al. ${ }^{17}$ investigated bacterial diversity along gradients of land use intensity and observed the highest bacterial diversity in moderately managed soils. The authors suggest that this effect is related to the stress response of the bacterial community. In highly stressed environments, as under high land use intensity, diversity decreases due to the dominance of competitive species and competitive exclusion, while in unstressed environments diversity decreases due to the dominance of adapted species through selection. In accordance with our hypothesis, we could find soil conditions such as $\mathrm{pH}$ that consistently drive bacterial community structure as well as diversity, while management regimes and therefore land use intensity have no significant influence. In addition, we could show that $\mathrm{pH}$ is the best predictor of bacterial communities.

Bacterial functioning in grassland and forest soils. We further hypothesized that bacterial functioning was driven in a similar manner as bacterial community structure and diversity. To clarify this hypothesis, we focused on pathways involved in the cycling of carbon, nitrogen, phosphorus, and sulfur (Fig. 3) and compared the relative abundances of key enzyme-encoding genes between the two land uses grassland and forest. Abundances of the enzyme-encoding genes were derived from a novel bioinformatic tool Taxa4Fun ${ }^{23}$. Tax4Fun transforms the SILVA-based OTUs into a taxonomic profile of KEGG organisms, which is normalized by the $16 \mathrm{~S}$ rRNA copy number (obtained from NCBI genome annotations). As soils harbor unknown or uncultured organisms, not all 16S sequences can be mapped to KEGG organisms. Spearman correlation analysis of functional profiles derived from whole metagenome sequencing and profiles deduced from $16 \mathrm{~S}$ rRNA gene sequences revealed a median of the correlation coefficient of 0.8706 for soils ${ }^{23}$. This indicated that Tax4Fun provides a good approximation to functional profiles obtained from metagenomic shotgun sequencing approaches. This is especially valuable to deduce functional profiles for a large number of samples derived from complex environments, as achieving representative coverage for each sample of a large sample set by metagenome shotgun sequencing would be a daunting task.

Most key enzyme-encoding genes involved in the cycling of $\mathrm{C}, \mathrm{N}, \mathrm{S}$, and $\mathrm{P}$ are either more abundant in grassland or forest soils (Mann-Whitney test, $\mathrm{P}<0.05$, Supplementary Material Table S5). For example, genes that encode acid phosphatases were observed at 1.4-fold higher abundances in the functional profile of the forest soils than in the grassland soils, while alkaline phosphatases showed the opposite trend. We assume that this effect could be attributed to the difference in $\mathrm{pH}$ between the land use types, as we showed that $\mathrm{pH}$ is the best predictor for bacterial communities. The genes encoding urease were 1.2-fold more abundant in the grassland. The availability of urea was higher in the grassland samples, as these are partly fertilized with manure or dung or were 

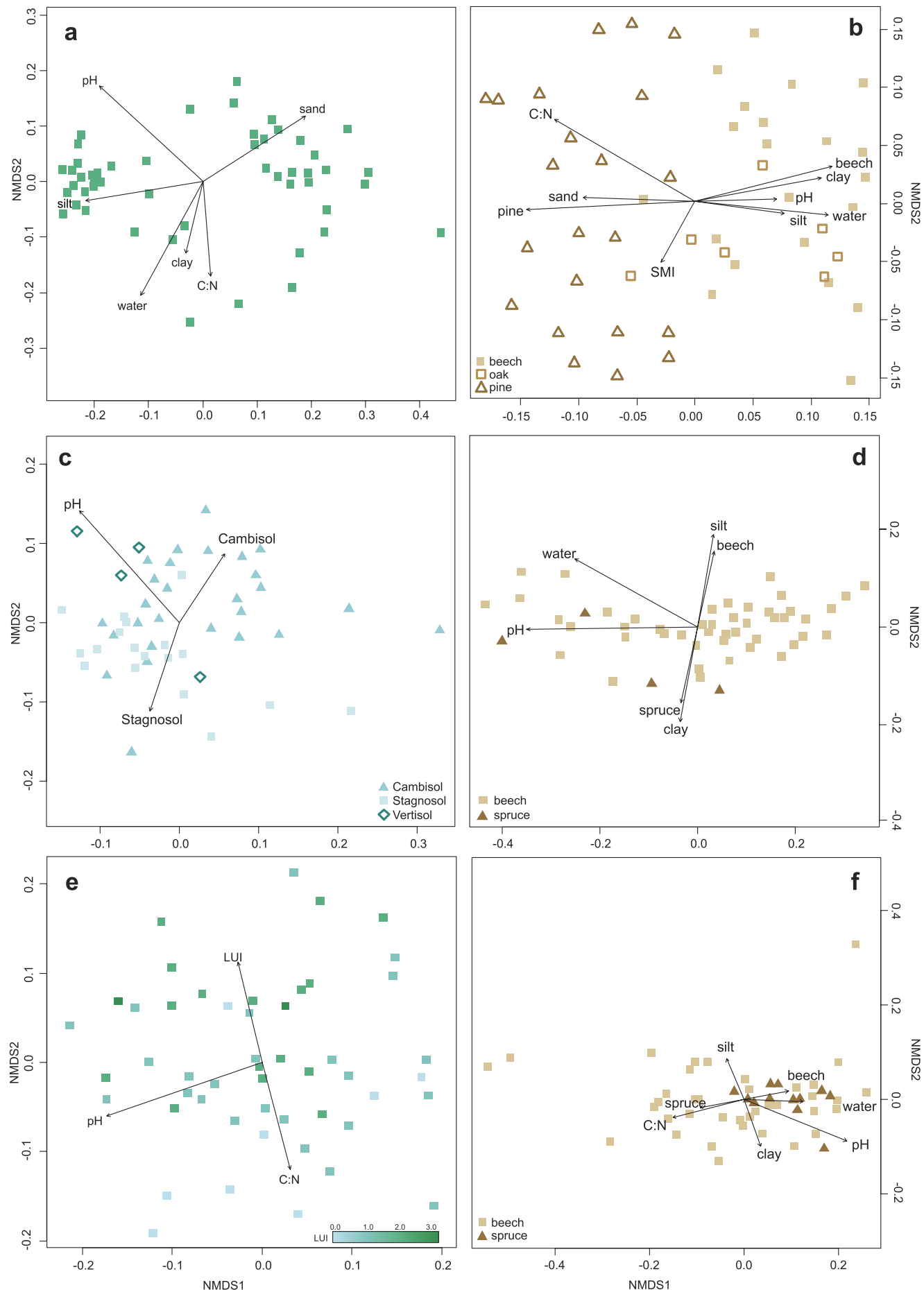

Figure 2. NMDS plots split by region and land use. NMDS plots based on Bray Curtis dissimilarities of grassland (a,c,e) and forest (b,d,f) bacterial communities. Environmental parameters that are significantly $(\mathrm{P}<0.05)$ correlated are indicated as arrows $(\mathrm{C}: \mathrm{N}$ : carbon: nitrogen ratio; water: gravimetric water content; sand: sand amount; silt: silt amount; clay: clay amount; LUI: land use intensity index in grasslands; SMI: silvicultural management index in forests). (a) Schorfheide-Chorin grassland samples; (b) Schorfheide-Chorin forest samples; (c) Hainich-Dün grassland samples; (d) Hainich-Dün forest samples; (e) Schwäbische Alb grassland samples; (f) Schwäbische Alb forest samples. Note that the NMDS axes have different scales for each ordination.

grazed by animals. Chitinase genes also showed a 1.2-fold higher abundance in grasslands compared to forest soils. This might result from the higher abundance of Actinobacteria in grassland soils, as this group is known 


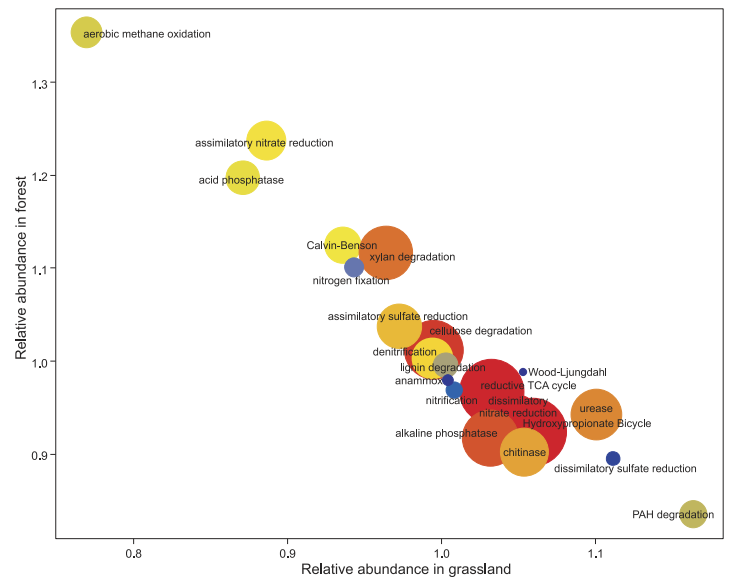

Figure 3. Relative abundances of key enzymes in grassland and forest. Key genes for nitrogen, sulfur, and methane metabolism, carbon fixation pathways, cellulose, xylan, lignin and polyaromatic-hydrocarbon (PAH) degradation, acid and alkaline phosphatases and urease were combined. Their mean abundance (relative to the mean in the complete dataset) in grasslands soil was plotted against the mean abundance in forest soils. Size and color of the circles indicate the mean abundance in the complete dataset. Low abundance: small blue circles; medium abundance: medium yellow circles; high abundance: large red circles. The enzymes included in the analysis are given in Supplementary Material Table S5.

to harbor a high number of chitinase genes ${ }^{35}$. Genes involved in polyaromatic hydrocarbon (PAH, here lignin) degradation are more abundant in grasslands. In forest systems, this process is primarily performed by ligninolytic fungi (mainly saprotrophic basidiomycetes), which are able to degrade wooden biomass ${ }^{36}$. One key enzyme for aerobic methane oxidation, methanol dehydrogenase, was notably more abundant in forest soils. Methane oxidation in forest soils is the largest biological sink for atmospheric methane ${ }^{4}$ and therefore plays a critical role in the flux of this greenhouse gas. Additionally, nitrous-oxide $\left(\mathrm{N}_{2} \mathrm{O}\right)$ reductase, which catalyzes the last step in denitrification and reduces $\mathrm{N}_{2} \mathrm{O}$ to $\mathrm{N}_{2}$, is also more abundant in forest soils (data not shown). These results indicate that temperate forest ecosystems not only play a crucial role in the regulation and removal of methane, but also of the greenhouse gas nitrous oxide.

Interestingly, the key enzyme of nitrogen fixation, the nitrogenase, is less abundant in grassland than in forest soils. In this study, only bulk soil was sampled and therefore presumably only free-living nitrogen-fixing bacteria could be detected. It is possible, that nitrogen fixation by free-living bacteria plays a greater role in forest systems, whereas symbiotic and rhizospheric bacteria, which were not covered by the study, carry out the major part of nitrogen fixation in grassland systems.

The obtained results suggest that the different land uses grassland and forest not only select for distinct bacterial populations, but also for specific functional traits within their bacterial communities. As the grasslands and forests analyzed in the present study are long-term established systems, it would be interesting to evaluate if a similar adaptation is also present in younger systems.

Soil $\mathrm{pH}$ is the best predictor of bacterial communities. In the present study, $\mathrm{pH}$ was the only factor, which influenced the bacterial community regardless of exploratory and land use. Furthermore, it not only affected bacterial community structure, but also the functional profile of the soil bacteria. As already mentioned, CCA analysis revealed that $\mathrm{pH}$ explains $26 \%$ of total variance in the community profile (Supplementary Figure S3). Thus, the $\mathrm{pH}$ was the strongest predictor for bacterial community structure.

We hypothesized that bacterial community structure and functioning would be shaped in a similar manner. Environmental correlations with the Tax4Fun-derived functional profile were tested by NMDS based on Bray-Curtis dissimilarities (Fig. 4). The results are similar to those obtained for the community structure. The $\mathrm{pH}$ played an important role in shaping the functional profile and explained $32 \%$ of the variance (tested by CCA, $\mathrm{P}<0.001$, Supplementary Figure S5). This supports our hypothesis that structure and functions of bacterial communities are shaped by similar mechanisms. The functional profile also showed a separation between grassland and forest systems.

Additionally, we found that $\mathrm{pH}$ is the strongest predictor of soil bacterial diversity $\left(\mathrm{P}<0.001, \mathrm{R}^{2}=0.4\right)$ (Fig. 5). It has already been shown that diversity of soil bacterial communities in the exploratories is positively correlated with $\mathrm{pH}^{9,22}$. However, our results indicate a more complex relationship between $\mathrm{pH}$ and diversity. Diversity was lowest at low $\mathrm{pH}$, then increased and appeared to be stable between $\mathrm{pH} 5$ and 7 and increases again under slightly alkaline conditions. This is in contrast to Fierer and Jackson ${ }^{7}$ and Lauber et al. ${ }^{8}$, who described a peak of soil bacterial diversity in near neutral soils.

Multinomial regression models revealed multiple responses of bacterial orders to soil $\mathrm{pH}$. To better understand the complex relationship of single bacterial groups and soil $\mathrm{pH}$, we applied multinomial regression models on the 30 most abundant orders of the dataset (Supplementary Material Figure S6). Four general 


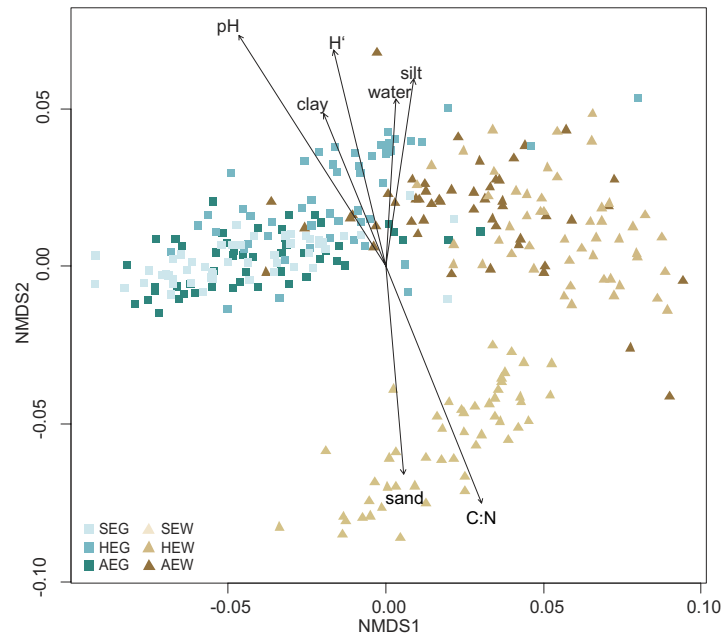

Figure 4. NMDS based on Bray Curtis dissimilarities of the functional profile. Statistically significant correlations of soil characteristics (C:N: carbon: nitrogen ratio; water: gravimetric water content; sand: sand amount; silt: silt amount; clay: clay amount) and the Shannon index $\left(\mathrm{H}^{\prime}\right)$ were indicated by arrows. Grassland soil samples are represented by brown squares, forest samples by green triangles. Samples from different regions are distinguished by color shading (SEG: Schorfheide-Chorin grassland; SEW: Schorfheide-Chorin forest; HEG: Hainich-Dün grassland; HEW: Hainich-Dün forest; AEG: Schwäbische Alb grassland; AEW: Schwäbische Alb forest).

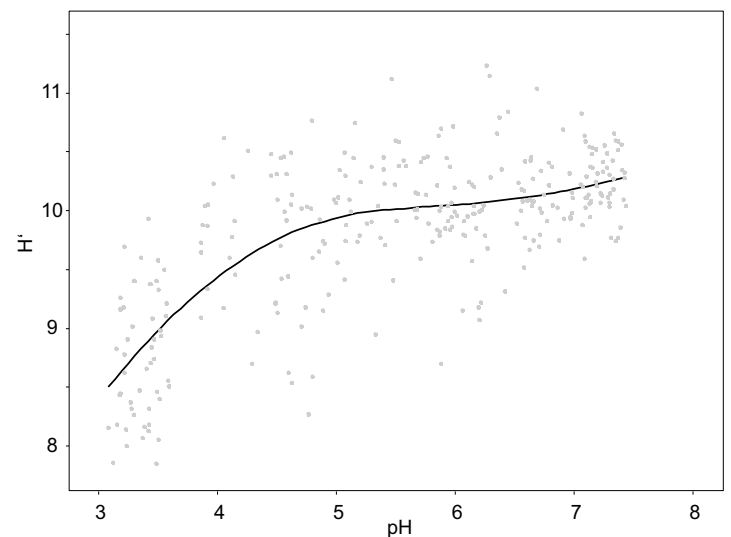

Figure 5. Relationship between soil bacterial diversity, represented by the Shannon index $\left(H^{\prime}\right)$ and soil pH. Points indicate observed Shannon indices for each sample, while the line represents the non-linear cubit regression fitted to the data (adjusted $\mathrm{R}^{2}=0.5337, \mathrm{P}<0.001$ ).

responses were observed: (1) decrease in abundance with increasing $\mathrm{pH}$ (Acidobacteriales, acidobacterial subgroup 3, Frankiales, Corynebacteriales), (2) increase in abundance with increasing pH (acidobacterial subgroup 6, Gaiellales, Acidimicrobiales, Propionibacteriales), (3) narrow $\mathrm{pH}$ range with high abundance (Rhizobiales, Rhodospirillales), and (4) relatively constant abundance across $\mathrm{pH}$ range (Bacillales, Gemmatimonadales, Sphingobacteriales) (Fig. 6). In their publication on niche theory, Austin and Smith ${ }^{37}$ described $\mathrm{pH}$ as a direct physiological gradient acting on organisms, resulting in unimodal, or skewed unimodal response curves restricted by growth limiting conditions at one end, and competition at the other end. This is supported by our observation of few highly abundant orders at low $\mathrm{pH}$ and many less abundant orders in near neutral soils. The ability to grow at low $\mathrm{pH}$ values is known as ATR (acid tolerance response) and confers a competitive advantage compared to other bacteria in soils.

To test which mechanisms are involved in acid tolerance of soil bacteria, we chose those genes reported to be involved in acid tolerance in Rhizobia ${ }^{38}$ and Gram positive bacteria ${ }^{39}$ that were present in the functional profile. Additionally, we analyzed the genes present of the KEGG pathway for biosynthesis of unsaturated fatty acids (ko01040) as well as 3-trans-2-decenoyl isomerase. This enzyme is involved in the generation of unsaturated fatty acids and was shown to increase acid tolerance in Streptococcus mutans by changing cell membrane composition $^{40}$. We found that the genes for biosynthesis of unsaturated fatty acids were highly abundant in low pH samples ( $\mathrm{pH} 3-4$ ), while decenoyl isomerase did not follow this trend (Fig. 7). Therefore, this gene might not be generally involved in acid tolerance in soil. Additionally, most genes involved in alkali production, two 


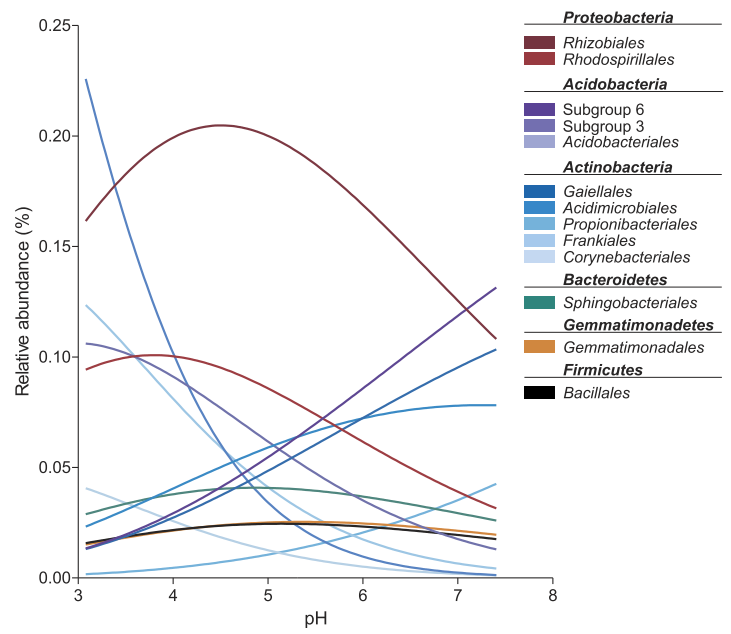

Figure 6. Response curves of selected bacterial orders towards $\mathrm{pH}$. Each line represents the predicted abundance changes along the measured $\mathrm{pH}$ gradient, based on predictions derived from multinomial regression models. A detailed version of this graph including the 30 most abundant orders is available as Supplementary Material Figure S4.
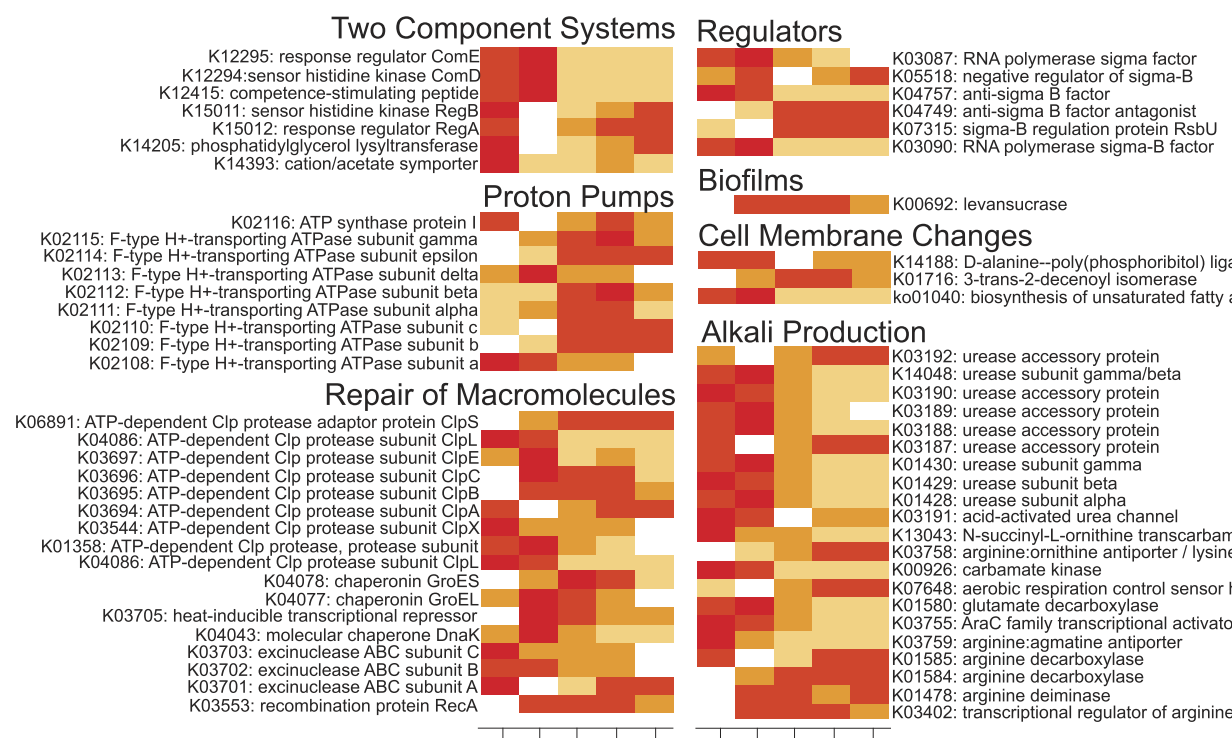

pH $3 \begin{array}{lllll}3 & 4 & 5 & 6 & 7\end{array}$

\section{Biofilms}
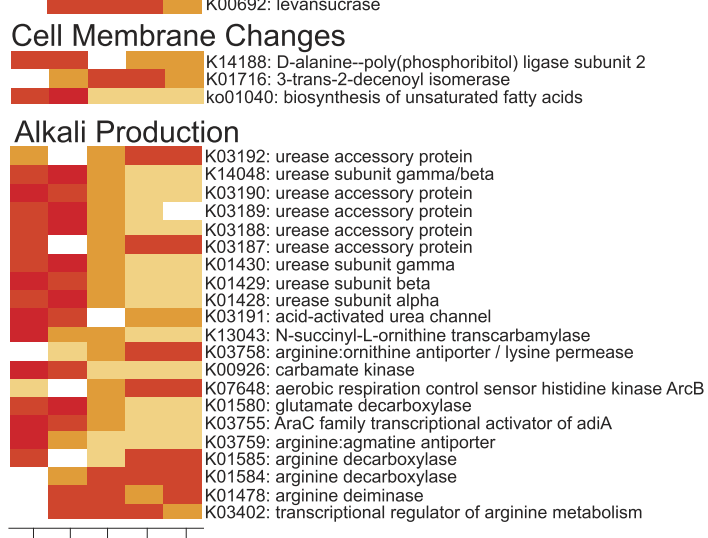

$\begin{array}{lllll}3 & 4 & 5 & 6 & 7\end{array}$

Figure 7. Heatmap based on mean abundances of genes putatively involved in ATR. Only genes with KEGG orthologs and present in the functional profile are shown. The KEGG pathway for biosynthesis of unsaturated fatty acids is included, also on the basis of the genes with KEGG orthologs in the functional profile. White: low relative abundance; yellow: mean relative abundance; red: high relative abundance.

component systems and repair of macromolecules were more abundant in the low $\mathrm{pH}$ samples compared to more neutral samples. Several genes involved in DNA repair were probably also involved in the ATR of soil-inhabiting bacteria, as well as levansucrase, a gene involved in biofilm formation. Our results suggest that bacteria can apply an active mechanism to cope with stressful $\mathrm{pH}$ conditions. Alkali production increases the $\mathrm{pH}$ in the immediate environment, improving bacterial survival chances. Additionally, macromolecule repair-enzymes protect and repair DNA and proteins, and bacteria seem to enhance $\mathrm{pH}$ tolerance by altering their cell wall components or protect themselves within biofilms.

\section{Conclusion}

During the last years, several studies targeting soil microbial communities and their driving forces came to the same conclusion that soil $\mathrm{pH}$ is the major driver of bacterial communities. This statement, however, falls short as it provides no direct answer about the complex interaction of soil bacteria with $\mathrm{pH}$. We showed that soil bacteria respond differently to changing $\mathrm{pH}$ conditions, being adapted to certain $\mathrm{pH}$ ranges or even stable over a broad $\mathrm{pH}$ range. Obtained data suggest that this adaptation is attributed to different mechanisms including 
alkali production and alteration of cell wall components. In addition to soil $\mathrm{pH}$, it is generally assumed that land use intensity drives bacterial community composition and diversity. However, the present study demonstrated that land use intensity plays a minor role, or that its effect is concealed by the tree species effect in forest. Biogeographic variations and the corresponding changing edaphic properties resulted in distinct patterns of soil bacteria, which explains regional differences and also the distinct patterns of bacterial communities in grasslands and forests. This is in line with our first and second hypothesis.

Large comparative studies are required to unravel the diverse interactions between bacteria and their environments, and how changes in community structure might reflect changes in bacterial functioning. With a total of 300 samples representing different land uses and gradients of land use intensity, this study provides comprehensive insights into soil bacterial communities present in temperate systems. Taking the enormous size and diversity of soil microbial communities into account, functional information on soil bacterial communities has been limited as it was so far mainly derived from small-scale comparative metagenomic approaches with a rather low coverage. However, the ability to focus on functional genes and enzymes offers novel insights in the nutrient cycling potential of soil bacterial communities. Consequently, the application of novel bioinformatic and statistical approaches, such as Tax4Fun and multinomial log-linear models, in microbial ecology resulted in a more holistic understanding of the links between bacteria and their environment.

\section{Materials and Methods}

Study regions. The present study was conducted as part of the German Biodiversity Exploratories initiative, which is a project investigating large-scale and long-term relationships of biodiversity and land use in Central European grasslands and forests ${ }^{21}$. Its unique design allows detailed analysis of bacterial communities along a regional north-south gradient in Germany. The study is based on 300 plots in three study regions (exploratories). They are located in the Schorfheide-Chorin, the Hainich-Dün and the Schwäbische Alb. Each study region covers the land use types forest and grassland. Grassland plots are $50 \mathrm{~m} \times 50 \mathrm{~m}$ and forest plots are $100 \mathrm{~m} \times 100 \mathrm{~m}$ in size.

The grassland land use intensity-gradient was represented by three different management regimes (meadows, pastures and mown pastures) that are non-fertilized or fertilized. Fertilization always represents higher land use intensity. The land use intensity index $\left(\mathrm{LUI}^{41}\right)$ combines and equally weights the three components of land use in grasslands: (1) fertilization, (2) mowing, and (3) grazing. To account for interannual variation in management practices, the LUI was calculated from 2006 (start of the experiment) to 2011 (sampling year) (Supplementary Table S1). It is therefore used as an index for long-term management and thereby allows the evaluation of long-term effects on bacterial communities.

In forests, the land use intensity-gradient was represented by different forest management systems (age class forest, selection forest and unmanaged forest). Additionally, forest plots were dominated by one of the following tree species: (1) European beech (Fagus sylvatica), (2) sessile/pedunculate oak (Quercus petrea/Quercus robur), (3) Scots pine (Pinus sylvestris) or (4) Norway spruce (Picea abies). The silvicultural management index (SMI) was used to assess the impact of management intensity in forest systems (Supplementary Table S1). This index integrates three characteristics of forest stands: (1) tree species, (2) stand age and (3) aboveground, living and dead wooden biomass ${ }^{42}$. Detailed information on land use, the applied management, dominant tree species, soil type and fertilization for every experimental plot is provided in Supplementary Material Table S2.

Sampling and soil properties. Soil samples were collected from all 300 experimental plots in May 2011. In brief, plots were sampled along two $36 \mathrm{~m}$ transects in forests and along two $18 \mathrm{~m}$ transects in grasslands. The top $10 \mathrm{~cm}$ of the soil layer were taken from 14 locations along the two transects in each plot with a split tube auger of $5 \mathrm{~cm}$ diameter. At forest sites, the litter layer was removed with a metal frame $(15 \times 15 \mathrm{~cm})$ prior to sampling. The soil cores were pooled and sieved to remove stones $>0.5 \mathrm{~cm}$ and roots.

Ten grams of the pooled soil samples were used to determine the gravimetric water content, which represents the water content of the respective sample at the sampling time. The subsamples were weighted and dried at $105^{\circ} \mathrm{C}$ to a constant weight. Air-dried soil samples sieved to $<2 \mathrm{~mm}$ were used for the determination of soil texture, soil $\mathrm{pH}$, and carbon $(\mathrm{C})$ and nitrogen $(\mathrm{N})$ concentrations as described previously ${ }^{43}$. Detailed information on soil characteristics is given in Supplementary Material Table S1.

DNA extraction, amplification of 16S rRNA genes and pyrosequencing. Total microbial community DNA was isolated from approximately $0.25 \mathrm{~g}$ soil per sample using the MoBio Power Soil DNA isolation kit (MoBio laboratories, Carlsbad, CA, USA) following the manufacturer's recommendations. This method was recently shown to perform equally well over a range of different soils ${ }^{44}$. It produces similar amounts of DNA and 16S rRNA gene copies for each soil tested and does not overestimate any of the abundant phyla detected throughout the soils. Therefore, extraction biases were limited and comparability given for all DNA extractions. DNA concentrations were quantified using a NanoDrop ND-1000 UV-Vis Spectrophotometer (NanoDrop Technologies, USA) as recommended by the manufacturer.

The V3-V5 region of the $16 \mathrm{~S}$ rRNA gene was amplified by PCR. The PCR reaction mixture $(50 \mu \mathrm{l})$ contained $10 \mu \mathrm{l} 5$-fold reaction buffer, $200 \mu \mathrm{M}$ of each of the four deoxyribonucleoside triphosphates, $2 \%$ DMSO, $2 \%$ BSA, $0.2 \mu \mathrm{M}$ of each of the primers, $0.5 \mathrm{U}$ of Phusion High fidelity DNA polymerase (Thermo Scientific, Waltham, MA, USA) and approximately $50 \mathrm{ng}$ of isolated DNA as template. The V3-V5 region was amplified with the following set of primers containing the Roche 454 pyrosequencing adaptors and a unique MID per sample (underlined): V3for 5'-CCATCTCATCCCTGCGTGTCTCCGACTCAG-MID-TACGGRAGGCAGCAG-3/45 and V5rev 5'-CCTATCCCCTGTGTGCCTTGGCAGTCTCAG-MID-CCGTCAATTCMTTTGAGT- $3^{\prime 46}$. The following thermal cycling scheme was used: initial denaturation at $98^{\circ} \mathrm{C}$ for $3 \mathrm{~min}, 25$ cycles of denaturation at $98^{\circ} \mathrm{C}$ for $10 \mathrm{~s}$, annealing at $58^{\circ} \mathrm{C}$ for $30 \mathrm{~s}$, and extension at $72^{\circ} \mathrm{C}$ for $30 \mathrm{~s}$ followed by a final extension at $72^{\circ} \mathrm{C}$ for $10 \mathrm{~min}$. All samples were amplified in triplicate, pooled in equal amounts and purified by gel electrophoresis using peqGOLD 
Gel Extraction kit as recommended by the manufacturer (Peqlab Biotechnologie GmbH, Erlangen, Germany). PCR products were quantified using the Quant-iT dsDNA HS assay kit and a Qubit fluorometer (Invitrogen $\mathrm{GmbH}$, Karlsruhe, Germany) as recommended by the manufacturer. The Göttingen Genomics Laboratory determined the 16S rRNA gene sequences employing the Roche GS-FLX+ pyrosequencer with Titanium chemistry (Roche, Mannheim, Germany).

Analysis of pyrosequencing data. Pyrosequencing-derived 16S rRNA gene sequences were processed using the QIIME software package version $1.8^{47}$. Following the extraction of raw data, reads shorter than $300 \mathrm{bp}$, with long homopolymer stretches ( $>8 \mathrm{bp}$ ), or primer mismatches $(>3)$ were removed. Subsequently, sequences were denoised employing Acacia version $1.53 \mathrm{~b}^{48}$. Cutadapt ${ }^{49}$ was employed to truncate remaining primer sequences. Chimeric sequences were removed using UCHIME implemented in USEARCH version (8.0.1623) first in de novo and subsequently in reference mode using the SILVA SSURef 123 NR database as reference database $^{50,51}$. Afterwards, processed sequences were clustered with UCLUST version 1.2.22q in operational taxonomic units (OTUs) at $97 \%$ and $80 \%$ genetic identity representing species and phylum level, respectively ${ }^{52}$. OTUs were classified by BLAST alignment against the most recent SILVA database (see above). Rarefaction curves, alpha diversity indices (Chao1, Shannon, Simpson) and Michaelis-Menten-Fit were determined using QIIME according to Wemheuer et al. ${ }^{53}$. The analysis was performed by using 5,311 sequences per sample (Supplementary Material Table S3). Non-metric multidimensional scaling plots were generated based on Bray Curtis dissimilarities or weighed UniFrac distances in R using the metaMDS function to visualize differences in bacterial community composition.

Statistical analyses. All statistical analyses were conducted employing R version $3.1^{54}$. The results of all statistical tests were regarded significant with $\mathrm{P} \leq 0.05$, and only significant results are shown and described throughout the manuscript. The median is used throughout the manuscript instead of the mean value, except stated otherwise. For all statistical analysis, the dataset calculated for $97 \%$ identity (species level) was used.

The Mann-Whitney-test and non-parametric Kruskal-Wallis one-way analysis of variance (ANOVA) were used due to the non-normal distribution of the data. They were performed to test for differences in soil parameters and bacterial diversity between land use systems, exploratories and management regimes. The effects of environmental parameters onto the variance of bacterial communities were analyzed using the envfit function as described previously ${ }^{55}$. Canonical correspondence analysis (CCA) on single soil properties was carried out using the $c c a$ function and subsequently tested for significance applying the permu.test function with 1000 permutations. All these functions are contained in the vegan package ${ }^{56}$. Response curves of bacterial orders toward $\mathrm{pH}$ were calculated employing a multinomial log-linear model (function multinom contained in the nnet package).

Functional profiles were predicted from obtained $16 \mathrm{~S}$ rRNA gene data using Tax4Fun ${ }^{23}$. Genes involved in acid tolerance (ATR) and encoding key enzymes in nutrient cycling were identified in the resulting profiles using their KEGG orthologs. The heatmap, based on the ATR-involved genes was calculated using the heatmap. 2 function of the gplots package ${ }^{57}$. Differences in the abundances of key genes involved in nutrient cycling were analyzed employing the Mann-Whitney test in R. The mean abundances of genes in grasslands and forests (relative to mean abundance in complete dataset) were plotted against each other using ggplot of the ggplot 2 package ${ }^{58}$.

Sequence data deposition. Sequence data were deposited in the Sequence Read Archive (SRA) of the National Center for Biotechnology Information (NCBI) under the accession number SRP065604.

\section{References}

1. Mooshammer, M. et al. Adjustment of microbial nitrogen use efficiency to carbon:nitrogen imbalances regulates soil nitrogen cycling. Nat Commun. 5, 3694 (2014).

2. van der Heijden, M. G., Bardgett, R. D. \& van Straalen, N. M. The unseen majority: soil microbes as drivers of plant diversity and productivity in terrestrial ecosystems. Ecol Lett. 11, 296-310 (2008).

3. Stursová, M., Zif̌ćáková, L., Leigh, M. B., Burgess, R. \& Baldrian, P. Cellulose utilization in forest litter and soil: identification of bacterial and fungal decomposers. FEMS Microbiol Ecol. 80, 735-746 (2012).

4. Kolb, S. The quest for atmospheric methane oxidizers in forest soils. Environ Microbiol Rep. 1, 336-346 (2009).

5. Thomson, A. J., Giannopoulos, G., Pretty, J., Baggs, E. M. \& Richardson, D. J. Biological sources and sinks of nitrous oxide and strategies to mitigate emissions. Philos Trans R Soc Lond B Biol Sci. 367, 1157-1168 (2012).

6. Hayat, R., Ali, S., Amara, U., Khalid, R. \& Ahmed, I. Soil beneficial bacteria and their role in plant growth promotion: a review. Ann Microbiol. 60, 579-598 (2010).

7. Fierer, N. \& Jackson, R. B. The diversity and biogeography of soil bacterial communities. Proc Natl Acad Sci USA. 103, 626-631 (2006).

8. Lauber, C. L., Hamady, M., Knight, R. \& Fierer, N. Pyrosequencing-based assessment of soil pH as a predictor of soil bacterial community structure at the continental scale. Appl Environ Microbiol. 75, 5111-5120 (2009).

9. Nacke, H. et al. Pyrosequencing-based assessment of bacterial community structure along different management types in German forest and grassland soils. PLoS One. 6, e17000 (2011).

10. de Vries, F. T. et al. Abiotic drivers and plant traits explain landscape-scale patterns in soil microbial communities. Ecol Lett. 15, 1230-1239 (2012).

11. Rasche, F. et al. Seasonality and resource availability control bacterial and archaeal communities in soils of a temperate beech forest. ISME J. 5, 389-402 (2011).

12. Cruz-Martinez, K., Suttle, K. B., Brodie, E. L., Power, M. E., Andersen, G. L. \& Banfield, J. F. Despite strong seasonal responses, soil microbial consortia are more resilient to long-term changes in rainfall than overlying grassland. ISME J. 3, 738-744 (2009).

13. Brockett, B. F. T., Prescott, C. E. \& Grayston, S. J. Soil moisture is the major factor influencing microbial community structure and enzyme activities across seven biogeoclimatic zones in western Canada. Soil Biol Biochem. 44, 9-20 (2010).

14. Fierer, N., Lauber, C. L., Ramirez, K. S., Zaneveld, J., Bradford, M. A. \& Knight, R. Comparative metagenomic, phylogenetic and physiological analyses of soil microbial communities across nitrogen gradients. ISME J. 6, 1007-1017 (2012).

15. Herzog, S., Wemheuer, F., Wemheuer, B. \& Daniel, R. Effects of fertilization and sampling time on composition and diversity of entire and active bacterial communities in german grassland soils. PLoS One. 10, e0145575 (2015). 
16. Lauber, C. L., Harnady, M., Knight, R. \& Fierer, N. Pyrosequencing-based assessment of soil pH as a predictor of soil bacterial community structure at the continental scale. Appl Environ Microbiol. 7, 1641-1650 (2013).

17. Tardy, V. et al. Shifts in microbial diversity through land use intensity as drivers of carbon mineralization in soil. Soil Biol Biochem. 90, 204-213 (2015).

18. Hartmann, M. et al. Significant and persistent impact of timber harvesting on soil microbial communities in Northern coniferous forests. ISME J. 6, 2199-2218 (2012).

19. Hartmann, M. et al. Resistance and resilience of the forest soil microbiome to logging-associated compaction. ISME J. 8, 226-244 (2014).

20. Urbanová, M., Šnajdr, J. \& Baldrian, P. Composition of fungal and bacterial communities in forest litter and soil is largely determined by dominant trees. Soil Biol Biochem. 84, 53-64 (2015).

21. Fischer, M. et al. Implementing large-scale and long-term functional biodiversity research: The Biodiversity Exploratories. Basic Appl Ecol. 11, 473-485 (2010).

22. Will, C. et al. Horizon-specific bacterial community composition of German grassland soils, as revealed by pyrosequencing-based analysis of 16S rRNA genes. Appl Environ Microbiol. 76, 6751-6759 (2010).

23. Aßhauer, K. P., Wemheuer, B., Daniel, R. \& Meinicke, P. Tax4Fun: predicting functional profiles from metagenomic $16 \mathrm{~S}$ rRNA data. Bioinformatics. 31, 2882-2884 (2015).

24. Prober, S. M. et al. Plant diversity predicts beta but not alpha diversity of soil microbes across grasslands worldwide. Ecol Lett. 18, 85-95 (2015).

25. Jeanbille, M. et al. Soil Parameters Drive the Structure, Diversity and Metabolic Potentials of the Bacterial Communities Across Temperate Beech Forest Soil Sequences. Microbial Ecol. 71, 1-12 (2015).

26. Oades, J. M. Soil organic matter and structural stability: mechanisms and implications for management. Plant Soil. 1984. 76, 319-337 (1984).

27. Schimel, D. S. et al. Climatic, edaphic, and biotic controls over storage and turnover of carbon in soils. Glob Biogeochem Cycles. 8, 279-293 (1994).

28. Heijnen, C. E. \& Veen, J. A. A determination of protective microhabitats for bacteria introduced into soil. FEMS Microbiol Lett. 85, 73-80 (1991).

29. Hartmann, M., Frey, B., Mayer, J., Mäder, P. \& Widmer, F. Distinct soil microbial diversity under long-term organic and conventional farming. ISME J. 9, 1177-1194 (2015).

30. Geisseler, D. \& Scow, K. M. Long-term effects of mineral fertilizers on soil microorganisms - A review. Soil Biol Biochem. 75, 54-63 (2014).

31. Thoms, C., Gattinger, A., Jacob, M., Thomas, F. M. \& Gleixner, G. Direct and indirect effects of tree diversity drive soil microbial diversity in temperate deciduous forest. Soil Biol Biochem. 42, 1558-1565 (2010).

32. Fried, J. S., Boyle, J. R., Tappeiner II, J. C. \& Cromack, K. Jr. Effects of bigleaf maple on soils in Douglas-fir forests. Can J For Res. 20, 259-266 (1990).

33. Hornung, M. Acidification of soils by trees and forests. Soil Use Manage. 1, 24-27 (1985).

34. Miller, J. D., Anderson, H. A., Cooper, J. M., Ferrier, R. C. \& Stewart, M. Evidence for enhanced atmospheric sulphate interception by Sitka spruce from evaluation of some Scottish catchment study data. Sci Total Environ. 103, 37-46 (1991).

35. Bai, Y., Eijsink, V. G., Kielak, A. M., van Veen, J. A. \& de Boer, W. Genomic comparison of chitinolytic enzyme systems from terrestrial and aquatic bacteria. Environ Microbiol. 18, 38-49 (2014).

36. Hammel, K. E. Mechanisms for polycyclic aromatic hydrocarbon degradation by ligninolytic fungi. Environ Health Perspect. 103, 41-43 (1995).

37. Austin, M. P. \& Smith, T. M. A new model for the continuum concept in Progress in theoretical vegetation science (eds Grabherr, G. et al.) 35-47 (Springer, 1990).

38. Dilworth, M. J., Howieson, J. G., Reeve, W. G., Tiwari, R. P. \& Glenn, A. R. Acid tolerance in legume root nodule bacteria and selecting for it. Aust J Exp Agric. 41, 435-446 (2001).

39. Cotter, P. D. \& Hill, C. Surviving the acid test: responses of gram-positive bacteria to low pH. Microbiol Mol Biol Rev. 67, 429-453 (2003).

40. Fozo, E. M. \& Quivey, R. G. The fabM gene product of Streptococcus mutans is responsible for the synthesis of monounsaturated fatty acids and is necessary for survival at low $\mathrm{pH}$. J Bacteriol. 186, 4152-4158 (2004).

41. Blüthgen, N. et al. A quantitative index of land-use intensity in grasslands: Integrating mowing, grazing and fertilization. Basic Appl Ecol. 13, 207-220 (2012).

42. Schall, P. \& Ammer, C. How to quantify forest management intensity in Central European forests. Eur J Forest Res. 132, 379-396 (2013).

43. Solly, E. et al. Factors controlling decomposition rates of fine root litter in temperate forests and grasslands. Plant Soil. 382, 203-218 (2014).

44. Wüst, P. K. et al. Estimates of soil bacterial ribosome content and diversity are significantly affected by the nucleic acid extraction method employed. Appl Environ Microbio. 82, 2595-2607 (2016).

45. Liu, Z., Lozupone, C., Hamady, M., Bushman, F. D. \& Knight, R. Short pyrosequencing reads suffice for accurate microbial community analysis. Nucleic Acids Res. 35, e120 (2007).

46. Wang, Y. \& Qian P. Y. Conservative fragments in bacterial $16 \mathrm{~S}$ rRNA genes and primer design for $16 \mathrm{~S}$ ribosomal DNA amplicons in metagenomic studies. PLoS One. 4, e7401 (2009).

47. Caporaso, J. G. et al. QIIME allows analysis of high-throughput community sequencing data. Nat Method. 7, 335-336 (2010).

48. Bragg, L., Stone, G., Imelfort, M., Hugenholtz, P. \& Tyson, G. W. Fast, accurate error-correction of amplicon pyrosequences using Acacia. Nat Methods. 9, 425-426 (2012).

49. Martin, M. Cutadapt removes adapter sequences from high-throughput sequencing reads. EMBnet.journal. 17, 10-12 (2011).

50. Quast, C. et al. The SILVA ribosomal RNA gene database project: improved data processing and web-based tools. Nucl Acids Res. 41, D590-D596 (2013).

51. Edgar, R. C., Haas, B. J., Clemente, J. C., Quince, C. \& Knight, R. UCHIME improves sensitivity and speed of chimera detection Bioinformatics. 27, 2194-2200 (2011).

52. Schloss, P. D. \& Handelsman, J. Introducing DOTUR, a computer program for defining operational taxonomic units and estimating species richness. Appl Environ Microbiol. 71, 1501-1506 (2005).

53. Wemheuer, B. et al. Impact of a phytoplankton bloom on the diversity of the active bacterial community in the southern North Sea as revealed by metatranscriptomic approaches. FEMS Microbiol Ecol. 87, 378-389 (2014).

54. R Development Core Team. R: A language and environment for statistical computing (R Foundation for Statistical Computing, Vienna, 2015).

55. Wietz, M. et al. Bacterial community dynamics during polysaccharide degradation at contrasting sites in the Southern and Atlantic Oceans. Environ Microbiol. 17, 3822-3831 (2015).

56. Oksanen, J. et al. vegan: Community Ecology Package. R package version 2.3-2. (2015).

57. Warnes, G. R. et al. gplots: Various R programming tools for plotting data. R package version 2.17 .0 (2015).

58. Wickham, H. ggplot2: elegant graphics for data analysis. (Springer Science \& Business Media, 2009). 


\section{Acknowledgements}

We thank the managers of the three exploratories, Kirsten Reichel-Jung, Swen Renner, Katrin Hartwich, Sonja Gockel, Kerstin Wiesner, and Martin Gorke for their work in maintaining the plot and project infrastructure; Christiane Fischer and Simone Pfeiffer for giving support through the central office, Michael Owonibi for managing the central data base, and Markus Fischer, Eduard Linsenmair, Dominik Hessenmöller, Jens Nieschulze, Daniel Prati, Ingo Schöning, François Buscot, Ernst-Detlef Schulze, Wolfgang W. Weisser and the late Elisabeth Kalko for their role in setting up the Biodiversity Exploratories project. The work has been (partly) funded by the Deutsche Forschungsgemeinschaft (DFG) Priority Program 1374 "Infrastructure-Biodiversity-Exploratories" (Grant ID DA374/4-1 and Grant ID DA374/6-1). In addition, we acknowledge support by the Open Access Publication Funds of the Göttingen University. Field work permits were issued by the responsible state environmental offices of Baden-Württemberg, Thüringen, and Brandenburg (according to $\$ 72 \mathrm{BbgNatSchG)}$ ). We further thank Andrea Thürmer of the Göttingen Genomics Laboratory for assistance with sequencing. Additionally, we would like to thank Peter Schall and Christian Ammer for the calculation of the SMI.

\section{Author Contributions}

R.D. and H.N. conceived the study and planned the experiments. K.K. and V.K. performed the experiments. K.K. and B.W. analyzed data. I.S. and M.S. contributed data. K.K., B.W., F.W. and R.D. wrote the manuscript. All authors interpreted the results and reviewed the manuscript.

\section{Additional Information}

Supplementary information accompanies this paper at http://www.nature.com/srep

Competing financial interests: The authors declare no competing financial interests.

How to cite this article: Kaiser, K. et al. Driving forces of soil bacterial community structure, diversity, and function in temperate grasslands and forests. Sci. Rep. 6, 33696; doi: 10.1038/srep33696 (2016).

(c) (i) This work is licensed under a Creative Commons Attribution 4.0 International License. The images or other third party material in this article are included in the article's Creative Commons license, unless indicated otherwise in the credit line; if the material is not included under the Creative Commons license, users will need to obtain permission from the license holder to reproduce the material. To view a copy of this license, visit http://creativecommons.org/licenses/by/4.0/

(C) The Author(s) 2016 


\section{Chapter III.3}

Tree Species EfFects on SoIl Microbial Communities 
III.3.

Manuscript ready for submission

\title{
Diversity and structure of soil microbial communities under European beech and Norway spruce at fine spatial scale in contrasting seasons
}

Running title: Tree Species Effects on Soil Microbial Communities

\author{
Heiko Nacke $^{1} \uparrow$, Kezia Goldmann ${ }^{2,3} \dagger$, Ingo Schöning ${ }^{4} \dagger$, Birgit Pfeiffer ${ }^{1}$, Kristin Kaiser ${ }^{1}$, \\ Genis Andres Castillo-Villamizar ${ }^{1}$, Susan Trumbore ${ }^{4}$, Marion Schrumpf ${ }^{4}$, François Buscot ${ }^{2,5}$, \\ Rolf Daniel ${ }^{1}$, Tesfaye Wubet ${ }^{2,5}$
}

${ }^{1}$ Department of Genomic and Applied Microbiology and Göttingen Genomics Laboratory, Institute of Microbiology and Genetics, Georg-August University, Göttingen, Germany

${ }^{2}$ Department of Soil Ecology, UFZ-Helmholtz Centre for Environmental Research, Halle (Saale), Germany

${ }^{3}$ Department of Biology II, University of Leipzig, Leipzig, Germany

${ }^{4}$ Max Planck Institute for Biogeochemistry, Jena, Germany

${ }^{5}$ German Centre for Integrative Biodiversity Research (iDiv) Halle-Jena-Leipzig, Leipzig, Germany

Author's contributions:

$\dagger \mathrm{HN}, \mathrm{KG}$, and IS contributed equally to this work.

Study design: HN, KG, IS, FB, RD and WB

Sampling: HN, KG, IS, and KK

Experiments: IS, ST, BP and GAC-V

Data analysis: HN, KK, KG, and IS

Writing of Manuskript: IS, KZ, IS

All authors contributed to the manuscript by commentary. 


\title{
TREE SPECIES EFFECTS ON SOIL MICROBIAL COMMUNITIES
}

\begin{abstract}
The complex interaction between trees and soil microbes in forests as well as its inherent seasonal and spatial variation is barely understood. In this study, we analyzed the effects of major European tree species (Fagus sylvatica L. and Picea abies (L.) Karst) on soil bacterial and fungal communities. Mineral soil samples were collected from different depths $(0-10 \mathrm{~cm}, 10-20 \mathrm{~cm})$ and different horizontal distances towards beech or spruce trunks $(0.5$, $1.5,2.5,3.5 \mathrm{~m}$ ) in early summer and autumn. We assessed diversity as well as composition of soil bacterial and fungal communities based on 16S and ITS rDNA sequences. At a genetic distance of 3\%, 23,727 bacterial and 1,336 fungal OTUs were detected. Diversity of both, bacteria and fungi, under beech and spruce was driven by abiotic soil properties (such as soil $\mathrm{pH}$ and clay contents). Seasonal effects on microbial diversity were not found and the distance from the tree trunk was only relevant for the diversity of bacteria under spruce $(P<0.01)$. Community composition of bacteria and fungi was significantly affected by tree species. Different ectomycorrhizal fungi (e.g. Tylospora) which are known to establish mutualistic associations with plant roots showed a tree species preference. Moreover, bacterial and fungal community composition showed spatial and seasonal shifts in soil surrounding beech and spruce. These shifts were partly a result of changes in nutrient availability, as organic carbon content decreased with increasing soil depth. With respect to horizontal distances from tree trunks, overall bacterial community composition showed significant variations under spruce trees. These variations might be partly due to changes in root impacts horizontally through soil profiles in the study area.
\end{abstract}

\section{Introduction}

Earth currently harbors approximately three trillion trees and only one gram of soil can contain billions of microbial cells (Rosselló-Mora and Amann, 2001; Crowther et al., 2015). The effect of trees on bacterial and fungal microorganisms in forest soils, however, comprising many taxa involved in decomposition of plant litter as well as deadwood, is still poorly understood. Trees substantially impact soil physical, chemical and biological properties by species-specific leaf and root litter inputs, root architecture, root exudates, and nutrient uptake (Priha and Smolander, 1999; Saetre, 1999, Augusto et al., 2002; Ayres et al., 2009; Cesarz et al., 2013). Furthermore, canopy structure and stem flow affect moisture and nutrient level in soil located close to tree trunks (Johnson and Lehmann, 2006). As a 
consequence of direct or indirect tree impacts, changes in the spatial distribution of microbes, vertically through the soil profile as well as horizontally, can occur (Saetre and Bååth, 2000; Ettema and Wardle, 2002).

European beech (Fagus sylvatica L.) and Norway spruce (Picea abies (L.) Karst) represent dominant forest trees in Central Europe (Hanewinkel et al., 2012; Cesarz et al., 2013). It has been indicated that these tree species cause soil microbial community shifts, e.g., by modification of soil characteristics such as $\mathrm{pH}$ or carbon stocks (Lejon et al., 2005; Schulp et al., 2008; Thoms et al., 2010; Nacke et al., 2011). Since the 19th century, reforestation of devastated forest sites using Norway spruce has been very common in Central Europe (Berger and Berger, 2012). Replacement of beech by spruce species is associated with changes in humus form, acidity and soil structure (Berger and Berger, 2012). Root system and exudation differs significantly between beech and spruce species. Spruce is typically shallow rooted, whereas beech is able to acquire nutrients from a wide range of soil horizons through its deep root system (so called 'base-pump'). The released root exudates can vary between Fagus sylvatica L. and Picea abies (L.) Karst, e.g., seasonally, in quantity as well as in composition (Geßler et al., 1998; Fender et al., 2013) and potentially affect microbial processes such as respiration (Cesarz et al., 2013). Besides roots, also crowns of broad-leaved trees undergo seasonal changes. As a consequence of litterfall, fresh organic matter accumulates on forest floor in autumn and early winter. Thus, substantial seasonal changes in nutrient availability for microorganisms occur under beech trees. The constitution as well as decomposability of leaf and needle litter originating from European beech and Norway spruce, respectively, varies significantly (Priha and Smolander, 1997). Components of needle litter from Norway spruce such as waxes and phenolic compounds are highly recalcitrant towards biological degradation, whereas beech leaf litter contains higher amounts of more easily decomposable water-soluble substances (Nykvist, 1963; Priha and Smolander, 1997). However, Fagus sylvatica L. litter decomposition rates are slower than those of other deciduous tree species including Acer spp., Carpinus betulus L., Fraxinus excelsior L. and Tilia spp. litter (Jacob et al., 2010). European beech and Norway spruce also differ in the magnitude of stemflow. In beech stands, the stemflow water contributes 5-20\% to the annual soil water input (Koch and Matzner 1993, Johnson and Lehmann, 2006). Stemflow in conifer forests is much lower (often below 1\%) compared to beech forests due to differences in branch angle, specific surface roughness of branches and bark (Johnson and Lehmann, 2006). Koch and Matzner (1993) analyzed the main chemical soil properties in a European beech and Norway spruce forest as influenced by the distance from the stem basis. Under a 144-year old beech forest, 


\section{TREE SPECIES EFFECTS ON SOIL MICROBIAL COMMUNITIES}

$\mathrm{pH}$ values of the whole soil profile $(0-50 \mathrm{~cm}$; Dystric Cambisol) were decreased in $10 \mathrm{~cm}$ and $40 \mathrm{~cm}$ distance from the stem basis compared to the soil $\mathrm{pH}$ in $>4 \mathrm{~m}$ distance from the stem basis. A similar effect could not be demonstrated under a 70-year-old Norway spruce forest. However, Koch and Matzner (1993) could not find any consistent significant effect for C and $\mathrm{N}$ concentrations as well as the $\mathrm{CN}$ ratio in relation to the distance to the stem basis.

A number of available studies describing drivers of soil microbial diversity and community structure have focused on the impacts of agricultural plants, whereas effects of different tree species have been rarely explored (Priha and Smolander, 1997; Acosta-Martínez et al., 2008; Haichar et al., 2008; Li et al., 2012; Wubet et al., 2012; Urbanová et al., 2015). An improved knowledge about tree impacts is essential to evaluate the importance of beech and spruce in shaping forest soil ecosystem characteristics. Currently, detailed information on soil bacterial and fungal community composition and the factors altering it in beech and spruce dominated forests is lacking. In many previous studies, methods providing coarse phylogenetic information were used to identify effects of tree species on soil microbial communities. Differences in the genetic structures of soil bacterial and fungal communities in spruce, Douglas-fir, oak and beech plots in France were indicated by automated ribosomal intergenic spacer analysis (ARISA) profiles (Lejon et al., 2005). Furthermore, Jiang et al. (2011) found distinct bacterial and fungal communities in soil beneath broad-leaved and coniferous species based on DGGE profiles. More recently, Tedersoo and colleagues (2015) analyzed pyrosequencing-derived ITS sequences to assess the effects of tree diversity on fungi, protists and meiofauna inhabiting Estonian and Finnish forest soil. Results indicated that compared to the effects of individual tree species and soil parameters, tree diversity per se had a minor influence on the taxonomic richness of soil biota (Tedersoo et al., 2016). In addition, based on amplicon pyrosequencing data, significant effects of tree species dominating study areas in the Czech Republic on soil bacterial and fungal community composition were reported by Urbánova et al. (2015).

In this study, we applied pyrosequencing of the V3-V5 16S and the ITS rDNA gene region to assess diversity as well as composition of soil bacterial and fungal communities, respectively, under European beech and Norway spruce. Since the life cycle of microbes inhabiting forest soils can be strongly affected by seasons through changes in abiotic and biotic factors (Thoms and Gleixner, 2013), samples collected in early summer and autumn were analyzed. Furthermore, to determine spatial tree effects, soil removed from different depths and horizontal distances towards tree trunks was considered within this survey. A total 
of 128 soil samples, allowing robust statistical analysis of tree effects on soil microbial communities, were collected under beech and spruce trees.

To our knowledge, this is the first survey combining seasonal and fine spatial scale to investigate tree impacts on diversity as well as composition of soil bacterial and fungal communities. We aim to verify (1) that soil microbial diversity and community composition show a strong host species effect and (2) that tree architecture determines seasonal and spatial patterns in soil microbial diversity and community composition.

\section{Materials and Methods}

\section{Sampling, soil properties and DNA extraction}

All soil samples were derived from a beech (Fagus sylvatica L.) and a spruce (Picea abies L. (Karst)) forest site located in the Hainich-Dün region in Germany (Fischer et al., 2010). The age of the trees at both sites ranged between 50 to 65 years. The mineral soil was sampled in 0---10 $\mathrm{cm}$ and 10-20 $\mathrm{cm}$ depth using split tubes with a diameter of $4.8 \mathrm{~cm}$ (Eijkelkamp Agrisearch Equipment, Giesbeck, Netherlands). Mineral soil samples were taken from different horizontal distances $(0.5,1.5,2.5$ and $3.5 \mathrm{~m})$ towards the trunks of four randomly selected trees per site (see Figure 1). Sampling was performed during two seasons, early summer and autumn. We applied a paired sampling approach, meaning that the sampling positions in autumn were $<30 \mathrm{~cm}$ away from the sampling points in early summer. Detailed information on location of selected trees and sampling points can be found in Supplementary Table S1. A total of 128 soil samples (2 sites x 2 soil depths x 4 trees x 4 horizontal sampling distances x 2 seasons), were immediately sieved $<4 \mathrm{~mm}$ mesh size in the field and homogenized. One aliquot of each sample was frozen $\left(-20^{\circ} \mathrm{C}\right)$ for nucleic acids extraction, and another aliquot was air-dried and sieved to $<2 \mathrm{~mm}$ for soil chemical analyses.

The $\mathrm{pH}$ values were measured in duplicate in the supernatant of 1:2.5 mixtures of soil and $0.01 \mathrm{M} \mathrm{CaCl}_{2}$ with a glass electrode. Additionally, the gravimetric water content of the airdried soil was determined. A previous study by Wäldchen et al. (2012) showed that the gravimetric water content of air-dried soil is well suited to predict clay contents in our study area. For simplification purposes the 'estimated clay contents' according to Wäldchen et al. (2012) are designated as 'clay contents' in the following sections. The remaining soil was ground to $<100 \mu \mathrm{m}$. Ground samples were analyzed for total carbon $(\mathrm{C})$ and nitrogen $(\mathrm{N})$ by dry combustion with the $\mathrm{CN}$ analyzer 'Vario Max' (Elementar Analysensysteme GmbH, Hanau, Germany). Inorganic carbon (IC) concentrations were determined with the same 


\section{TREE SPECIES EFFECTS ON SOIL MICROBIAL COMMUNITIES}

analyzer after the ignition of samples for 16 hours at $450^{\circ} \mathrm{C}$. The organic carbon concentrations equaled the differences between total carbon concentration and inorganic carbon concentration.

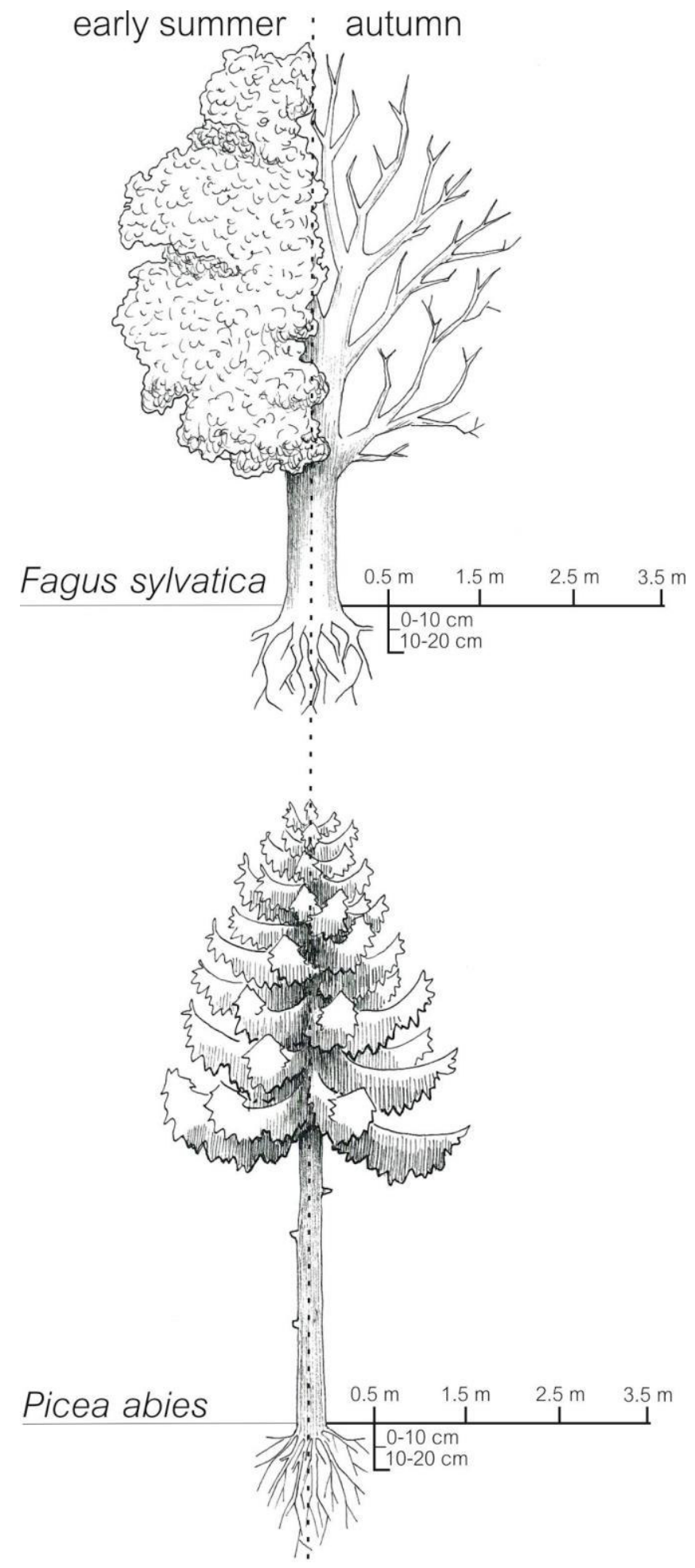

Figure 1. Sampling design: In early summer and autumn 2012 samples were taken in $0.5 \mathrm{~m}, 1.5 \mathrm{~m}, 2.5 \mathrm{~m}$ and $3.5 \mathrm{~m}$ distance from the tree trunks of four European beech and four Norway spruce trees (tree replicates); at all sampling points soil samples from $0-10 \mathrm{~cm}$ and $10-20 \mathrm{~cm}$, were taken. 
Total microbial community DNA was extracted from approximately $2 \mathrm{~g}$ of frozen soil per sample using the PowerSoil total RNA isolation kit, the PowerSoil DNA elution accessory kit, and the PowerClean DNA Clean-Up kit (MoBio Laboratories, Carlsbad, CA, USA) according to the manufacturer's instruction. DNA concentrations were quantified using a NanoDrop UV-Vis spectrophotometer (Peqlab Biotechnologie GmbH, Erlangen, Germany) according to the manufacturer's protocol.

\section{Amplification and pyrosequencing of partial 16S rRNA genes and ITS rDNA}

The V3-V5 region of bacterial 16S rRNA genes was amplified by PCR. The PCR reaction mixture $(50 \mu \mathrm{l})$ contained $10 \mu \mathrm{l}$ fivefold reaction buffer (Phusion HF buffer, Thermo Fisher Scientific Inc., Germany), $200 \mu \mathrm{M}$ of each of the four deoxynucleoside triphosphates, 5\% DMSO, $1 \mathrm{U}$ Phusion high fidelity DNA polymerase (Thermo Fisher Scientific Inc.), approximately $25 \mathrm{ng}$ DNA as template, and $4 \mu \mathrm{M}$ of each of the primers. Primers used were 343F (Liu et al., 2007) containing a sample-specific MID (Extended Multiplex Identifier, size: ten nucleotides) and the Roche 454 pyrosequencing adaptor A (underlined), and 907R (Cuesta Garrote et al., 2011) containing Roche 454 pyrosequencing adaptor B (underlined) (343F, 5'-CCATCTCATCCCTGCGTGTCTCCGACTCAG-MID-TACGGRAGGCAGCAG3'; 907R, 5'-CCTATCCCCTGTGTGCCTTGGCAGTCTCAGCCGTCAATTCMTTTGAGT$\left.3^{\prime}\right)$. The PCR reactions were initiated at $98{ }^{\circ} \mathrm{C}(2 \mathrm{~min})$, followed by 25 cycles of $98{ }^{\circ} \mathrm{C}(45$ sec), $58^{\circ} \mathrm{C}(45 \mathrm{sec})$ and $72{ }^{\circ} \mathrm{C}(40 \mathrm{sec})$, and ended with incubation at $72^{\circ} \mathrm{C}$ for $5 \mathrm{~min}$.

To produce fungal ITS rDNA amplicon libraries primer ITS1F (Gardes and Bruns, 1993) containing Roche 454 pyrosequencing adaptor B and a sample-specific MID, as well as primer ITS4 (White et al., 1990) containing Roche 454 pyrosequencing adaptor A have been used (see also Wubet et al,. 2012). The PCR reactions were performed in a total volume of 50 $\mu 1$ reaction mix containing $1 \mu \mathrm{l}$ DNA template (7-15 ng), $25 \mu \mathrm{l}$ Go Taq Green Master mix (Promega, Mannheim, Germany) and $1 \mu 125$ pmol of each of the ITS region-specific primers. Touchdown PCR conditions as described by Wubet et al. (2012) were used to amplify fungal ITS rDNA.

All samples were amplified in triplicate, purified using the peqGold gel extraction kit (Peqlab Biotechnologie $\mathrm{GmbH}$ ) and the Qiagen gel extraction kit (Qiagen, Hilden, Germany) as recommended by the manufacturer, and pooled in equal amounts. Quantification of PCR products was performed using the Quant-iT dsDNA BR assay kit and a Qubit fluorometer (Life Technologies GmbH, Karlsruhe, Germany). Sequences of partial 16S rRNA genes and fungal ITS rDNA were decoded at the Göttingen Genomics Laboratory and the Department of 


\section{TREE SPECIES EFFECTS ON SOIL MICROBIAL COMMUNITIES}

Soil Ecology (UFZ-Helmholtz Centre for Environmental Research, Halle, Germany), respectively, by using a Roche GS-FLX 454 pyrosequencer (Roche, Mannheim, Germany) and Titanium chemistry as recommended by the manufacturer.

\section{Pyrosequencing data processing and analysis}

All generated sequences were reassigned to single samples based on the different MIDs. Bacterial 16S rRNA gene sequence datasets were preprocessed as described by Broszat et al. (2014). Uclust (Edgar, 2010), implemented in QIIME (Caporaso et al., 2010), was used to determine bacterial OTUs at a genetic distance of 3\%. To taxonomically classify OTUs, partial 16S rRNA gene sequences were compared with the SILVA SSU database release 119 (Pruesse et al., 2007). OTUs classified as chloroplast or mitochondrion as well as unclassified OTUs were removed from 16S rRNA gene sequence datasets.

Fungal ITS rDNA sequence datasets were preprocessed as described by Goldmann et al. (2015). Cd-hit ( $\mathrm{Li}$ and Godzik, 2006) was applied to determine fungal OTUs at $3 \%$ genetic distance. To identify fungi and taxonomically classify OTUs, ITS rDNA sequences were queried against the UNITE database (Kõljalg et al., 2013) by using the classify.seq comment as implemented in MOTHUR (Schloss et al., 2009). After discarding unclassified OTUs, BLASTn search (e.g. Johnson et al., 2008) against the NCBI GenBank database (Benson et al., 2015) was subjected to improve taxonimical resolution.

Bacterial and fungal OTUs comprising only one or two sequences (singleton and doubleton OTUs) were removed from the datasets. The number of analyzed sequences per sample can have an effect on the predicted number of OTUs (Morales et al., 2009). Therefore, OTUbased comparisons were performed at the same level of surveying effort (bacteria: 2,540 sequences per sample; fungi: 1,996 sequences per sample). OTUs identified at a genetic distance of 3\% were used to calculate the Shannon index (Shannon, 1948).

\section{Statistical analyses}

The response of main soil characteristics (e.g. CN ratio, clay content) to soil depth, season and distance from the tree trunk was assessed for both study areas separately by analysis of covariance (ANCOVA) using the aov command of the R-package stats. The random effects of the four sampling transects per study area were considered in the analysis by including them as a factor in our linear models (tree replicate). Additional ANCOVA's were calculated to identify the major drivers of bacterial and fungal shannon diversities. In these analyses, we considered tree replicate, soil $\mathrm{pH}$, estimated clay contents, soil depth, season and distance 
from the tree trunk as explanatory variables. We additionally considered all two way interactions with soil $\mathrm{pH}$. Normal distribution of residuals and equality of variances were tested with the diagnostic plots offered by the statistical software R.

To assess the effect of removing rare OTUs on the bacterial and fungal community composition, respectively, we calculated non-metric multidimensional scaling (NMDS) ordination with 20 random starts from the complete datasets and the datasets without singletons and doubletons. In order to test the congruence between ordinations, we used the Procrustes analysis and its protest command (Peres-Neto et al., 2006) implemented in the vegan package (Oksanen et al., 2012) of R (R Development Core Team, 2015). Significance of congruence was tested using a Monte Carlo procedure with 999 permutations. We found that neither bacterial nor fungal community composition was affected by the presence or absence of rare OTUs (bacteria: Procrustes correlation coefficient $=0.991, P<0.001$; fungi: Procrustes correlation coefficient $=0.986, P<0.001$ ). Thus, as mentioned above, singleton and doubleton OTUs were not considered with respect to amplicon sequence-based analysis of bacterial and fungal communities. Furthermore, to improve comparability of datasets and avoid inclusion of potential artificial sequences resulting from amplicon generation and pyrosequencing bias, singletons should be removed (Zhou et al., 2011).

The effect of tree species on soil bacterial and fungal community composition, respectively, was visualized using principal coordinates analysis plots generated with emperor (VázquezBaeza et al., 2013).

In order to test the effects of tree replicate, soil $\mathrm{pH}$, clay content, soil depth, sampling season and horizontal distance away from tree trunk on bacterial and fungal community composition, we performed multivariate analysis of variance (MANOVA) under usage of the adonis command of the R-package vegan (Oksanen et al., 2012) based on weighted UniFrac (Lozupone et al., 2011) distance matrices. These analyses were conducted for the microbial communities under each tree species individually.

To further identify individual taxa strongly associated with a specific tree species, season or spatial position in soil, the multipatt algorithm and the IndVal function in the $\mathrm{R}$ package indicspecies (De Cáceres and Legendre, 2009) has been used based on relative abundance of bacterial genera and fungal OTUs, respectively. The PAST statistical package (Hammer et al., 2001) was used for the performance of Mann-Whitney U test and Spearman's rank correlations. We applied Mann-Whitney $U$ test to identify dominant genera showing significant differences in relative abundance between soil surrounding beech and spruce, seasons, upper $(0-10 \mathrm{~cm})$ and lower $(10-20 \mathrm{~cm})$ mineral soil increments or different soil 


\section{TREE SPECIES EFFECTS ON SOIL MICROBIAL COMMUNITIES}

sampling distances from tree trunks. Spearman's rank correlations were used to correlate relative abundances of dominant genera with soil parameters.

\section{Accession numbers}

The 16S rRNA gene and ITS rDNA sequences were deposited in the National Center for Biotechnology Information (NCBI) Sequence Read Archive (SRA) under study accession numbers SRP040766 and SRP044665, respectively.

\section{Results and Discussion}

\section{General characteristics of soil samples and amplicon datasets}

Both forest stands grow on lime stone which is covered with a loess layer of variable thickness. The loess layer is thinner at the spruce than at the beech forest site. Therefore, $\mathrm{pH}$ values in 0-10 cm depth ranged between 3.1 and 5.9 at the spruce site and between 3.7 and 4.4 at the beech site (Table 1, Table S2). At 5 out of 32 sampling locations in the spruce forest the $\mathrm{pH}$ in $0-10 \mathrm{~cm}$ depth was $>5.5$ indicating that the loess layer was less pronounced or absent and that the parent material mainly originated from lime stone. In 10-20 cm depth the average $\mathrm{pH}$ increased by 0.9 units in the spruce stand whereas it decreased by 0.2 units in the beech stand which is again a result of the lower loess layer thickness in the spruce compared to the beech stand. This was confirmed by the clay content $(0-10 \mathrm{~cm})$ which was with $388 \pm 15.2 \mathrm{~g}$ $\mathrm{kg}^{-1}$ (mean \pm standard error) on average higher at the spruce than at the beech site with $276 \pm 4.4$ $\mathrm{g} \mathrm{kg}^{-1}$. The soils contained in $0-10 \mathrm{~cm}$ depth on average $32.6 \pm 2.3 \mathrm{~g} \mathrm{~kg}^{-1}$ and $26.2 \pm 0.8 \mathrm{~g} \mathrm{~kg}^{-1}$ organic $\mathrm{C}$ in the spruce and beech stand, respectively. The organic $\mathrm{C}$ concentrations decreased with depth. Organic C concentrations in $0-10 \mathrm{~cm}$ were strongly related to estimated clay contents $(\mathrm{r}=0.79, \quad P<0.001)$. Due to colinearity between clay contents, organic $\mathrm{C}$ concentrations, and $\mathrm{CN}$ ratios we only included clay contents in the following statistical analyses. 
Table 1. Basic soil properties at the beech and spruce site.

\begin{tabular}{llll}
\hline & & Beech & Spruce \\
\hline $\mathrm{pH}[-]$ & $0-10 \mathrm{~cm}$ & $4.0 \pm 0.0$ & $4.0 \pm 0.2$ \\
& $10-20 \mathrm{~cm}$ & $3.8 \pm 0.0$ & $4.9 \pm 0.2$ \\
\hline Clay Content $\left[\mathrm{g} \mathrm{kg}^{-1}\right]$ & $0-10 \mathrm{~cm}$ & $276 \pm 4.4$ & $388 \pm 15.2$ \\
\hline Organic Carbon $[\mathrm{g} \mathrm{kg-1]}$ & $10-20 \mathrm{~cm}$ & $249 \pm 4.2$ & $380 \pm 14.0$ \\
\hline CN ratio [-] & $0-10 \mathrm{~cm}$ & $26.2 \pm 0.77$ & $32.6 \pm 2.30$ \\
& $10-20 \mathrm{~cm}$ & $14.5 \pm 0.55$ & $15.1 \pm 0.65$ \\
\hline
\end{tabular}

Data on diversity as well as composition of soil bacterial and fungal communities was obtained by pyrosequencing of $16 \mathrm{~S}$ rRNA genes and the ITS region, respectively. Amplicon data preprocessing yielded a total of 864,096 (bacteria) and 255,488 (fungi) high-quality sequences with an average length of 464 and $300 \mathrm{bp}$, respectively. At a genetic distance of $3 \%, 23,727$ bacterial and 1,336 fungal OTUs were identified across all analyzed soil samples (singleton- and doubleton-OTUs were not considered). After subsampling (see Materials and Methods section), the number of OTUs per individual soil sample ranged from 505 to 1,440 (bacteria) and 45 to 191 (fungi).

\section{Microbial diversity under beech and spruce trees}

In our study areas, the Shannon index of soil bacteria was higher under beech $(6.28 \pm 0.02)$ than under spruce $(6.05 \pm 0.15)$ (Figure 2). In contrast, the Shannon index of soil fungi was higher under spruce $(2.55 \pm 0.06)$ than under beech $(2.26 \pm 0.10)$. The Shannon index of both, bacteria and fungi, was mainly controlled by soil $\mathrm{pH}(P<0.001)$ (Table 2$)$. Only the diversity of soil fungi under spruce was not significantly affected by $\mathrm{pH}$. The $\mathrm{pH}$, however, was significantly different for the four tree replicates in the spruce forest (Table S2) which significantly affected diversity and which were considered first in the linear model. A positive effect of soil $\mathrm{pH}$ on soil bacterial diversity and metabolic richness in temperate forest soils was also shown by Jeanbille et al. (2016). They underline that this could be a result of the release of aluminium to soil solution in acid soils. The aluminium toxicity could partly explain the sharp decline in bacterial diversity at $\mathrm{pH}$ values $<4$ in our study areas. The $\mathrm{pH}$ effect on soil fungi is in contrast to a previous large scale study on fungal diversity across 


\section{TREE SPECIES EFFECTS ON SOIL MICROBIAL COMMUNITIES}

Germany, where general soil properties did not correlate significantly with either general fungal OTU richness or fungal Shannon diversity (Goldmann et al., 2015). The previous study, however, already showed that ectomycorrhizal fungal OTU richness and Shannon diversity is positively related with $\mathrm{pH}$ and negatively with $\mathrm{C} / \mathrm{N}$ ratio. It seems that the factors driving fungal diversity strongly depend on spatial scale and parent material of the respective studies. In addition to $\mathrm{pH}$, bacterial and fungal diversity responded to soil texture that determines soil moisture, the organic $\mathrm{C}$ content and the nutrient status of soils. Carson et al. 2010 showed that bacterial diversity was highest at a $\leq 56 \%$ water-filled pore space and they suggest that pore connectivity provides a principle to explain high diversities in soil (Carson et al., 2010). Our study did not show any significant effect of soil depth on bacterial and fungal diversity. This is in contrast to previous studies where bacterial and fungal Shannon diversity was decreasing with soil depth (Eilers et al., 2012; López-Mondéjar et al., 2015, Voříšková et al., 2014). Our results show that the previously shown decrease in bacterial and fungal diversity with depth could be related to changes in soil $\mathrm{pH}$ or clay content with depth. There was also no direct effect of season on bacterial and fungal diversity (Table 2). In accordance with this result, Kuffner et al. (2012) identified no statistically significant seasonal differences in bacterial diversity when analyzing mineral soil (top $5 \mathrm{~cm}$ ) derived from temperate forest dominated by Norway spruce. Voříšková et al. (2014) analyzed seasonal effects on soil fungal communities in deciduous forest (temperate oak forest). They found that summer communities were marginally more diverse than winter communities, but similar to our results, they detected no significant differences between summer and autumn samples. An effect of distance was found for bacterial diversity under spruce and not at all for fungal diversity. Former studies displayed bacterial clustering within small spatial scales (see review by Vos et al., 2013). Patchy distribution as well as colony forming might explain the significant relations between bacterial diversity and distance from spruce trunks. Certain fungi (e.g.ectomycorrhizal fungi) tend to form dense networks of hyphae which can be widely extended around host trees (Agerer, 2001; Kluber et al., 2010). Such fungal mats seem to maintain constant fungal diversity across distances under both beech and spruce. 
TREE SPECIES EFFECTS ON SOIL MICROBIAL COMMUNITIES

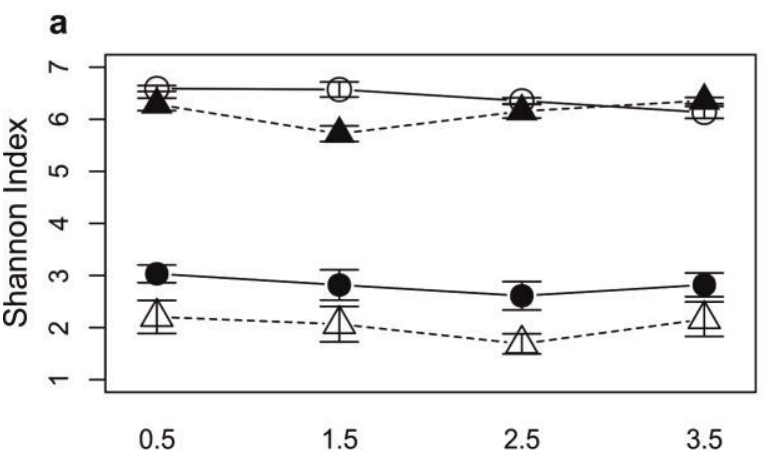

b
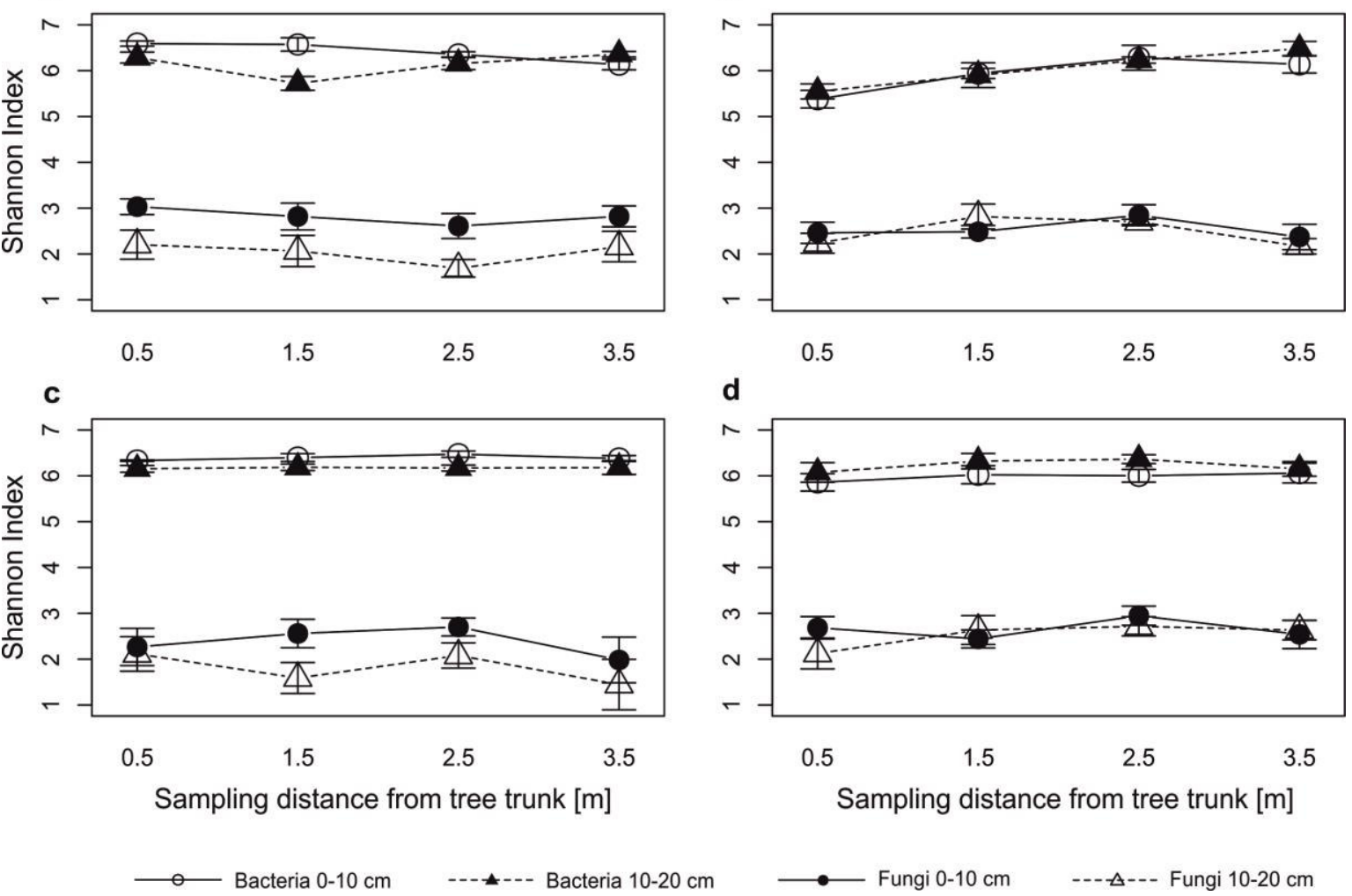

Figure 2. Line plots showing soil bacterial and fungal diversity as assessed by Shannon index at $3 \%$ genetic distance under beech in a) early summer, c) autumn and under spruce in b) early summer d) autumn. 
Table 2. Analysis of covariance shannon diversities of bacteria and fungi in the beech and spruce stands with tree replicate, $\mathbf{p H}$, clay content, soil depth, season und distance as response variable. Explanatory variables are given in rows in the order of entering the analysis. This table presents degrees of freedom (df), mean squares (MS) and F-values. Significant results are indicated by $* \mathrm{P}<0.05, * * \mathrm{P}<0.01, * * * \mathrm{P}<0.001$.

\begin{tabular}{|c|c|c|c|c|c|c|c|c|c|}
\hline & & \multicolumn{4}{|c|}{ Beech } & \multicolumn{4}{|c|}{ Spruce } \\
\hline & & \multicolumn{2}{|c|}{ bacterial diversity } & \multicolumn{2}{|c|}{ fungal diversity } & \multicolumn{2}{|c|}{ bacterial diversity } & \multicolumn{2}{|c|}{ fungal diversity } \\
\hline & df & MS & $\mathrm{F}$ & MS & F & MS & $\mathrm{F}$ & MS & $\mathrm{F}$ \\
\hline Tree replicate & 3 & 0.03 & 0.6 & 1.50 & $4.4^{* *}$ & 0.45 & $3.7^{*}$ & 0.71 & $3.9^{*}$ \\
\hline $\mathrm{pH}$ & 1 & 0.79 & $14.1 * * *$ & 6.70 & $19.6^{* * *}$ & 1.82 & $15.0 * * *$ & 0.24 & 1.3 \\
\hline Clay & 1 & 0.24 & $4.3^{*}$ & 2.63 & $7.7^{* *}$ & 0.24 & 2.0 & 0.95 & $5.2 *$ \\
\hline Depth & 1 & 0.16 & 2.9 & 0.62 & 1.8 & 0.02 & 0.2 & 0.47 & 2.5 \\
\hline Season & 1 & 0.02 & 0.4 & 1.09 & 3.2 & 0.03 & 0.2 & 0.02 & 0.1 \\
\hline Distance & 1 & 0.01 & 0.2 & 0.29 & 0.8 & 1.26 & $10.4 * *$ & 0.01 & 0.1 \\
\hline pH: Replicate & 3 & 0.05 & 1.0 & 0.29 & 0.8 & 0.13 & 1.1 & 0.08 & 0.4 \\
\hline pH: Clay & 1 & 0.02 & 0.3 & 0.12 & 0.4 & 0.10 & 0.8 & 0.40 & 2.2 \\
\hline pH: Depth & 1 & 0.01 & 0.3 & 0.37 & 1.1 & 0.02 & 0.2 & 0.60 & 3.3 \\
\hline pH: Season & 1 & 0.10 & 1.7 & 0.00 & 0.0 & 0.38 & 3.1 & 0.05 & 0.3 \\
\hline pH: Distance & 1 & 0.12 & 2.1 & 0.94 & 2.7 & 0.00 & 0.0 & 0.24 & 1.3 \\
\hline Residuals & 48 & 0.06 & & 0.34 & & 0.12 & & 0.18 & \\
\hline
\end{tabular}

\section{Soil bacterial and fungal community profiles}

The bacterial phyla and proteobacterial classes detected in each individual soil sample

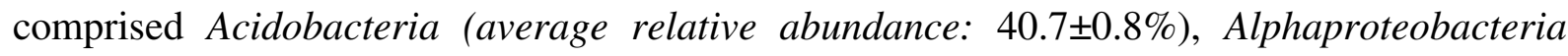

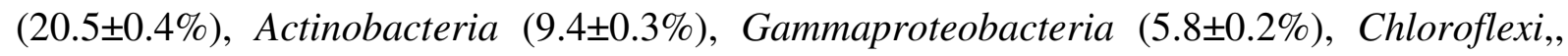

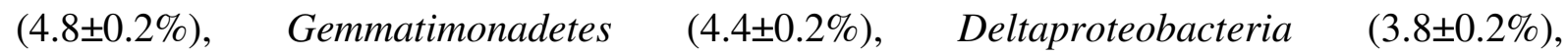
Betaproteobacteria $(3.3 \pm 0.1 \%)$, Bacteroidetes $(2.1 \pm 0.1 \%)$ and candidate division WPS-2 $(1.5 \pm 0.1 \%)$ (Figure 3). These taxonomic groups were also encountered in recent DNA- as well as RNA-based microbial analyses of other forest soils (Fierer et al., 2012; Nacke et al., 2014; DeAngelis et al., 2015, Schneider et al., 2015). The detected phyla and proteobacterial classes were reported in similar relative abundances in a meta-analysis of soil-derived $16 \mathrm{~S}$ rRNA gene libraries (Janssen, 2006). 


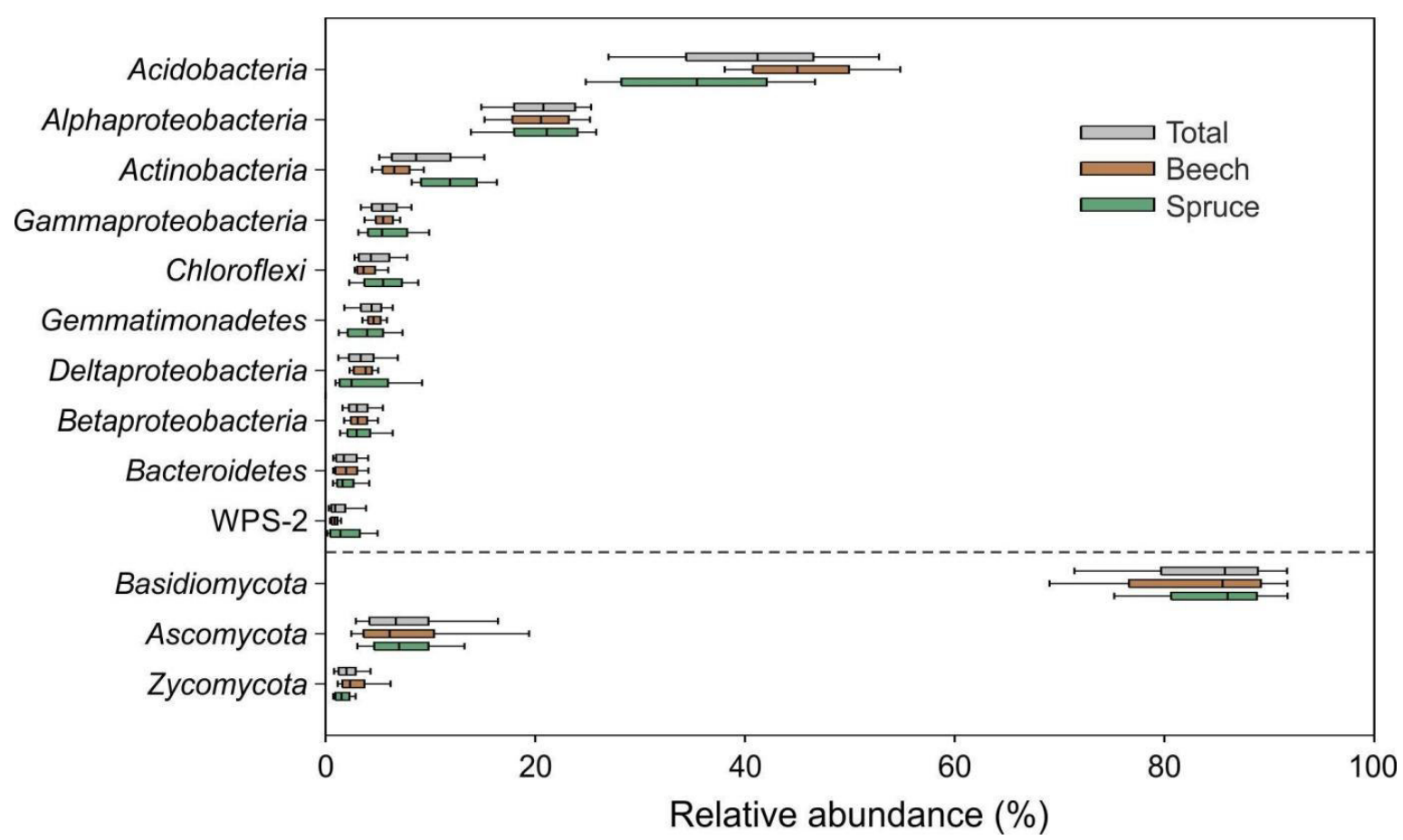

Figure 3. Box-and-whiskers plot showing relative abundances of bacterial and fungal phyla as well as proteobacterial classes detected in each of the analyzed 128 soil samples. Relative abundances of taxa across all samples (grey color) as well as separately with respect to soil surrounding beech (brown color) and spruce (green color) are depicted. The dashed line separates relative abundances of bacterial and fungal taxa.

With respect to genus level-based analysis of amplicon data, bacteria previously isolated from roots (e.g, Rhizomicrobium) (Ueki et al., 2010) as well as forest soil (e.g., Reyranella) (Kim et al., 2013), known to form symbiotic relationships with trees (e.g., Bradyrhizobium) (Ferro et al., 2000) or utilizing plant material (e.g., Acidothermus, Mucilaginibacter, and Sorangium) (Mohagheghi et al., 1986; Pankratov et al., 2007; Schneiker et al., 2007) were detected in high relative abundance (Figure 4). Acidobacteria represent the most abundant phylum in our study. Subgroups 2 (average relative abundance: $14.1 \pm 0.6 \%), 1(11.1 \pm 0.5 \%), 3(10.1 \pm 0.3 \%)$, and $6(2.8 \% \pm 0.3 \%)$ showed the highest average relative abundance among acidobacterial representatives. All other subgroups $(4,5,7,9,10,11,12,13,15,17,18,20,22,25$, and 26) showed average relative abundances < 1\%. Recently, López-Mondéjar et al. (2015) also reported that subgroups 1,2, and 3 of the Acidobacteria were most abundant when analyzing temperate deciduous forest soil. Currently, little is known about ecological functions of Acidobacteria in soil. Although the number of Acidobacteria isolates is increasing (George et al., 2011; García-Fraile et al., 2015; Pascual et al., 2015), many subgroups (e.g., subgroup 2) lack cultured representatives which could be used to study metabolic functions. It can be assumed that acidobacterial taxa substantially contribute to decomposition of plant-derived biopolymers, cell walls of fungi, and exoskeletons of arthropods in forest soils as genomic 


\section{TREE SPECIES EFFECTS ON SOIL MICROBIAL COMMUNITIES}

and culture characteristics of subgroup 1 and 3 strains revealed utilization of cellulose, hemicellulose and chitin as carbon source (Ward et al., 2009; García-Fraile et al., 2015).

The fungal phyla Basidiomycota, Ascomycota and Zygomycota represent on average $87.7 \pm 0.7 \%, 8.9 \pm 0.6 \%$ and $2.5 \pm 0.2 \%$ of the relative abundance of all fungi found in this study (Figure 3). The primer pairs applied in this study are known to favor Asco- and Basidiomycota (Bellemain et al., 2010) which might explain the high amount of detected basidiomycotous OTUs. Ectomycorrhizal fungi, which are common and abundant in temperate forest ecosystems (Tedersoo et al., 2010) were also dominated by members of the Basidiomycota followed by Ascomycota in our study.
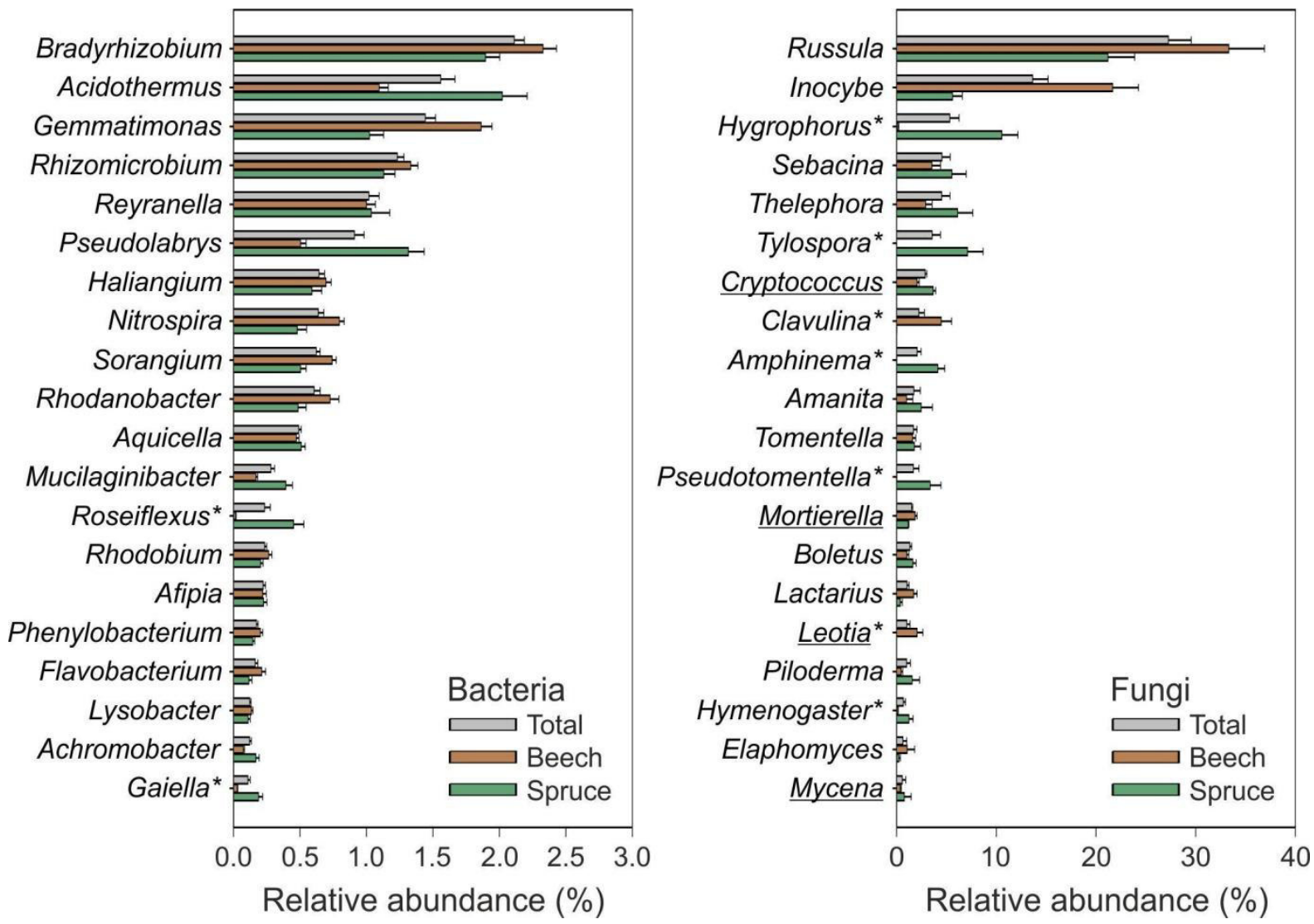

Figure 4. Relative abundances of dominant bacterial and fungal genera detected in the analyzed soil samples. The data represent mean values and standard errors of relative abundances with respect to the twenty most abundant bacterial and fungal genera, respectively. Acidobacteria were analyzed at the subgroup level and therefore not considered within this figure. Relative abundances of taxa across all samples (grey color) as well as separately with respect to soil surrounding beech (brown color) and spruce (green color) are depicted. Asterisks indicate taxa showing an at least five-fold difference in mean relative abundance between spruce and beech as well as $\mathrm{P}<0.001$ regarding Mann-Whitney $\mathrm{U}$ test. Underlined taxa: saprotrophic fungi (all other depicted fungal genera represent ectomycorrhizal fungi).

Among the 20 most abundant fungal genera, 16 are known to be ectomycorrhizal fungi (Figure 4) (Tedersoo et al., 2010). Russula and Inocybe are widely distributed mutualists (Kirk et al., 2008) and were highly abundant in the analyzed soil samples. The soil related yeast Cryptococcus, as well as the multi-cellular Mortierella, Leotia and Mycena were also 
detected in high relative abundance. These fungi are reported to contribute to decay processes and live as saprotrophic fungi in humus, dead wood or plant litter (Wang et al., 2006, Yurkov et al., 2011, Haňáčková et al., 2015).

Similar to Shannon diversity, microbial community composition was significantly affected by $\mathrm{pH}$ and clay content (Table 3). Several previous studies identified soil $\mathrm{pH}$ as a major driver of soil bacterial community composition across different regions and land use types (e.g., Lauber et al., 2009; Kaiser et al. submitted). In accordance with our results, $\mathrm{pH}$ also explained a substantial fraction of variance in microbial community composition within other deciduous and coniferous forest soils (Lauber et al., 2009; Thoms et al., 2010; Goldmann et al., 2015).

Table 3. Multivariate analysis of variance based on weighted UniFrac distances with tree replicate, $\mathbf{p H}$, clay content, soil depth, season and distance as response variable. Explanatory variables are given in rows in the order of entering the analysis. This table presents degrees of freedom (df), mean squares (MS) and $\mathrm{R}^{2}$-values. Significant results are indicated by $* \mathrm{P}<0.05, * * \mathrm{P}<0.01, * * * \mathrm{P}<0.001$

\begin{tabular}{|c|c|c|c|c|c|c|c|c|c|}
\hline & & \multicolumn{4}{|c|}{ Beech } & \multicolumn{4}{|c|}{ Spruce } \\
\hline & \multirow[b]{2}{*}{ df } & \multicolumn{2}{|c|}{$\begin{array}{l}\text { bacterial } \\
\text { community }\end{array}$} & \multicolumn{2}{|c|}{ fungal community } & \multicolumn{2}{|c|}{$\begin{array}{l}\text { bacterial } \\
\text { community }\end{array}$} & \multicolumn{2}{|c|}{ fungal community } \\
\hline & & MS & $\mathrm{R}^{2}$ & MS & $\mathrm{R}^{2}$ & MS & $\mathrm{R}^{2}$ & MS & $\mathrm{R}^{2}$ \\
\hline Tree replicate & 3 & 0.03 & $0.06 *$ & 1.64 & $0.23 * * *$ & 0.2 & $0.17 * * *$ & 2.23 & $0.32 * * *$ \\
\hline $\mathrm{pH}$ & 1 & 0.22 & $0.17 * * *$ & 0.68 & $0.03 * *$ & 0.38 & $0.11 * * *$ & 0.99 & $0.05 * * *$ \\
\hline Clay & 1 & 0.09 & $0.07 * * *$ & 0.52 & $0.02 *$ & 0.05 & 0.01 & 0.45 & $0.02 * *$ \\
\hline Depth & 1 & 0.04 & $0.03 * *$ & 0.33 & 0.02 & 0.13 & $0.04 *$ & 0.32 & 0.02 \\
\hline Season & 1 & 0.08 & $0.06 * * *$ & 0.44 & $0.02 *$ & 0.08 & 0.02 & 0.43 & $0.02 *$ \\
\hline Distance & 1 & 0.02 & 0.02 & 0.62 & $0.03 *$ & 0.25 & $0.07 * * *$ & 0.46 & $0.02 * *$ \\
\hline pH:Replicate & 3 & 0.01 & 0.03 & 0.34 & 0.05 & 0.06 & $0.05 *$ & 0.36 & $0.05 * * *$ \\
\hline pH:Clay & 1 & 0.01 & 0.01 & 0.1 & 0.01 & 0.04 & 0.01 & 0.41 & $0.02 *$ \\
\hline pH:Depth & 1 & 0.02 & 0.02 & 0.14 & 0.01 & 0.05 & 0.01 & 0.3 & 0.01 \\
\hline pH:Season & 1 & 0.01 & 0.01 & 0.17 & 0.01 & 0.23 & $0.07 * * *$ & 0.32 & 0.02 \\
\hline pH:Distance & 1 & 0.02 & 0.01 & 0.35 & 0.02 & 0.02 & 0.01 & 0.29 & 0.01 \\
\hline Residuals & 48 & 0.01 & 0.51 & 0.25 & 0.56 & 0.03 & 0.43 & 0.19 & 0.43 \\
\hline
\end{tabular}

\section{Tree species effects on microbial community composition}

Principal coordinates analysis based on weighted UniFrac distances revealed that samples collected under beech and spruce tend to cluster separately and, thus, indicates similarity in bacterial and fungal community composition in soils from the same forest site (Figure 5). Differences in relative abundances of microbial taxa could be identified between soil under beech and spruce (Figure 4). Furthermore, indicator microorganisms for soil surrounding 


\section{TREE SPECIES EFFECTS ON SOIL MICROBIAL COMMUNITIES}

beech or spruce were identified by considering individual bacterial and fungal OTUs comprising at least 10 sequences (Table S3).

Acidobacteria subgroups 2, 3, 7, 10, 12, and 13 showed higher relative abundances in soil under beech than in soil under spruce, whereas the opposite trend was found for Acidobacteria subgroups 11, 18, and 25. Moreover, the majority of OTUs representing indicators at the beech site were affiliated to Acidobacteria (mainly subgroup 2) (Table S3a). This is partly a result of the different $\mathrm{pH}$ levels in the two forest stands. The relative abundances of subgroups 2 and 13 decreased with increasing soil $\mathrm{pH}$ whereas those of 11 and 18 were positively correlated with $\mathrm{pH}(P<0.001)$. Similar correlations between relative abundances of these subgroups and $\mathrm{pH}$ were found in soils from across North and South America as well as the Hoosfield strip at Rothamsted research (UK) (Jones et al., 2009; Rousk et al., 2010).
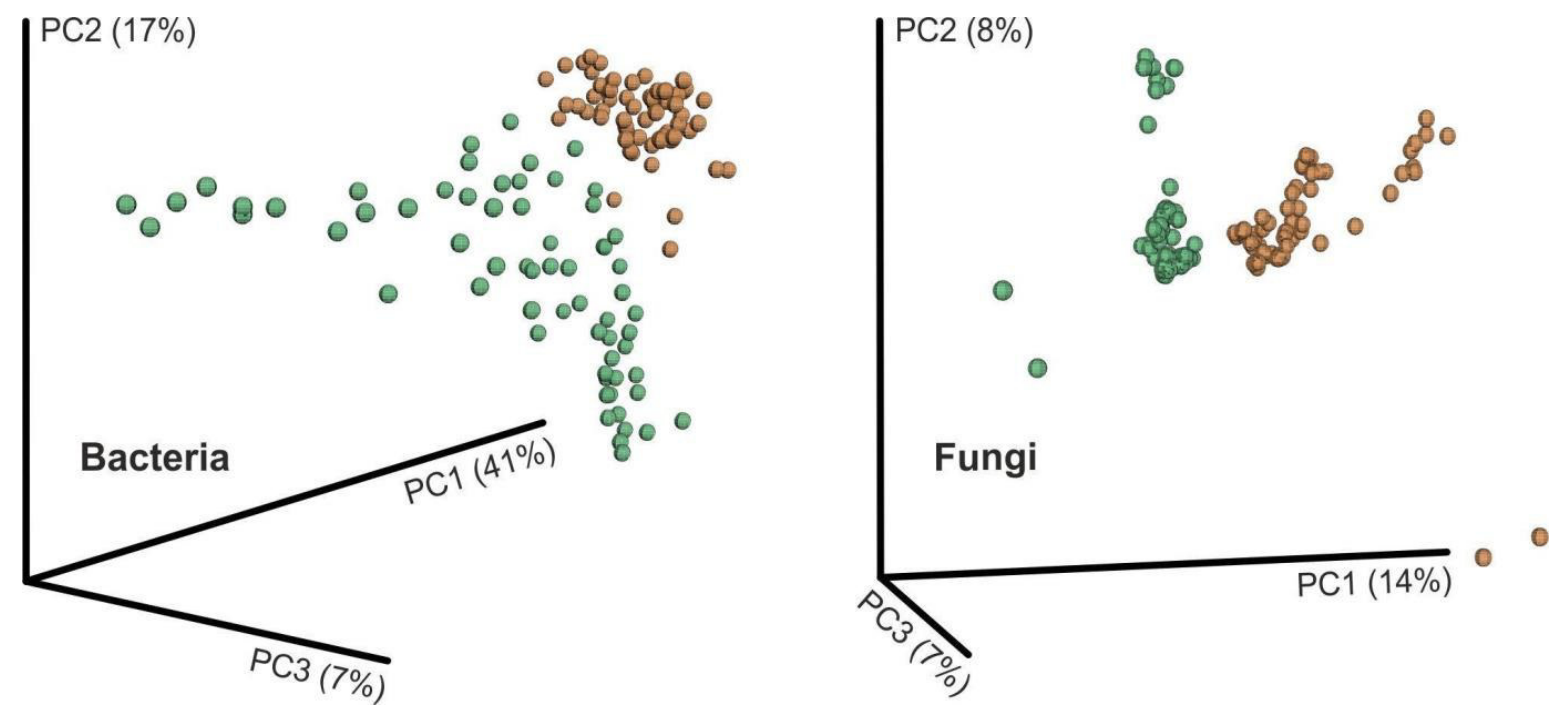

Figure 5. Principal coordinates analysis plots based on weighted UniFrac distances calculated at $3 \%$ genetic distance. Brown circles represent samples derived from beech surrounding soil and samples derived from spruce surrounding soil are depicted as green circles.

With respect to dominant bacterial genera, Gaiella and Roseiflexus showed more than fivefold higher relative abundances in soil under spruce than under beech (Figure 4). As several potential plant compound breakdown genes have been identified in Chloroflexi (Hug et al., 2013; Houghton et al., 2015), it is possible that Roseiflexus (a member of the Chloroflexi) plays an important role in decomposition of spruce litter. Information on abundance and function of Gaiella representatives in forest soil ecosystems is rare. The so far only cultured representative of the genus Gaiella, Gaiella occulta (recovered from a deep mineral aquifer in Portugal), shows optimal growth within a $\mathrm{pH}$ range of 6.5 to 7.5 , but no growth occurs at $\mathrm{pH}$ 5.0 (Albuquerque et al., 2011). In our study, highest relative abundances of Gaiella were 
detected in soils under spruce exhibiting $\mathrm{pH}$ values $<5.0$ (1.1 and $1.2 \%$ relative abundance in soil with a $\mathrm{pH}$ of 4.2 and 4.5 , respectively).

Recent studies pointed out that forest vegetation (in particular dominant tree species) is important for distribution of mutualistic and saprotrophic fungi (Lauber et al., 2008; Aleklett and Hart, 2013). The fungal genera Hygrophorus, Tylospora, Amphinema, Hymenogaster and Pseudotomentella showed more than fivefold higher relative abundance in soil under spruce than in soil surrounding beech, whereas the opposite trend was found for Clavulina and Leotia (Figure 4). Except Leotia, all of these genera represent ectomycorrhizal fungi which establish mutualistic associations with plant roots (Smith and Read, 2008) and can show tree species preferences. Thoms et al. (2010) presume that specific direct interactions are most reasonable for mycorrhizal fungi which showed significant correlations with percentage of Fagus and Tilia litter within their survey. In accordance with our study, Goldmann et al. (2015) and Miyamoto et al. (2015) reported that Tylospora shows a preference for coniferous trees.

For both tree species eight fungal OTUs were identified as potential indicators (Table S3c and d). OTU38 (Mortierella elongata) and OTU99, a Trichoderma species, were indicators for saprotrophic keyplayers under beech. To our knowledge, genera of these fungi were described ubiquitous (Wuczkowski et al., 2003; Nagy et al., 2011). The same can be said for the most abundant OTU of our dataset - Russula cyanoxantha which is known to be widespread ectomycorrhizal fungus not just under beech (Grebenc and Kraigher, 2007). In contrast, the ECM fungus Xerocomus chrysenteron (Otu0054) is known to have a preference for beech (Shi et al., 2002). Indicator species for spruce were three OTUs classified as saprotrophic fungi. Exophiala (OTU75) was already described as fungal genus decaying leafs in rain forests (Polishook et al., 1996) or as rhizospheric fungus in temperate sites (Summerbell, 2005). Another two Penicillium OTUs (OTU94 and OTU116) were identified as saprotrophic indicators for spruce. Already 1980, Johansson and Marklund reported Penicillium to be antagonistic to Fomes, a well-known fungus infecting spruce trees (Schmidt, 2013). The indicative ECM under spruce, Hygrophorus (OTU5 and OTU8) as well as Amphinema (OTU19), were abundant and already described for spruce ecosystems (Scattolin et al., 2008; Velmala et al., 2013).

Spatial and seasonal variability of microbial community composition under beech and spruce

Bacterial community composition varied significantly with depth under beech and spruce (Table 3). Previous surveys based on DGGE analysis as well as Sanger sequencing and 


\section{TREE SPECIES EFFECTS ON SOIL MICROBIAL COMMUNITIES}

pyrosequencing of $16 \mathrm{~S}$ rRNA genes also revealed differences in bacterial community composition between topsoils and subsoils (Hansel et al., 2008; Eilers et al., 2012; Huang et al., 2013). This is a result of changes in soil characteristics such as organic $\mathrm{C}$ or $\mathrm{N}$ concentrations along soil profiles (Hansel et al., 2008; Will et al., 2010). Here, we found that relative abundances of the dominant genus Gaiella were negatively correlated with organic C concentration $(P<0.001)$ and higher in $10-20 \mathrm{~cm}$ depth than in $0-10 \mathrm{~cm}$ depth. The relative abundance of the dominant bacterial genus Mucilaginibacter also showed variations with soil depth. It was higher in $0-10 \mathrm{~cm}$ depth than in10-20 $\mathrm{cm}$ depth $(P<0.001)$. Different Mucilaginibacter representatives are capable of pectin, xylan, and laminarin degradation (Pankratov et al., 2007). In addition, Mucilaginibacter has been previously associated with cellulose decomposition based on Stable Isotope Probing (Štursová et al., 2012). Leaf litter contains high amounts of the plant cell wall components xylan, pectin, and cellulose, and enters the upper mineral soil first. This might explain the increased relative abundance of Mucilaginibacter in upper $(0-10 \mathrm{~cm})$ mineral soil layers.

Recently, McGuire et al. (2013) found discrete fungal communities in different soil horizons in boreal and tropical forest. This can be explained by changing carbon and nutrient contents in combination with decay abilities (McGuire et al., 2010; Prescott, 2010). Assumtions that fungal taxa underlay similar mechanisms in temperate forests were not verified by our results (Table 3). However, the detected saprotrophic fungi tend to be associated with the upper (0-10 cm depth) mineral soil layers which are rich in organic C (Figure S1). Additionally, the indicator species analysis identified mainly saprotrophic OTUs in the upper $10 \mathrm{~cm}$ of studied soil. Influenced by the litter layer, the upper $10 \mathrm{~cm}$ show a high heterogeneity and competition for space and nutrient availability is strongly given (Kadowaki et al., 2013). Yet, ECM fungal taxa are connected to plant roots and receive carbon through this mutualistic connection (Smith and Read 2008). Therefore, ECM fungi are not C-limited and may colonize deeper soil layers (McGuire et al. 2013). Accordingly, in this study ECM fungi were abundant within 0$10 \mathrm{~cm}$ as well as $10-20 \mathrm{~cm}$ soil depth (Figure $\mathrm{S} 1$ ).

A significant seasonal effect on bacterial community composition in soil under beech $(P<$ 0.001) (Table 3) has been revealed by MANOVA. We found that genera belonging to the Rhizobiales (Bradyrhizobium and Rhodobium) showed significantly higher relative abundance within soil under beech in autumn than in early summer $(P<0.001)$. Recently, LópezMondéjar et al. (2015) reported that bacterial communities undergo seasonal changes in mineral soil of a Quercus petraea (Matt.) Liebl forest. They assume that seasonal differences in the activity of tree roots are a major driver of soil bacterial community composition in 
deciduous forest. As Rhizobiales are known to interact with plants, seasonal root impacts might affect their abundance in temperate deciduous forest. Furthermore, seasonal shifts in soil moisture and temperature may also affect bacterial community composition in the analyzed soil (Kaiser et al., 2010).

Seasonal impacts on fungi as found in this study (beech: $P=0.05$; spruce: $\mathrm{P}=0.011$ ), were reported previously (e.g. Buée et al., 2005; Moll et al., 2015; Vargas-Gastelum et al., 2015). In contrast to our findings Vořŕšková et al. (2014) detected no significant seasonal effect on fungal community composition within mineral soil in oak forests. Nevertheless, in the litter horizon, which was not analyzed in our study, seasonal changes in fungal community composition were identified in other studies (Voříšková et al., 2014). These changes are associated with the input of nutrients from fresh litter which occurs in temperate deciduous forests each autumn (Voříšková et al., 2014). Despite, Stevenson et al. (2014) found that sampling season had a higher impact on bacterial than on fungal communities when analyzing soil derived from a region with temperate climate in New Zealand.

Spatial horizontal variations of overall bacterial community composition were significant in soil under spruce $(\mathrm{P}<0.001)$. It is known that spatial distribution of soil microbes can reflect the zone of influence and positioning of individual trees in forests (Saetre and Bååth 2000; Ettema and Wardle 2002). Changes in root impacts horizontally in the tree surrounding might alter occurrence and abundance of bacteria under the selected gymnosperm trees. We found that relative abundances of the dominant bacterial genus Nitrospira were significantly higher at 3.5 than at $0.5 \mathrm{~m}$ horizontal distance toward spruce trunks. Furthermore, a Nitrospirales OTU was identified as indicator for horizontal distances of 2.5 and $3.5 \mathrm{~m}$ toward spruce trunks (Table S3b). N demand of spruce trees in summer and autumn is mainly met by uptake of $\mathrm{N}$ compounds from soil and subsequent transport of reduced $\mathrm{N}$ from the roots to the shoot via transpiration stream (Weber et al., 1998). Due to a negative relationship between fine root biomass and distance to spruce trunk (steep decrease of fine root biomass at distances $>2 \mathrm{~m}$ toward spruce trunk) (Petritan et al., 2011), uptake of $\mathrm{N}$ compounds via roots might be more pronounced in soil located close to the analyzed coniferous tree trunks. This potentially explains the spatial horizontal variations in occurrence of nitrifying bacteria belonging to Nitrospirales under spruce. Under beech trees, the relative abundance of Pseudolabrys differed significantly between 0.5 and $3.5 \mathrm{~m}$ horizontal soil sampling distance from trunks. Higher relative abundances were detected in soil located close to tree trunks. This effect was recorded with respect to both analyzed soil depths $(P<0.05)$. The taxon Pseudolabrys, representing one of the most abundant genera detected in this study (see Figure 4), belongs to 


\section{TREE SPECIES EFFECTS ON SOIL MICROBIAL COMMUNITIES}

the Rhizobiales which are known to interact with plants (Erlacher et al., 2015). A higher root density may be a major reason for high relative abundance of Pseudolabrys in soil located close to beech trunks.

Fungal community composition differs significantly at different horizontal distances away from tree trunks (Table 3). Previous studies revealed an increase in $\mathrm{pH}$ away from trunks of different tree species (Koch and Matzner, 1993; Branco et al., 2013) in conjunction with changing appearances of single fungal species (Branco et al., 2013). The significant correlation between distance and $\mathrm{pH}$ found under spruce (Table S2) might be explanatory for the different fungal communities. However, $\mathrm{C} / \mathrm{N}$ ratio and clay content were related to changing distances under spruce, whereas additionally organic carbon and nitrogen content correlate with distance under beech (Table S2). These differences in soil chemistry at different distances away from tree trunks could be additional accountable for changes in fungal community composition. Branco et al. (2013) reported that water stem flow and through fall account also for the differences in fungal community structure. Spatial heterogeneity under spruce can arise for instance by canopy gap formation (Bardgett, 2005) or decrease of fine root biomass (Petritan et al., 2011), too. A missing canopy at $3.5 \mathrm{~m}$ horizontal distance could alter litter fall or soil temperature and consequently soil fungal communities.

\section{Conclusion}

Our study showed that beech and spruce trees strongly shaped the community composition of soil bacteria and fungi in temperate forests. Tree species-specific preferences with respect to bacterial and fungal genera such as Gaiella, Roseiflexus or Hygrophorus and Clavulina were identified. In contrast to community composition, bacterial and fungal diversity were not significantly affected by tree species, but mainly controlled by abiotic soil properties such as soil $\mathrm{pH}$ and clay contents.

Trees also have manifold impacts on the seasonal and spatial distribution of microorganisms. In our study, both, bacterial diversity and community composition were strongly affected by horizontal distance towards spruce trunks, probably because of higher fine root biomass near the spruce trunks. Indicator species analyses showed a vertical variation with a higher importance of saprotrophic bacterial and fungal taxa in the upper soil layer $(0-10 \mathrm{~cm})$ compared to the soil in $0-20 \mathrm{~cm}$. Overall, our results indicate that trees influence the spatial variation of bacteria and fungi mainly by their above and belowground litter inputs and not through their diverse patterns in stemflow. 
Thus, additional studies considering root architecture and exudation patterns, and the influence of tree canopy on the spatial distribution of leaf litter fall are necessary to further elucidate interactions between trees and soil microbes.

\section{Acknowledgements}

We thank the managers of the three Exploratories, Kirsten Reichel-Jung, Swen Renner, Katrin Lorenzen, Sonja Gockel, Kerstin Wiesner, and Martin Gorke for their work in maintaining the plot and project infrastructure; Christiane Fischer and Simone Pfeiffer for giving support through the central office, Michael Owonibi for managing the central data base, and Markus Fischer, Eduard Linsenmair, Dominik Hessenmöller, Jens Nieschulze, Daniel Prati, ErnstDetlef Schulze, Wolfgang W. Weisser and the late Elisabeth Kalko for their role in setting up the Biodiversity Exploratories project. The work has been funded by the DFG Priority Program 1374 "Infrastructure-Biodiversity-Exploratories" (DA 374/6-1, Core Project 10 SCHR 1181/2-2 and Core Project 11 - BU 941/22-1). Field work permits were issued by the responsible state environmental office of Thüringen (according to $\S 72 \mathrm{BbgNatSchG).} \mathrm{This}$ work was further supported by Helmholtz Impulse and Networking Fund through Helmholtz Interdisciplinary Graduate School for Environmental Research (HIGRADE). Likewise we kindly thank Beatrix Schnabel for her help while sampling, lab work and together with Melanie Günther and Sigrid Härtling for 454 sequencing. Furthermore we thank Sandra Klemmer, Theresa Klötzing and Jessica Schäfer for their field and/or lab assistance. We finally thank Carla Porges for the drawings of our sampling design. 


\section{References}

1. Acosta-Martínez V, Dowd S, Sun Y, Allen V. (2008). Tag-encoded pyrosequencing analysis of bacterial diversity in a single soil type as affected by management and land use. Soil Biol Biochem 40:2762-2770.

2. Agerer R. (2001). Exploration types of ectomycorrhizae. Mycorrhiza 11:107-114.

3. Albuquerque L, França L, Rainey FA, Schumann P, Nobre MF, Da Costa MS. (2011). Gaiella occulta gen. nov., sp. nov., a novel representative of a deep branching phylogenetic lineage with the class Actinobacteria and proposal of Gaiellaceae fam. nov. and Gaiellales ord. nov. Syst Appl Microbiol 34:595-599.

4. Aleklett K, Hart M. (2013). The root microbiota-a fingerprint in the soil? Plant Soil 370:671-686.

5. Amend AS, Seifert KA, Bruns TD. (2010). Quantifying microbial communities with 454 pyrosequencing: does read abundance count? Mol Ecol 19:5555-5565.

6. Augusto L, Ranger J, Binkley D, Rothe A. (2002). Impact of several common tree species of European temperate forests on soil fertility. Ann For Sci 59:233-253.

7. Ayres E, Steltzer H, Berg S, Wallenstein MD, Simmons BL, Wall DH. (2009). Tree species traits influence soil physical, chemical, and biological properties in high elevation forests. PLoS ONE 4: e5964.

8. Bardgett RD. (2005). The biology of soil: a community and ecosystem approach. Oxford University Press: Oxford.

9. Bellemain E, Carlsen T, Brochmann C, Coissac E, Taberlet P, Kauserud H. (2010). ITS as an environmental DNA barcode for fungi: an in silico approach reveals potential PCR biases. BMC Microbiology 10:189.

10. Benson DA, Clark K, Karsch-Mizrachi I, Lipman DJ, Ostell J, Sayers EW. (2015). GenBank. Nucleic Acids Res 43:D30-35.

11. Berger TW, Berger P. (2012). Greater accumulation of litter in spruce (Picea abies) compared to beech (Fagus sylvatica) stands is not a consequence of the inherent recalcitrance of needles. Plant Soil 358:349-369.

12. Branco S, Bruns TD, Singleton I. (2013). Fungi at a small scale: spatial zonation of fungal assemblages around single trees. PLoS ONE 8:e78295. 
13. Broszat M, Nacke H, Blasi R, Siebe C, Huebner J, Daniel R et al. (2014). Wastewater irrigation increases the abundance of potentially harmful gammaproteobacteria in soils in Mezquital Valley, Mexico. Appl Environ Microbiol 80:5282-5291.

14. Buée M, Vairelles D, Garbaye J. (2005). Year-round monitoring of diversity and potential metabolic activity of the ectomycorrhizal community in a beech (Fagus sylvatica) forest subjected to two thinning regimes. Mycorrhiza 15:235-245.

15. Caporaso JG, Kuczynski J, Stombaugh J, Bittinger K, Bushman FD, Costello EK, et al. (2010). QIIME allows analysis of high-throughput community sequencing data. Nat Methods 7:335-336.

16. Carson JK, Gonzalez-Quiñones V, Murphy DV, Hinz C, Shaw JA, Gleeson DB. (2010). Low por connectivity increases bacterial diversity in soil. Appl Environ Microbiol 76:3936-3942.

17. Cesarz S, Fender A-C, Beyer F, Valtanen K, Pfeiffer B, Gansert D, et al. (2013). Roots from beech (Fagus sylvatica L.) and ash (Fraxinus excelsior L.) differentially affect soil microorganisms and carbon dynamics. Soil Biol Biochem 61:23-32.

18. Crowther TW, Glick HB, Covey KR, Bettigole C, Maynard DS, Thomas SM et al. (2015). Mapping tree density at a global scale. Nature 525:201-205.

19. Cuesta Garrote N, Sánchez Navarro MM, Arán Aís F, Orgíles Barceló (2011). Natural antimicrobial agents against the microbiota associated with insoles. In: Méndez-Vilas A (ed). Science and technology against microbial pathogens: research, development and evaluation. World Scientific Publishing Co. Pte. Ltd.: Singapore, pp 109-113.

20. DeAngelis KM, Pold G, Topçuoğlu BD, van Diepen LT, Varney RM, Blanchard JL, et al. (2015). Long-term forest soil warming alters microbial communities in temperate forest soils. Front Microbiol 6:104.

21. De Cáceres M, Legendre P. (2009). Associations between species and groups of sites: indices and statistical inference. Ecology 90:3566-3574.

22. Edgar RC (2010). Search and clustering orders of magnitude faster than BLAST. Bioinformatics 26:2460-2461.

23. Eilers KG, Debenport S, Anderson S, Fierer N. (2012). Digging deeper to find unique microbial communities: The strong effect of depth on the structure of bacterial and archaeal communities in soil. Soil Biol Biochem 50:58-65.

24. Erlacher A, Cernava T, Cardinale M, Soh J, Sensen CW, Grube M, et al. (2015). Rhizobiales as functional and endosymbiontic members in the lichen symbiosis of Lobaria pulmonaria L. Front Microbiol 6:53. 


\section{TREE SPECIES EFFECTS ON SOIL MICROBIAL COMMUNITIES}

25. Ettema CH, Wardle DA. (2002). Spatial soil ecology. Trends Ecol Evol 17:177-183.

26. Fender AC, Gansert D, Jungkunst HF, Fiedler S, Beyer F, Schützenmeister K et al. (2013). Root-induced tree species effects on the source/sink strength for greenhouse gases $\left(\mathrm{CH}_{4}, \mathrm{~N}_{2} \mathrm{O}\right.$ and $\left.\mathrm{CO}_{2}\right)$ of a temperate deciduous forest soil. Soil Biol Biochem 57:587-597.

27. Ferro M, Lorquin J, Ba S, Sanon K, Promé JC, Boivin C. (2000). Bradyrhizobium sp. strains that nodulate the leguminous tree Acacia albida fucosylated and partially sulfated nod factors. Appl Environ Microbiol 66:5078-5082.

38. Fierer N, Leff JW, Adams BJ, Nielsen UN, Bates ST, Lauber CL, et al. (2012). Cross-biome metagenomic analyses of soil microbial communities and their functional attributes. Proc Natl Acad Sci USA 109:21390-21395.

39. Fischer M, Bossdorf O, Gockel S, Hänsel F, Hemp A, Hessenmöller D, et al. (2010). Implementing large-scale and long-term functional biodiversity research: The Biodiversity Exploratories. Basic Appl Ecol 11:473-485.

40. García-Fraile P, Benada O, Cajthaml T, Baldrian P, Lladó S. (2016). Terracidiphilus gabretensis gen. nov., sp. nov.: an abundant and active forest soil Acidobacteria important in organic matter transformation. Appl Environ Microbiol 82:560-569.

41. Gardes M, Bruns T. (1993). ITS primers with enhanced specificity for basidiomycetes application to the identification of mycorrhizae and rusts. Mol Ecol 2:113-118.

42. George IF, Hartmann M, Liles MR, Agathos SN. (2011). Recovery of as-yetuncultured soil acidobacteria on dilute solid media. Appl Environ Microbiol 77:81848188

43. Geßler A, Schneider S, Weber P, Hanemann U, Rennenberg H. (1998). Soluble N compounds in trees exposed to high loads of $\mathrm{N}$ : a comparison between the roots of Norway spruce (Picea abies) and beech (Fagus sylvatica) trees grown under field conditions. New Phytol 138:385-399.

44. Goldmann, K., Schöning, I., Bucot, F., Wubet, T. (2015). Forest management type influences diversity and community composition of soil fungi across temperate forest ecosystems. Front Microbiol 6:1300.

45. Grebenc T, Kraigher H. (2007). Types of ectomycorrhiza of mature beech and spruce at ozone-fumigated and control forest plots. Environ Monit Assess 128:47-59.

46. Haichar FZ, Marol C, Berge O, Rangel-Castro JI, Prosser JI, Balesdent J, et al. (2008). Plant host habitat and root exudates shape soil bacterial community structure. ISME J 2:1221-1230. 
47. Hammer $\varnothing$, Harper DAT, Ryan PD. (2001). PAST: Paleontological statistics software package for education and data analysis. Palaeontol Electron 4:1-9.

48. Haňáčková Z, Koukol O, Štursová M, Kolařík M, Baldrian P. (2015). Fungal succession in the needle litter of a montane Picea abies forest investigated through strain isolation and molecular fingerprinting. Fungal Ecol 13:157-166.

49. Hanewinkel M, Cullmann DA, Schelhaas M-J, Nabuurs G-J, Zimmermann NE. (2012). Climate change may cause severe loss in the economic value of European forest land. Nat Clim Chang 3:203-207.

50. Hansel CM, Fendorf S, Jardine PM, Francis CA. (2008). Changes in bacterial and archaeal community structure and functional diversity along a geochemically variable soil profile. Appl Environ Microbiol 74:1620-1633.

51. Houghton KM, Morgan XC, Lagutin K, MacKenzie AD, Vyssotski M, Mitchell KA et al. (2015). Thermorudis pharmacophila WKT50.2T sp. nov., a novel isolate of class Thermomicrobia isolated from geothermal soil, and emended descriptions of Thermomicrobium roseum, Thermomicrobium carboxidum, Thermorudis peleae and Sphaerobacter thermophilus. Int J Syst Evol Microbiol doi:10.1099/ijsem.000598.

52. Huang J, Sheng X, He L, Huang Z, Wang Q, Zhang Z. (2013). Characterization of depth-related changes in bacterial community compositions and functions of a paddy soil profile. FEMS Microbiol Lett 347:33-42.

53. Hug LA, Castelle CJ, Wrighton KC, Thomas BC, Sharon I, Frischkorn KR. (2013). Community genomic analyses constrain the distribution of metabolic traits across the Chloroflexi phylum and indicate roles in sediment carbon cycling. Microbiome 1. doi:10.1186/2049-2618-1-22.

54. Jacob M, Viedenz K, Polle A, Thomas FM. (2010). Leaf litter decomposition in temperate deciduous forest stands with a decreasing fraction of beech (Fagus sylvatica). Oecologia 164:1083-1094.

55. Janssen PH. (2006). Identifying the dominant soil bacterial taxa in libraries of $16 \mathrm{~S}$ rRNA and 16S rRNA genes. Appl Environ Microbiol 72:1719-1728.

56. Jeanbille M, Buée M, Bach C, Cébron A, Frey-Klett P, Turpault MP, et al. (2016). Soil parameters drive the structure, diversity and metabolic potentials of the bacterial communities across temperate beech forest soil sequences. Microb Ecol 71:482-493.

57. Jiang Y, Chen C, Xu Z, Liu Y. (2011). Effects of single and mixed species forest ecosystems on diversity and function of soil microbial community in subtropical China. J Soils Sediments 12:228-240. 


\section{TREE SPECIES EFFECTS ON SOIL MICROBIAL COMMUNITIES}

58. Johansson M, Marklund E. (1980). Antagonists of Fomes annosus in the rhizosphere of grey alder (Alnus incana) and Norway spruce (Picea abies). Eur J Forest Pathol 10:385-395.

59. Johnson MS, Lehmann J. (2006). Double-funneling of trees: stemflow and rootinduced preferential flow. Ecoscience 13:324-333.

60. Johnson M, Zaretskaya I, Raytselis Y, Merezhuk Y, Mcginnis S, Madden TL. (2008). NCBI BLAST: a better web interface. Nucleic Acids Res 36:W5-9.

61. Jones RT, Robeson MS, Lauber CL, Hamady M, Knight R, Fierer N. (2009). A comprehensive survey of soil acidobacterial diversity using pyrosequencing and clone library analyses. ISME J 3:442-453.

62. Kadowaki K, Sato H, Yamamoto S, Tanabe AS, Hidaka A, Toju H. (2013). Detection of the horizontal spatial structure of soil fungal communities in a natural forest. Popul Ecol 56:301-310.

63. Kaiser C, Koranda M, Kitzler B, Fuchslueger L, Schnecker J, Schweiger P, et al. (2010). Belowground carbon allocation by trees drives seasonal patterns of extracellular enzyme activities by altering microbial community composition in a beech forest soil. New Phytol 187:843-858.

64. Kaiser K, Wemheuer B, Korolkow V, Wemheuer F, Nacke H, Schöning I, et al. (2016). Driving forces of soil bacterial community structure, diversity, and function in temperate grasslands and forests. Submitted to Scientific Reports.

65. Kim SJ, Ahn JH, Lee TH, Weon HY, Hong SB, Seok SJ et al. (2013). Reyranella soli sp. nov., isolated from forest soil, and emended description of the genus Reyranella Pagnier et al. 2011. Int J Syst Evol Microbiol 63:3164-3167.

66. Kirk PM, Ainsworth GC. (2008): Ainsworth \& Bisby's Dictionary of the Fungi. CAB International: Wallingford.

67. Kluber LA, Tinnesand KM, Caldwell BA, Dunham SM, Yarwood RR, Bottomley PJ, et al. (2010). Ectomycorrhizal mats alter forest soil biogeochemistry. Soil Biol Biochem 42:1607-1613.

68. Koch AS, Matzner E. (1993). Heterogeneity of soil and soil solution chemistry under Norway Spruce (Picea abies Karst) and European Beech (Fagus sylvatica L.) as influenced by distance from the stem basis. Plant Soil 151:227-237.

69. Kõljalg U, Nilsson RH, Abarenkov K, Tedersoo L, Taylor AF, Bahram M, et al. (2013). Towards a unified paradigm for sequence-based identification of fungi. Mol Ecol 22:5271-5277. 
70. Kuffner M, Hai B, Rattei T, Melodelima C, Schloter M, Zechmeister-Boltenstern S, et al. (2012). Effects of season and experimental warming on the bacterial community in a temperate mountain forest soil assessed by $16 \mathrm{~S}$ rRNA gene pyrosequencing. FEMS Microbiol Ecol 82:551-562.

71. Lauber CL, Strickland MS, Bradford MA, Fierer N. (2008). The influence of soil properties on the structure of bacterial and fungal communities across land-use types. Soil Biol Biochem 40:2407-2415.

72. Lauber CL, Hamady M, Knight R, Fierer N. (2009). Pyrosequencing-based assessment of soil $\mathrm{pH}$ as a predictor of soil bacterial community structure at the continental scale. Appl Environ Microbiol 75:5111-5120.

73. Lejon DP, Chaussod R, Ranger J, Ranjard L. (2005). Microbial community structure and density under different tree species in an acid forest soil (Morvan, France). Microb Ecol 50:614-625.

74. Li W, Godzik A. (2006). Cd-hit: a fast program for clustering and comparing large sets of protein or nucleotide sequences. Bioinformatics 22:1658-1659.

75. Liu Z, Lozupone C, Hamady M, Bushman FD, Knight R. (2007). Short pyrosequencing reads suffice for accurate microbial community analysis. Nucleic Acids Res 35:e120.

76. López-Mondéjar R, Voř́ššková J, Větrovský T, Baldrian P. (2015). The bacterial community inhabiting temperate deciduous forests is vertically stratified and undergoes seasonal dynamics. Soil Biol Biochem 87:43-50.

77. Lozupone C, Lladser ME, Knights D, Stombaugh J, Knight R. (2011). Unifrac: an effective distance metric for microbial community comparison. ISME J 5:169-172.

78. McGuire KL, Bent E, Borneman J, Majumder A, Allison SD, Treseder KK. (2010) Functional diversity in resource use by fungi. Ecology 91:2324-2332.

79. McGuire KL, Allison SD, Fierer N, Treseder KK. (2013).: Ectomycorrhizaldominated boreal and tropical forests have distinct fungal communities, but analogous spatial patterns across soil horizons. PLoS ONE 8:e68278.

80. Miyamoto Y, Sakai A, Hattori M, Nara K. (2015). Strong effect of climate on ectomycorrhizal fungal composition: evidence from range overlap between two mountains. ISME J 9:1870-1879.

81. Mohagheghi A, Grohmann K, Himmel M, Leighton L, Updegraff DM. (1986). Isolation and characterization of Acidothermus cellulolyticus gen. nov., sp. nov., a new 
TREE SPECIES EFFECTS ON SOIL MICROBIAL COMMUNITIES

genus of thermophilic, acidophilic, cellulolytic bacteria. Int J Syst Evol Microbiol 36:435-443.

82. Moll J, Goldmann K, Kramer S, Hempel S, Kandeler E, et al. (2015). Resource type and availability regulate fungal communities along arable soil profiles. Microb Ecol 70:390-399.

83. Morales SE, Cosart TF, Johnson JV, Holben WE. (2009). Extensive phylogenetic analysis of a soil bacterial community illustrates extreme taxon evenness and the effects of amplicon length, degree of coverage, and DNA fractionation on classification and ecological parameters. Appl Environ Microbiol 75:668-675.

84. Nacke H, Thürmer A, Wollherr A, Will C, Hodac L, Herold N, et al. (2011). Pyrosequencing-based assessment of bacterial community structure along different management types in German forest and grassland soils. PLoS ONE 6:e17000.

85. Nacke H, Fischer C, Thürmer A, Meinicke P, Daniel R. (2014). Land use type significantly affects microbial gene transcription in soil. Microb Ecol 67:919-930.

86. Nagy LG, Petkovits T, Kovacs GM, Voigt K, Vagvolgyi C, Papp T. (2011). Where is the unseen fungal diversity hidden? A study of Mortierella reveals a large contribution of reference collections to the identification of fungal environmental sequences. New Phytol 191:789-794

87. Nykvist N. (1963). Leaching and decomposition of water-soluble organic substances from different types of leaf and needle litter. Stud For Suec 3:1-31.

88. Oksanen J, Blanchet G, Kindt R, Legendre P, Minchin PR, O'Hara RB, et al. (2012). vegan: Community Ecology Package.

89. Pankratov TA, Tindall BJ, Liesack W, Dedysh SN. (2007). Mucilaginibacter paludis gen. nov., sp. nov. and Mucilaginibacter gracilis sp. nov., pectin-, xylan- and laminarin-degrading members of the family Sphingobacteriaceae from acidic Sphagnum peat bog. Int J Syst Evol Microbiol 57:2349-2354.

90. Pascual J, Wüst PK, Geppert A, Foesel BU, Huber KJ, Overmann J. (2015). Novel isolates double the number of chemotrophic species and allow the first description of higher taxa in Acidobacteria subdivision 4. Syst Appl Microbiol doi: 10.1016/j.syapm.2015.08.001

91. Peres-Neto PR, Legendre P, Dray S, Borcard D. (2006). Variation partitioning of species data matrices: estimation and comparison of fractions. Ecology 87:2614-2625. 
92. Petritan IC, von Lupke B, Petritan AM. (2011). Fine roots of overstory Norway spruce (Picea abies): distribution and influence on growth of underplanted beech (Fagus sylvatica) and Douglas-fir (Pseudotsuga menziesii) saplings. Forest Syst 20:407-419.

93. Prescott CE (2010) Litter decomposition: what controls it and how can we alter it to sequester more carbon in forest soils? Biogeochem 101:133-149.

94. Priha O, Smolander A. (1997). Microbial biomass and activity in soil and litter under Pinus sylvestris, Picea abies and Betula pendula at originally similar field afforestation sites. Biol Fert Soils 24:45-51.

95. Priha O, Smolander A. (1999). Nitrogen transformations in soil under Pinus sylvestris, Picea abies and Betula pendula at two forest sites. Soil Biol Biochem 31:965-977.

96. Pruesse E, Quast C, Knittel K, Fuchs BM, Ludwig W, Peplies J, et al. (2007). SILVA: a comprehensive online resource for quality checked and aligned ribosomal RNA sequence data compatible with ARB. Nucleic Acids Res 35:7188-7196.

97. R Development Core Team. (2015). R: A language and environment for statistical computing. R Foundation for Statistical Computing: Vienna.

98. Rosselló-Mora R, Amann R. (2001). The species concept for prokaryotes. FEMS Microbiol Rev 25:39-67.

99. Rousk J, Bååth E, Brookes PC, Lauber CL, Lozupone C, Caporaso JG et al. (2010). Soil bacterial and fungal communities across a $\mathrm{pH}$ gradient in an arable soil. ISME $\mathbf{J}$ 4:1340-1351.

100. Saetre P. (1999). Spatial patterns of ground vegetation, soil microbial biomass and activity in a mixed spruce-birch stand. Ecography 22:183-192.

101. Saetre P, Bååth E. (2000). Spatial variation and patterns of soil microbial community structure in a mixed spruce-birch stand. Soil Biol Biochem 32:909-917.

102. Scattolin L, Montecchio L, Mosca E, Agerer R. (2008). Vertical distribution of the ectomycorrhizal community in the top soil of Norway spruce stands. Eur J For Res $127: 347-357$.

103. Schloss PD, Westcott SL, Ryabin T, Hall JR, Hartmann M, Hollister EB, et al. (2009). Introducing mothur: open-source, platform-independent, community-supported software for describing and comparing microbial communities. Appl Environ Microbiol 75:7537-7541.

104. Schmidt O. (2013). Holz-und Baumpilze: Biologie, Schäden, Schutz, Nutzen. Springer-Verlag: Berlin. 


\section{TREE SPECIES EFFECTS ON SOIL MICROBIAL COMMUNITIES}

105. Schneider D, Engelhaupt M, Allen K, Kurniawan S, Krashevska V, Heinemann M et al. (2015). Impact of lowland rainforest transformation on diversity and composition of soil prokaryotic communities in Sumatra (Indonesia). Front Microbiol 6: 1339.

106. Schneiker S, Perlova O, Kaiser O, Gerth K, Alici A, Altmeyer MO et al. (2007). Complete genome sequence of the myxobacterium Sorangium cellulosum. Nat Biotechnol 25:1281-1289.

107. Schulp CJE, Nabuurs GJ, Verburg PH, de Waal RW. (2008). Effect of tree species on carbon stocks in forest floor and mineral soil and implications for soil carbon inventories. For Ecol Manage 256:482-490.

108. Shannon CE. (1948). A mathematical theory of communication. Bell Syst Tech J 27:379-423.

109. Shi L, Guttenberger M, Kottke I, Hampp R. (2002). The effect of drought on mycorrhizas of beech (Fagus sylvatica L.): changes in community structure, and the content of carbohydrates and nitrogen storage bodies of the fungi. Mycorrhiza 12:303311.

110. Smith SE, Read DJ. (2008). Mycorrhizal symbiosis. Academic press: London.

111. Stevenson BA, Hunter DWF, Rhodes PL. (2014). Temporal and seasonal change in microbial community structure of an undisturbed, disturbed, and carbon-amended pasture soil. Soil Biol Biochem 75:175-185.

112. Štursová M, Žifčáková L, Leigh MB, Burgess R, Baldrian P. (2012). Cellulose utilization in forest litter and soil: identification of bacterial and fungal decomposers. FEMS Microbiol Ecol 80:735-746.

113. Summerbell RC. (2005). Root endophyte and mycorrhizosphere fungi of black spruce, Picea mariana, in a boreal forest habitat: influence of site factors on fungal distributions. Stud Mycol 53:121-145.

114. Tedersoo L, May TW, Smith ME. (2010). Ectomycorrhizal lifestyle in fungi: global diversity, distribution, and evolution of phylogenetic lineages. Mycorrhiza 20:217263.

115. Tedersoo L, Bahram M, Cajthaml T, Põlme S, Hiiesalu L, Anslan S, et al. (2016). Tree diversity and species identity effects on soil fungi, protists and animals are context dependent. ISME J 10:346-362.

116. Thoms C, Gattinger A, Jacob M, Thomas FM, Gleixner G. (2010). Direct and indirect effects of tree diversity drive soil microbial diversity in temperate deciduous forest. Soil Biol Biochem 42:1558-1565. 
117. Thoms C, Gleixner G. (2013). Seasonal differences in tree species' influence on soil microbial communities. Soil Biol Biochem 66:239-248.

118. Ueki A, Kodama Y, Kaku N, Shiromura T, Satoh A, Watanabe K, et al. (2010). Rhizomicrobium palustre gen. nov., sp. nov., a facultatively anaerobic, fermentative stalked bacterium in the class Alphaproteobacteria isolated from rice plant roots. $\mathbf{J}$ Gen Appl Microbiol 56:193-203.

119. Urbanová M, Šnajdr J, Baldrian P. (2015). Composition of fungal and bacterial communities in forest litter and soil is largely determined by dominant trees. Soil Biol Biochem 84:53-64.

120. Vargas-Gastelum L, Romero-Olivares AL, Escalante AE, Rocha-Olivares A, Brizuela C, Riquelme M. (2015). Impact of seasonal changes on fungal diversity of a semi-arid ecosystem revealed by 454 pyrosequencing. FEMS Microbiol Ecol 91 fiv044.

121. Vázquez-Baeza Y, Pirrung M, Gonzalez A, Knight R. (2013). Emperor: a tool for visualizing high-throughput microbial communitiy data. Gigascience 2:16.

122. Velmala S, Rajala T, Haapanen M, Taylor A, Pennanen T. (2013). Genetic host-tree effects on the ectomycorrhizal community and root characteristics of Norway spruce. Mycorrhiza 23:21-33.

123. Voř́šková J, Brabcová V, Cajthaml T, Baldrian P. (2014). Seasonal dynamics of fungal communities in a temperate oak forest soil. New Phytol 201:269-278.

124. Vos M, Wolf AB, Jennings SJ, Kowalchuk GA. (2013). Micro-scale determinants of bacterial diversity in soil. FEMS Microbiol Rev 37:936-954.

125. Wäldchen J, Schöning I, Mund M, Schrumpf M, Bock S, Herold N, et al. (2012). Estimation of clay content from easily measurable water content of air-dried soil._J Plant Nutr Soil Sci 175:367-376.

126. Wang Z, Binder M, Schoch CL, Johnston PR, Spatafora JW, Hibbett DS. (2006). Evolution of helotialean fungi (Leotiomycetes, Pezizomycotina): a nuclear rDNA phylogeny. Mol Phylogenet Evol 41:295-312.

127. Ward NL, Challacombe JF, Janssen PH, Henrissat B, Coutinho PM, Wu M, et al. (2009). Three genomes from the phylum Acidobacteria provide insight into the lifestyles of these microorganisms in soils. Appl Environ Microbiol 75:2046-2056.

128. Weber P, Stoermer H, Geßler A, Schneider S, Von Sengbusch D, Hanemann U, et al. (1998). Metabolic responses of Norway spruce (Picea abies) trees to long-term forest management practices and acute $\left(\mathrm{NH}_{4}\right)_{2} \mathrm{SO}_{4}$ fertilization: transport of soluble nonprotein nitrogen compounds in xylem and phloem. New Phytol 140:461-475. 
TREE SPECIES EFFECTS ON SOIL MICROBIAL COMMUNITIES

129. White TJ, Bruns T, Lee S, Taylor JW. (1990). Amplification and direct sequencing of fungal ribosomal RNA genes for phylogenetics. In: Innis MA, Gelfand DH, Sninsky JJ, White TJ (eds). PCR Protocols: A Guide to Methods and Applications. Academic Press: New York, pp 315-322.

130. Will C, Thürmer A, Wollherr A, Nacke H, Herold N, Schrumpf M et al. (2010). Horizon-specific bacterial community composition of German grassland soils, as revealed by pyrosequencing-based analysis of $16 \mathrm{~S}$ rRNA genes. Appl Environ Microbiol 76:6751-6759.

131. Wubet T, Christ S, Schöning I, Boch S, Gawlich M, Schnabel B, Fischer M, et al. (2012). Differences in soil fungal communities between European beech (Fagus sylvatica L.) dominated forests are related to soil and understory vegetation. PLoS ONE 7:e47500.

132. Wuczkowski M, Druzhinina I, Gherbawy Y, Klug B, Prillinger H, Kubicek CP. (2003). Species pattern and genetic diversity of Trichoderma in a mid-European, primeval floodplain-forest. Microbiol Res 158:125-133.

133. Yurkov AM, Kemler M, Begerow D. (2011). Species accumulation curves and incidence-based species richness estimators to appraise the diversity of cultivable yeasts from beech forest soils. PLoS ONE 6:e23671.

134. Zhou J, Wu L, Deng Y, Zhi X, Jiang YH, Tu Q, et al. (2011). Reproducibility and quantitation of amplicon sequencing-based detection. ISME J 5:1303-1313. 
TREE SPECIES EFFECTS ON SOIL MICROBIAL COMMUNITIES

\section{SUPPLEMENTARY INFORMATION}

Supplementary figures and tables are provided along with the electronic version of this thesis (on DVD), under the following paths:

Figure S1:

Table S1:

Table S2:

Table S3:
Supplementary Information/Chapter III.3/Figure S1.docx Supplementary Information/Chapter III.3/ Table S1.docx Supplementary Information/Chapter III.3/ Table S2.docx Supplementary Information/Chapter III.3/ Table S3.doc 


\section{CHAPTER III.4}

GROUP-SPECIFIC EFFECTS OF GRASSLAND LAND USE ON SADS 
GROUP-SPECIFIC EFFECTS OF GRASSLAND LAND USE ON SADS

III.4.

Submitted to Agriculture, Ecosystem \& Environment

\section{Contrasting effects of grassland management modes on species abundance distributions of multiple groups}

Running headline: Group-specific Effects of Grassland Land Use on SADs

Nadja K. Simons ${ }^{\mathrm{a}^{*}}$, Thomas Lewinsohn ${ }^{\mathrm{b}}$, Nico Blüthgen ${ }^{\mathrm{c}}$, François Buscot ${ }^{\mathrm{d}, \mathrm{e}}$, Steffen Boch ${ }^{\mathrm{f}}$, Martin M. Gossner ${ }^{\mathrm{a}}$, Kirsten Jung ${ }^{\mathrm{g}}$, Kristin Kaiser ${ }^{\mathrm{h}}$, Jörg Müller ${ }^{\mathrm{i}}$, Daniel Prati ${ }^{\mathrm{f}}$, Swen C. Renner $^{\mathrm{j}, \mathrm{k}}$, Stephanie Socher ${ }^{\mathrm{f}}$, Ilja Sonnemann ${ }^{1}$, Christiane Weiner ${ }^{\mathrm{c}}$, Michael Werner ${ }^{\mathrm{c}}$, Tesfaye Wubet $^{\mathrm{d}, \mathrm{e}}$, Susanne Wurst ${ }^{1}$, Wolfgang W. Weisser ${ }^{\mathrm{a}}$

${ }^{a}$ Technical University Munich, Terrestrial Ecology Research Group, Department for Ecology and Ecosystem Management, Center for Life and Food Sciences Weihenstephan, Hans-Carlvon-Carlowitz-Platz 2, D-85354 Freising, Germany

${ }^{\mathrm{b}}$ Department of Animal Biology, IB, UNICAMP - University of Campinas, Campinas, São Paulo, CEP 13083-970, Brazil

c Technische Universität Darmstadt, Department of Biology, Schnittspahnstr. 3, D-64287 Darmstadt, Germany

d Helmholtz Centre for Environmental Research -UFZ, Department of Soil Ecology, Theodor-Lieser-Straße 4, D-06120 Halle-Saale, Germany

${ }^{\mathrm{e}}$ German Centre for Integrative Biodiversity Research (iDiv) Halle-Jena-Leipzig, Deutscher Platz 5e, D-04103 Leipzig, Germany

f University of Bern, Institute of Plant Sciences, Altenbergrain 21, CH-3013 Bern, Switzerland 


\section{GROUP-SPECIFIC EFFECTS OF GRASSLAND LAND USE ON SADS}

g University of Ulm, Evolutionary Ecology and Conservation Genomics, Albert-EinsteinAllee 11, D-89069 Ulm, Germany

${ }^{\mathrm{h}}$ Department of Genomic and Applied Microbiology, Institute of Microbiology and Genetics, Georg-August-University Göttingen, Grisebachstr. 8, D-37077 Göttingen, Germany

${ }^{\mathrm{i}}$ Institute of Biochemistry and Biology, University of Potsdam, Maulbeerallee 1, D-14469 Potsdam, Germany

${ }^{\mathrm{j}}$ University of Natural Resources and Life Sciences, Institute of Zoology, Gregor-MendelStrasse 33, AU-1180 Vienna, Austria

${ }^{\mathrm{k}}$ Smithsonian Conservation Biology Institute at the National Zoological Park, 1500 Remount Rd, Front Royal, VA 22630, United States

${ }^{1}$ Freie Universität Berlin, Dahlem Centre of Plant Sciences, Königin-Luise-Str. 1/3, D-14195 Berlin, Germany

\section{Author's contributions:}

NKS \& WWW conceived and developed the idea for the manuscript. NKS, TL \& WWW refined the intellectual content and scope. NS conducted all analyses and wrote the first draft. FB, NB, SB, RD, MMG, KJ, KK, JM, DP, SCR, SS, IS, CW, MW, SW, TW organized or conducted data collection in the field and commented on the manuscript. 


\section{GROUP-SPECIFIC EFFECTS OF GRASSLAND LAND USE ON SADS}

\section{Summary}

Intensive land use is a major cause of biodiversity loss, but most studies employ simple diversity measures, and analyses of other community attributes are only recently gaining attention. Species abundance distributions (SADs) are one of such community attributes. Their analysis can not only reveal changes in the overall abundance structure within a community but also indicate whether those changes are driven by the abundant or the rare species.

We tested the effect of grassland management intensity (including the land-use modes fertilization, mowing, grazing and a combined measure of land-use intensity) on species richness and SADs for three belowground (arbuscular mycorrhizal fungi, prokaryotes and insect larvae) and seven aboveground groups (vascular plants, bryophytes and lichens; arthropod herbivores; arthropod pollinators; bats and birds). Three descriptors of SADs were evaluated: general shape (abundance decay rate), proportion of rare species (rarity) and proportional abundance of the commonest species (dominance).

Across groups, species richness was largely unaffected by intensification and only decreased with increasing mowing intensity. Of the three SAD descriptors, only the abundance decay rate became steeper with increasing land-use intensity across groups. This change was driven by a decrease in rarity among plants, which were the only group individually reacting to combined land-use intensity. Among the individual groups, bats and birds showed the most differentiated changes in rarity with effects of grazing being positive and effects of fertilization being negative. Decay rate and dominance in insect larvae were affected by mowing and grazing intensity.

Effects of land-use intensity on abundance distributions were not consistent between different groups or land-use modes. Therefore, analyses of individual land-use modes are needed to understand the mechanisms behind overall effects. We also caution against the use of single taxa as surrogates of diversity in other groups. Results suggest that SADs are widely applicable to investigate global and regional changes in terrestrial ecosystems, since effects on dominant and rare species can be clearly disentangled. 


\section{GROUP-SPECIFIC EFFECTS OF GRASSLAND LAND USE ON SADS}

\section{Introduction}

Intensification of land use is one of the main global drivers of biodiversity decline (Vitousek, 1994; Newbold et al., 2015). Many studies on the effect of land-use intensity on biodiversity rely however on single diversity measures, such as species richness or abundance-weighted indices, such as Shannon or Simpson.

While synthetic indices like Shannon or Simpson are clearly useful and incorporate species abundances, they are often used as indicators of changes in diversity without an interpretation of the underlying changes in abundance. The information on species abundances can be exploited in more detail by analyzing species abundance distribution (SADs). In contrast to diversity measures, SADs give information about how the composition of a community changes along a gradient such as land-use intensity (Simons et al., 2016). As two communities with identical diversity can differ markedly in their abundance structure, species composition or functional diversity, much progress has been made towards understanding such differences. For instance by analyzing beta diversity to distinguish species turnover (i.e. changes in composition) from nestedness (Baselga, 2010; Solar et al., 2015), or by calculating mean functional traits and functional trait diversity (Birkhofer et al., 2015; Simons et al., In press). However, species-abundance distributions (SADs) have seldom been used to assess the effects of global or regional changes on species assemblages (McGill et al,. 2007; Simons et al., 2015). This is surprising, given that the typical abundance structure of species communities with few dominant and many rare species had been recognized as a fundamental principle in ecology already in the 1930s (Motomura, 1932).

SADs can be quantified by the slope of a regression between the logarithm of species abundances and species ranks (Figure 1). Variations in this slope among communities reflect differences in the numerical hierarchy of species in a community, which in turn often reflects their competitive ranking. In addition, SADs contain information on the dominance structure of a community (i.e. the relative abundance of the most abundant species) and on the proportion of rare species in a community (i.e. the length of the SAD tail) (Figure 1). With those three descriptors of SADs, one can first estimate the overall change in the abundance structure of communities along environmental gradients (by changes in the SAD's steepness) and then disentangle the two possible mechanisms (i.e. change in dominance vs. change among the rare species) which can lead to a change in the overall shape. Previous studies have shown that land-use intensity in grassland has more pronounced effects on rare than on common species (Allan et al., 2014), indicating that land-use intensity can have variable 
effects on different portions of an SAD. Unawareness of such differences can substantially bias our expectations or conclusions on how land use affects community resistance and resilience, interactions within communities, ecosystem functions or ecosystem services (Naeem and Wright, 2003; Cadotte et al., 2011; Wood et al., 2015).
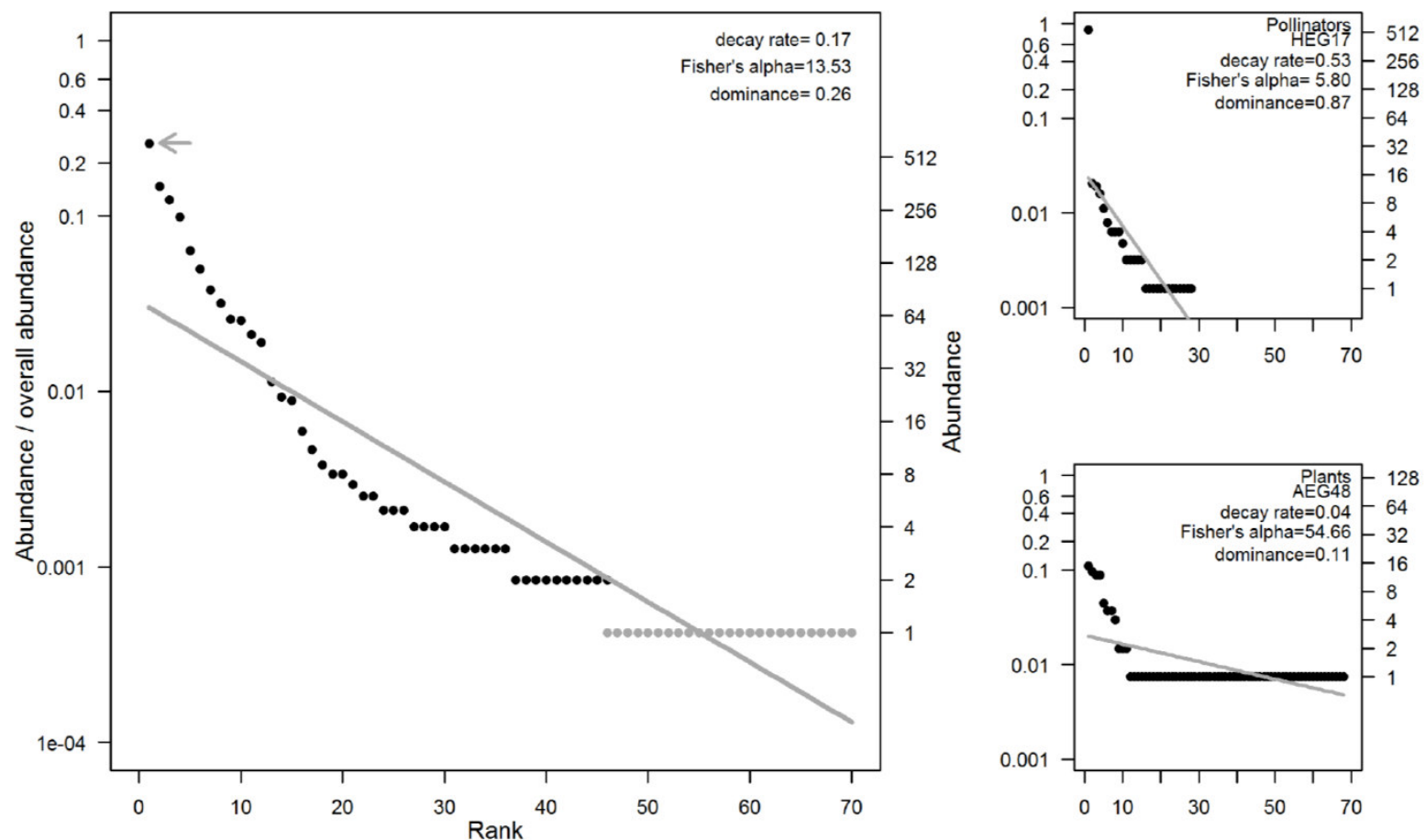

Figure 1: Conceptual figure of the three SAD descriptors (left graph) and examples of species-abundance distributions from our data set (right graphs). The abundance decay rate indicates the steepness of the distribution (indicated by the grey solid line). Berger-Parkers dominance is a descriptor of the dominance of the most common species and calculated as the relative abundance of this commonest species in relation to the overall abundance (indicated by the grey arrow). Fisher's alpha is a descriptor of the proportion of rare species (indicated by the grey points). The upper right graph shows data from pollinators which were sampled on an unfertilized, grazed grassland in the region Hainich-Dün and was selected as it shows the highest abundance decay rate in a community with more than 20 species. The lower right graph shows data from plants (i.e. vascular plants, bryophytes and lichens) which were sampled on an unfertilized, grazed grassland in the region Schwäbische Alb and was selected as it shows the lowest abundance decay rate among the communities with a similar number of species as the other examples.

In a recent study, Simons et al. (2015) found that land-use intensity leads to steeper abundance distributions in arthropod communities by way of an increase in dominance. The effect on dominance was mainly driven by fertilization, whereas other land-use modes, i.e. grazing and mowing, affected the number of rare species. The different grassland land-use modes -grazing, mowing or fertilization- were also found to have distinct effects on the species richness of plants (Socher et al., 2013) and to have opposing effects on the functional diversity of arthropods (Simons et al., In press). Differentiated effects of land-use modes have also been shown in forests, where structural properties and structural complexity of individual stands showed a variety of effects on species abundance patterns of different taxa (Jung et al., 


\section{GROUP-SPECIFIC EFFECTS OF GRASSLAND LAND USE ON SADS}

2012; Gossner et al., 2014). Despite differences between single modes, compound measures of land-use intensity are useful to compare effects across ecosystems, landscapes or management approaches. They sometimes are also effective predictors of species richness across taxonomic groups (Gossner et al., 2014). Nonetheless, it is important to disentangle the effects of single land-use modes on diversity in order to better understand the mechanisms behind the loss of biodiversity in managed landscapes.

By disentangling the effects of different land-use modes on abundance structures in grassland arthropods and by comparing the two mechanisms behind changes in SADs, Simons et al. (2015) showed that intensive land use (especially fertilization) increases the dominance within communities. While we have surely gained valuable new insights from this study, we should not assume that changes in other taxonomic groups are driven by the same mechanisms. In fact, effects are likely to differ among some taxonomic groups and converge between others. Therefore, the effects of land-use intensity on species-abundance distributions should be assessed on the widest possible range of functionally relevant organisms. We collected abundance data from ten taxonomic and/or functional groups which were sampled on the same plots along a gradient of grassland land-use intensity to answer the following questions:

1. Does land-use intensity increase the steepness of the species-abundance distribution in all groups?

2. Are changes in SAD steepness driven by changes in the dominance of the most abundant species or by changes in the number of rare species?

3. Do the strength of land-use intensity effects and the mechanisms behind the observed changes differ between groups?

4. Do different land-use modes have similar or divergent effects on SAD descriptors? 


\section{GROUP-SPECIFIC EFFECTS OF GRASSLAND LAND USE ON SADS}

\section{Material and Methods}

\section{Study system and land use}

The study was conducted within the large-scale and long-term Biodiversity Exploratory project (Fischer et al., 2010), which comprises three regions in Germany: (1) the UNESCO Biosphere Reserve Schorfheide-Chorin in the North-East $\left(53^{\circ} 02^{\prime} \mathrm{N} 13^{\circ} 83^{\prime} \mathrm{E}\right.$, about $1300 \mathrm{~km}^{2}$ in size, 3-140 m a.s.1.), (2) the National Park Hainich and its surrounding areas in Central Germany $\left(51^{\circ} 20^{\prime} \mathrm{N} 10^{\circ} 41^{\prime} \mathrm{E}\right.$, about $1300 \mathrm{~km}^{2}, 285-550 \mathrm{~m}$ a.s.1.), and (3) the UNESCO Biosphere Reserve Schwäbische Alb in the Swabian Jura in the South-West $\left(48^{\circ} 43^{\prime} \mathrm{N}\right.$ $9^{\circ} 37^{\prime} \mathrm{E}$, about $422 \mathrm{~km}^{2}, 460-860 \mathrm{~m}$ a.s.1.). In each of the three regions, 50 plots of $50 \mathrm{~m} \times$ $50 \mathrm{~m}$ size were selected on managed grasslands to cover the entire range of land-use intensity and land-use modes representative for these regions (see Fischer et al., 2010, for details). All grasslands are continually managed by farmers as meadows (only mown), pastures (only grazed) or mown pastures (mown and grazed), which are either unfertilized or fertilized.

Land-use intensity on each plot was assessed yearly through standardized questionnaires since 2006. Mowing intensity was expressed as the number of cutting events per year. Grazing intensity was represented by the standardized number of grazer individuals (cattle, sheep and/or horses) per hectare times the number of days the plots were grazed per year. Fertilization intensity includes nitrogen amounts from chemical fertilizer, manure or slurry per hectare (see Blüthgen et al., 2012, for a more detailed description). Intensities of the three land-use modes were standardized by dividing the values by the corresponding mean from the respective region and then combined into a standardized index of land-use intensity (LUI) by summing the resulting values for the three modes and taking the square-root to achieve more evenly distributed data (Blüthgen et al., 2012). We used the mean LUI and the mean intensity of the single land-use modes over three years (2006-2008) to better represent long-term land use.

\section{Biodiversity sampling}

We compiled biodiversity data from ten taxonomic and/or functional groups for which richness and abundance data was available, comprising three belowground groups (soil prokaryotes, arbuscular mycorrhizal fungi and insect larvae) and seven aboveground groups (vascular plants, bryophytes, lichens, herbivorous arthropods, pollinators, bats and birds). All taxa within each group were sampled within the same assessment, i.e. with the same method on different subplots within the $50 \mathrm{~m} \times 50 \mathrm{~m}$ plots. 


\section{GROUP-SPECIFIC EFFECTS OF GRASSLAND LAND USE ON SADS}

Belowground groups were sampled from soil cores. Prokaryotes and arbuscular mycorrhizal fungi $(A M F)$ were sampled from 14 soil cores (40 cm length, $5 \mathrm{~cm}$ diameter) per plot, taken in May 2011. All soil cores per plot were homogenized and combined into one sample per plot (see also Solly et al., 2014). Total microbial DNA was isolated from soils using a MoBioPowerSoil DNA Isolation Kit. Operational taxonomic units (OTUs) of prokaryotes were determined to species level based on pyrosequenced V3-V5 regions of the 16S rRNA gene using the QIIME software package version 1.8 (Caporaso et al., 2010). The NS31-AM1 fragment of the fungal 18S rDNA was amplified using arbuscular mycorrhizal fungal specific primers (Morris et al., 2013) and sequenced using a Genome Sequencer FLX+ 454 System. The reads were quality filtered using MOTHUR (Schloss et al., 2009) and classified using the MaarjaM AMF reference database (Opik et al., 2010). Detailed description of the data processing is presented in Supplementary Information (Appendix S1). Insect larvae were extracted from an additional soil core per plot $(5 \mathrm{~cm}$ depth, $20 \mathrm{~cm}$ diameter) sampled in April 2011, by means of a heat/moisture gradient in the cores (Kempson et al., 1963) over a period of eight days. Extracted larvae were stored in $70 \%$ ethanol until identification to family level (Stehr, 1991; 2005). Although belowground taxa were sampled two years after the aboveground taxa and are likely affected by the land use in the years 2009 and 2010, we used the 2006-2008 index for the entire dataset. Given that the combined landuse intensity over this triennium is highly correlated with the combined land-use intensity from 2009 to $2011\left(F_{1,148}=746.26, p<0.001 ; \mathrm{R}^{2}=0.83\right.$; slope $\left.=0.99 \pm 0.04\right)$ the choice of index should not affect the results.

Vascular plants, bryophytes and lichens were assessed in $4 \mathrm{~m} \times 4 \mathrm{~m}$ subplots in each plot in early summer 2008. Species abundances were estimated as percentage of ground cover. For details on vascular plant sampling see Socher et al. (2012) and for bryophyte and lichen sampling Müller et al. (2012). Vascular plants, bryophytes and lichen were then combined as one group (hereafter referred to as "plants"), because of low species richness of bryophytes and lichens on some plots. Herbivorous arthropods were sampled twice, in June and August 2008, by sweep-netting with a total of 60 double-sweeps in transects along three plot borders (Simons et al. 2014). Only twice-sampled plots were analyzed and data from the two samples were pooled. Hemiptera: Cicadina (Cicadomorpha, Fulgoromorpha), Hemiptera: Heteroptera, Coleoptera and Orthoptera were determined to species level. Only adult individuals and herbivorous species were included in the analysis. The assignment of feeding guilds followed Gossner et al., (2015). Abundances of pollinators were assessed in 2008 during peak flowering (May to August). On 31 plots, no flowering plants were observed at the 


\section{GROUP-SPECIFIC EFFECTS OF GRASSLAND LAND USE ON SADS}

time of visit, mainly due to grazing or mowing. On the remaining plots, 162 surveys were conducted (Alb: 63; Hainich: 51; Schorfheide: 48) in total, sampling 29 plots up to four times as pollinator composition changes during the flowering period. Each survey covered a transect area of $200 \mathrm{~m} \times 3 \mathrm{~m}$ three times during six hours of morning and afternoon sampling. Only insects posed directly in the center of the flowers while seemingly feeding on pollen or nectar were caught with an insect net or with help of an exhauster. Insects resting on petals were not taken into consideration. Bird species and their abundances were scored by standardized audio-visual point-counts for five periods of 5 minutes per point count, locality and season (Renner et al., 2014). Since abundances in each year were very low, we combined counts from the years 2008 to 2012. Bats were assessed with standardized acoustic surveys (Jung et al., 2012) between June and September in the years 2008 to 2012. Acoustic monitoring does not allow the identification of individuals, therefore we used the cumulative number of species presence records per plot within the five year study period as a measure of abundance. Bats and birds were analyzed together because of low species richness of the individual groups in some plots.

We used different levels of taxonomic resolution (species, family or operational taxonomic unit) depending on the taxon. Hence, taxonomic richness instead of species richness is used to describe effects on diversity. Individuals which could not be identified to species (plants, aboveground arthropods) or family level (belowground insect larvae) were excluded from the analysis.

\section{Land-use effects on SAD descriptors}

As species-abundance distributions (SADs) can only be calculated above a minimum number of species and individuals, we excluded plots with fewer than three taxonomic units or fewer than five counts overall (5 individuals or 5\% cover) per group. Six plots were excluded for insect larvae, three plots for birds plus bats, two plots for AMF and one plot for pollinators. All other groups were sampled with at least five counts and at least three taxonomic units on all plots. For each group and plot, we counted the overall number and abundance of taxonomic units (species, families, OTUs) to which we fitted species abundance distributions. All analyses were conducted in R v.3.1.2 (R Core Team, 2014).

Three descriptors were extracted from the SADs: abundance decay rate to describe the overall shape of the SAD, the Berger-Parker index to describe dominance, and the standardized value of Fisher's alpha to describe rarity. The abundance decay rate was calculated from the geometric series, or niche pre-emption model (Motomura, 1932), in which 


\section{GROUP-SPECIFIC EFFECTS OF GRASSLAND LAND USE ON SADS}

the expected abundance $n$ of a species $i$ is defined by the total number of individuals $N$ of all species, the estimated abundance decay rate $r$ per rank and by a constant factor $C$ (defined by $r$ and the number of species $S$ ) (McGill, 2011):

$$
n_{i}=N C r(1-r)^{i-1} \text { with } C=[1-(1-r) S]^{-1}
$$

Although the above model includes two parameters ( $r$ and $C$ ), it can be treated as a oneparameter model, because $C$ is defined by $r$ (Oksanen et al., 2012). The abundance decay rate $r$ is the fitted parameter and represents the slope of the model. We extracted the abundance decay rate $r$ from the niche pre-emption model using the R package 'vegan' (Oksanen et al., 2012). The dominance $d$ (May, 1975) and Fisher's alpha were extracted from the log-series distribution (Fisher et al., 1943) fitted with the R package 'sads' (Inacio Prado and Dantas Miranda, 2013). Dominance $d$, or Berger-Parker Index (May, 1975), is calculated as the count of the most abundant taxonomic unit (N1) divided by the total count over all taxonomic units (N). The value for Fisher's alpha was corrected by the number of taxonomic units (alpha/S). Restriction to plots for which SAD descriptors were obtained for all groups would have almost halved the number of observations (to 87 of 150 plots), therefore missing data from individual groups were coded as NA (not available) in the dataset. The number of plots with data for each group are shown in Table 1.

The effect of land-use intensity on each of the three descriptors was analyzed with linear mixed effect models within the R package 'ImerTest' (Kuznetsova et al., 2014). Each model included an interaction between land-use intensity (one of the three modes or all three combined) and the groups as fixed effects. Both the abundance decay rate and dominance were positively correlated with the number of taxonomic units (richness), hence we used the residuals from linear models between richness and abundance decay rate or dominance, respectively. We were not interested in estimating the differences in effects between regions, instead we allowed random variation of slopes and intercepts between regions within the groups. Therefore, we included two random effects in the model:

response $\sim$ Land use*Group+ (1lGroup:Region)+(0+LUIlGroup:Region) 


\section{GROUP-SPECIFIC EFFECTS OF GRASSLAND LAND USE ON SADS}

Table 1: Overall number of taxa and counts as well as average and extreme values per plot in each sampled group. Taxonomic resolution is organizational taxonomic units on species level (3\% genetic divergence) for procaryotes and arbuscular mycorrhizal fungi (AMF), family for insect larvae and species for other groups. Each group can include several taxonomic groups, but each group was assessed with the same method (see Method section for more detail). Nr plots indicates the number of plots which were sampled/on which the group was recorded.

\begin{tabular}{lrrrrrrrrrr} 
Group & \multicolumn{1}{c}{ Richness } & \multicolumn{4}{c}{ Abundance* } & \multicolumn{3}{c}{ Nr. plots Reference } \\
& total & min & mean & max & total & min & mean & max & & \\
\hline Prokaryotes & 7017 & 599 & 778.41 & 1149 & 807,188 & 3482 & 5381.25 & 9983 & $150 / 150$ & 1 \\
AMF & 270 & 1 & 29.30 & 67 & 33,849 & 4 & 225.66 & 546 & $150 / 150$ & 1 \\
Insect larvae & 31 & 1 & 5.85 & 11 & 5,075 & 1 & 33.83 & 120 & $150 / 150$ & 1 \\
\hline Vascular plants & 269 & 9 & 24.45 & 57 & & $63 \%$ & $132 \%$ & $195 \%$ & $145 / 145$ & 2 \\
Bryophytes & 50 & 1 & 2.71 & 14 & & $1 \%$ & $12 \%$ & $133 \%$ & $146 / 144$ & 1 \\
Lichens & 63 & 1 & 9.64 & 25 & & $1 \%$ & $11 \%$ & $32 \%$ & $145 / 14$ & 1 \\
Herbivores & 382 & 9 & 29.50 & 55 & 54,181 & 33 & 389.79 & 2690 & $139 / 139$ & 2 \\
Pollinators & 739 & 2 & 39.64 & 95 & 25,309 & 3 & 212.68 & 662 & $119 / 119$ & 3 \\
Bats & 9 & 1 & 3.73 & 7 & 1,200 & 1 & 8.00 & 24 & $150 / 148$ & 1 \\
Birds & 85 & 1 & 5.78 & 25 & 2,993 & 1 & 19.95 & 239 & $150 / 144$ & 4 \\
\hline
\end{tabular}

* for prokaryotes: number of detected sequences; for vascular plants, bryophytes and lichens: \% cover.

1: data published in the Supplementary Material of this publication. 2: data published in Simons etal. (2014) PLoS One

9:e107033. 3: data published in Weiner etal. (2014) Ecology 95:466-474. 4: data published in Renner etal. (2014) PLoS One 9:e1 12347

Including two random effects in the model ensured that the variation in slopes and variation in intercepts were uncorrelated. If one of the two random effects did show zero variation, it was excluded from the model. The overall effects of land-use intensity, group and their interaction on the three descriptors were tested for significance using F-values from ANOVA with Satterthwaite approximation for degrees of freedom. For the overall effect for land-use intensity the groups are ignored, hence one intercept and one slope across all data points is calculated. A significant effect of group indicates that intercepts differ between groups. The interaction term between land-use intensity and group tests if slopes differ between groups but does not show which of the groups differ from each other. Differences in intercepts and slopes between the groups were tested for significance using t-Tests with the same approximation for degrees of freedom. Note however that differences are only tested for each group against the first group (i.e. the reference or control). In our analyses, soil prokaryotes are the reference group, hence a significant t-Test for plants would show that the intercept of plants differs significantly from the intercept of soil prokaryotes. Equivalently, a significant t-Test for the interaction between land-use intensity and plants would show that the slope of plants is significantly different from the slope of soil prokaryotes. If intercept or slope of soil prokaryotes differ significantly from zero and none of the t-Tests with the other groups is significant, one can infer that intercepts and slopes are significantly different from zero in all 


\section{GROUP-SPECIFIC EFFECTS OF GRASSLAND LAND USE ON SADS}

groups. Both F-tests and t-tests were run in the R package 'lmerTest' (Kuznetsova et al., 2014).

\section{Results}

Across all groups and all 150 plots, 84,565 individuals of insects (below-and aboveground) and 4,193 individuals of vertebrates together with 841,037 sequences of soil prokaryote and arbuscular mycorrhizal fungi DNA were recorded, which represent 7,287 organizational taxonomic units of prokaryotes and mycorrhiza, 31 families of insect larvae, 1,121 species of insects and 94 vertebrate species. Additionally, 382 species of vascular plants, bryophytes and lichens were recorded (Table 1).

Table 2: Linear mixed effect model results (F-values) for the effect of land-use intensity (LUI), and the three land-use modes on taxonomic richness and SAD descriptors. Land-use modes are grazing (Graz), fertilization (Fert) and mowing (Mow) intensity. SAD (species-abundance distribution) descriptors are abundance decay rate (for the general shape of the SAD), corrected Fisher's alpha (corrected for the number of taxa, i.e. equivalent to proportion of rare species) and Berger-Parker dominance (the proportional abundance of the most abundant taxon). Models included random variation of slopes and intercepts between regions within groups (for full statistics see Tables S1-S8). For abundance decay rate and dominance, residuals were taken from linear models with taxonomic richness, to correct for effects of taxonomic richness on those two descriptors. Significance levels are based on F-values, calculated by a type III analysis of variance with Satterthwaite approximation for degrees of freedom within the 'ImerTest' package in R (Kuznetsova et al. 2014). Number of observations: 966; number of groups: 7, number of regions: 3 . ***: $\mathrm{p}<0.001 /{ }^{*}: \mathrm{p}<0.01 / *$ : $\mathrm{p}<0.05$.

Taxonomic richness Abundance decay rate Fisher's alpha Dominance

\begin{tabular}{lrrrr}
\hline Land-use intensity & 0.38 & $7.63^{*}$ & 1.20 & 3.21 \\
Group & $300.02 * * *$ & $6.84^{* * *}$ & $5.59^{* *}$ & $2.93^{*}$ \\
LUI:Group & 0.56 & $2.30^{* *}$ & $3.85^{* *}$ & $1.10^{*}$ \\
\hline Fertilization intensity & 0.23 & $7.53^{*}$ & $2.76^{* *}$ & $5.92^{*}$ \\
Group & $219.58^{* * *}$ & $8.22^{* * *}$ & $20.87^{* * *}$ & $3.84^{* *}$ \\
Fert:Group & 0.06 & $0.93^{*}$ & $2.80^{*}$ & 1.46 \\
\hline Mowing intensity & 1.71 & 3.39 & $3.86^{* *}$ & 1.56 \\
Group & $320.28 * *$ & $3.47^{* *}$ & $9.95^{* * *}$ & 1.81 \\
Mow:Group & 0.69 & $2.01^{* *}$ & $0.81^{*}$ & 1.50 \\
\hline Grazing intensity & 0.00 & $0.61^{* * *}$ & 0.36 & $0.84^{* *}$ \\
Group & $332.26 * * *$ & $44.80^{* *}$ & $12.10^{* * *}$ & $4.83^{* *}$ \\
Graz:Group & 0.06 & $3.78^{* *}$ & 2.94 & $3.16^{* *}$ \\
\hline
\end{tabular}




\section{GROUP-SPECIFIC EFFECTS OF GRASSLAND LAND USE ON SADS}

We found no overall effect of combined land-use intensity on taxonomic richness (Table 2) and effects among individual groups were also not significant (Figure S1A \& Table S1). Among the single land-use modes, mowing intensity did not show an overall effect on taxonomic richness (Table 2) but negative effects for individual groups (Figure S1B, Table S2). Both fertilization and grazing intensity did not show significant overall effects on taxonomic richness, and also did not influence the richness of the individual groups (Table S3-S4, \& Figure S1C-D).

\section{Land-use intensity effects on SAD descriptors}

The combined land-use intensity showed a significant but weak positive overall effect on abundance decay rate (Table 2, Table S5). Among the individual groups, the slope of soil prokaryotes (i.e. the reference group) was not significantly different from zero and only plants had a significantly greater slope (Figure 2A, Table S5). However, this significant difference did not lead to a significant interaction between land-use intensity and group (Table 1). Hence, the overall effect can also be driven by differences in the average abundance decay rate across groups with increasing land-use intensity. In fact, insect larvae had a significantly higher average abundance decay rate (indicated by significant differences in the groups' intercepts), and plants had significantly lower abundance decay rates than soil prokaryotes (Table S5 \& Figure 2A). We found no overall effect of combined land-use intensity on neither dominance nor rarity (Table 2). However, we found a significant interaction between the combined land-use intensity and the groups for rarity (Table 2). This interaction was driven by a significant decrease in rarity for plants with increasing combined land-use intensity (Figure 2B \& Table S6). The combined land-use intensity did neither have an overall significant effect nor an effect on dominance for the individual groups (Figure 2C, Table S7). In summary, plants showed the clearest response such that rarity decreased with increasing combined land-use intensity. The combined land-use intensity increased the steepness of the abundance distributions across groups, mainly due to the effect on plants and the differences in the average level of abundance decay rates. 


\section{GROUP-SPECIFIC EFFECTS OF GRASSLAND LAND USE ON SADS}
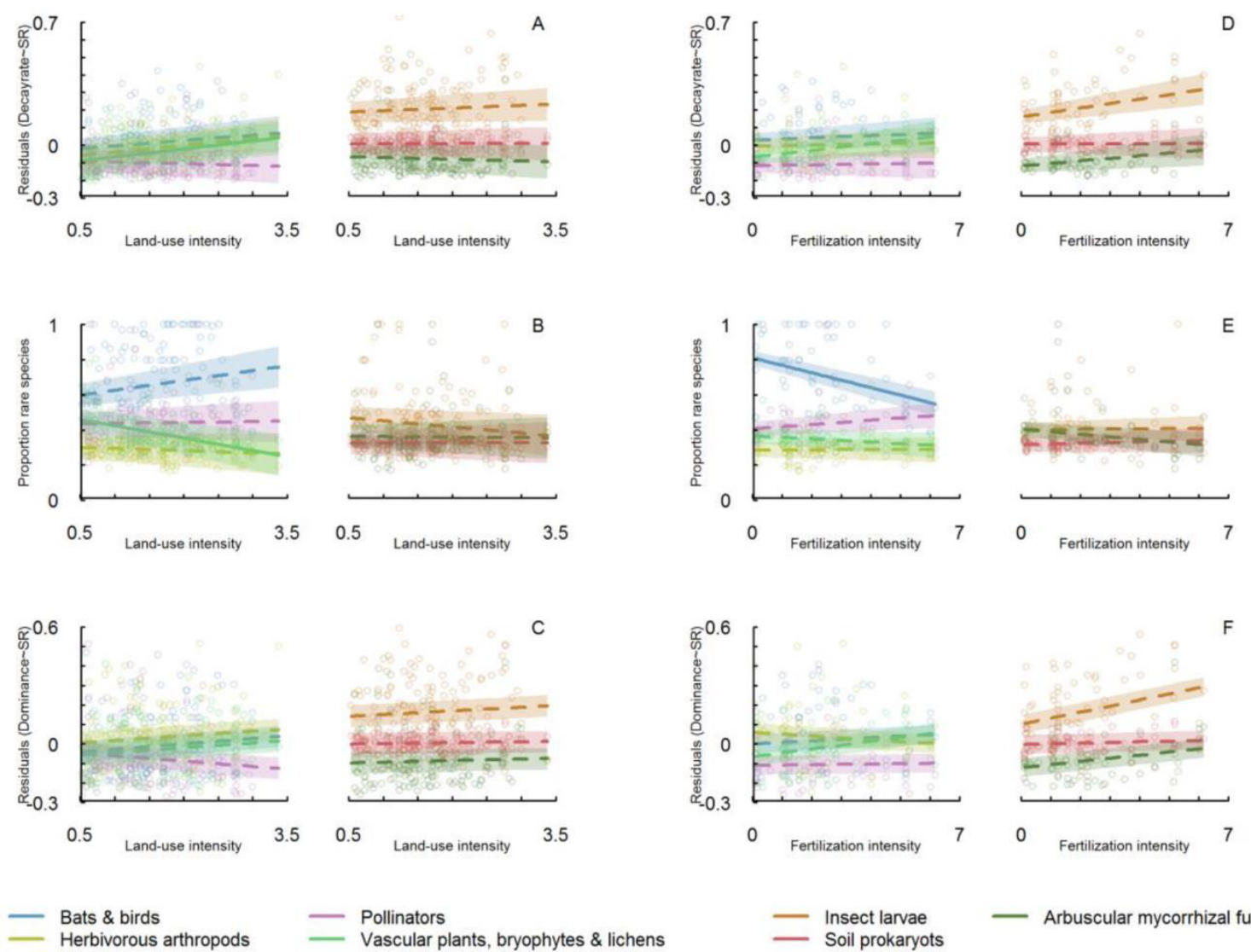

Bats \& birds
Herbivorous arthropods

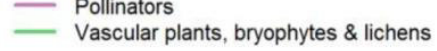

- Soil prokaryots

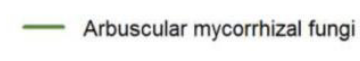

Figure 2: Effects of combined land-use intensity (A-C) and fertilization intensity (D-F) on the three descriptors of the species-abundance curves. The seven groups are indicated by different colors. Lines show the predicted values from linear mixed effect models with the shaded area indicating the standard deviation of the slope and intercept between regions within groups. For abundance decay rate and dominance, mixed effect models were calculated for residuals taken from linear models between taxonomic richness and abundance decay rate and dominance, respectively to estimate the effect of land-use intensity independent of the effects of taxonomic richness. Solid lines indicate significant $(\mathrm{p}<0.05)$ interactions between the respective group and the slope from post-hoc tests conducted on the linear mixed effect models. Dashed lines indicate non-significant post-hoc tests.

\section{Effects of land-use mode on SAD descriptors}

We found a significant but weak positive overall effect of fertilization intensity on abundance decay rate (Table 2, Table S8), but none of the individual groups showed significant changes in decay rate (Table S8, Figure 2D). The analysis for rarity showed a significant interaction between fertilization intensity and group, driven by a significant decrease in vertebrate rarity (Table S9 \& Figure 2E) with increasing fertilization. Fertilization intensity had an overall effect on dominance across groups but no effect on the dominance in individual groups (Table S10, Figure 2F).

Mowing intensity showed no overall effect on abundance decay rate (Table 2). Among the individual groups, insect larvae showed a significantly greater slope for abundance decay 


\section{GROUP-SPECIFIC EFFECTS OF GRASSLAND LAND USE ON SADS}

rate than the soil prokaryotes, for which slope was not different from zero (Table S11 \& Figure 3A). However, this did not lead to a significant interaction between mowing intensity and group (Table S11). Mowing intensity did not show an overall or group-specific effect on rarity (Table S12, Figure S3B). While mowing intensity did not have an effect on dominance across groups (Table 2), insect larvae showed a significantly greater slope for dominance than the reference group (Table S13, Figure S3C).
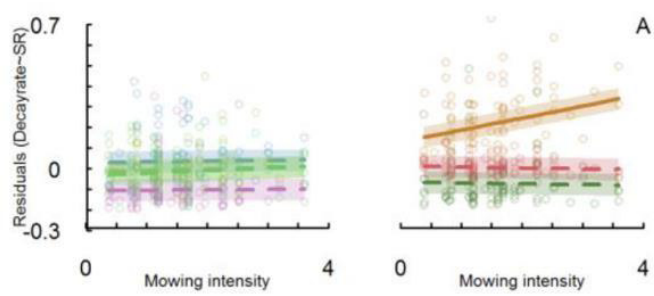

A
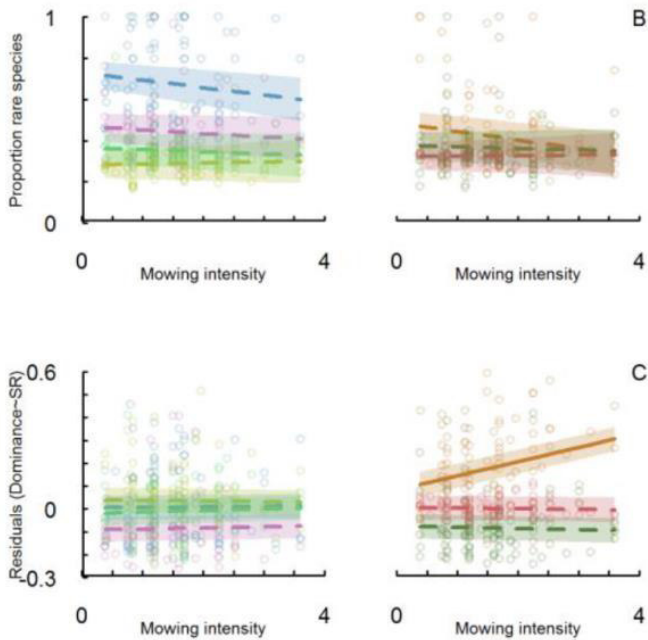

- Bats \& birds

Herbivorous arthropods
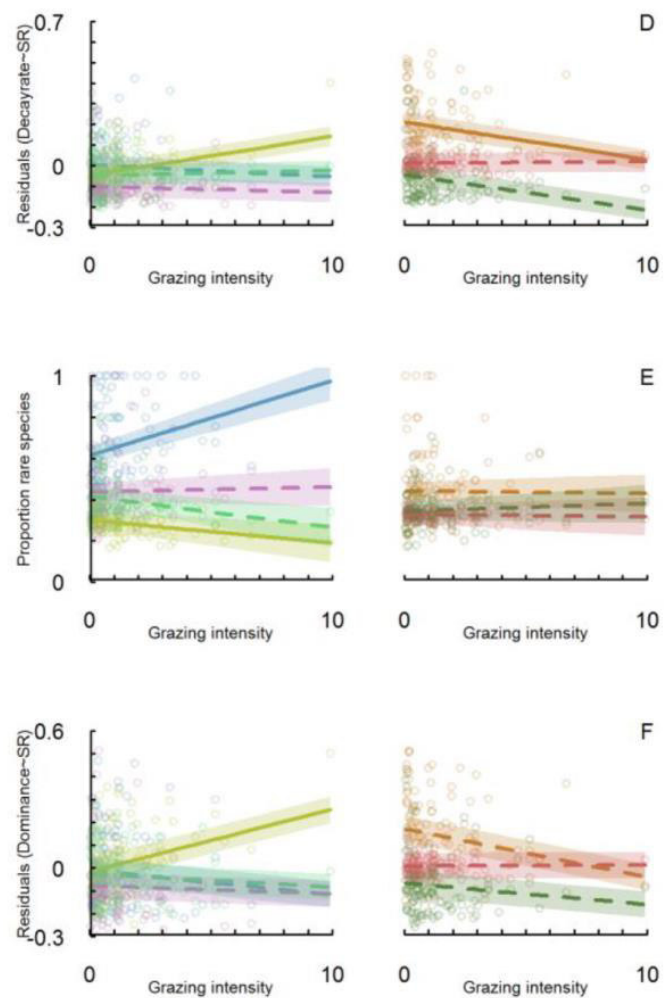

Insect larvae
- Soil prokaryots

D

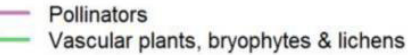

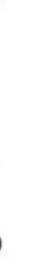

Figure 3: Effects of mowing (A-C) and grazing (D-F) intensity on the three descriptors of the peciesabundance curves. The seven groups are indicated by different colors. Lines show the predicted values from linear mixed effect models with the shaded area indicating the standard deviation of the slope and intercept between regions within groups. For abundance decay rate and dominance, mixed effect models were calculated for residuals taken from linear models between taxonomic richness and abundance decay rate and dominance, respectively to estimate the effect of land-use independent of effects of taxonomic richness. Solid lines indicate significant $(\mathrm{p}<0.05)$ interactions between the respective group and the slope from post-hoc tests conducted on the linear mixed effect models. Dashed lines indicate non-significant post-hoc tests.

Grazing intensity did not show an overall effect on abundance decay rate but the model results showed a significant interaction between grazing intensity and the groups (Table 2). This interaction was driven by a significant decrease in the abundance decay rate of insect larvae and a significant increase in abundance decay rate of herbivorous arthropods with increasing grazing intensity (Table S14, Figure 3D). While grazing intensity showed no 


\section{GROUP-SPECIFIC EFFECTS OF GRASSLAND LAND USE ON SADS}

significant overall effect on rarity, vertebrates had a significantly greater slope for rarity than soil prokaryotes (Table S15, Figure 3E). As for abundance decay rate, grazing intensity showed a significant interaction with group for its effect on dominance (Table 2), driven by a significantly greater slope for herbivorous arthropods compared to the reference group (Table S16, Figure 3F). The effect of grazing intensity on abundance decay rate and dominance of insect larvae and herbivorous arthropods were strongly influenced by one plot with a very high grazing intensity (compare to results without the most extreme grazing value in Table S17-Table S20).

In summary, we found that only fertilization intensity shows the same effect on abundance decay rate across groups as the combined land-use intensity. Instead, different land-use modes show distinct effects on abundance decay rate and rarity for individual groups.

\section{Discussion}

The combined land-use intensity affected species richness and descriptors of abundance structures only in plants. Regarding differences between groups and land-use modes, rarity of vertebrates showed the most differentiated reaction with effects of grazing being opposite to effects of fertilization. Across individual land-use modes, effects on dominance were mostly consistent with the effects on abundance decay rate, indicating that changes in decay rates are often driven by changes in dominance.

\section{Species-abundance distributions as indicators of changes in communities}

As well as abundance-corrected diversity indices, species-abundance distributions (SADs) can be used to compare changes in communities even if they are sampled by different methods or intensities, because the abundance decay rate is calculated from relative abundances. However, both the abundance decay rate and Fisher's alpha are strongly related to species richness, hence it is important to correct both values for species richness when more than one dataset is compared. When analyzing effects across different groups, the correct interpretation of the statistical results is also crucial. Effects across groups can either be driven by significant effects in all individual groups (i.e. individual groups show the same effect direction and similar effect strength) or by a shift in the occurrence of groups with different average values along the gradient (i.e. values of individual groups do not change significantly). An overall significant effect of land-use intensity on the abundance decay rate 


\section{GROUP-SPECIFIC EFFECTS OF GRASSLAND LAND USE ON SADS}

and missing effects among individual groups in our results indicate that the abundance distributions of the individual groups did not change with increasing land-use intensity, but a higher number of groups with steep abundance distributions was sampled under intensive land use than under extensive land use. Effects of single land-use modes on the abundance decay rate in single groups were more often accompanied by an effect on dominance than by an effect on rarity. This indicates that the change in abundance decay rate is mostly caused by an increase in the relative abundance of the most abundant taxon (species or equivalent). The close link between abundance decay rate and dominance suggests that a simple index such as the Berger-Parker dominance is a useful index for rapid community structure assessments.

\section{Responses in different groups}

This study includes belowground taxa that are often ignored in multi-group biodiversity studies due to difficulties in sampling, even though they play an important role for many ecosystem processes (Blossey and Hunt-Joshi, 2003). Here they were sufficiently well represented to allow the comparative assessment of response of above and below-ground groups to land-use modes and intensification.

The average abundance decay rate and dominance differed more strongly among belowground groups than among aboveground groups. Even though the taxonomic diversity of prokaryotes and arbuscular mycorrhizal fungi was much higher than those of insect larvae, these differences were not responsible for the differences within the belowground groups, as both values were corrected for taxonomic richness. Among the belowground groups, arbuscular mycorrhizal fungi showed the lowest dominance and shallow, i.e. even, abundance curves. Several other studies have found that species abundance structures of arbuscular mycorrhizal fungi fit better to lognormal or broken stick models than geometric models (Dumbrell et al., 2010, Unterseher et al., 2011, Moebius-Clune et al., 2013). McGill et al. (2007) nicely summarizes that "[the] geometric model predicts extremely uneven abundances, broken stick [...] extremely even abundances [and] lognormal and logseries are intermediate with distinct predictions about the proportions of very rare species - high in logseries, low in lognormal", hence arbuscular mycorrhizal fungi communities show generally more even distributions, which are characterized by many rare species rather than strong dominance. One notable exception is the study by Moebius-Clune et al. (2013), which found a very pronounced dominance of the top ranked taxon. However, this study was conducted in maize fields and might therefore represent a very specific type of community. The generality of even distributions in soil microbes, particularly the prokaryotes and arbuscular mycorrhizal fungi 


\section{GROUP-SPECIFIC EFFECTS OF GRASSLAND LAND USE ON SADS}

across our plots (i.e. the absence of a land-use effect), might also be due to the ubiquitous distribution of the majority of the dominant OTU's of these microbes in this ecosystem. A lack of strong land-use effects on the community structure of arbuscular mycorrhizal fungi was also found across a range of agricultural soils in Switzerland (Jansa et al., 2014). In contrast to the soil microbes, insect larvae abundance distributions showed high dominance of few families and were more similar to the abundance structures of above-ground groups. This is not surprising, as insect larvae spend only a part of their life cycle below ground, in their adult stages they are found aboveground. We might hence conclude that there is a fundamental difference in the abundance structures of below- and aboveground groups which deserves further exploration.

None of the individual belowground groups, and only plants among aboveground groups, showed a significant reaction to the combined land-use intensity. The increase in the steepness of the abundance distributions and the decrease in the proportion of rare species among plants is not surprising as more intense grassland management aims at increasing productivity, thereby fostering fast-growing and highly competitive plants (Gaujour et al., 2012). This in turn suppresses the growth of less-competitive species, i.e. mostly herbs which comprise the majority of rare species (Socher et al., 2013). While the proportion of rare plant species decreased with increasing land-use intensity, the relative abundance of the most abundant species (i.e. dominance) did not change. This indicates that increased nutrient availability does not only promote one species, but several of the more abundant species.

\section{Differences between land-use modes}

As intensification of land-use intensity in grasslands generally serves the purpose of increasing biomass production, one might expect similar effects with an increase in the intensity of individual land-use modes and a strong effect of a combined index of land-use intensity. In particular, because both grazing and mowing reduce above-ground plant biomass, and fertilization intensity is known to be associated with higher mowing intensity (Blüthgen $e t$ al., 2012). In clear contrast to this expectation, we did not find stronger effects of the combined land-use intensity compared to the single land-use modes across groups and even contrasting effects among the single land-use modes.

Insect larvae showed steeper abundance distributions with increasing mowing intensity, driven by an increase in dominance. The three families with the highest relative abundance were either Bibionidae, Staphylinidae or Cecidomyiidae (they comprised between $80 \%$ and $96 \%$ of all individuals on plots with high mowing frequency). Larval abundance has been 


\section{GROUP-SPECIFIC EFFECTS OF GRASSLAND LAND USE ON SADS}

found to increase with the percentage cover of bare soil, and facilitation of larval development due to elevated soil temperature has been suggested as underlying mechanism (Sonnemann, pers. comm.). Percentage cover of bare soil and thus soil temperature also increases after mowing. While optimal soil temperatures should benefit all larvae, positive effects are expected to be most pronounced in dominant families, which may exhibit a more $\mathrm{r}$ strategic life history, and for which season and other environmental factors are apparently also optimal at time of sampling. While mowing increases soil temperature evenly across a grassland, grazing creates patches of dry-warm and cold-moist soil. This increase in diversity of niches may lead to the reduced steepness of the abundance distribution in insect larvae.

For vertebrates (i.e. bats \& birds), a higher level of grazing intensity entailed a higher proportion of rare species, while the proportion of rare species decreased with increasing fertilization intensity. Possible mechanisms behind the negative effect of fertilization intensity could be a more homogeneous vegetation structure which is not attractive for groundbreeding birds. Ground-breeding birds such as the Eurasian skylark (Alauda arvensis) have been found to be very sensitive to agricultural activities in grasslands (Donald et al,. 2002). A homogenous canopy structure also lacks taller plants (e.g. thistles) which are used by different birds as stalking aids. Grazing however leads to heterogeneous and patchy vegetation including spots of bare soil (important as dust baths for some birds) or water holes. The feces of the grazing animals might also increase the abundance of insects (dung beetles, flies, etc.) as food source. Those can hide less well in the short vegetation and are hence easily accessible for birds and bats. Additionally, the dominance of herbivorous arthropods increased with increasing grazing intensity, indicating that resource availability for carnivorous birds increases. All those factors should lead to a decreased competition for resources on grazed sites, which allows more species to persist ('More Individuals Hypothesis'; Srivastava and Lawton, 1998). Despite those possible local-scale factors, birds and bats are generally more affected by heterogeneity on the landscape scale (e.g. structural elements such as hedges, forest patches or old buildings). An analysis on the direct and indirect effect of land use across different scales on bats has indeed found that land-use changes at larger spatial scales are more important than the local land use (Treitler et al., submitted, pers. communication K. Jung). Due to their high mobility, bats and birds can easily evade to alternative sites when the local land-use intensity changes. Thus their use as biodiversity surrogates or indicators for local- and plot-scale effects of land use in European grassland systems concerning the diversity of other taxa is limited. The use of birds as surrogates should hence be limited to ecologically very similar groups only. Several other 


\section{GROUP-SPECIFIC EFFECTS OF GRASSLAND LAND USE ON SADS}

authors (Lawton et al., 1998; Billeter et al., 2007; Dormann et al., 2007; Gossner et al., 2013) have already cautioned against the use of single indicator taxa for management or conservation strategies and our results strengthen their argument.

\section{Conclusions}

We showed that the intensification of different land-use modes has variable effects on community abundance structures and that effects are not consistent between taxonomic groups. Hence, effects of individual land-use modes on diversity should be considered as well as the effect of overall intensification. We also caution against the use of single taxa or trophic groups as indicators of overall biodiversity changes because we did not find consistent patterns of land-use effects across groups. A negative effect of intensive land use on diversity is mostly not contested (Sala et al., 2000; Newbold et al., 2015), its effects on the structure of communities are however still not considered by default. Changes in abundances within communities are however important for ecosystem production, function and services as those are more strongly affected by species abundances than by species numbers (e.g. Soliveres $e t$ $a l$. , in press). While rare species are generally considered to be not as important for ecosystem functions as common species (one reason why Shannon or other indices basically ignore rare species, depending on the Hill coefficient), they are important for biodiversity conservation. Therefore, we recommend to include species abundance distributions in the standard toolkit of biodiversity studies in terrestrial habitats. They are easy to use, comparable across groups and disentangle effects on common and rare species. 


\section{GROUP-SPECIFIC EFFECTS OF GRASSLAND LAND USE ON SADS}

\section{Acknowledgements}

We thank Esther Pašalić, Manfred Türke, Markus Lange, Rolf Daniel, Sandra Klemmer and Marco Tschapka for their help in organizing and conducting the data sampling for this

publication. We thank the managers of the three Exploratories, Katrin Lorenzen, Sonja Gockel, Kerstin Wiesner, and Martin Gorke as well as their predecessors for their work in maintaining the plot and project infrastructure; Christiane Fischer and Simone Pfeiffer for giving support through the central office, Michael Owonibi for managing the central data base, and Markus Fischer, Eduard Linsenmair, Dominik Hessenmöller, Jens Nieschulze, Ingo Schöning, Ernst-Detlef Schulze and the late Elisabeth Kalko for their role in setting up the Biodiversity Exploratories project.

The work has been funded by the DFG Priority Program 1374 "Infrastructure-BiodiversityExploratories" (DFG-WE 3081/21-1.). Field work permits were issued by the responsible state environmental offices of Baden-Württemberg, Thüringen, and Brandenburg (according

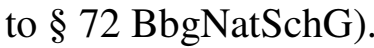




\section{GROUP-SPECIFIC EFFECTS OF GRASSLAND LAND USE ON SADS}

\section{References}

1. Allan E, Bossdorf O, Dormann CF, Prati D, Gossner MM, Tscharntke T. (2014). Interannual variation in land-use intensity enhances grassland multidiversity. Proc Nat Acad Sci USA 111:308-313.

2. Baselga A. (2010). Partitioning the turnover and nestedness components of beta diversity. Global Ecol Biogeogr 19:134-143.

3. Billeter R, Liira J, Bailey D, Bugter R, Arens P, Augenstein I, et al. (2007). Indicators for biodiversity in agricultural landscapes: a pan-European study. Appl Ecol 45:141150.

4. Birkhofer K, Diehl E, Andersson J, Ekroos J, Früh-Müller A, Machnikowski F, et al. (2015). Ecosystem services - current challenges and opportunities for ecological research. Front Ecol Evol 2:87.

5. Blossey B, Hunt-Joshi TR. (2003). Belowground herbivory by insects: influence on plants and aboveground herbivores. Annu Rev Entomol 48:521-547.

6. Blüthgen N, Dormann CF, Prati D, Klaus VH, Kleinebecker T, Hölzel N, et al. (2012). A quantitative index of land-use intensity in grasslands: Integrating mowing, grazing and fertilization. Basic Appl Ecol 13:207-220.

7. Cadotte MW, Carscadden K, Mirotchnick N. (2011). Beyond species: functional diversity and the maintenance of ecological processes and services. J Appl Ecol 48:1079-1087.

8. Caporaso JG, Kuczynski J, Stombaugh J, Bittinger K, Bushman FD, Costello EK, et al. (2010). QIIME allows analysis of high-throughput community sequencing data. Nat Methods 7:335-336.

9. Donald PF, Evans AD, Muirhead LB, Buckingham DL, Kirby WB, Schmitt SIA. (2002). Survival rates, causes of failure and productivity of Skylark Alauda arvensis nests on lowland farmland. Ibis 144:652-664.

10. Dormann CF, Schweiger O, Augenstein I, Bailey D, Billeter R, de Blust G, et al. (2007). Effects of landscape structure and land-use intensity on similarity of plant and animal communities. Global Ecol Biogeogr 16:774-787.

11. Dumbrell AJ, Nelson M, Helgason T, Dytham C, Fitter AH. (2010). Relative roles of niche and neutral processes in structuring a soil microbial community. ISME J 4:337345. 


\section{GROUP-SPECIFIC EFFECTS OF GRASSLAND LAND USE ON SADS}

12. Fischer, M., O. Bossdorf, S. Gockel, F. Hänsel, A. Hemp, D. Hessenmöller, et al. (2010). Implementing large-scale and long-term functional biodiversity research: The Biodiversity Exploratories. Basic Appl Ecol 11:473-485.

13. Fisher RA, Corbet, Williams CB. (1943). The relation between the number of species and the number of individuals in a random sample of an animal population. J Anim Ecol 12:42-58.

14. Gaujour E, Amiaud B, Mignolet C, Plantureux S. (2012). Factors and processes affecting plant biodiversity in permanent grasslands. A review. Agron Sustain Dev 32:133-160.

15. Gossner MM, Getzin S, Lange M, Pašalić E, Türke M, Wiegand K, et al. (2013). The importance of heterogeneity revisited from a multiscale and multitaxa approach. Biol Conserv 166:212-220.

16. Gossner MM, Schall P, Ammer C, Ammer U, Engel K, Schubert H, et al. (2014). Forest management intensity measures as alternative to stand properties for quantifying effects on biodiversity. Ecosphere 5.

17. Gossner MM, Simons NK, Achtziger R, Blick T, Dorow WHO, Dziock F, et al. (2015). A summary of eight traits of Coleoptera, Hemiptera, Orthoptera and Araneae, occurring in grasslands in Germany. Scientific Data 2:150013.

18. Inacio Prado P, Dantas Miranda M. (2013). Fitting species abundance model with maximum likelihood. http://sads.r-forge.r-project.org/.

19. Jansa J, Erb A, Oberholzer HR, Smilauer P, Egli S. (2014). Soil and geography are more important determinants of indigenous arbuscular mycorrhizal communities than management practices in Swiss agricultural soils. Mol Ecol 23:2118-2135.

20. Jung K, Kaiser S, Bohm S, Nieschulze J, Kalko EKV. (2012). Moving in the dimensions: effects of structural complexity on occurrence and activity of insectivorous bats in managed forest stands. J Appl Ecol 49:523-531.

21. Kempson D, Lloyd M, Ghelardi R. (1963). A new extractor for woodland litter. Pedobiologia 3:1-21.

22. Kuznetsova A, Brockhoff PB, Christensen RHB. (2014). lmerTest: Tests in linear mixed effects models. R package, http://CRAN.R-project.org/package=lmerTest.

23. Lawton JH, Bignell DE, Bolton B, Bloemers GF, Eggleton P, Hammond PM, et al. (1998). Biodiversity inventories, indicator taxa and effects of habitat modification in tropical forest. Nature 391:72-76. 


\section{GROUP-SPECIFIC EFFECTS OF GRASSLAND LAND USE ON SADS}

24. May RM. (1975). Patterns of species abundance and diversity. In: Cody ML, Diamond JM (eds). Ecology and evolution of communities. Harvard University Press: Cambridge, pp 81-120.

25. McGill BJ. (2011). Species abundance distributions. In: Magurran AE, McGill BJ (eds). Biological Diversity: frontiers in measurement and assessment. Oxford University Press: New York, pp 105-122.

26. McGill BJ, Etienne RS, Gray JS, Alonso D, Anderson MJ, Benecha HK, et al. (2007). Species abundance distributions: moving beyond single prediction theories to integration within an ecological framework. Ecol Lett 10:995-1015.

27. Moebius-Clune DJ, Anderson ZU, Pawlowska TE. (2013). Arbuscular mycorrhizal fungi associated with a single agronomic plant host across the landscape: The structure of an assemblage. Soil Biol Biochem 64:181-190.

28. Morris EK, Buscot F, Herbst C, Meiners T, Obermaier E, Waschke NW, et al. (2013). Land use and host neighbor identity effects on arbuscular mycorrhizal fungal community composition in focal plant rhizosphere. Biodivers Conserv 22:2193-2205.

29. Motomura I. (1932). On the statistical treatment of communities. Jpn J Zool 44:379383.

30. Müller J, Klaus VH, Kleinebecker T, Prati D, Holzel N, Fischer M. (2012). Impact of land-use intensity and productivity on bryophyte diversity in agricultural grasslands. PLoS One 7:e51520.

31. Naeem S, Wright JP. (2003). Disentangling biodiversity effects on ecosystem functioning: deriving solutions to a seemingly insurmountable problem. Ecol Lett 6:567-579.

32. Newbold T, Hudson LN, Hill SL, Contu S, Lysenko I, Senior RA, et al. (2015). Global effects of land use on local terrestrial biodiversity. Nature 520:45-50.

33. Oksanen J, Blanchet FG, Kindt R, Legendre P, Minchin PR, O'Hara RB, et al. (2012). Community Ecology Package 'vegan'. package, http://vegan.r-forge.r-project.org/.

34. Opik M, Vanatoa A, Vanatoa E, Moora M, Davison J, Kalwij JM, et al. (2010). The online database MaarjAM reveals global and ecosystemic distribution 685 patterns in arbuscular mycorrhizal fungi (Glomeromycota). New Phytol 188:223-241.

35. R Core Team. (2014). R: A language and environment for statistical computing. R Foundation for Statistical Computing, Vienna, Austria. 


\section{GROUP-SPECIFIC EFFECTS OF GRASSLAND LAND USE ON SADS}

36. Renner SC, Gossner MM, Kahl T, Kalko EK, Weisser WW, Fischer M, et al. (2014). Temporal changes in randomness of bird communities across Central Europe. PLoS One 9:e112347.

37. Sala OE, Chapin FS, Armesto JJ, Berlow E, Bloomfield J, Dirzo R, Huber-Sanwald E., et al. (2000). Global biodiversity scenarios for the year 2100. Science 287:1770-1774.

38. Schloss PD, Westcott SL, Ryabin T, Hall JR, Hartmann M, Hollister EB, et al. (2009). Introducing mothur: open-source, platform-independent, community-supported software for describing and comparing microbial communities. Appl Environ Microbiol 75:7537-7541.

39. Simons NK, Gossner MM, Lewinsohn TM, Boch S, Lange M, Muller J, Pasalic E, et al. (2014). Resource-mediated indirect effects of grassland management on arthropod diversity. PLoS One 9:e107033.

40. Simons NK, Gossner MM, Lewinsohn TM, Lange M, Türke M, Weisser WW. (2015). Effects of land-use intensity on arthropod species abundance distributions in grasslands. J Anim Ecol 84:143-154.

41. Simons NK, Weisser WW, Gossner MM. (2016). Multi-taxa approach shows consistent shifts in arthropod functional traits along grassland land-use intensity gradient. Ecology 97:754-764.

42. Socher SA, Prati D, Boch S, Müller J, Baumbach H, Gockel S, et al. (2013). Interacting effects of fertilization, mowing and grazing on plant species diversity of 1500 grasslands in Germany differ between regions. Basic Appl Ecol 14:126-136.

43. Socher SA, Prati D, Boch S, Müller J, Klaus VH, Hölzel N, et al. (2012). Direct and productivity-mediated indirect effects of fertilization, mowing and grazing on grassland species richness. J Ecol 100:1391-1399.

44. Solar RRD, Barlow J, Ferreira J, Berenguer E, Lees AC, Thomson JR, et al. (2015). How pervasive is biotic homogenization in human-modified tropical forest landscapes? Ecol Lett 18:1108-1118.

45. Soliveres S, Manning P, Prati P, Gossner MM, Alt F, Arndt H, et al.(2016). Locally rare species influence grassland ecosystem multifunctionality. Phil Trans T Soc B $371: 20150269$.

46. Solly EF, Schöning I, Boch S, Kandeler E, Marhan S, Michalzik B, et al. (2014). Factors controlling decomposition rates of fine root litter in temperate forests and grasslands. Plant Soil 382:203-218. 


\section{GROUP-SPECIFIC EFFECTS OF GRASSLAND LAND USE ON SADS}

47. Srivastava DS, Lawton JH. (1998). Why more productive sites have more species: An experimental test of theory using tree-hole communities. Am Nat 152:510-529.

48. Stehr FW. (1991). Immature Insects. Kendall/Hunt: Dubuque, Iowa.

49. Stehr FW. (2005). Immature Insects. Kendal//Hunt: Dubuque, Iowa.

50. Unterseher M, Jumpponen A, Opik M, Tedersoo L, Moora M, Dormann CF, et al. (2011). Species abundance distributions and richness estimations in fungal metagenomics - lessons learned from community ecology. Mol Ecol 20:275-285.

51. Vitousek PM. (1994). Beyond global warming: ecology and global change. Ecology 75:1861-1876.

52. Wood SA, Karp DS, DeClerck F, Kremen C, Naeem S, Palm CA. (2015). Functional traits in agriculture: agrobiodiversity and ecosystem services. Trends Ecol Evol 30:531-539. 


\section{GROUP-SPECIFIC EFFECTS OF GRASSLAND LAND USE ON SADS}

\section{SUPPLEMENTARY INFORMATION}

Supplementary figures and tables are provided along with the electronic version of this thesis (on DVD), under the following paths:

Appendix S1: References:

Figure S1:

Table S1:

Table S2:

Table S3:

Table S4:

Table S5:

Table S6:

Table S7:

Table S8:

Table S9:

Table S10:

Table S11:

Table S12:

Table S13:

Table S14:

Table S15:

Table S16:

Table S17:

Table S18:

Table S19:

Table S20:
Supplementary Information/Chapter III.4/Appendix S1.docx Supplementary Information/Chapter III.4/References.docx Supplementary Information/Chapter III.4/Figure S1.docx Supplementary Information/Chapter III.4/ Table S1.docx Supplementary Information/Chapter III.4/ Table S2.docx Supplementary Information/Chapter III.4/ Table S3.doc Supplementary Information/Chapter III.4/ Table S4.docx Supplementary Information/Chapter III.4/ Table S5.docx Supplementary Information/Chapter III.4/ Table S6.doc Supplementary Information/Chapter III.4/ Table S7.docx Supplementary Information/Chapter III.4/ Table S8.docx Supplementary Information/Chapter III.4/ Table S9.doc Supplementary Information/Chapter III.4/ Table S10.docx Supplementary Information/Chapter III.4/ Table S11.docx Supplementary Information/Chapter III.4/ Table S12.doc Supplementary Information/Chapter III.4/ Table S13.docx Supplementary Information/Chapter III.4/ Table S14.docx Supplementary Information/Chapter III.4/ Table S15.doc Supplementary Information/Chapter III.4/ Table S16.docx Supplementary Information/Chapter III.4/ Table S17.doc Supplementary Information/Chapter III.4/ Table S18.docx Supplementary Information/Chapter III.4/ Table S19.docx Supplementary Information/Chapter III.4/ Table S20.doc 
Chapter III.5.

Forest MANAGEMENT AND BIODIVERSITY 
FOREST MANAGEMENT AND BIODIVERSITY

III.5.

Manuscript ready for submission

\section{Unforeseeable effects of forest management systems on biodiversity of temperate European beech forests - habitat heterogeneity dilution}

Runnging title: Forest Management and Biodiversity

Peter Schall ${ }^{\mathrm{a}}$, Martin M. Gossner ${ }^{\mathrm{b}}$, Steffi Heinrichs ${ }^{\mathrm{a}}$, Steffen Boch ${ }^{\mathrm{c}}$, Daniel Prati ${ }^{\mathrm{c}}$, Kirsten Jung $^{\mathrm{d}}$, Vanessa Baumgartner ${ }^{\mathrm{e}}$, Stefan Blaser ${ }^{\mathrm{c}}$, Stefan Böhm ${ }^{\mathrm{d}}$, Rolf Daniel ${ }^{\mathrm{f}}$, Kezia Goldmann ${ }^{\mathrm{g}}$, Kristin Kaiser $^{\mathrm{f}}$, Markus Lange ${ }^{\mathrm{h}, \mathrm{i}}$, Jörg Müller ${ }^{\mathrm{j}}$, Jörg Overmann ${ }^{\mathrm{e}}$, Esther Pašalić ${ }^{\mathrm{h}}$, Swen C. Renner $^{\mathrm{d}, \mathrm{k}}$, Johannes Sikorski ${ }^{\mathrm{e}}$, Marco Tschapka ${ }^{\mathrm{d}, \mathrm{l}}$, Manfred Türke ${ }^{\mathrm{h}, \mathrm{m}, \mathrm{n}}$, Bernd Wemheuer ${ }^{\mathrm{f}}$, Tesfaye Wubet ${ }^{\mathrm{g}, \mathrm{m}}$, François Buscot ${ }^{\mathrm{g}, \mathrm{m}}$, Markus Fischer ${ }^{\mathrm{c}}$, Ernst-Detlef Schulze ${ }^{\mathrm{i}}$, Wolfgang W. Weisser ${ }^{\mathrm{b}}$, Christian Ammer ${ }^{\mathrm{a}}$

\section{Author affiliation}

${ }^{a}$ Department Silviculture and Forest Ecology of the Temperate Zones, University of Göttingen, D-37077 Göttingen, Germany

${ }^{\mathrm{b}}$ Terrestrial Ecology Research Group, Department of Ecology and Ecosystem Management, School of Life Sciences Weihenstephan, Technische Universität München, D-85354 Freising, Germany

${ }^{c}$ Institute of Plant Sciences, University of Bern, CH 3013 Bern, Switzerland

${ }^{\mathrm{d}}$ Institute of Evolutionary Ecology and Conservation Genomics, University of Ulm, D-89069 Ulm, Germany

${ }^{\mathrm{e}}$ Leibniz-Institute DSMZ - German Collection of Microorganism and Cell Cultures, D38124, Braunschweig, Germany

${ }^{\mathrm{f}}$ Department of Genomic and Applied Microbiology, University of Göttingen, D-37077 Göttingen, Germany

${ }^{\mathrm{g}}$ Department of Soil Ecology, UFZ-Helmholtz Centre for Environmental Research, D-06120 Halle-Saale, Germany 


\section{FOREST MANAGEMENT AND BIODIVERSITY}

${ }^{\mathrm{h}}$ Institute of Ecology, Friedrich-Schiller-University, 07743 Jena, Germany

${ }^{\mathrm{i}}$ Max-Planck Institute for Biogeochemistry, D-07745 Jena, Germany

${ }^{\mathrm{j}}$ Department of Biodiversity Research/Systematic Botany, University of Potsdam, D-14469

Potsdam, Germany

${ }^{\mathrm{k}}$ Institut für Zoologie, Universität für Bodenkultur Wien, 1180 Wien, Austria

${ }^{1}$ Smithsonian Tropical Research Institute, Roosvelt Ave., Balboa, Panama

${ }^{\mathrm{m}}$ German Centre for Integrative Biodiversity Research (iDiv) Halle-Jena-Leipzig, D-04103

Leipzig, Germany

${ }^{\mathrm{n}}$ Institute for Biology, Leipzig University, Johannisallee 21, D-04103 Leipzig, Germany

Author contributions:

PS and CA designed research, PS, MMG and CA analyzed the data and outlined the manuscript, PS, MMG, SH and CA wrote the paper. SBo, DP, KJ, E-DS and TW contributed to writing. MMG, SBo, SBl, SBö, VB, RD, KG, KK, ML, JM, JO, EP, DP, KJ, SR, JS, M.Ts., MTü, BW, TW, FB, MF and WWW contributed data. SB1, SBö, VB, RD, KG, KK, ML, JM, JO, EP, SR, JS, MTs, MTü, BW, FB, MF and WWW commented on the manuscript. 


\section{Abstract}

The need for forest management approaches that integrate commodity production and biodiversity conservation has increasingly been recognized over the last decades. While there is much evidence that biodiversity benefits from replacing clear-cuts by retention tree approaches, knowledge on the effects of spatially more fine-grained management systems, such as single tree selection cutting, on biodiversity is scarce. Nevertheless, finer-grained systems leading to uneven-aged forests are advocated because they are believed to mimic natural small scale gap dynamics of many temperate forests and to promote structural complexity. Here we tested how even-aged forests resulting from shelterwood cuttings and uneven-aged forests affect biodiversity of 15 taxonomic groups. We compared gamma-, beta-, and alpha-diversity in a region where both management systems co-occur. Gamma-diversities of animals, plants, fungi and bacteria were higher in even-aged than in uneven-aged forests, also when focusing on forest specialist species. Differences were driven by a higher betadiversity in even-aged forests. In addition, both management systems showed limited complementarity in species composition at the landscape scale as the percentage of exclusive species was low in uneven-aged compared to even-aged forests. Our results suggest that coarse-grained heterogeneity of forest landscapes provided by differently aged tree cohorts is more important for biodiversity than fine-grained heterogeneity within uneven-aged stands. Fine-grained heterogeneity may dilute the variability of environmental conditions within agecohorts in forests. The results question the recent trend towards a replacement of even-aged management in European temperate forests and suggest habitat-heterogeneity-dilution as the mechanism linking the habitat-heterogeneity-hypothesis and the intermediate-disturbancehypothesis in temperate forests.

\section{Significance Statement}

Forest management seeks for approaches which integrate production goals and nature conservation to avoid further biodiversity loss. In Central Europe single tree selection cutting is strongly promoted at the expense of even-aged forest management because it is considered to better preserve biodiversity due to enhanced within stand heterogeneity. In contrast to this expectation, we show that biodiversity across multiple trophic groups including bacteria, fungi, plants and animals consistently benefits from the even-aged forest management. Dilution of habitat-heterogeneity was most likely the cause for the lower biodiversity in 


\section{FOREST MANAGEMENT AND BIODIVERSITY}

uneven-aged forests. Our findings have important implications for the management of temperate forests as they contradict current forest policy and conservation strategies.

\section{Introduction}

Around the world new forest management and conservation approaches are discussed in order to better integrate production goals and nature conservation (Messier et al., 2015). Interest in approaches other than the classical even-aged management system has greatly increased in many parts of the world over the last decades (Puettmann et al., 2015). The alternative approaches, ranging from the 'close-to-nature' forestry in Europe to the 'new forestry' ecosystem management approach in North America, emphasize not only commodity production but address equally other objectives, such as intrinsic ecosystem values or maintaining species and structural diversity (Puettmann et al., 2015). The basic question, whether or not alternative silvicultural approaches can promote biodiversity by simultaneously improving harvest revenues, soil protection, resilience and recreational value, to name just a few, is the same in North America and Central Europe. However, the systems traditionally applied differ strongly between the two continents (Figure $1 A$ and $B$ ). In temperate North America the traditional clear-cut system is contrasted by the alternative retention tree approach (Lindenmayer et al., 2012; Gustafsson et al., 2010). In Central Europe the shelterwood system, in which a cohort of even-aged trees is replaced by a new evenly aged cohort through repeated cuttings over decades, is contrasted by the alternative single tree selection system, where single trees are harvested on a rather fine grain resulting in unevenaged forests (Pommerening et al., 2004; Figure $1 A$ and $B$ ). Both alternative approaches attempt to ensure habitat continuity (Grove et al., 2002; Fritz et al., 2008). There is much evidence that biodiversity generally benefits from the retention tree approach when compared to clear-cutting (Lindenmayer et al., 2012; Fedrowitz et al., 2014; Vanderwel et al., 2007; Figure $1 \mathrm{~B}$ ). Knowledge on the effects of the fine-grained approach on biodiversity in comparison to traditional management is, however, scarce. Nevertheless, all over temperate Europe, fine-grained systems are advocated over the traditional shelterwood system (Pro Silva, 2012). This is because the fine-grained approach is assumed to mimic small scale gap dynamics of natural European beech (Fagus sylvatica) forests (Hobi et al., 2015), a forest type which would dominate across Central Europe and which has traditionally been managed without clear-cutting. Single tree selection is therefore considered as a 'close-to-nature' management strategy, even though it has limited resemblance to natural forest dynamics 
(O'Hara et al., 2016)). It was shown that even fine-grained management may affect particular taxonomic groups negatively when compared to no management (Paillet et al., 2010; Bässler et al., 2014; Birkhofer et al., 2012), but it is generally assumed to facilitate alpha-biodiversity (Klopfer and MacArthur, 1960; Carey et al., 1999; Brunet et al., 2010) by enhancing within stand horizontal and vertical structural complexity and by promoting a high diversity of microhabitats and thus niches for species.

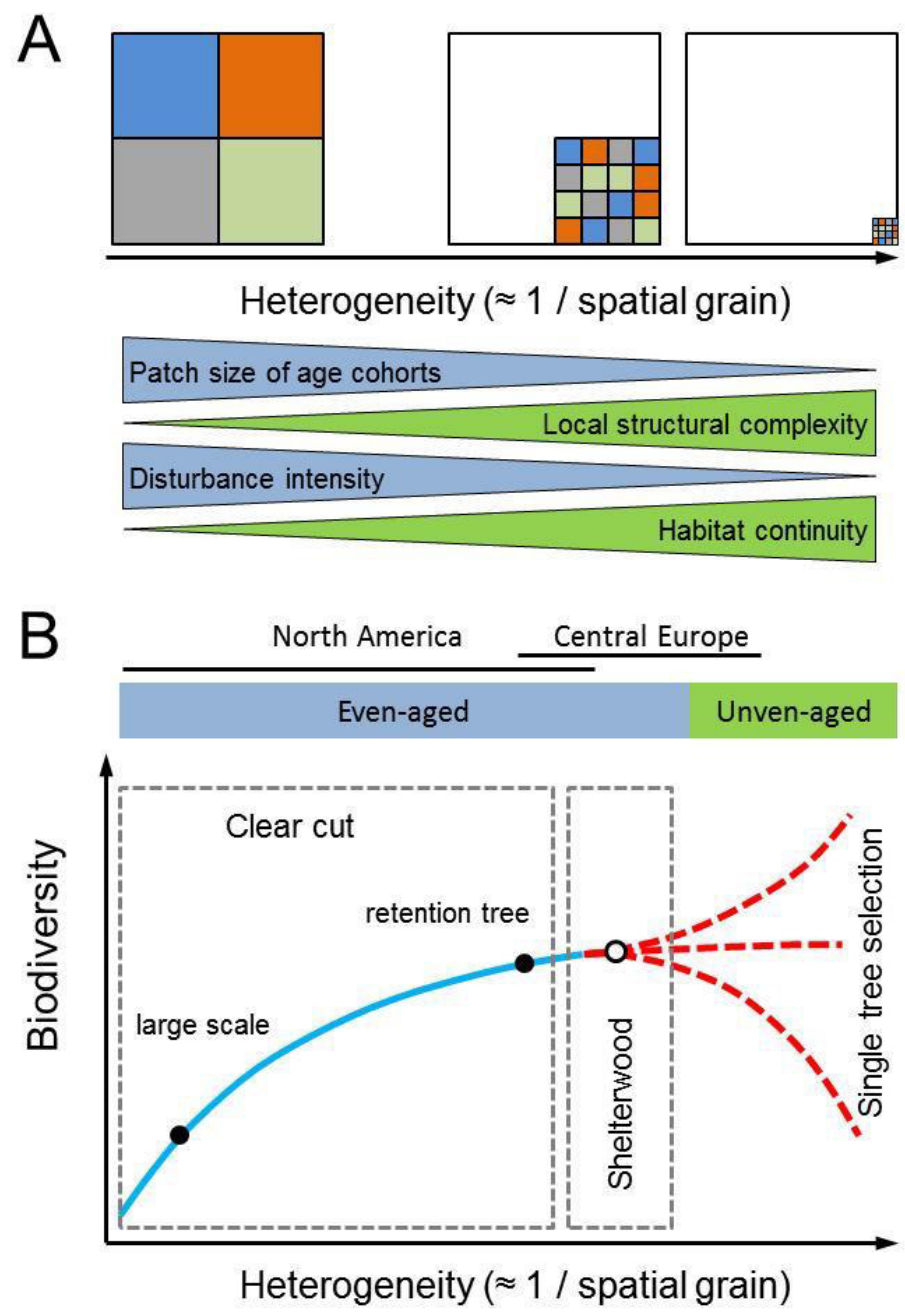

Figure 1. Conceptual framework of possible effects of spatial grain on biodiversity resulting from different forest management systems. (A) Forest management systems basically differ in the patch size of cohorts of even-aged trees resulting in different structural complexity on the confined area of a forest stand. Man-made (or natural) disturbance is the driver of spatial grain and also affects local habitat continuity. (B) North America and Central Europe differ in the most frequently applied final harvest approaches. While age-class forest management resulting from clear-cuts with and without retention trees is mainly applied across temperate North America, clear-cuts are abandoned in Central Europe. In European temperate deciduous forests age-class forests traditionally result from shelterwood cuttings over 30 to $40 \mathrm{y}$. The blue line, indicating an increase in biodiversity with increasing spatial heterogeneity, is supported by recent findings from retention tree approaches reporting positive effects for biodiversity. The red dashed line indicates the potential biodiversity effect of forest management systems which further increase spatial heterogeneity, e.g. by single tree selection resulting in uneven-aged forests. 


\section{FOREST MANAGEMENT AND BIODIVERSITY}

The assumption of facilitating alpha-biodiversity by increasing within stand heterogeneity is based on a main principle of community ecology that suggests a positive relationship between habitat heterogeneity and species diversity (habitat-heterogeneityhypothesis; MacArthur and MacArthur, 1961; Wilson, 2000). Thus, increasing heterogeneity within stands by fine-grained management, e.g. by creating high variation in tree diameter, height and age is expected to promote biodiversity (Pro Silva, 2012). However, the areaheterogeneity-tradeoff-hypothesis challenges the generality of the positive heterogeneitydiversity relationship (Allouche et al., 2012; Stein et al., 2014). It is suggested that within a fixed space an increase in habitat heterogeneity reduces the average amount of effective area available for an individual species and will increase its likelihood of extinction. Within a confined area the heterogeneity-diversity relationship may therefore be rather unimodal (Chocron et al., 2015; Figure 1 B).

Which of these mechanisms are more important in temperate European forest landscapes that are subject to conversion of traditional to alternative forest management is unclear. While the traditional coarse-grained shelterwood cutting results in a coarse heterogeneity of different age-cohorts that represent different forest developmental phases across the landscape, the currently favored fine-grained single-tree selection approach maximizes small-scale vertical and horizontal complexity within a single stand (Figure $1 A$ ). Although alpha-diversity, particularly of forest specialist species is expected to increase with decreasing grain size of heterogeneity, the potential outcome for biodiversity at the landscape scale is still an open and challenging question (Figure $1 B$.). Ideal study sites to test the two contradicting hypotheses are forests that have already been managed for decades in contrasting grain size at a large spatial scale.

We investigated the effect of coarse- and fine-grained heterogeneity as a result of different forest management systems (FMS) on alpha-, beta- and gamma-diversity of 15 taxonomic groups by using presence/absence data collected within the framework of the Biodiversity Exploratories (Fischer et al., 2010). The 'Hainich' -Exploratory in Central Germany allows a direct comparison of even-aged (EA, $\mathrm{N}=17$, traditional) and uneven-aged (UEA, $\mathrm{N}=13$, alternative) forest management systems under comparable climatic and edaphic conditions and a similar spatial arrangement between plots within a region (Table S1). The uneven-aged beech forests of 'Hainich' are exceptional in extent and continuity for broadleaved forests of the temperate zone. Whereas uneven-aged forest management is applied in mixed mountain forests of beech, fir, and spruce in several European countries 
(Schütz, 2001), its application to broadleaved forests in the 'Hainich' is to our knowledge unique across the Holarctic.

In addition, the 'Hainich'-Exploratory comprises unmanaged (UNM, N = 13, reference) forests (Table S1). However, in Central Europe we face the situation that unmanaged forests are generally scarce and confined to distinct areas (e.g. National parks). In our study region UNM are spatially blocked within the Hainich National Park. The closer distance between UNM plots may affect alpha- and beta-diversity. Therefore, we present results on gamma-diversity for EA and UEA using UNM as a reference, whereas alpha- and beta-diversity is contrasted only between EA and UEA (but see results for EA, UEA and UNM in SI).

The structural differences of EA, UEA and UNM might support complementary of species assemblages. Thus, a mix of FMS within a forest landscape is believed to enhance landscape scale biodiversity (Redon et al., 2014). By randomly combining plots (two- and threefold combinations of EA, UEA and UNM), we analyzed if mixing of FMS indeed increases gamma-diversity. To disentangle complementarity further, we analyzed the fraction of exclusive species in each FMS. We considered total species per FMS and the subgroups of forest specialists (narrow niche) and non-forest specialists (wide niche).

We used sample-size based rarefaction and extrapolation to compare gamma-diversity for Hill-numbers ${ }^{0} \mathrm{D}$ (species richness), ${ }^{1} \mathrm{D}$ (Shannon diversity) and ${ }^{2} \mathrm{D}$ (Simpson diversity), which successively increase weighting of abundant species (Chao et al., 2014), between FMS and a two- and threefold mixtures of FMS. Beta-diversity was quantified as (multi-site) species turnover (Baselga, 2012).

\section{Methods}

\section{Study sites and forest management.}

The study forests are located in central Germany, federal state of Thuringia, along the forested hill chains of Hainich, Westerwald, and Dün $\left(51^{\circ} 02^{\prime} 45^{\prime}, \mathrm{N}\right.$ to $51^{\circ} 22^{\prime} 12^{\prime}{ }^{\prime} \mathrm{N}, 10^{\circ}$ $12^{\prime} 28^{\prime}$ ' E to $10^{\circ} 32^{\prime} 03$ ' ' E), and are part of the Biodiversity Exploratories project (Fischer et $a l ., 2010)$. The geological surface is Triassic limestone, locally covered by periglacial loess. Natural vegetation is a mesophytic deciduous forest dominated by Fagus sylvatica on nutrient-rich soils, with only minor contributions of admixed tree species (Fraxinus excelsior, Acer pseudoplatanus, Carpinus betulus, Tilia sp., Ulmus sp.) in mid and late successional stages (Bohn et al., 2004). Study forests were chosen to represent prevalent forest 


\section{FOREST MANAGEMENT AND BIODIVERSITY}

management systems (FMS) of the region, which are even-aged (EA, $N=17$ ), uneven-aged (UEA, $\mathrm{N}=13$ ) and unmanaged (UNM, $\mathrm{N}=13$ ). In avoiding clear-cuts and species change the even-aged and the uneven-aged FMS are variants of continuous cover forestry that vary only in the grain of management operations. Plots (100 m x $100 \mathrm{~m}$ in size) of different FMS are separated at minimum $3 \mathrm{~km}$ to factor out species spillover between FMS. Characteristics of the environment, spatial arrangement and stand structure of the FMS are listed in Table S1. The even-aged forests are managed as stands of about 4 ha in size with a rotation of 120 to 140 years following regeneration through seeds from shelterwood trees. Proportional to the share on rotation we selected plots from the developmental phases of thicket, pole wood, immature timber, mature timber, and thicket with shelterwood $(3,3,4,4$, and 3 plots, respectively). This traditional system of beech forestry has become increasingly uncommon during the last decades and is being replaced by finer-grained regeneration systems that rely on final harvest of single trees (so called target diameter harvest spanning about 3 decades), groups of trees, and, infrequently, of small areas (canopy opening up to $1000 \mathrm{~m}^{2}$ ). In fact, current good practice guidelines of forest management strongly discourage the shelterwood system being claimed 'not natural', 'too large in scale', 'too high in disturbance intensity', and 'homogenizing within stand variability' (FSC Working Group Germany, 2012). However, in our study area the classical shelterwood management system is still implemented. Unevenaged forests are managed by single tree harvest and thinning. This single tree selection system is traceable back $140 \mathrm{y}$ at Hainich and $250 \mathrm{y}$ at Dün sites (Wäldchen et al., 2013). Unmanaged forest plots are located in the Hainich National Park mainly within the UNESCO World Heritage Site "Primeval Beech Forests of the Carpathians and the Ancient Beech Forests of Germany". In the $19^{\text {th }}$ century these forests have been managed as coppice with standards for firewood and timber, and then underwent a transformation process into high forests for several decades. Time since abandonment of management is $20 \mathrm{y}$ ( 5 plots $)$ to $70 \mathrm{y}$ ( 8 plots).

Environmental conditions and spatial structure of plots are comparable for EA and UEA, while UNM are located at lower elevation in closer distance (Table S1). Additionally, for UNM we found no relationship between distance and compositional dissimilarity (Table S6). This missing effect of distance in UNM may not only affect beta-diversity negatively, but gamma-diversity as well. Alpha-diversity of mobile taxa, in contrast, may be enhanced. Therefore we report results for UNM in SI, but do not contrast unmanaged forests with managed forests for alpha- and beta-diversity. 


\section{Species community data.}

Arthropods, bryophytes, and lichens were sampled in 2008 and vascular plants in 2009. Birds and bats were assessed in 2009 and 2010, dead-wood fungi in 2010 and 2011, and ectomycorrhizal fungi (DNA) and bacteria (RNA and DNA) in 2011. Selected sampling methods adequately represent the local community within a taxon. Two pitfall traps and four flight-interception traps (two in the understorey and two in the canopy) were used for arthropod sampling. Arthropods were then separated into spiders, harvestmen including pseudoscorpions, beetles, hymenopterans, lacewings and true bugs. Vascular plants, bryophytes, lichens, and dead-wood fungi were sampled in $20 \mathrm{~m} \times 20 \mathrm{~m}$ quadrats in the center of each plot. Birds were monitored by the number of singing males, and bats by their flight activities. Assessment of belowground taxa (Ectomycorrhizal fungi DNA, Bacteria RNA/DNA) is based on soil samples from a sampling campaign for microbial analysis. All taxa cover a broad spectrum of functional groups, but are also assumed to respond in different ways to forest management, driven by variation in mobility and structural and microclimatic habitat requirements.

\section{Statistical analyses.}

To compare species gamma-diversity for the 15 taxonomic groups between FMS we used a methods framework published recently (Chao et al., 2014). This 'diversity accumulation curve' framework extended methods for rarefaction and extrapolation of species richness (species accumulation curve) (Colwell et al., 2012). It a) provides estimators for inter- and extrapolation of higher order Hill numbers (Jost, 2006), b) allows to estimate sample completeness (Chao et al., 2012) and by this enables a sample-coverage-based estimation, and c) uses a bootstrapping method for constructing confidence intervals around Hill numbers based on the unconditional variance (Colwell et al., 2012). This facilitates the comparison of multiple assemblages (Figure S2). Hill numbers ${ }^{\mathrm{q}} \mathrm{D}$ quantify diversity in units of equivalent numbers of equally abundant species by increasingly weighting abundance with the order of diversity q. Diversities with orders $<1$ disproportionally favor rare species, at order 1 species are weighted proportionally to their frequency in the samples, while all orders $>1$ disproportionally favor common species. This allows us to analyze the effects of FMS on the diversity of rare and common species within one framework. We estimated species diversity curves for orders 0,1 , and $2:{ }^{0} \mathrm{D}$ species richness, ${ }^{1} \mathrm{D}$ the exponential of Shannon's entropy, ${ }^{2} \mathrm{D}$ the inverse of Simpson's concentration, for all species of taxonomic groups, forest specialists, and non-forest specialists (SI Methods). 


\section{FOREST MANAGEMENT AND BIODIVERSITY}

Diversity of even-aged and uneven-aged FMS was compared for a range of base sample sizes (BSS) to assess the robustness of the findings. As BSS we used minimum reference sample size (Min. RSS, i.e. classical rarefaction), maximum reference sample size (Max. RSS, extrapolation of UEA and UNM to the number of samples of EA), and an intermediate value (extrapolation of UEA and UNM and rarefaction of EA) (Table S2). We did not extrapolate beyond max. RSS to factor out differences in the quality of species pool estimates between FMS and taxa, which can affect the shape of the accumulation curve when extrapolating. This was observed for species poor taxonomic groups due to a more random occurrence of singleton species. In Figures 2 and 3 we generally present results of max. RSS, except for bats, harvestmen, lacewings, and lichens. For these taxa, we present results for rarefaction (min. RSS), as estimated pool size (Chao's estimator) of a single FMS exceeded the pool size of the combined FMSs (bats in EA, harvestmen, lacewings, and lichens in UNM). Note that neither the trend nor the significance of the findings was affected by this conservative presentation of results. Significantly different estimates are indicated by pairwise non-overlapping 95\% confidence intervals, obtained by bootstrapping based on 200 replications.

Differently managed forests may host different species assemblages, so that landscape scale species diversity increases when mixing management types due to complementarity. To assess complementarity of EA and UEA, we analyzed gamma-diversity for hypothetical mixed forest landscapes composed of 50\% EA and 50\% UEA plots, using the same approach as for single FMS. Based on 500 resamplings of 9 plots per FMS (out of 17 for EA and 13 for UEA) gamma-diversity of mixed assemblages was quantified by rarefaction, and characterized by mean and 95\% quantile (Table S2). Other combinations (two- and threefold) of FMS were analyzed analogously. We identified complementarity when diversity of the mixed system exceeded the diversity of the richer assemblage (Edwards et al., 2014). The partial contribution of alpha- and beta-diversity to gamma-diversity is controlled by the plot level sampling effort. Generally, with increasing sampling effort, e.g. more traps or more frequent bird monitoring, alpha-diversity increases on the cost of beta-diversity (as a larger percentage of the species pool is already found within plots). This is why we used alpha- and beta-diversity to compare the structure of assemblages in forests managed differently rather than to characterize the assemblages in absolute terms. Beta-diversity share on gamma diversity was quantified as species turnover, which, other than species nestedness and total beta, is the beta component that effectively contributes to gamma-diversity. This facilitates comparisons between FMS that are unbiased by nestedness and richness differences of 
samples within an assemblage. Choosing between the two approaches to quantify species turnover, pairwise site dissimilarity and multiple-site dissimilarity, we selected multiple-site dissimilarity, because the mean of pairwise dissimilarities is a biased estimator for assemblages (Baselga, 2012). However, variability of multiple-site dissimilarities can be assessed only by resampling. Therefore, we quantified beta-diversity as multiple-site turnover component of Jaccard dissimilarity (Baselga, 2012) based on 200 resamplings of 9 plots per FMS (out of 17 for EA and 13 for UEA) (Table S3, Fig. 1 D, E, F). For testing differences between EA and UEA we used pairwise comparison of resamplings (i.e. for two-sided $\mathrm{p}<$ 0.05 at least 196 of 200 comparisons showed larger values for one FMS) (Baselga and Orne, 2012), and for indicating variability the $90 \%$ quantile. Alpha-diversity was measured as species richness and tested for differences between EA and UEA using ANOVA (Table S4, Figure $1 \mathrm{G}, \mathrm{H}, \mathrm{I})$.

Complementarity of FMS and exclusiveness of species in FMS are linked, since there is no complementarity without exclusive species. However, complementarity does not quantify the fraction of exclusive species in FMS. As number of plots per FMS differed, we determined exclusive species by resampling. Based on 500 resamplings of 9 plots per FMS (out of 17 for EA and 13 for UEA) we quantified the fraction of exclusive species per FMS, relating exclusive species to species richness per resampling (Table S5, Figure 3). Differences between EA and UEA were assessed by pairwise comparison (i.e. for two-sided $\mathrm{p}<0.05$ at least 488 of 500 resamplings showed larger values for one FMS). Note that the percentage of exclusive species characterizes resamplings $(\mathrm{N}=9)$ rather than 'true' species assemblages of FMS. However, differences between FMS are indicative.

For analyzing gamma-diversity the package 'iNEXT' version 2.0 (Chao et al., 2014) and for beta-diversity the package 'betapart' version 1.3 (Baselga et al., 2012) were used in R version 3.1.2 (R Core Team, 2014).

\section{Results and Discussion}

Gamma-diversity $\left({ }^{0} \mathrm{D},{ }^{1} \mathrm{D}\right.$ and ${ }^{2} \mathrm{D}$ ) was higher in EA compared to UEA (up to $77 \%$ ) for six of the 15 taxonomic groups, at least for one of the Hill-numbers, while nine groups showed no difference (Figure 2). Spiders, beetles and vascular plants showed consistently higher diversities in EA $\left({ }^{0} \mathrm{D},{ }^{1} \mathrm{D}\right.$ and $\left.{ }^{2} \mathrm{D}\right)$. The consistent response of taxa across Hill-numbers suggests that higher gamma-diversity in EA is robust against weighting of rare and abundant species. This pattern was confirmed when focusing on forest specialists among spiders, 


\section{FOREST MANAGEMENT AND BIODIVERSITY}

beetles and vascular plants (Table S2). This is an important finding as it is often argued that higher diversities in EA forests is a consequence of an invasion of common and disturbance tolerant non-forest specialist species, especially in plants (Boch et al., 2013). The results suggest that coarse-grained heterogeneity provided by developmental phases of EA is more important for biodiversity than the fine-grained heterogeneity of UEA within stands.
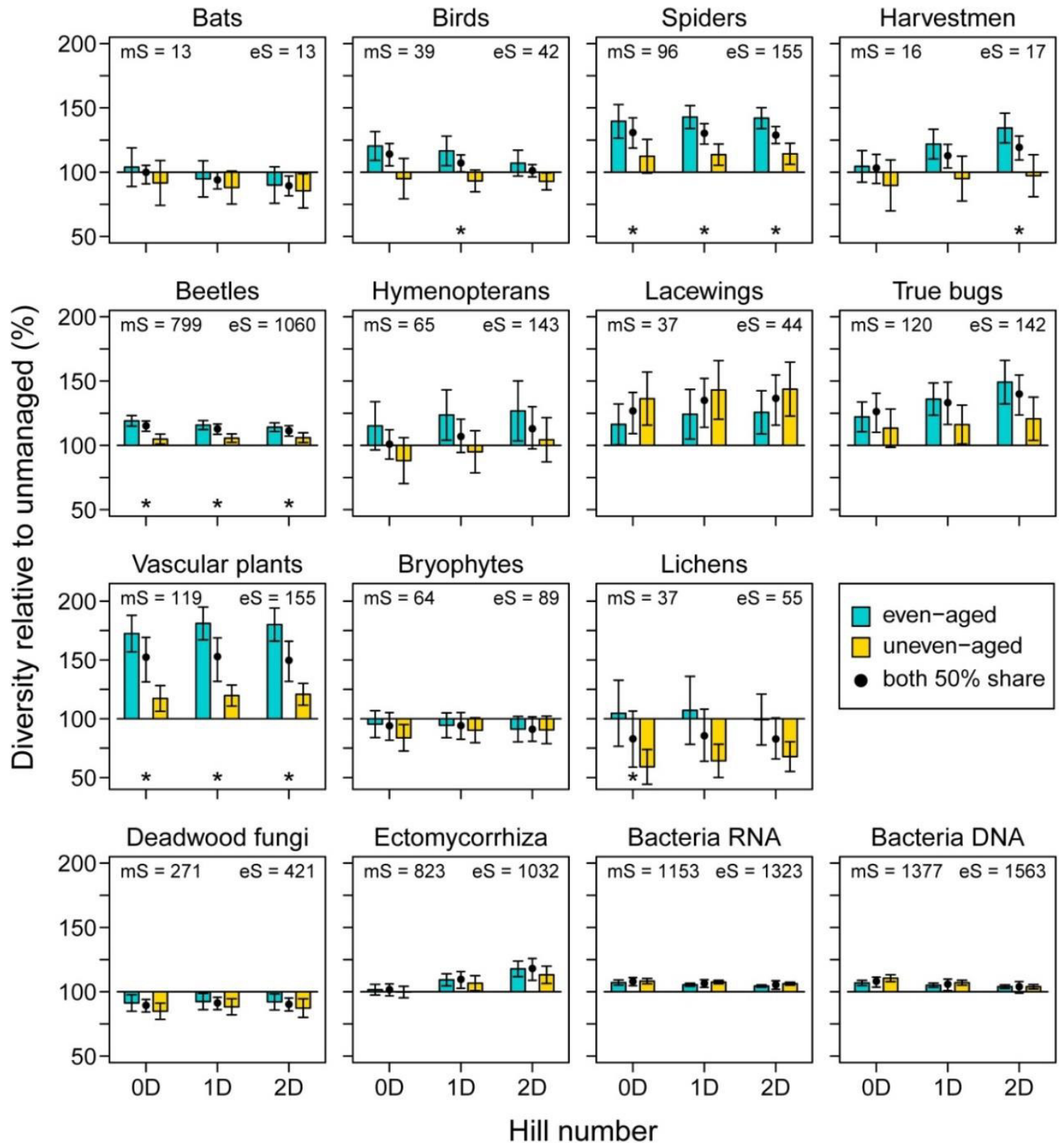

Figure 2. Gamma-diversity of forest management systems for 15 taxonomic groups. Even-aged (EA), uneven-aged (UEA) and equal proportion mixtures of both (dots) were related to unmanaged forests (Table S2). Diversity was quantified for Hill-numbers ${ }^{0} \mathrm{D},{ }^{1} \mathrm{D}$, and ${ }^{2} \mathrm{D}$, which increasingly weight abundance of species, using sample-size based rarefaction and extrapolation to factor out differences in sample size. $* \mathrm{p}<0.05$ significant difference between EA and UEA. We found higher diversities only for EA (compared to UEA) irrespective of weighting of rare and abundant species. Consistently higher diversities across Hill-numbers for EA were observed for the species rich taxa of spiders, beetles and vascular plants. Species assemblages of EA and UEA (as assessed by equal proportion mixtures) were not complementary for the vast majority of taxa. Rather, UEA comprised a subset of the assemblage of EA. Measured $(\mathrm{mS})$ and estimated species richness (eS, Chao's incidence estimator) of the pooled data indicate the completeness of sampling. 
Thereby it is important to keep in mind that the removal of mature even-aged European beech forests through shelterwood cuttings lasts at least 20 to $40 \mathrm{y}$, i.e. the forest area is never cleared. The observed loss of biodiversity with a decreasing grain-size of forest management suggests that mechanisms of the area-heterogeneity-tradeoff are acting in UEA. This would imply that alpha-diversity is negatively affected in UEA through species extinctions by insufficient size of suitable area (Carnicer et al., 2013).

However, when focusing on species richness $\left({ }^{0} \mathrm{D}\right)$ we found no overall effect of FMS on alpha-diversity across taxonomic groups (Figure 3 A, Table S4). The lower gammadiversity can therefore not be explained by an area-heterogeneity-tradeoff. Birds, regarding total species as well as forests specialists, even showed a higher diversity in UEA (Figure $3 \mathrm{~A}$, $D)$, in accordance with the habitat-heterogeneity-hypothesis, as firstly demonstrated by MacArthur \& MacArthur (1961). However, as only birds responded positively to fine-grained management, support for the habitat-heterogeneity-hypothesis is also rather weak. With respect to the young developmental phases of EA, the weak management effects on alphadiversity detected here oppose other studies (Cale et al., 2013; Gao et al., 2014), that showed a dampening effect of young homogenous forests on alpha-diversity. When disentangling the components of gamma-diversity further, we found that mainly beta-diversity is affected by grain-size of forest management. Besides an overall $4 \%$ reduction, five individual taxa (spiders, birds, hymenopterans, vascular plants, and lichens) showed lower beta-diversity in UEA compared to EA (Figure $3 B$, Table S3). The response of forest specialists was even higher $(-10 \%)$ and was found in three of the six taxa for which we could distinguish forest specialists (Figure $3 E$ ). Beta-diversity is not only lower in UEA but is also driven by different factors compared to EA. Matrix correlations revealed that species turnover in UEA is related to geographic distance between plots for a variety of taxa (vascular plants, beetles, and spiders; Table S6) rather than to environmental conditions (Table S7, Table S8). However, geographic distance reflects only physical properties of the study area, which should also affect the similarly distributed EA plots (Table S1). In EA distance was most likely masked by the higher dissimilarity between forest developmental phases. In this FMS microclimate within plots (expressed as daily temperature range) explained turnover of beetles, spiders and birds (Table S7) as previously found for saproxylic beetles (Müller et al., 2015). 

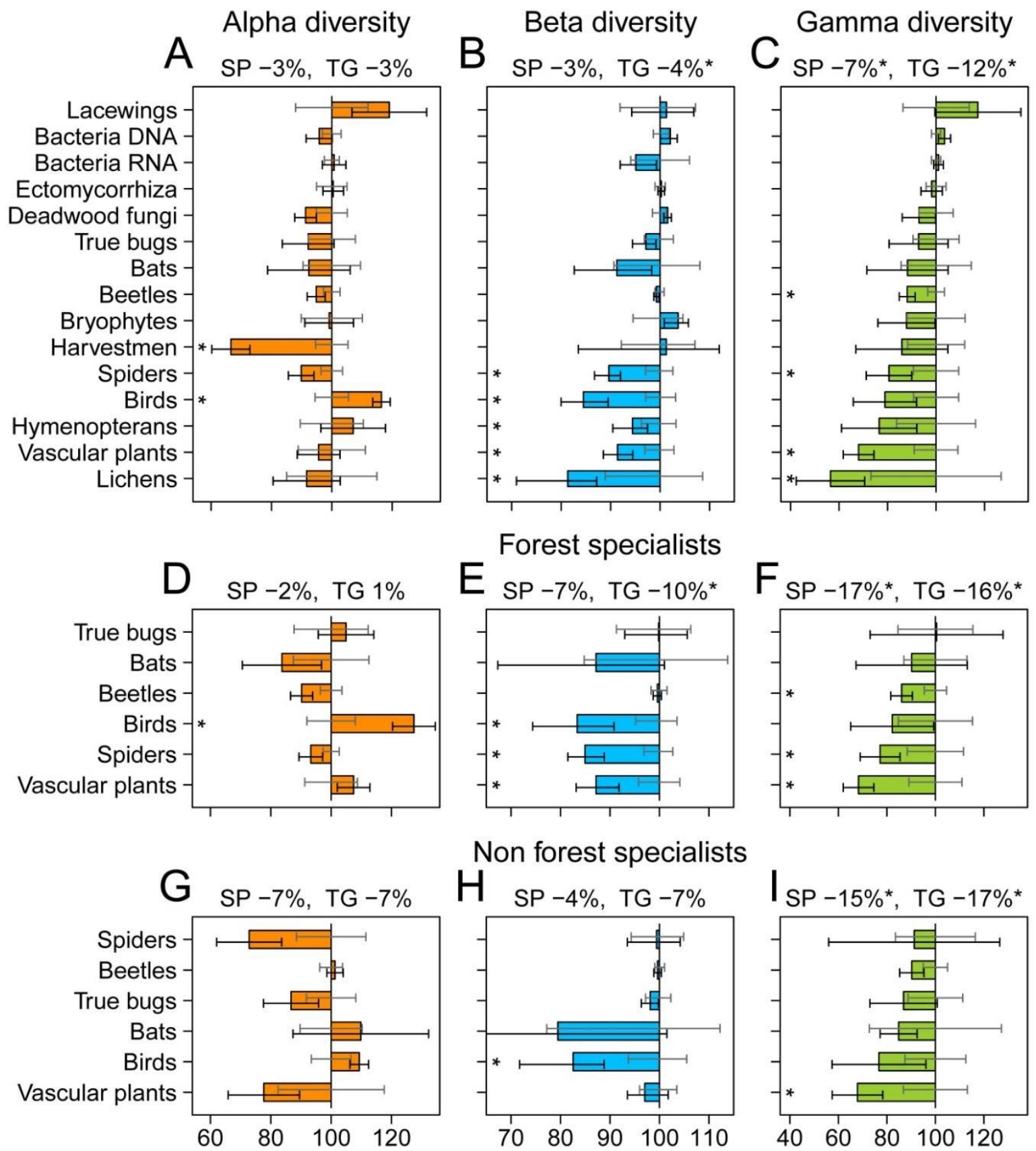

Non forest specialists
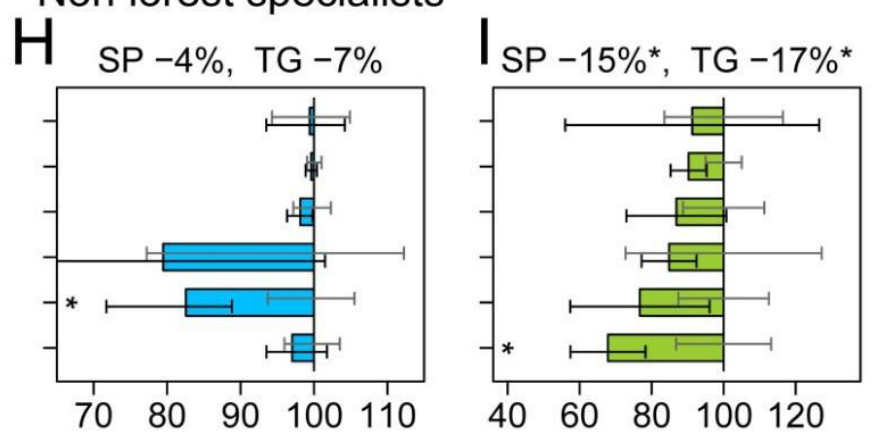

Uneven-aged relative to even-aged forest management (\%)

Figure 3. Alpha- $(A, D, G)$, beta- $(B, E, H)$ and gamma- $(C, F, I)$ diversity of even-aged and uneven-aged forest management systems for 15 taxonomic groups. We distinguished all species of a taxon $(A-C)$ and groups of forest $(D-F)$ and of non-forest specialist species $(G-I)$. Diversity of the uneven-aged (UEA) was standardized to the even-aged forest management system (EA) accounting for differences in sample size (Table S2, S3, S4). The overall response is given for taxonomic groups (TG) and species (SP, square root weighting of species number). Error bars (UEA: black, EA: grey) indicate 95\% confidence interval for gamma- and alphadiversity, and $90 \%$ quantile for beta-diversity. $* \mathrm{p}<0.05$ significant difference between even-aged and unevenaged forests. Gamma-diversity $(C, F, I)$ was analyzed using sample-size-based rarefaction and extrapolation. Confidence intervals were obtained by bootstrapping based on 200 replications. Beta-diversity $(B, E, H)$ was measured as multiple-site beta turnover component of Jaccard dissimilarity and quantified using 200 resamplings of 9 plots per FMS (out of 17 for EA and 13 for UEA). Differences between EA and UEA (at least 196 of 200 comparisons show larger values in one FMS) and $90 \%$ quantiles are based on resamplings. Alpha-diversity ( $A$, $D, G)$ was analyzed using ANOVA. 
In EA the daily temperature amplitude during the vegetation period is elevated and more variable between plots than in UEA and UNM. This can be explained by a more variable canopy height and canopy cover of developmental phases. The highest amplitudes were observed in thickets (daily range: $10 \pm 1.1{ }^{\circ} \mathrm{C}$, daily maximum: $19.0 \pm 0.9{ }^{\circ} \mathrm{C}$ ) while the mature timber phase resembled the microclimate of UEA and UNM (Table S1).

Intermingling of age-cohorts within a stand with decreasing grain size results in increasing heterogeneity of differently aged and sized neighboring trees. This is commonly described as high structural complexity. However, our results reveal that this does not result in 'effective' habitat heterogeneity, as different properties of habitats (provided by tree agecohorts) in terms of environmental factors and resources (e.g. temperature, radiation, dead wood) are diluted by fine-grained intermingling (Table S1). This habitat-heterogeneitydilution, therefore, explains our findings on beta- and gamma-diversity more coherently than the habitat-heterogeneity-hypothesis or an area-heterogeneity-tradeoff.

When compared with UNM eight groups showed higher gamma-diversity in EA with consistency across Hill-numbers for spiders, beetles, vascular plants, bacteria RNA and bacteria DNA. In UEA five taxa were more (consistently across Hill-numbers for bacteria RNA and DNA) and two less divers (lichens ${ }^{0} \mathrm{D},{ }^{2} \mathrm{D}$; deadwood fungi ${ }^{0} \mathrm{D}$ ) compared to UNM (Table S3). Gamma-diversity of forest specialists among spiders, beetles and vascular plants was more divers across Hill-numbers in EA compared to UNM, whereas no differences were found between UEA and UNM. This suggests that in Central European landscapes which were intensively managed during historic times, today's unmanaged forests are still too young (maximum time of no management within the 'Hainich'-Exploratory is $70 \mathrm{y}$ ) to develop a structural complexity that provides a niche diversity comparable to primeval forests.

The question arises whether by mixing of different management regimes gamma-diversity can be increased at the landscape scale due to complementarity in species assemblages (Redon et $a l ., 2014)$. Only for true bugs ( ${ }^{0} \mathrm{D}$ of total species driven by non-forest specialists) and ectomycorrhizal fungi (subtle increase in ${ }^{0} \mathrm{D},{ }^{1} \mathrm{D}$ and ${ }^{2} \mathrm{D}$ ) a higher gamma-diversity was achieved by mixing EA and UEA (total species Figure 2, Table S2; forest specialists Table S2). For the other taxa complementarity between EA and UEA was too low to enhance landscape scale biodiversity. Moreover, the limited complementarity indicates that UEA comprised mainly a subset of the species assemblage of EA. We consider these findings even more robust as they were consistent for the species rich taxa of vascular plants, beetles and spiders, independent of abundance weighting $\left({ }^{0} \mathrm{D},{ }^{1} \mathrm{D}\right.$ and $\left.{ }^{2} \mathrm{D}\right)$, irrespective of the degree of linkage to forests, and across trophic levels (producers, consumers and predators). 


\section{FOREST MANAGEMENT AND BIODIVERSITY}

Mixing of EA and UNM resulted in higher gamma-diversity of forest specialist birds $\left({ }^{0} \mathrm{D},{ }^{1} \mathrm{D}\right.$ and $\left.{ }^{2} \mathrm{D}\right)$, harvestmen $\left({ }^{0} \mathrm{D}\right)$, forest specialist beetles $\left({ }^{2} \mathrm{D}\right)$ bryophytes $\left({ }^{0} \mathrm{D}\right.$ and $\left.{ }^{1} \mathrm{D}\right)$, lichens $\left({ }^{2} \mathrm{D}\right)$ and ectomycorrhizal fungi $\left({ }^{0} \mathrm{D}\right)$ (Table $\left.S 2\right)$. However, the effect of mixing is very limited for all of these taxa except ectomycorrhizal fungi (i.e. less than 1 species equivalent). In ectomycorrhizal fungi complementarity may be promoted by higher tree species richness and lower dominance of European beech in UNM (Table S1), which both are legacies of the former coppice-with-standards management within the Hainich National Park.

Complementarity between UEA and UNM was higher as for both combinations with EA. Gamma-diversity in a mixed UEA and UNM landscape was higher for birds $\left({ }^{0} \mathrm{D}\right)$, bats $\left({ }^{0} \mathrm{D}\right.$ of total species and forest specialists), spiders $\left({ }^{0} \mathrm{D}\right.$ of total species, and ${ }^{0} \mathrm{D}$ and ${ }^{1} \mathrm{D}$ of forest specialists), beetles ( ${ }^{0} \mathrm{D}$ and ${ }^{1} \mathrm{D}$ of total species, ${ }^{0} \mathrm{D},{ }^{1} \mathrm{D}$ and ${ }^{2} \mathrm{D}$ of forest specialists), forest specialist true bugs $\left({ }^{2} \mathrm{D}\right)$, vascular plants $\left({ }^{0} \mathrm{D}\right.$ and ${ }^{1} \mathrm{D}$ of total species and forest specialists), and ectomycorrhizal fungi $\left({ }^{0} \mathrm{D}\right)$ compared to landscapes composed of UEA or UNM only (Table S2). However, the resulting gamma-diversity of mixing UEA and UNM was always lower than in a landscape composed only of EA.

A mixture of all three FMS showed no overall increase in gamma-diversity. We found that a landscape with equal proportions of EA, UEA und UNM generally showed lower gammadiversity than a landscape composed only of EA or of EA and UNM (except for ${ }^{0} \mathrm{D}$ of lacewings). Thus, biodiversity across taxa, irrespective of forest linkage, is probably best maintained by traditional coarse-grained forest management (EA) combined with unmanaged areas (highest diversity of bryophytes and deadwood fungi in UNM, and highest forest specialist bird diversity when UNM mixed with EA).

The higher diversity in EA compared to UEA is driven by a larger proportion of exclusive species (Figure $\mathrm{S} 1 A, B, C$ ). This was consistent in trend and significance for total species (significant for birds, spiders, harvestmen and vascular plants) and the subgroups of forest specialists (spiders and vascular plants), and non-forest specialists (birds and spiders). Thus, our results cannot be ascribed to the occurrence of disturbance indicators only (Boch et al., 2013), but are rather driven by the habitat-heterogeneity of forest developmental phases within EA. Thereby, the early developmental phases most likely promote species of earlysuccessional forest stages that were shown to be important for biodiversity (Swanson et al., 2010), but are missing in UEA. The late developmental phases of the EA on the other hand seem to even provide a more suitable habitat for forest specialists than UEA. Hence, the proportion of exclusive species also suffered from a dilution of habitat-heterogeneity. Based on our findings we suggest habitat-heterogeneity-dilution as the mechanism linking the 
habitat-heterogeneity-hypothesis and the intermediate-disturbance-hypothesis (Figure 1, Roxburgh et al., 2004) in temperate forests.

Globally forest management shifts from clear-cuts with a complete tree removal at a large scale towards silvicultural approaches which include retention trees or cuttings which are carried out at a smaller scale and with lower intensities (Puettmann et al., 2015, Lindenmayer et al., 2012). In conclusion, our findings show that biodiversity is sensitive to different types of forest management even when clear-cuts are avoided. Moreover, our study highlights that biodiversity responds positively to forest management if silviculture creates a variety of environmental conditions at the landscape scale (Sebek et al., 2015). Against the background of the framework presented in Figure 1 we conclude from existing knowledge and from our results that both extremes, large-scale clear-cuts and single tree selection cuttings, result in low heterogeneity at the landscape scale compared to systems acting at intermediate spatial grains. In contrast, maximizing fine grained within stand heterogeneity seems to have no additional positive effect on biodiversity. We therefore support recent views that nature-based silviculture should vary across time and at larger spatial scale (O'Hara et al., 2016). Moreover, we question the current trend towards a replacement of even-aged management by the single tree selection system, which we consider to be driven by beliefs rather than by evidence. Additionally, we argue that studies focusing on alpha-diversity only may be misleading because compositional variability between plots is ignored (Gossner et al., 2013).

Our findings have not only important implications for forest management and nature conservation but also point out the large impact of natural dynamics on species diversity. Recent large scale inventories in primeval European beech forests in the Carpathians revealed that forest structure was mainly driven by small-scale disturbances (Hobi et al., 2015). Within the more oceanic distribution of European beech, the natural disturbance regime may be more intense. This is supported by studies reporting severe storm events in old-growth forests across oceanic parts of the temperate zone (D'Amato and Orwig, 2008; Yamashita et al., 2002; Nagel et al., 2014). We therefore assume that, in contrast to eastern European forests, primeval Atlantic European beech forests had shown some coarse-grained structural heterogeneity. If so, this natural dynamic could nicely be mimicked by traditional even-aged forest management combined with forest reserves. 


\section{FOREST MANAGEMENT AND BIODIVERSITY}

\section{Acknowledgements}

We are grateful to Boris Büche, Roland Achtziger, Thomas Wagner, Frank Köhler, Theo Blick, Michael-Andreas Fritze for arthropod species identification. We thank Michael Owonibi for maintainance of the database and Spaska Forteva, Falk Hänsel, Thomas Nauss, and Stephan Wöllauer for managing climatic data. The work has been funded by the DFG Priority Program 1374 "Infrastructure-Biodiversity-Exploratories". Field work permits were issued by the state of Thüringen. 


\section{References}

1. Allouche O, Kalyuzhny M, Moreno-Rueda G, Pizarro M, Kadmon R. (2012). Areaheterogeneity tradeoff and the diversity of ecological communities. Proc Natl Acad Sci USA 109:17495-17500.

2. Baselga A. (2012). The relationship between species replacement, dissimilarity derived from nestedness, and nestedness. Glob Ecol Biogeogr 21:1223-1232.

3. Baselga A, Orme, CDL. (2012). betapart: an R package for the study of beta diversity. Meth Ecol Evol 3:808-812.

4. Bässler C, Ernst R, Cadotte M, Heibl C, Müller J. (2014). Near-to-nature logging influences fungal community assembly processes in a temperate forest. J Appl Ecol 51:939-948.

5. Birkhofer K, Schöning I, Alt F, Herold N, Klarner B, Maraun M, et al. (2012). General relationships between abiotic soil properties and soil biota across spatial scales and different land-use types. Plos One 7:e43292.

6. Boch S, Prati D, Müller J, Socher S, Baumbach H, Buscot F, et al. (2013). High plant species richness indicates management-related disturbances rather than the conservation status of forests. Basic Appl Ecol 14:496-505.

7. Bohn U, Neuhäusl R. (2004). Map of the natural vegetation of Europe (BfNSchriftenvertrieb im Landwirtschaftsverlag, Münster).

8. Brunet J, Fritz Ö, Richnau G. (2010). Biodiversity in European beech forests-a review with recommendations for sustainable forest management. Ecol Bull 53:77-94.

9. Cale JA, McNulty SA, Teale SA, Castello JD. (2013). The impact of beech thickets on biodiversity. Biol Invas 15:699-706.

10. Carey AB, Lippke BR, Sessions J (1999). Intentional systems management: managing forests for biodiversity. J Sustain For 9:83-125.

11. Carnicer J, Brotons L, Herrando S, Sol D. (2013). Improved empirical tests of areaheterogeneity tradeoffs. Proc Natl Acad Sci USA 110:E2858-60.

12. Chao A, Gotelli NJ, Hsieh TC, Sander EL, Ma KH, Colwell RK, et al. (2014). Rarefaction and extrapolation with Hill numbers: a framework for sampling and estimation in species diversity studies. Ecol Monogr 84:45-67.

13. Chao A, Jost L. (2012). Coverage-based rarefaction and extrapolation: standardizing samples by completeness rather than size. Ecology 93:2533-2547.

14. Chocron R, Flather CH, Kadmon R. (2015). Bird diversity and environmental heterogeneity in North America: a test of the area-heterogeneity trade-off. Glob Ecol Biogeogr 24:1225-1235.

15. Colwell RK, Chao A, Gotelli NJ, Lin S-Y, Mao CX, Chazdon RL, et al. (2012). Models and estimators linking individual-based and sample-based rarefaction, extrapolation and comparison of assemblages. J Plant Ecol 5:3-21. 
16. D'Amato AW, Orwig DA. (2008). Stand and landscape-level disturbance dynamics in oldgrowth forests in western Massachusetts. Ecol Monogr 78:507-522.

17. Edwards DP, Gilroy JJ, Woodcock P, Edwards FA, Larsen TH, Andrews DJR, et al. (2014). Land-sharing versus land-sparing logging: reconciling timber extraction with biodiversity conservation. Glob Change Biol 20:183-191.

18. Fedrowitz K, Koricheva J, Baker SC, Lindenmayer DB, Palik B, Rosenvald R, et al. (2014). Can retention forestry help conserve biodiversity? A meta-analysis. J Appl Ecol 51:1669-1679.

19. Fischer M, Bossdorf O, Gockel S, Hänsel F, Hemp A, HEssenmöller D, et al. (2010). Implementing large-scale and long-term functional biodiversity research. The Biodiversity Exploratories. Basic Appl Ecol 11:473-485.

20. Fritz Ö, Gustafsson L, Larsson K. (2008). Does forest continuity matter in conservation?A study of epiphytic lichens and bryophytes in beech forests of southern Sweden. Biol Conserv 141:655-668.

21. FSC Working Group Germany. (2012). German FSC-Standard and Small Forest Standard. FSC-STD-DEU-02-2012. https://ic.fsc.org/en/certification/national-standards/europerussia/germany.

22. Gao T, Hedblom M, Emilsson T, Nielsen AB. (2014). The role of forest stand structure as biodiversity indicator. For Ecol Manage 330:82-93.

23. Gossner MM, Getzin S, Lange M, Pašalić E, Türke M, Wiegang K, et al. (2013). The importance of heterogeneity revisited from a multiscale and multitaxa approach. Biol Conserv 166:212-220.

24. Grove SJ. (2002). Saproxylic insect ecology and the sustainable management of forests. Annu Rev Ecol Syst 1:1-23.

25. Gustafsson L, Kouki J, Sverdrup-Thygeson A. (2010). Tree retention as a conservation measure in clear-cut forests of northern Europe: a review of ecological consequences. Scan J For Res 25:295-308.

26. Hobi ML, Commarmot B, Bugmann H. (2015). Pattern and process in the largest primeval beech forest of Europe (Ukrainian Carpathians). J Veg Sci 26:323-336.

27. Jost L (2006) Entropy and diversity. Oikos 113:363-375.

28. Klopfer PH, MacArthur RH. (1960). Niche size and faunal diversity. Am Nat 94:293-300.

29. Lindenmayer DB, Franklin JF, Lõhmus A, Baker SC, Bauhus J, Beese W, et al. (2012). A major shift to the retention approach for forestry can help resolve some global forest sustainability issues. Conserv Lett 5:421-431.

30. MacArthur RH, MacArthur JW. (1961). On bird species diversity. Ecology 42:594-598.

31. Messier C, Puettmann K, Chazdon R, Andersson KP, Angers VA, Brotons L, et al. (2015). From management to stewardship: viewing forests as complex adaptive systems in an uncertain world. Conserv Lett 8:368-377. 
32. Müller J, Brustel H, Brin A, Bussler H, Bouget C, Obermaier E, et al. (2015). Increasing temperature may compensate for lower amounts of dead wood in driving richness of saproxylic beetles. Ecography 38:499-509.

33. Nagel TA, Svoboda M, Kobal M. (2014). Disturbance, life history traits, and dynamics in an old-growth forest landscape of southeastern Europe. Ecol Appl 24:663-679.

34. O'Hara KL. (2016). What is close-to-nature silviculture in a changing world? Forestry 89:1-6.

35. Paillet Y, Bergès L, Hjälten J, Ódor P, Avon C, Brenhardt-Römermann M, et al. (2010). Biodiversity Differences between Managed and Unmanaged Forests. Meta-Analysis of Species Richness in Europe. Conserv Biol 24:101-112.

36. Pommerening A, Murphy ST. (2004). A review of the history, definitions and methods of continuous cover forestry with special attention to afforestation and restocking. Forestry $77: 27-44$.

37. Pro Silva. (2012). Pro Silva and biodiversity. https://prosilvaeurope.wordpress.com/prosilva-forestry-principles-2012/.

38. Puettmann KJ, MacG Wilson S, Baker SC, Donoso PJ, Drössler L, Amente G, et al. (2015). Silvicultural alternatives to conventional even-aged forest management-what limits global adoption? For Ecosyst 2:1-16.

39. R Core Team. (2014). R: A Language and Environment for Statistical Computing (R Foundation for Statistical Computing, Vienna).

40. Redon M, Luque S, Gosselin F, Cordonnier T. (2014). Is generalisation of uneven-aged management in mountain forests the key to improve biodiversity conservation within forest landscape mosaics? Ann For Sci 71:751-760.

41. Roxburgh SH, Shea K, Wilson JB. (2004). The intermediate disturbance hypothesis: patch dynamics and mechanisms of species coexistence. Ecology 85:359-371.

42. Sebek P, Bace R, Bartos M, Benes J, Chlumska Z, Dolezal J, et al. (2015). Does a minimal intervention approach threaten the biodiversity of protected areas? A multi-taxa short-term response to intervention in temperate oak-dominated forests. For Ecol Manage 358:80-89.

43. Schütz J. (2001). Plenterwald und weitere Formen strukturierter und gemischter Wälder. (Parey, Berlin).

44. Stein A, Gerstner K, Kreft H. (2014). Environmental heterogeneity as a universal driver of species richness across taxa, biomes and spatial scales. Ecol Lett 17:866-880.

45. Swanson ME, Franklin JF, Beschta RL, Crisafulli CM, DellaSala DA, Hutto RL, et al. (2010). The forgotten stage of forest succession: early-successional ecosystems on forest sites. Front Ecol Environ 9:117-125.

46. Vanderwel MC, Malcolm JR, Mills SC. (2007) A meta-analysis of bird responses to uniform partial harvesting across North America. Conserv Biol 21:1230-1240. 
47. Wäldchen J, Schulze E, Schöning I, Schrumpf M, Sierra C. (2013). The influence of changes in forest management over the past 200 years on present soil organic carbon stocks. For Ecol Manage 289:243-254.

48. Wilson, SD. (2000). Heterogeneity, diversity and scale in plant communities. In: Hutchings MJ, John EA, Stewart AJA (eds). The ecological consequences of environmental heterogeneity. Blackwell Science: Oxford, pp 53-69.

49. Yamashita A, Sano J, Yamamoto S. (2002). Impact of a strong typhoon on the structure and dynamics of an old-growth beech (Fagus crenata) forest, southwestern Japan. Folia Geobot 37:5-16. 
FOREST MANAGEMENT AND BIODIVERSITY

\section{SUPPLEMENTARY INFORMATION}

Supplementary figures and tables are provided along with the electronic version of this thesis (on DVD), under the following paths:

SI Methods:

SI References:

Figure S1:

Figure S2:

Table S1:

Table S2:

Table S3:

Table S4:

Table S5:

Table S6:

Table S7:

Table S8:
Supplementary Information/Chapter III.5/SI Methods.docx Supplementary Information/Chapter III.5/SI References.docx Supplementary Information/Chapter III.5/Figure S1.docx Supplementary Information/Chapter III.5/Figure S2.docx Supplementary Information/Chapter III.5/ Table S1.docx Supplementary Information/Chapter III.5/ Table S2.docx Supplementary Information/Chapter III.5/ Table S3.doc Supplementary Information/Chapter III.5/ Table S4.docx Supplementary Information/Chapter III.5/ Table S5.docx Supplementary Information/Chapter III.5/ Table S6.doc Supplementary Information/Chapter III.5/ Table S7.docx Supplementary Information/Chapter III.5/ Table S8.docx 


\section{CHAPTER III.6}

BACTERIAL ENDOPHYTES IN IMPORTANT GRASS SPECIES 
BACTERIAL ENDOPHYTES IN IMPORTANT GRASS SPECIES

III.6.

For submission to Frontiers in Microbiology (Specialty Section: Plant Biotic Interactions)

Grasses are not equal green: the impact of management regimes on bacterial endophyte community composition and function differs with grass species

Running title: Bacterial endophytes in important grass species

Franziska Wemheuer ${ }^{1, *}$, Kristin Kaiser $^{2}$, Rolf Daniel ${ }^{2}$, Stefan Vidal ${ }^{1}$, Bernd Wemheuer ${ }^{2}$

${ }^{1}$ Section of Agricultural Entomology, Department of Crop Sciences, Georg-AugustUniversity Göttingen, Grisebachstr.6, D-37077 Göttingen, Germany.

${ }^{2}$ Department of Genomic and Applied Microbiology, Institute of Microbiology and Genetics, Georg-August-University Göttingen, Grisebachstr. 8, D-37077 Göttingen, Germany

Author contributions:

Study design and experiments: FW, SV, RD, BW

Data analysis and interpretation: FW, KK, BW

Wrote the manuscript: FW, KK, BW

All authors were involved in revision of the manuscript and provided commentary on the results. 


\title{
BACTERIAL ENDOPHYTES IN IMPORTANT GRASS SPECIES
}

\begin{abstract}
Despite the important role of endophytic bacteria for plant growth and health, our understanding of the complex interactions between these bacteria, their host plant and agricultural practices is still limited. To investigate the influence of fertilizer application and mowing frequency on bacterial endophytes in three agricultural important grass species, plant samples were collected over two consecutive years (2010 and 2011). Samples were taken on the GRASSMAN experimental field which was set up to address these particular questions in a multidisciplinary approach. Structural responses were assessed by pyrotag sequencing of $16 \mathrm{~S}$ rRNA genes. Bacterial communities were dominated by different bacterial genera including Pseudomonas and Stenotrophomas which are known as plant growth-promoting bacteria. Fertilizer application resulted in grass species-specific responses of bacterial endophyte communities, whereas mowing frequency affected bacterial communities only in combination with fertilization and grass species. We identified several indicator species being highly associated with grass species and fertilizer application and thus most likely responsible for the observed differences in community composition. Obtained data suggests that the applied regimes may directly influence bacterial endophyte communities through the modification of plant physiology as grass-specific responses towards fertilizer application were visible. In addition, we predicted artificial metagenomes from obtained 16S rRNA gene data to study functional response as well. Genes involved in plant growth promotion, i.e., nitrogenases, differed in their abundances between plants and also between the different management regimes. However, the grass species itself rather than the applied management regimes explained most of the observed variance in the investigated datasets as the response of bacterial endophytes towards agricultural practices is plant species dependent. Our study provides novel insights into the complex interaction of endophytes and their host plants and thus might be useful for the future development of a sustainable agricultural production.
\end{abstract}

\section{Introduction}

Endophytic bacteria have been found in a wide range of plants and comprised of many bacterial genera and species (Kobayashi and Palumbo, 2000; Hardoim et al., 2015). They can promote plant's growth and/or resistance to diseases and environmental stress conditions by a 


\section{BACTERIAL ENDOPHYTES IN IMPORTANT GRASS SPECIES}

variety of mechanisms (Sturz et al., 1999; Lodewyckx et al., 2002; Ryan et al., 2008) including the fixation of atmospheric nitrogen (Stoltzfus et al., 1997; Reinhold-Hurek and Hurek, 1998) or the production of antibiotics and phytohormones (Rosenblueth and MartinezRomero, 2006; Ryan et al., 2008; Compant et al., 2010). Moreover, it is widely recognized that endophytic bacteria can be used for a variety of applications in agricultural cropping systems (Kobayashi and Palumbo, 2000; Sturz et al., 2000; Senthilkumar et al., 2011). However, our understanding of the complex interactions between bacterial endophytes, their host plants and agricultural practices is still limited.

Recent studies showed that bacterial endophytic communities in species within the Poaceae family were strongly influenced by fertilizer application (e.g., Robinson et al., 2015; Rodríguez-Blanco et al., 2015; Wemheuer et al., 2016). In a study on the effect of nitrogen fertilization on nitrogen-fixing (diazotrophic) bacteria of two maize genotypes, fertilization increased the number of endophytic diazotrophs in roots and stems (Rodríguez-Blanco et al., 2015). Tan et al. (2003) found a rapid change of the diazotrophic population structure in rice roots within 15 days after fertilizer application. Nonetheless, most previous research focused on the effect of fertilizer application on diazotrophic and/or root endophytic bacteria in a single grass species (Fuentes-Ramírez et al., 1999; Tan et al., 2003; Seghers et al., 2004; Prakamhang et al., 2009; Rodríguez-Blanco et al., 2015). Consequently, the impact of different agricultural practices on the entire bacterial community in aerial plant parts has not been investigated so far. Moreover, large comparative studies on structural and functional changes of endophyte communities in different plant species towards agricultural practices are still missing.

Hence, we investigated the influence of management regimes on bacterial endophyte communities in the agricultural important grass species Dactylis glomerata L., Festuca rubra L. and Lolium perenne L. We have chosen these three grass species because they differ in their indicator values such as tolerance against mowing (Dierschke and Briemle, 2002). In a previous study, we analyzed the effect of fertilizer application and different mowing frequencies on the bacterial endophyte communities in these grass species by denaturing gradient gel electrophoresis (DGGE) (Wemheuer et al., 2016). Although DGGE fingerprints revealed that management regimes influenced the bacterial endophyte communities in a plant species-specific manner, the phylogenetic resolution of this approach is limited. As a consequence, we applied pyrotag sequencing targeting the 16S rRNA gene to gain deeper insights into structural changes of the endophyte communities. In addition, functional predictions (artificial metagenomes) were calculated from obtained 16S rRNA data using 


\section{BACTERIAL ENDOPHYTES IN IMPORTANT GRASS SPECIES}

Tax4Fun (Aßhauer et al., 2015) to investigate functional changes as response to applied management regimes. We focused on three main hypotheses: (1) the three grass species show differences in endophyte diversity and exhibit distinct endophytic communities as they differ in their physiological traits and in their recruitment strategy, (2) applied management regimes affect the diversity and community structure of bacterial endophytes in a grass speciesspecific manner as these grass species differ in their response to environmental conditions, and (3) although structural changes of endophytic communities occur, community functions are unaffected by agricultural practices

\section{Materials and Methods}

\section{Sampling}

Sampling was performed as described previously (Wemheuer et al., 2016). In brief, aerial plant material of L. perenne, F. rubra, and D. glomerata was collected on $19^{\text {th }}$ September 2010 and $12^{\text {th }}$ September 2011 from the Grassland Management Experiment (GrassMan). The experimental design included four treatments (no fertilization and mown once or thrice per year, respectively, and fertilization with nitrogen/phosphorous/potassium (NPK) and mown once or thrice per year, respectively). For a detailed description of the design and the applied management regimes see Wemheuer et al. (2016) and Petersen et al. (2012). Three samples per treatment and grass species were taken in both sampling years with one exception: only two L. perenne samples were collected in 2010 due to the lack of this plant species on the study site. In total, 71 plant samples were analyzed in this study (Supplementary Table S1). One sample comprised ten individual plants. Collected plants did not show obvious disease symptoms such as leaf spots, chlorosis, or other types of pathogen-induced lesions. The plant samples were immediately cooled down (below $4^{\circ} \mathrm{C}$ ) and transported to the laboratory. During the study period, precipitation and mean temperature were $93.6 \mathrm{~mm}$ and $11.42^{\circ} \mathrm{C}$ in September 2010 and $54.75 \mathrm{~mm}$ and $14.75^{\circ} \mathrm{C}$ in September 2011, respectively.

\section{Surface sterilization and extraction of total community DNA}

Surface sterilization of collected plant material and the control of this process were performed as described in Wemheuer et al. (2016). Further analysis confirmed that the surface sterilization was effective in eliminating both cultivable as well as noncultivable epiphytic bacteria as well as potential DNA traces from the plant surfaces (data not shown). The 


\section{BACTERIAL ENDOPHYTES IN IMPORTANT GRASS SPECIES}

surface-sterilized plant material was ground to a fine powder in liquid nitrogen using an autoclaved mortar and pestle. Ground tissue powder aliquots were subsequently stored at $20^{\circ} \mathrm{C}$ until DNA extraction. Total microbial community DNA was extracted employing the peqGOLD Plant DNA Mini Kit (Peqlab, Erlangen, Germany) according to the manufacturer's instructions with two modifications as described previously (Wemheuer et al., 2016).

\section{Amplification of the 16S rRNA genes}

Bacterial endophyte communities were assessed by a nested PCR approach targeting the $16 \mathrm{~S}$ rRNA gene. For details of the first PCR reaction mixture and the thermal cycling scheme see (Wemheuer et al., 2016). In brief, the primers 799f (AACMGGATTAGATACCCKG) (Chelius and Triplett, 2001) and 1492R (GCYTACCTTGTTACGACTT) (Lane, 1991) were used in the first PCR to suppress co-amplification of plant chloroplast 16S rRNA genes (Chelius and Triplett, 2001). PCR amplification resulted in two PCR products: a mitochondrial product with approximately $1.1 \mathrm{kbp}$ and a bacterial product of approximately 735 bp. Genomic DNA of Bacillus licheniformis DSM13 was used as template in the positive control to select for the bacterial product. Three independent PCRs were performed per sample. Bacterial-specific bands were purified using the peqGOLD Gel Extraction Kit (Peqlab) according to the manufacturer's instructions, quantified using a Nanodrop (ND1000) (Peqlab) and subjected to the nested PCR reaction (one per triplicate). The V6-V8 region of the $16 \mathrm{~S}$ rRNA gene was amplified with primers containing the Roche 454 pyrosequencing adaptors and key as well as one unique MID per sample (underlined): F968 5'-CCATCTCATCCCTGCGTGTCTCCGAC-TCAG-(dN) $\underline{16}^{-}$AACGCGAAGAACCTTAC 3' and R1401 5'-CCTATCCCCTGTGTGCCTTGGCAGTC-TCAG-

CGGTGTGTACAAGACCC -3' (Nübel et al., 1996). The PCR reaction $(25 \mu \mathrm{l})$ contained $5 \mu 1$ of five-fold Phusion HF buffer, $200 \mu \mathrm{M}$ of each of the four deoxynucleoside triphosphates, $4 \mu \mathrm{M}$ of each primer, $2 \mathrm{U}$ of Phusion high fidelity hot start DNA polymerase (Thermo Scientific, Waltham, MA, USA) and approximately $10 \mathrm{ng}$ of the PCR product as template. The following thermal cycling scheme was used: initial denaturation at $98^{\circ} \mathrm{C}$ for $30 \mathrm{~s}, 30$ cycles of denaturation at $98^{\circ} \mathrm{C}$ for $15 \mathrm{~s}$, annealing at $53^{\circ} \mathrm{C}$ for $30 \mathrm{~s}$, followed by extension at $72^{\circ} \mathrm{C}$ for $30 \mathrm{~s}$. The final extension was carried out at $72^{\circ} \mathrm{C}$ for $2 \mathrm{~min}$. Negative controls were performed using the reaction mixture without template. Obtained PCR products were controlled for appropriate size and subsequently purified using the peqGOLD Gel Extraction Kit (Peqlab) as recommended by the manufacturer. Quantification of the PCR products was performed using the Quant-iT dsDNA HS assay kit and a Qubit fluorometer (Thermo 


\section{BACTERIAL ENDOPHYTES IN IMPORTANT GRASS SPECIES}

Scientific) as recommended by the manufacturer. Purified PCR products from the three independent PCRs were subsequently pooled in equal amounts. The Göttingen Genomics Laboratory determined the $16 \mathrm{~S}$ rRNA gene sequences employing the Roche GS-FLX+ pyrosequencer with Titanium chemistry (Roche, Mannheim, Germany).

\section{Processing of pyrosequencing derived data}

Generated 16S rRNA datasets were processed and further analysed employing the QIIME 1.8.0 software package (Caporaso et al., 2010) and other tools. Short sequences $(<250 \mathrm{bp}$,) with long homopolymer stretches ( $>8 \mathrm{bp}$ ) and too many primer mismatches ( $>3 \mathrm{bp}$ ) were removed prior to denoising with Acacia version 1.53b (Bragg et al., 2012). Remaining reverse primer sequences were truncated employing cutadapt (version 1.0) (Martin, 2011). Chimeric sequences were removed with Usearch (version 7.0.190, Edgar, 2010) and sequences of all samples were subsequently joined and clustered in operational taxonomic units (OTUs) at 3\% genetic distance as described previously (Wemheuer et al., 2015) (Supplementary Table S2). To determine taxonomy, a consensus sequence for each OTU was classified by BLAST alignment against the Silva SSURef 119 NR database using QIIME (Camacho et al., 2009; Quast et al., 2013). Rarefaction curves, alpha diversity indices (Richness, Chao1 and Shannon,) were determined using in R (version 3.1.2; R Developmental Core Team, 2013) using the vegan package (Supplementary Table S3). In addition, the drc package was used in $\mathrm{R}$ to determine the Michaelis-Menten-Fit. Functional profiles were predicted from obtained 16S rRNA data using Tax4Fun (Asshauer et al., 2015) with short read mode disabled (Supplementary Table S4).

\section{Statistical analysis}

The impact of applied management regimes as well as putative differences between the three investigated grass species and the two sampling years was statistically analyzed using R. For this purpose, ordination plots (NMDS; non-metric multidimensional scaling) for community structures were generated based on Bray-Curtis dissimilarities using the metaMDS function within the vegan package (Oksanen et al., 2013). Furthermore, the impact of the applied treatment was evaluated using the envfit function as described by Wietz et al. (2015). Differences in richness and diversity were analyzed by pairwise $t$ test with Bonferronicorrected $\mathrm{P}$ values. Changes were considered significant at $\mathrm{P} \leq 0.05$. Plots for community functions were generated by redundancy analysis (RDA) using the Tax4Fun profiles. Samples taken in 2010 and 2011 were analyzed separately to overcome temporal pseudoreplication. 


\section{BACTERIAL ENDOPHYTES IN IMPORTANT GRASS SPECIES}

To further identify the bacterial assemblages associated with the different grasses, correlationbased indicator species analysis was performed using multipatt (indicSpecies) (De Cáceres and Legendre, 2009). The abundance of all OTUs affiliated to the same genus were summarized prior to analysis. Low abundant taxa representing less than $0.01 \%$ of the whole community were excluded from the analysis as they tend to be unique and erroneously may be declared as indicator species. In total, 393 bacterial taxa (from a total of 729 on genus level) were taken into consideration. For visualization, a bipartite network was generated using the three grasses per treatment, i.e., each grass as either fertilized or non-fertilized, as source nodes, and the genera as target nodes. All taxa with a possible association were visualized but only those with significant $(\mathrm{P} \leq 0.05)$ associations were identified in the networks. Network generation was performed using the edge-weighted spring embedded layout algorithm in Cytoscape (Shannon et al., 2003), with the edge weight corresponding to the association strength of each genus with each treatment.

\section{Nucleotide sequence accession numbers}

Sequence data are deposited in the Sequence Read Archive (SRA) of the National Center for Biotechnology Information (NCBI) under the accession number SRA419370.

\section{Results and discussion}

\section{Bacterial endophyte community is dominated by a few abundant phyla}

The response of bacterial endophytic communities in three agriculturally important grass species to different fertilization and mowing regimes was assessed by pyrotag sequencing of $16 \mathrm{~S}$ rRNA genes. After data processing, more than 57,000 high-quality sequences with approx. 711 sequences per sample were used to analyze endophyte community structure and diversity (Supplementary Table S2). Calculated rarefaction curves (data not shown) as well as diversity indices (see Supplementary Table S3) revealed that a major fraction $(>50 \%)$ of the bacterial community was recovered by the surveying effort.

Obtained 16S rRNA gene sequences were clustered into 7,192 bacterial OTUs (Supplementary Table S2). We calculated an average number of 62 OTUs per plant sample at the same surveying effort (Supplementary Table S2). Seven abundant phyla including Proteobacteria, Actinobacteria and Firmicutes were present in all samples and accounted for more than $96 \%$ of all sequences analyzed in this study (Figure 1) Proteobacteria $(76.10 \%)$ 


\section{BACTERIAL ENDOPHYTES IN IMPORTANT GRASS SPECIES}

were predominant across all samples. This is in line with previous studies of bacterial endophytes (see Table 1 in (Hardoim et al., 2015) Sequences assigned to this phylum mainly belonged to Betaproteobacteria (40.86\%) followed by Gammaproteobacteria (22.09\%), Alphaproteobacteria (11.13\%) and Deltaproteobacteria (2.01\%). Actinobacteria (6.22\%) and Firmicutes $(6.02 \%)$ were the second and the third most abundant bacterial phyla, respectively. Other identified phyla that were present in all samples were Bacteroidetes $(4.63 \%)$, Acidobacteria (1.74\%), and Deinococcus-Thermus (1.23\%). samples were Bacteroidetes (4.63\%), Acidobacteria (1.74\%), and Deinococcus-Thermus (1.23\%). These findings are in agreement with previous studies of bacterial endophytes in different grass species (Sessitsch et al., 2012; Bulgarelli et al., 2015; Maropola et al., 2015; Robinson et al., 2015) as well as in leaves of other plant species including Arabidopsis and Solanum (Bodenhausen et al., 2013; Romero et al., 2014).

At genus level, Massilia (11.49\%) was predominant across all samples (Figure 1). Members of this genus are typical bacteria in rhizosphere and soil as well as root colonizers (Nagy et al., 2005; Zhang et al., 2006; Ofek et al., 2012). Moreover, this genus was detected in the phyllosphere of tomato and crofton weed (Enya et al., 2007; Zhou et al., 2010) as well as in soybean stems (Ikeda et al., 2009) and sweet pepper shoots (Rasche et al., 2006). In a previous study on bacterial communities associated with roots and leaves of Arabidopsis, Massilia was prevalent in both samples (Bodenhausen et al., 2013). Isolates of Massilia are able to reduce nitrate (Zhang et al., 2006) suggesting the important role of this genus in the soil nitrogen cycle. Moreover, some Massilia isolates exhibited in vitro attributes related to plant growth promotion, such as Indole-3-acetic acid (IAA) production (Kuffner et al., 2010). In another study, an isolate of Massilia showed in vitro antagonism towards the pathogen Phytophthora infestans (Weinert et al., 2010). Other abundant genera observed in this study were Pseudomonas (10.0\%), Limnohabitans (5.02\%), Acidovorax (4.51\%), Rhodanobacter (3.42\%), Rhizobium (2.63\%) and Methylobacterium (1.86\%). 


\section{BACTERIAL ENDOPHYTES IN IMPORTANT GRASS SPECIES}

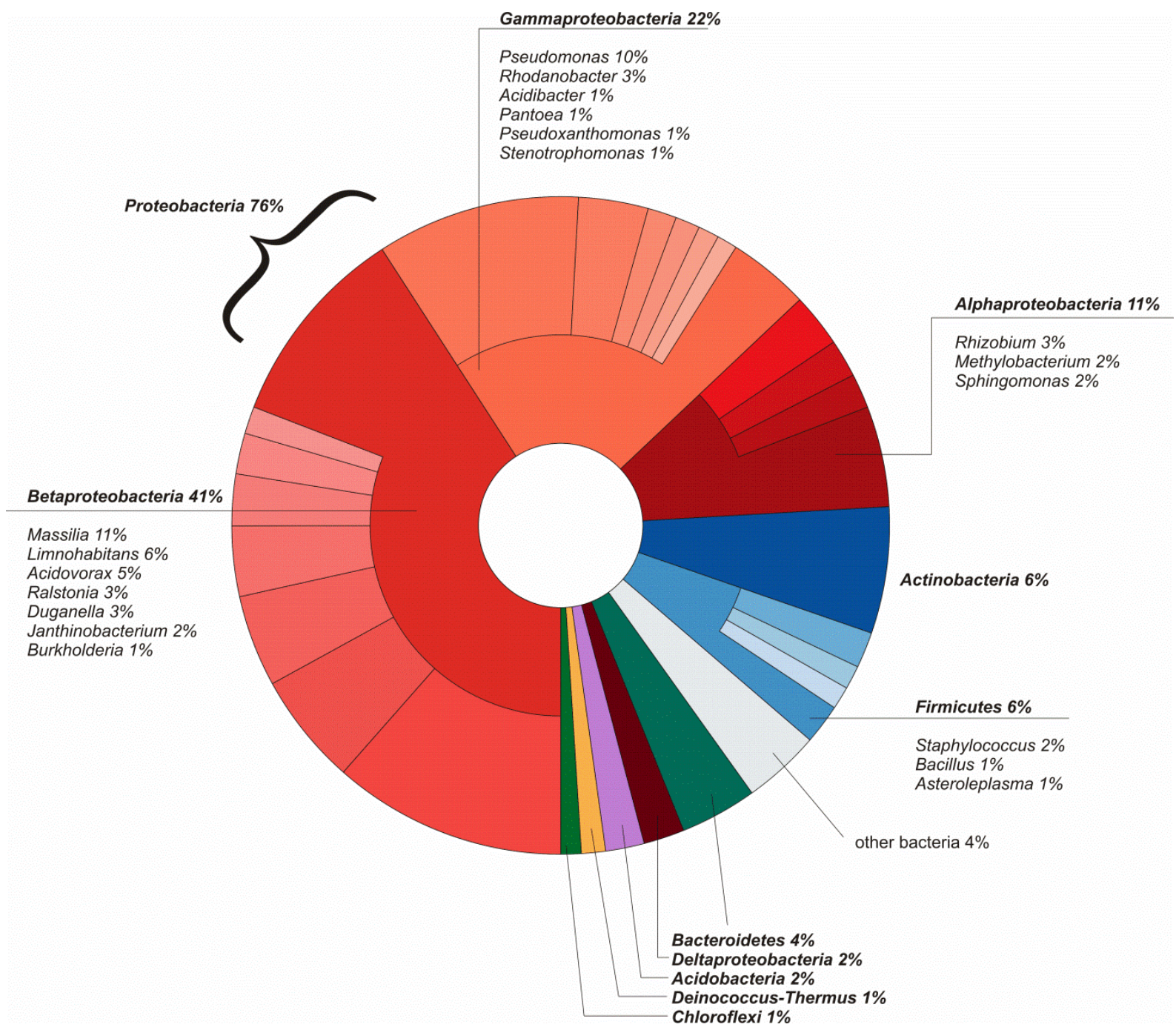

Figure 1. Abundant bacterial phyla and corresponding classes in the three investigated grass species as revealed by pyrotag sequencing. Only groups with an average abundance $>1 \%$ in at least one of the investigated grass species are shown. Taxonomy is derived from the SILVA SSURef 119 NR database.

The most commonly observed endophytic genera such as Massilia, Pseudomonas, Bacillus, and Rhizobium are also members of common soil bacterial communities (Lodewyckx et al., 2002). As consequence, some authors suggest that the endophyte microbiome is a subset of the rhizosphere or soil (e.g., (Seghers et al., 2004; Gottel et al., 2011). Moreover, genera such as Pseudomonas, Rhizobium, Stenotrophomonas, and Burkholderia are well-known for their plant growth-promoting functions and/or for the production of secondary metabolites including antibiotics or antifungal compounds (Lodewyckx et al., 2002; Lugtenberg et al., 2002; Glick, 2012). In addition, genera including Bacillus, Burkholderia, Pseudomonas, and Rhizobium are reported as the most significant phosphate solubilizing bacteria (Bhattacharyya and Jha, 2012). As these bacteria play an important role for plant growth and, thus, in 


\section{BACTERIAL ENDOPHYTES IN IMPORTANT GRASS SPECIES}

agriculture, it is of crucial importance to analyze the influence of management regimes on endophytic communities.

\section{Grass species harbor distinct bacterial endophyte communities}

We compared bacterial diversity (represented by the Shannon index H') and richness (number of observed OTUs) with respect to the three grass species (Supplementary Table S3). Interestingly, we detected differences between both sampling years. In 2011, richness and diversity of bacterial endophytes in L. perenne were significantly higher compared to those of D. glomerata, whereas no significant effect of grass species was recorded in 2010 (data not shown). To analyze putative diversity patterns of endophytic communities with regard to grass species and applied management regimes, community profiles were analyzed by NMDS. We found distinct bacterial communities in 2011 and 2010 (Figure 2) although this result derived from pseudoreplicated data. The observed differences might be attributed to the community structure in D. glomerata which was more divers compared to those of the other two grass species.

Further statistical analysis revealed that plant species significantly influenced endophytic community composition in 2011 (Table 1). This finding is in accordance with a previous study of McInroy and Kloepper (1995) who found differences in the bacterial endophyte population in field-grown sweet corn and cotton grown side by side. They suggested that internal plant niches are colonized by a wide range of bacteria. Different plant hosts also differed in their ability to be colonized by the same bacteria (Rosenblueth and MartinezRomero, 2006). Moreover, different plant species vary in their biochemical composition, which may affect bacterial endophyte community (Hallmann and Berg, 2006). According to Hallmann (2006), the differences in bacterial endophytic community structures between different plant species growing next to each other can only be explained by plant speciesspecific selection mechanisms. 

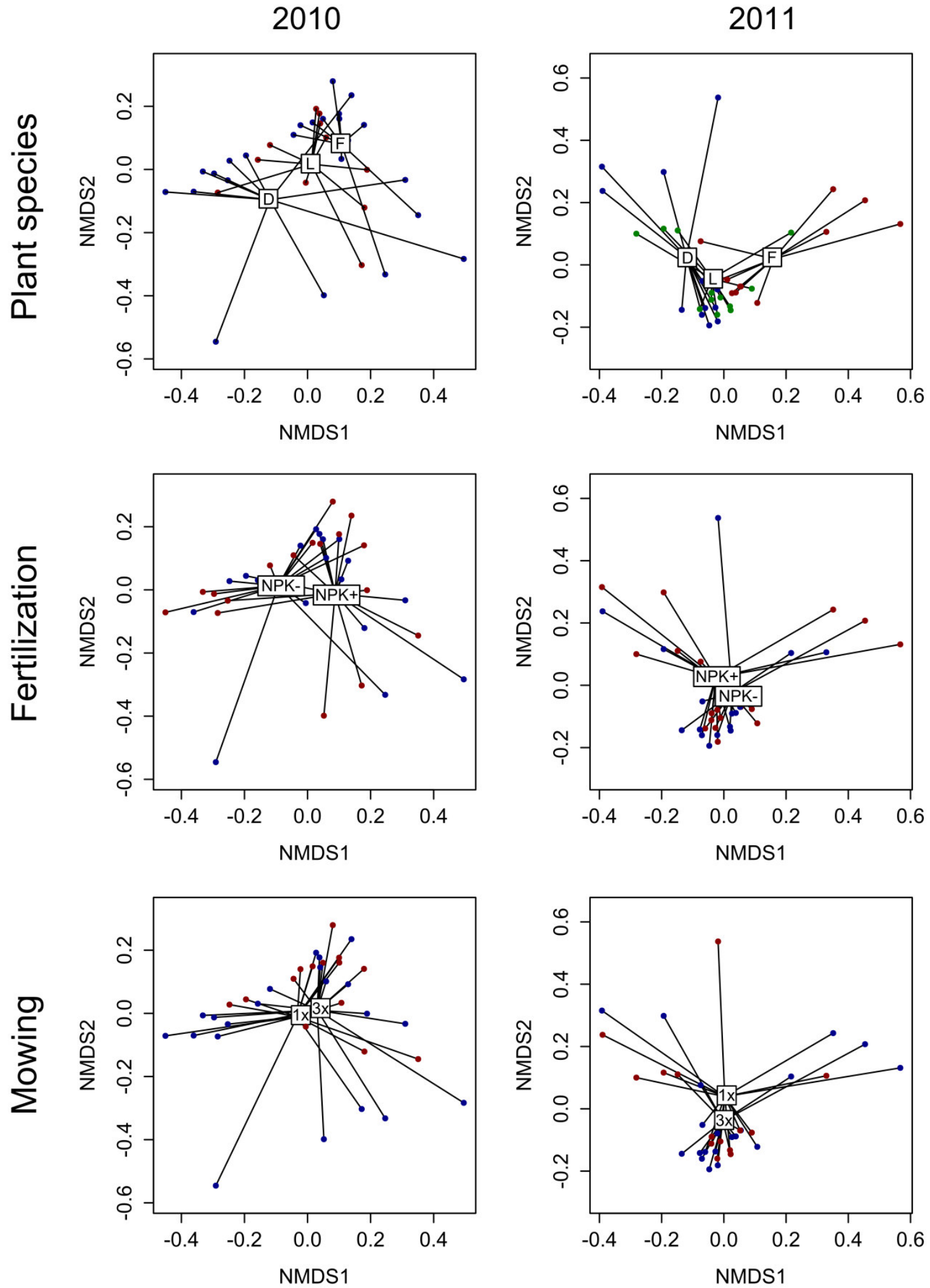

Figure 2. NMDS ordination of bacterial communities. Ordination of communities is based on Bray-Curtis dissimilarities. Samples were linked according to plant species, fertilization and mowing regime separately for 2010 and 2011, to identify potential drivers of community structure. D: Dactylis glomerata; L: Lolium perenne; F: Festuca rubra; NPK-: without fertilization; NPK+: with fertilization (sodium, phosphate and potassium); 1x: mown once; $3 \mathrm{x}$ : mown thrice. 


\section{BACTERIAL ENDOPHYTES IN IMPORTANT GRASS SPECIES}

Table 1. Results of the envfit analysis for the full 16S rRNA dataset and the predicted functional profiles. Significant $(\mathrm{P} \leq 0.05)$ and marginal significant $(\mathrm{P} \leq 0.10)$ parameters are underlined or written in italics, respectively.

\begin{tabular}{|c|c|c|c|c|}
\hline \multirow[t]{2}{*}{ Management regime } & \multicolumn{2}{|c|}{2010} & \multicolumn{2}{|c|}{2011} \\
\hline & r2 & $\mathbf{P}$ & $\mathbf{r} 2$ & $\mathbf{P}$ \\
\hline \multicolumn{5}{|c|}{ Community composition } \\
\hline Plant & 0.095 & 0.176 & $\underline{0.265}$ & $\underline{0.001}$ \\
\hline Fertilization & $\underline{0.119}$ & $\underline{0.013}$ & $\overline{0.005}$ & $\overline{0.848}$ \\
\hline Mowing & $\overline{0.007}$ & $\overline{0.795}$ & 0.003 & 0.895 \\
\hline Plant + Fertilization & $\underline{0.346}$ & $\underline{0.007}$ & $\underline{0.321}$ & $\underline{0.010}$ \\
\hline Plant + Mowing & 0.168 & 0.351 & $\underline{0.318}$ & $\underline{0.006}$ \\
\hline Fertilization + Mowing & 0.145 & 0.122 & 0.068 & 0.581 \\
\hline Plant + Fertilization + Mowing & $\underline{0.561}$ & $\underline{0.005}$ & $\underline{0.526}$ & $\underline{0.006}$ \\
\hline \multicolumn{5}{|c|}{ Community function } \\
\hline Plant & 0.075 & 0.272 & 0.212 & $\underline{0.001}$ \\
\hline Fertilization & 0.006 & 0.847 & $\overline{0.003}$ & $\overline{0.907}$ \\
\hline Mowing & 0.037 & 0.32 & 0.069 & 0.061 \\
\hline Plant + Fertilization & 0.160 & 0.404 & $\underline{0.240}$ & $\underline{0.036}$ \\
\hline Plant + Mowing & 0.141 & 0.506 & $\underline{0.328}$ & $\underline{0.002}$ \\
\hline Fertilization + Mowing & 0.112 & 0.265 & $\overline{0.089}$ & $\overline{0.403}$ \\
\hline Plant + Fertilization + Mowing & 0.340 & 0.371 & $\underline{0.469}$ & $\underline{0.022}$ \\
\hline
\end{tabular}

Bacterial community composition and diversity is influenced by fertilization but not by mowing frequency

We did not find any influence of mowing frequency on bacterial richness and diversity in both sampling years (Supplementary Table S5). Interestingly, no significant effect of fertilizer application on bacterial richness or diversity was observed in 2011, while richness and diversity were significantly reduced on fertilized plots in 2010. Similarly, a higher diazotrophic bacterial diversity in the roots of rice cultivated in unfertilized and previously uncultivated soil than in paddy soil amended with nitrogen fertilizer were recorded by Prakamhang et al. (2009). In contrast to this, Rodriguez-Blanco et al. (2015) found that Nfertilization increased both the diversity and richness of diazotrophic bacteria in roots and stems of maize. However, only the diazotrophic endophyte communities were investigated in these studies.

To analyze the effect of applied management regimes onto bacterial community structures, community profiles were analyzed by multivariate analysis. Interestingly, the endophyte communities build distinct clusters as response to fertilizer application in 2010 but not in 2011 while mowing treatments had no impact on community structure in both sampling years (Figure 2). The statistical analysis further revealed that the interaction of plant species with 
fertilization explained approximately $34 \%$ or $32 \%$ of the variance in 2010 and 2011, respectively. Although mowing frequencies did not have any significant impact on community structure, more than $50 \%$ of the variance in the dataset is explained by a combination of plant species, fertilizer application, and mowing frequency (Table 1).

We further evaluated the impact of applied management regimes on bacterial communities for the three grass species separately. Statistical analysis revealed that fertilizer application and mowing frequencies significantly affected bacterial community composition in D. glomerata in 2010 explaining more than $60 \%$ of the variance (Table 2). Although not significant, a similar result was observed for L. perenne in 2011 . Whereas only $10 \%$ of the variance was explained by fertilizer application and mowing solely, its combination resulted in more than $58 \%$ explained variance. Interestingly, we detected no impact of applied management regimes on community functions in D. glomerata whereas both management regimes affected community functions in both, F. rubra and L perenne.

Table 2. Results of the envfit analysis for the different plant species. Significant correlations $(P \leq 0.05)$ are underlined. $($ Fert. $=$ Fertilization $)$

\begin{tabular}{|c|c|c|c|c|c|c|c|c|c|c|c|c|}
\hline \multirow{3}{*}{$\begin{array}{l}\text { Manage } \\
\text { ment } \\
\text { regime }\end{array}$} & \multicolumn{4}{|c|}{ Dactylis glomerata } & \multicolumn{4}{|c|}{ Festuca rubra } & \multicolumn{4}{|c|}{ Lolium perenne } \\
\hline & \multicolumn{2}{|c|}{2010} & \multicolumn{2}{|c|}{2011} & \multicolumn{2}{|c|}{2010} & \multicolumn{2}{|c|}{2011} & \multicolumn{2}{|c|}{2010} & \multicolumn{2}{|c|}{2011} \\
\hline & $\mathbf{r} 2$ & $\mathbf{P}$ & $\mathbf{r} 2$ & $\mathbf{P}$ & $\mathbf{r} 2$ & $\mathbf{P}$ & $\mathbf{r} 2$ & $\mathbf{P}$ & $\mathbf{r} 2$ & $\mathbf{P}$ & $\mathbf{r} 2$ & $\mathbf{P}$ \\
\hline \multicolumn{13}{|c|}{ Community composition } \\
\hline Fert. & $\underline{0.4029}$ & $\underline{0.007}$ & 0.1999 & 0.16 & 0 & 0.495 & 0.1779 & 0.167 & 0.1226 & 0.289 & 0.1015 & 0.343 \\
\hline Mowing & $\overline{0.0905}$ & $\overline{0.425}$ & 0.0858 & 0.222 & 0 & 0.906 & 0.0156 & 0.869 & 0.0301 & 0.728 & 0.0917 & 0.405 \\
\hline \multicolumn{13}{|l|}{ Fert.+ } \\
\hline Mowing & $\underline{0.6016}$ & $\underline{0.008}$ & 0.3142 & 0.368 & 0.2002 & 0.285 & 0.3812 & 0.189 & 0.1561 & 0.793 & 0.5827 & 0.073 \\
\hline \multicolumn{13}{|c|}{ Community function } \\
\hline Fert. & 0.0259 & 0.992 & 0.054 & 0.662 & 0.0521 & 0.761 & 0.0424 & 0.668 & 0.0643 & 0.761 & 0.1629 & 0.174 \\
\hline Mowing & 0.0547 & 0.851 & 0.1049 & 0.274 & 0.0342 & 0.883 & 0.167 & 0.156 & 0.1715 & 0.084 & 0.0574 & 0.632 \\
\hline Fert. + & & & & & & & & & & & & \\
\hline Mowing & 0.1659 & 0.976 & 0.2627 & 0.498 & 0.1738 & 0.881 & $\underline{0.4937}$ & $\underline{0.049}$ & 0.3032 & 0.429 & $\underline{0.5315}$ & $\underline{0.026}$ \\
\hline
\end{tabular}

It has been proposed that the bacterial endophyte community is a subset of the rhizosphere and/or root-associated bacterial community as many of the bacterial endophytes originated from the corresponding rhizosphere (Germida et al., 1998; Sessitsch et al., 2002; Gottel et al., 2011). As consequence, factors shaping the soil community will also influence the endophyte community. In a recent study on the effect of fertilizer application on soil bacterial communities conducted at the GRASSMAN experimental field, soil bacterial communities were strongly influenced by fertilization (Herzog et al., 2015).

Effects of fertilizer application on endophytes as observed here are in line with previous studies (Tan et al., 2003; Prakamhang et al., 2009; Wemheuer et al., 2016). Endophytic 


\section{BACTERIAL ENDOPHYTES IN IMPORTANT GRASS SPECIES}

populations in cotton roots are affected by application of nitrogen-containing chitin as an organic amendment (Hallmann et al., 1999). According to Tan et al. (2003), a rapid change of both the population and the activity of nitrogen-fixing bacteria in rice roots was observed within 15 days after $\mathrm{N}$-fertilization. However, most previous research focused on the effect of fertilizer application or on diazotrophic and/or root endophytic bacteria in a single grass species (Fuentes-Ramírez et al., 1999; Tan et al., 2003; Seghers et al., 2004; Prakamhang et al., 2009; Rodríguez-Blanco et al., 2015).

As the recorded effects on endophytic communities were different between the three grass species examined in this study, it is most likely that also the grasses are affected differently by management regimes. The grass species investigated in this study differ in their indicator values such as tolerance against mowing or grazing (Dierschke and Briemle, 2002). Both D. glomerata and L. perenne have a higher tolerance against mowing than F. rubra. In contrast, L. perenne has a higher indicator value for nitrogen compared to the other two grass species. Tan et al. (2003) showed that environmental conditions strongly influenced the diazotrophic endophytic community structure in rice roots. During the study period, precipitation and mean temperature differed between the two sampling years which might affect the endophyte communities as well.

\section{Identification of indicator species with regard to grass species and management regimes revealed differences}

To identify bacterial taxa most likely responsible for the observed differences between the investigated plant species, we performed an indicator species analysis to identify genera significantly associated with one or all plant species. This analysis is based on the relative frequency (occurrence in a certain plant species) and relative average abundance. Taxa which are shared between two of the grass species are not shown. Approximately $20 \%$ of the OTUs did not show significant differences in relative abundance and frequency (Figure 3). This core community is represented by 142 members across the bacterial phyla. However, several taxa were only associated with one of the three grasses. Although approximately $10.3 \%$ of all bacterial taxa were exclusively associated with F. rubra, only the genera Pseudoclavibacter and Luteimonas were significantly associated with this grass species. Recently, Pseudoclavibacter endophyticus was isolated from healthy roots of Glycyrrhiza uralensis (Li et al., 2016). Several members of this genus were isolated from rhizosphere soil (Kim and Jung, 2009; Du et al., 2015). In a study on the microbiome of lettuce, Luteimonas was found as abundant genus in the rhizosphere (Erlacher et al., 2015). Several members of this genus 


\section{BACTERIAL ENDOPHYTES IN IMPORTANT GRASS SPECIES}

were isolated from the rhizosphere of different plant species (Cheng et al., 2015; Ngo and Yin, 2016), whereas the recently-described Luteimonas cucumeris sp. nov, was isolated from cucumber leaves (Sun et al., 2012). As this isolate was able to reduce nitrogen, Luteimonas might play an important role in the nitrogen cycle.

Interestingly, only the genus Streptococcus was significantly associated with D. glomerata, whereas 23 genera including Neorhizobium, Gaiella and Dyella were significantly associated with L. perenne. These findings are in line with the study of Zinniel et al. (2002) who showed that different agronomic crops and prairie plant species harbor a significant variation of indigenous bacterial endophytes although there was a lack of strict specificity. However, only isolated endophytes were investigated in this study. Members of the genera Neorhizobium and Dyella are interesting due to their ability to promote the growth of the plants. Dyella ginsengisoli has originally been isolated from a ginseng field in South Korea (Jung et al., 2009), but was also observed as endophyte in rice seeds (Hardoim et al., 2012). The Dyella ginsengisoli strain ATSB10 exhibited 1-aminocyclopropane-1-carboxylate (ACC) deaminase activity and was able to solubilize inorganic phosphate (Anandham et al., 2008). In addition, this strain has been reported to increase the root length of canola seedlings by $145 \%$. In a recent study about effects of Neorhizobium huautlense strain T1-17 on hot pepper, the fruit biomass was increased (Chen et al., 2016). Genome analysis of ten Neorhizobium galegae strains revealed plant growth promoting properties of several strains (Österman et al., 2015). In the present study, all three grass species investigated were associated with a wide range of endophytic species, a core community (Figure 3). This is in line with a previous study showing a core community of bacterial endophytes in different maize species (JohnstonMonje and Raizada, 2011). As the three grass species investigated in the present study shared approximately $20 \%$ of all taxa (on genus level), there must be additional factors besides plant species-specific selection mechanisms. There are different lifestyle strategies of endophytic species as previously described (Gaiero et al., 2013; Hardoim et al., 2015). Many bacteria are obligate endophytes which are strictly bound to life inside plants during their entire lifespan (Hardoim et al., 2008). This might also determine the core community as observed in the present study. 


\section{BACTERIAL ENDOPHYTES IN IMPORTANT GRASS SPECIES}

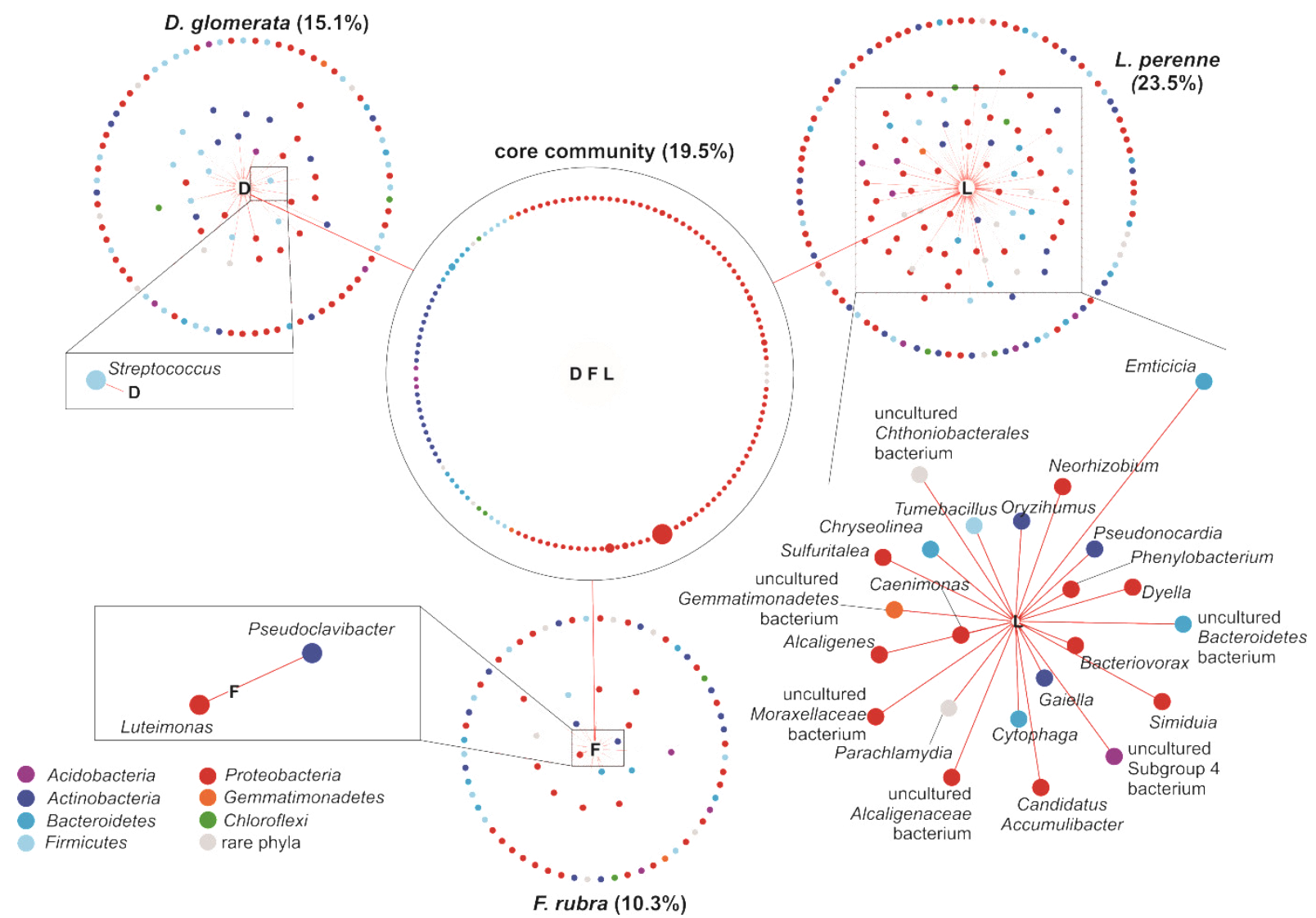

Figure 3. Number of taxa (genus level) shared between the three grass species). Circular layouts represent all associated taxa, while significant associations are enlarged for each plant. Node size corresponds to the relative abundance of each taxon in the whole dataset.Only uniquely associated taxa or those associated with all three plant species (designated as core community) are shown.

As mentioned earlier, plants vary in their biochemical composition which might explain differences in the bacterial endophytic community (Hallmann and Berg, 2006). Hallmann et al. (1999) suggested that changes in plant physiology may result in the development of distinct bacterial endophytic communities. Endophytic bacteria rely on the nutritional supply offered by their host plant. As consequence, any factor influencing the nutritional or physiological status of the host plant may consequently have an influence on the endophytic community in the plant (Hallmann et al., 1997; Fuentes-Ramírez et al., 1999). Several factors, such as temperature or precipitation, have a direct effect on the plant physiology and thus an indirect impact on the colonization and the survival of bacteria in the endosphere (Hallmann et al., 1997; Hardoim et al., 2012).

As only fertilizer application had a strong effect on the structure of the endophyte community in the three grass species, we carried out the indicator analysis under the two fertilization regimes. Interestingly, 18 of the 393 genera analyzed showed a significant association (Figure 4). Additionally, the associated bacterial taxa differed in the grass species according to the 


\section{BACTERIAL ENDOPHYTES IN IMPORTANT GRASS SPECIES}

treatment. The only exceptions were Bacteriovorax and Caenimonas which were significantly associated with L. perenne regardless of the treatment. In the fertilized treatment, the only significantly associated genus Sporocytophaga was shared with L. perenne. Regarding the non-fertilized treatments, Limnobacter and Oryzihumus were associated with L. perenne, while Geobacter, Telmatobacter and a Solirubrobacterales member were associated with D. glomerata. In the fertilized plants, Tepidimonas, Schlegelella and Anoxybacillus were associated with D. glomerata. In addition, Tumebacillus, Gaiella and Planomicrobium showed unique associations with $L$. perenne plants growing on fertilized plots.

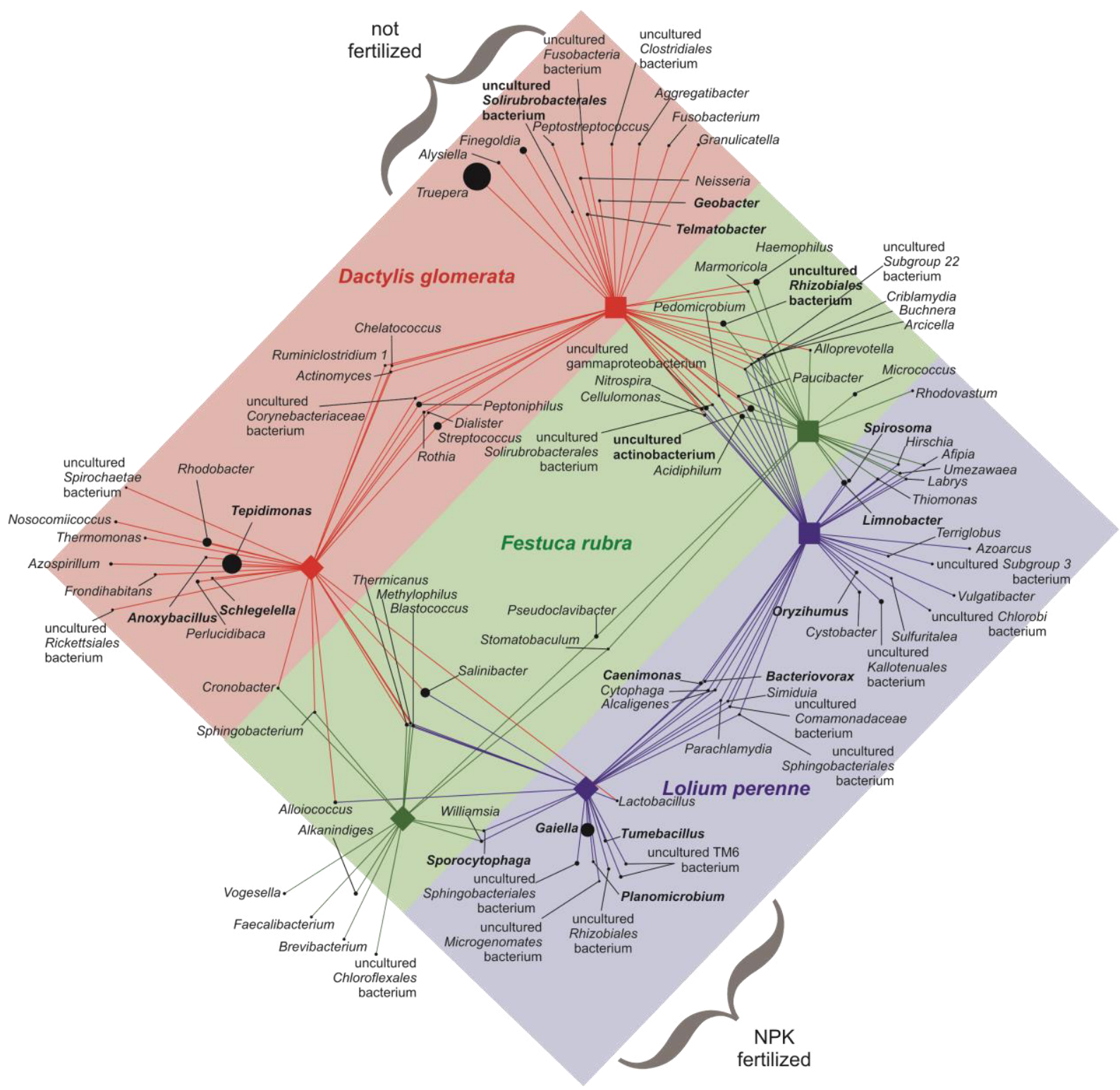

Figure 4. Bipartite association network of taxa with different treatments. Node size corresponds to the relative abundance of each taxon in the whole dataset. Significantly associated taxa are given in bold. 


\section{BACTERIAL ENDOPHYTES IN IMPORTANT GRASS SPECIES}

\section{Functional profiles of endophytic bacteria}

To investigate the impact of applied management regimes on endophyte functioning, artificial metagenomes were calculated from 16S rRNA gene data using Tax4Fun (Asshauer et al., 2015). Statistical analysis revealed that functional profiles were affected by the host plant in 2011 but not in 2010 (Figure 5). A combination of the applied treatments with plant species showed significant correlations with calculated functional profiles as well (Table 1). We further focused on genes involved in plant growth promotion, i.e., nitrilase, amidases or nitrogenase (Figure 6) as well as on genes involved in the nitrogen cycle. These genes differed in their abundances between plants and also between the different treatments (Figure 6). This is supported by the statistical analysis (Table 3). Fertilizer application significantly affected the relative abundance of 523 genes in the functional profile of endophytes in D. glomerata in 2010, but only 20 genes in 2011. For L. perenne, a similar response was found. Mowing influenced the functional profiles of endophytes in L. perenne in 2011 and in F. rubra in 2010.
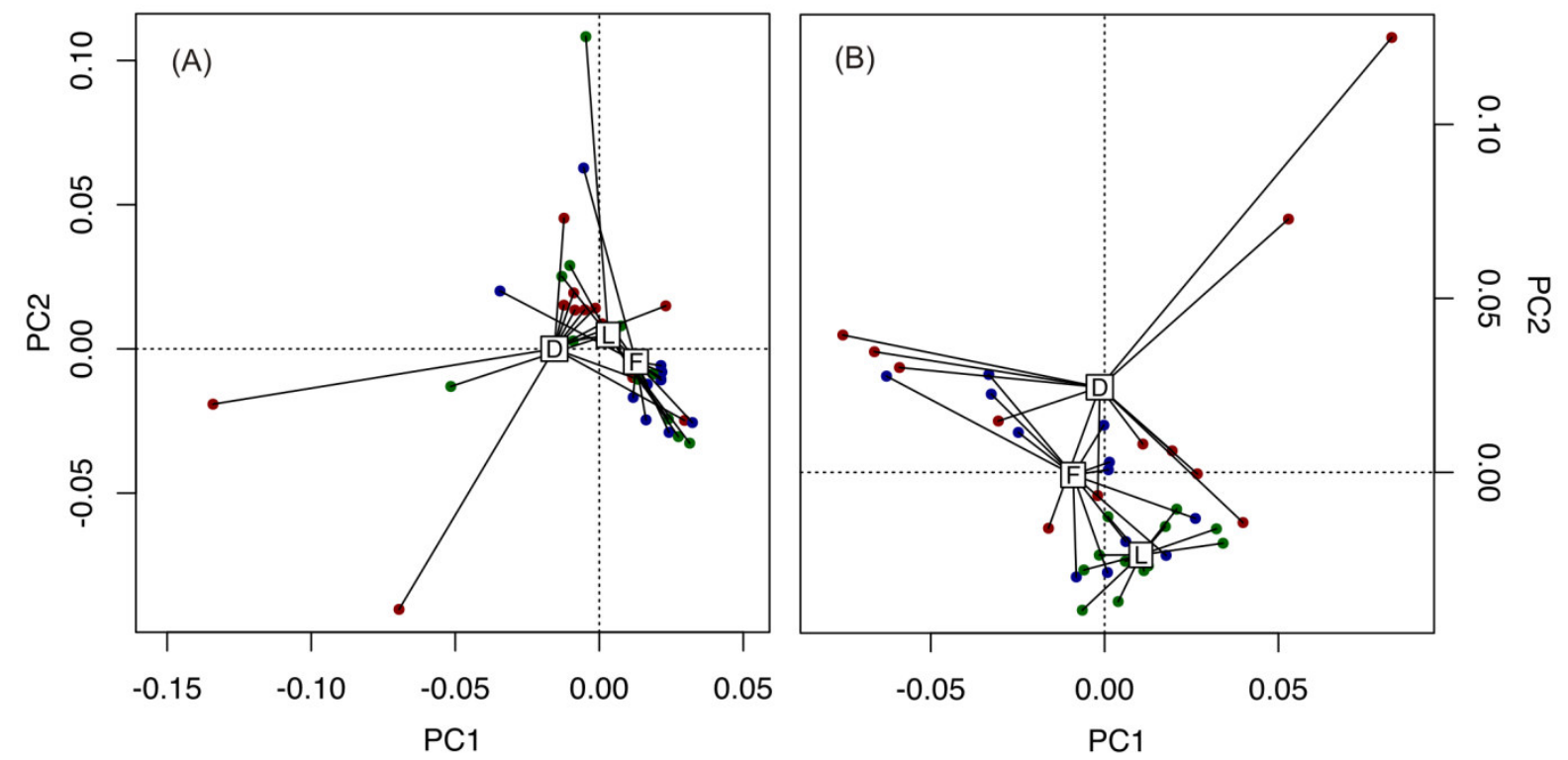

Figure 5. NMDS ordination of the functional profile based on Bray-Curtis dissimilarities. (A) Functional profiles of the endophytic communities of the different plants (L: Lolium perenne; F: Festuca rubra; D: Dactylis glomerata) in 2010 and (B) 2011.

Moreover, most genes were found in higher abundances in D. glomerata compared to the other two grass species (Figure 5). In addition, genes involved in plant growth promotion such as amidase or nitrilase were found in higher abundances in D. glomerata samples of fertilized plots mown once year, whereas genes of the nitrogen cycle were more abundant in D. glomerata samples mown three times a year compared to those mown once a year. 


\section{BACTERIAL ENDOPHYTES IN IMPORTANT GRASS SPECIES}

Table 3. Number of genes significantly influenced by applied management regimes. The number in brackets refers to the percentage of genes influenced divided by the total number of genes predicted from 16S rRNA data $(\mathrm{n}=6408)$. Fert. $=$ Fertilization .

\begin{tabular}{|c|c|c|c|c|c|c|c|c|c|c|c|c|}
\hline Management & \multicolumn{4}{|c|}{ Dactylis glomerata } & \multicolumn{4}{|c|}{ Festuca rubra } & \multicolumn{4}{|c|}{ Lolium perenne } \\
\hline regime & \multicolumn{2}{|c|}{2010} & \multicolumn{2}{|c|}{2011} & \multicolumn{2}{|c|}{2010} & \multicolumn{2}{|c|}{2011} & \multicolumn{2}{|c|}{2010} & \multicolumn{2}{|c|}{2011} \\
\hline Fert. & 523 & $(8.16 \%)$ & 20 & $(0.31 \%)$ & 48 & $(0.75 \%)$ & 41 & $(0.64 \%)$ & 128 & $(2.00 \%)$ & 280 & $(4.37 \%)$ \\
\hline Mowing & 151 & $(2.36 \%)$ & 353 & $(5.51 \%)$ & 94 & $(1.47 \%)$ & 756 & $(11.8 \%)$ & 783 & $(12.2 \%)$ & 202 & $(3.15 \%)$ \\
\hline Fert.+ Mowing & 180 & $(2.81 \%)$ & 37 & $(0.58 \%)$ & 98 & $(1.53 \%)$ & 577 & $(9.00 \%)$ & 33 & $(0.51 \%)$ & 1492 & $(23.3 \%)$ \\
\hline
\end{tabular}

In F. rubra, the abundance of nitrilase genes did not differ between the treatments. In contrast to this, higher average abundances were observed in L. perenne and D. glomerata samples of unfertilized plots mown one a year or fertilized plots mown once a year, respectively. This observation was also true for most of the genes investigated including the ACC deaminase and the amidase. The ACC deaminase is involved in stress alleviation in plants (Hardoim et al., 2015). ACC is a precursor of ethylene, which is a key regulator of the colonization of plant tissue by bacteria (Hardoim et al., 2008) and inhibits the nodule formation in legumes (Rocha et al., 2007). Nitrilases and amidases have been reported to play a role in plant hormone production (Hardoim et al., 2015). Nitrilases are further involved in the utilization of nitrogen compounds and in detoxification (as reviewed in (Howden and Preston, 2009). Howden et al. (2009) found a nitrilase from Pseudomonas fluorescens to be involved in the detoxification of cyano-compounds. Nitrogenase plays an important role in endophytic communities as it is putatively involved in the fixation of atmospheric nitrogen. It was also found to be significantly more abundant in endophytes compared to phytopathogens, suggesting its important role in enhancing plant productivity under nitrogen limitation (Hardoim et al., 2015).

However, it remains unclear why the genes encoding these enzymes were more abundant in D. glomerata under fertilization and mown once a year, as well as in L. perenne without fertilization and mown once a year. Similar results were obtained when investigating genes involved in plant colonization and establishment (Supplementary Figure S1, Supplementary Table S5). These genes differed in their abundances between plants with higher abundances observed in D. glomerata. Moreover, they differed in L. perenne and D. glomerata between the treatments investigated, while most of them were relatively stable in F. rubra. It is further not clear, why the abundance of genes seems generally lower in this grass species. So far, our knowledge about functional changes of endophyte communities as response to management regimes in different grass species is still limited 


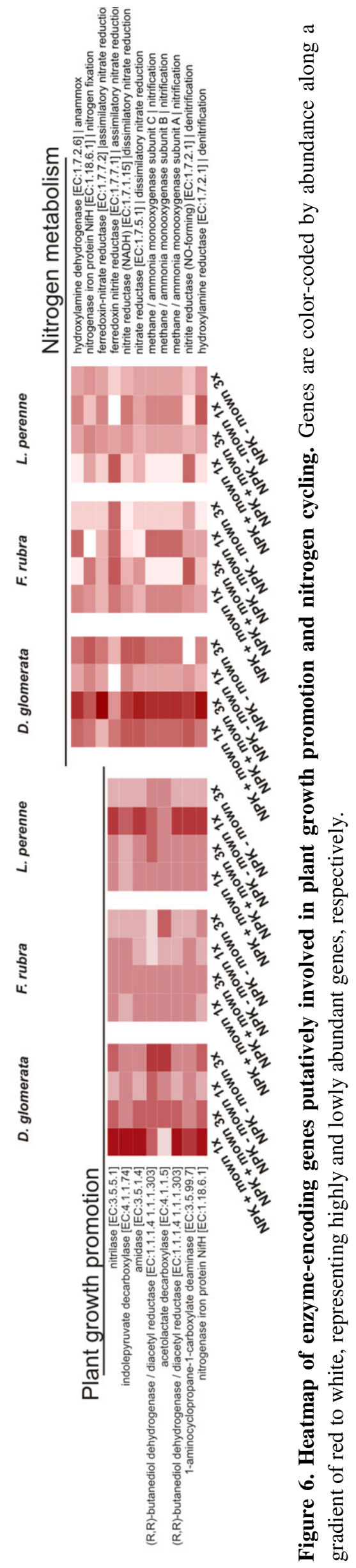




\section{BACTERIAL ENDOPHYTES IN IMPORTANT GRASS SPECIES}

\section{Conclusion}

The majority of studies on endophyte diversity with respect to management regimes examined the effect of only one management regime in one single year, or focused on culturable endophytes or one functional group only. In this study, the influence of different management regimes on three agricultural important grass species was investigated in two consecutive years by high-throughput sequencing. According to our hypothesis (1), the three grass species show differences in endophyte diversity and exhibit distinct endophytic communities. However, approximately $20 \%$ of the taxa analyzed were shared between the grass species. Our results demonstrate further that the influence of management varied between the applied management regimes. Fertilizer application had a strong effect on richness and community composition, whereas mowing frequency had no significant effect. However, the combination of mowing, fertilization and plant species explained more than $50 \%$ of the variance of community composition observed. Interestingly, the effect of different management regimes is dependent on the host plant which is in line with hypothesis (2). Functional analysis revealed that the abundance of genes involved in plant growth promotion differed between the three grass species investigated. Moreover, the abundances of genes encoding for many enzymes such as amidase or nitrogenase were affected by the applied management regimes. At this stage we cannot determine if management regimes directly influence the endophyte community or indirectly through the modification of plant physiology. Nevertheless, this study provides first insights into structural and functional changes of endophyte communities in three agricultural important grass species as response to combined fertilizer application and mowing regimes. More studies targeting the influence of management regimes in combination with the impact of sampling year and plant species are required to unravel the diversity of interactions between endophytic bacteria, plant species and management regimes.

\section{Acknowledgements}

We thank all persons involved in the installation and maintenance of the GrassMan experiment in the Solling. This study was funded by the Ministry of Science and Culture of Lower Saxony and the 'Niedersächsisches Vorab' as part of the Cluster of Excellence 'Functional Biodiversity Research'. 


\section{BACTERIAL ENDOPHYTES IN IMPORTANT GRASS SPECIES}

\section{References}

1. Anandham R, Gandhi PI, Madhaiyan M, Sa T. (2008). Potential plant growth promoting traits and bioacidulation of rock phosphate by thiosulfate oxidizing bacteria isolated from crop plants. J Basic Microbiol 48:439-447.

2. Aßhauer KP, Wemheuer B, Daniel R, Meinicke P. (2015). Tax4Fun: predicting functional profiles from metagenomic 16S rRNA data. Bioinformatics 31:2882-2884.

3. Bhattacharyya PN, Jha DK. (2012). Plant growth-promoting rhizobacteria (PGPR): emergence in agriculture. World J Microb Biot 28:1327-1350.

4. Bodenhausen N, Horton MW, Bergelson J. (2013). Bacterial communities associated with the leaves and the roots of Arabidopsis thaliana. PLoS ONE 8:e56329.

5. Bragg L, Stone G, Imelfort M, Hugenholtz P, Tyson GW. (2012). Fast, accurate errorcorrection of amplicon pyrosequences using Acacia. Nat Meth 9:425-426.

6. Bulgarelli D, Garrido-Oter R, Münch PC, Weiman A, Dröge J, Pan Y, et al. (2015). Structure and function of the bacterial root microbiota in wild and domesticated barley. Cell Host Microbe 17:392-403.

7. Camacho C, Coulouris G, Avagyan V, Ma N, Papadopoulos J, Bealer K, et al. (2009). BLAST+: architecture and applications. BMC Bioinformatics 10:1.

8. Caporaso JG, Kuczynski J, Stombaugh J, Bittinger K, Bushman FD, Costello EK, et al. (2010). QIIME allows analysis of high-throughput community sequencing data. Nat Methods 7:335-336.

9. Chelius MK, Triplett EW. (2001). The diversity of archaea and bacteria in association with the roots of Zea mays L. Microb Ecol 41:252-263.

10. Cheng J, Zhang MY, Wang WX, Manikprabhu D, Salam N, Zhang TY, et al. (2015). Luteimonas notoginsengisoli $\mathrm{sp}$. nov., isolated from rhizosphere soil. Int J Syst Evol Microbiol 66:946-950.

11. Compant S, Clément C, Sessitsch A. (2010). Plant growth-promoting bacteria in the rhizo- and endosphere of plants: Their role, colonization, mechanisms involved and prospects for utilization. Soil Biol Biochem 42:669-678.

12. De Cáceres MD, Legendre P. (2009). Associations between species and groups of sites: indices and statistical inference. Ecology 90:3566-3574.

13. Dierschke H, Briemle G. (2002). Kulturgrasland- Wiesen, Weiden und verwandte Staudenfluren. Verlag Eugen Ulmer: Stuttgart. 


\section{BACTERIAL ENDOPHYTES IN IMPORTANT GRASS SPECIES}

14. Du J, Singh H, Yang JE, Yin CS, Kook M, Yu H, et al. (2015). Pseudoclavibacter terrae sp. nov. isolated from rhizosphere soil of Ophiopogon japonicus. Int J Syst Evol Microbiol 65:4202-4207.

15. Edgar RC. (2010). Search and clustering orders of magnitude faster than BLAST. Bioinformatics 26:2460-2461.

16. Enya J, Shinohara H, Yoshida S, Tsukiboshi T, Negishi H, Suyama K, et al. (2007). Culturable leaf-associated bacteria on tomato plants and their potential as biological control agents. Microb Ecol 53:524-536.

17. Erlacher A, Cardinale M, Grosch R, Grube M, Berg G. (2015). The impact of the pathogen Rhizoctonia solani and its beneficial counterpart Bacillus amyloliquefaciens on the indigenous lettuce microbiome. Front Microbiol 5:175.

18. Fuentes-Ramírez LE, Caballero-Mellado J, Sepúlveda J, Martínez-Romero E. (1999). Colonization of sugarcane by Acetobacter diazotrophicus is inhibited by high $\mathrm{N}$ fertilization. FEMS Microbiol Ecol 29:117-128.

19. Gaiero JR, Mccall CA, Thompson KA, Day NJ, Best AS, Dunfield KE. (2013). Inside the root microbiome: bacterial root endophytes and plant growth promotion. Am J Bot 100:1738-1750.

20. Germida JJ, Siciliano SD, Renato De Freitas J, Seib AM. (1998). Diversity of rootassociated bacteria associated with field-grown canola (Brassica napus L.) and wheat (Triticum aestivum L.). FEMS Microbiol Ecol 26:43-50.

21. Glick BR. (2012). Plant growth-promoting bacteria: mechanisms and applications. Scientifica 15:9634901.

22. Gottel NR, Castro HF, Kerley M, Yang Z, Pelletier DA, Podar M, et al. (2011). Distinct microbial communities within the endosphere and rhizosphere of Populus deltoides roots across contrasting soil types. Appl Environ Microbiol 77:5934-5944.

23. Hallmann J, Berg G. (2006). Spectrum and population dynamics of bacterial root endophytes. In: Schulz BE, Boyle CC, Sieber T (eds). Microbial Root Endophytes. Springer: Berlin Heidelberg, pp 15-31.

24. Hallmann J, Quadt-Hallmann A, Mahaffee WF, Kloepper JW. (1997). Bacterial endophytes in agricultural crops. Can J Microbiol 43:895-914.

25. Hallmann J, Rodríguez-Kábana R, Kloepper JW. (1999). Chitin-mediated changes in bacterial communities of the soil, rhizosphere and within roots of cotton in relation to nematode control. Soil Biol Biochem 31:551-560. 


\section{BACTERIAL ENDOPHYTES IN IMPORTANT GRASS SPECIES}

26. Hardoim PR, Hardoim CCP, Van Overbeek LS, Van Elsas JD. (2012). Dynamics of seed-borne rice endophytes on early plant growth stages. PLoS ONE 7:e30438.

27. Hardoim PR, Van Overbeek LS, Berg G, Pirttila AM, Compant S, Campisano A, et al. (2015). The hidden world within plants: ecological and evolutionary considerations for defining functioning of microbial endophytes. Microbiol Mol Biol Rev 79:293-320.

28. Hardoim PR, Van Overbeek LS, Elsas JDV. (2008). Properties of bacterial endophytes and their proposed role in plant growth. Trends Microbiol 16:463-471.

29. Herzog S, Wemheuer F, Wemheuer B, Daniel R. (2015). Effects of fertilization and sampling time on composition and diversity of entire and active bacterial communities in German grassland soils. PLoS ONE 10:e0145575.

30. Howden AJ, Jill Harrison C, Preston GM. (2009). A conserved mechanism for nitrile metabolism in bacteria and plants. Plant J 57:243-253.

31. Howden AJ, Preston GM. (2009). Nitrilase enzymes and their role in plant-microbe interactions. Microb Biotechnol 2:441-451.

32. Ikeda S, Kaneko T, Okubo T, Rallos LEE, Eda S, Mitsui H, et al. (2009). Development of a bacterial cell enrichment method and its application to the community analysis in soybean stems. Microb Ecol 58:703-714.

33. Johnston-Monje D, Raizada MN. (2011). Conservation and diversity of seed associated endophytes in Zea across boundaries of evolution, ethnography and ecology. PLoS One 6: e20396.

34. Jung H-M, Ten LN, Kim K-H, An DS, Im W-T, Lee S-T. (2009). Dyella ginsengisoli sp. nov., isolated from soil of a ginseng field in South Korea. Int J Syst Evol Microbiol 59:460-465.

35. Kim MK, Jung HY. (2009). Pseudoclavibacter soli sp. nov., a $\beta$-glucosidaseproducing bacterium. Int J Syst Evol Microbiol 59:835-838.

36. Kobayashi D, Palumbo J. (2000). Bacterial endophytes and their effects on plants and uses in agriculture. In: Bacon CW, White JF (eds). Microbial endophytes. Marcel Dekker: New York, pp 199-236.

37. Kuffner M, De Maria S, Puschenreiter M, Fallmann K, Wieshammer G, Gorfer M, et al. (2010). Culturable bacteria from Zn-and Cd-accumulating Salix caprea with differential effects on plant growth and heavy metal availability. J Appl Microbiol 108:1471-1484.

38. Lane DJ. (1991). 16S/23S rRNA sequencing. International Society for Microbial Ecology. 


\section{BACTERIAL ENDOPHYTES IN IMPORTANT GRASS SPECIES}

39. Li YQ, Li L, Fu YS, Cui ZQ, Duan YQ, Salam N, et al. (2016). Pseudoclavibacter endophyticus sp. nov., isolated from roots of Glycyrrhiza uralensis. Int J Syst Evol Microbiol 66:1287-1292.

40. Lodewyckx C, Vangronsveld J, Porteous F, Moore ERB, Taghavi S, Mezgeay M, et al. (2002). Endophytic bacteria and their potential applications. Crc Rev Plant Sci 21:583-606.

41. Lugtenberg BJ, Chin AWTF, Bloemberg GV. (2002). Microbe-plant interactions: principles and mechanisms. Antonie Van Leeuwenhoek 81:373-383.

42. Maropola MK, Ramond JB, Trindade M. (2015). Impact of metagenomic DNA extraction procedures on the identifiable endophytic bacterial diversity in Sorghum bicolor (L. Moench). J Microbiol Methods 112:104-117.

43. Martin M. (2011). Cutadapt removes adapter sequences from high-throughput sequencing reads. EMBnet.journal 17:10-12.

44. Mcinroy J, Kloepper J. (1995). Survey of indigenous bacterial endophytes from cotton and sweet corn. Plant Soil 173:337-342.

45. Nagy ML, Pérez A, Garcia-Pichel F. (2005). The prokaryotic diversity of biological soil crusts in the Sonoran Desert (Organ Pipe Cactus National Monument, AZ). FEMS Microbiol Ecol 54:233-245.

46. Ngo HT, Yin CS. (2016). Luteimonas terrae sp. nov., isolated from rhizosphere soil of Radix ophiopogonis. Int J Syst Evol Microbiol 66:1920-1925.

47. Nübel U, Engelen B, Felske A, Snaidr J, Wieshuber A, Amann RI, et al. (1996). Sequence heterogeneities of genes encoding 16S rRNAs in Paenibacillus polymyxa detected by temperature gradient gel electrophoresis. J Bacteriol 178:5636-5643.

48. Ofek M, Hadar Y, Minz D. (2012). Ecology of root colonizing Massilia (Oxalobacteraceae). PLoS ONE 7:e40117.

49. Oksanen J, Blanchet FG, Kindt R, Legendre P, Minchin PR, O'Hara RB, et al. (2013). Vegan: community ecology package. R package version 2.0-10.

50. Österman J, Mousavi SA, Koskinen P, Paulin L, Lindström K. (2015). Genomic features separating ten strains of Neorhizobium galegae with different symbiotic phenotypes. BMC Genomics 16:1-14.

51. Petersen U, Wrage N, Köhle, L, Leuschner C, Isselstein J. (2012). Manipulating the species composition of permanent grasslands-A new approach to biodiversity experiments. Basic Appl Ecol 13:1-9. 


\section{BACTERIAL ENDOPHYTES IN IMPORTANT GRASS SPECIES}

52. Prakamhang J, Minamisawa K, Teamtaisong K, Boonkerd N, Teaumroong N. (2009). The communities of endophytic diazotrophic bacteria in cultivated rice (Oryza sativa L.). Appl Soil Ecol 42:141-149.

53. Quast C, Pruesse E, Yilmaz P, Gerken J, Schweer T, Yarza P, et al. (2013). The SILVA ribosomal RNA gene database project: improved data processing and webbased tools. Nucleic Acids Res 41:D590-D596.

54. Rasche F, Trondl R, Naglreiter C, Reichenauer TG, Sessitsch A. (2006). Chilling and cultivar type affect the diversity of bacterial endophytes colonizing sweet pepper (Capsicum anuum L.). Can J Microbiol 52:1036-1045.

55. Reinhold-Hurek B, Hurek T. (1998). Life in grasses: diazotrophic endophytes. Trends Microbiol 6:139-144.

56. Robinson RJ, Fraaije BA, Clark IM, Jackson RW, Hirsch PR, Mauchline TH. (2015). Endophytic bacterial community composition in wheat (Triticum aestivum) is determined by plant tissue type, developmental stage and soil nutrient availability. Plant Soil doi:10.1007/s11104-015-2495-4.

57. Rocha FR, Papini-Terzi FS, Nishiyama MY, Vêncio RZ, Vicentini R, Duarte RD, et al. (2007). Signal transduction-related responses to phytohormones and environmental challenges in sugarcane. BMC genomics 8:71.

58. Rodríguez-Blanco A, Sicardi M, Frioni L. (2015). Plant genotype and nitrogen fertilization effects on abundance and diversity of diazotrophic bacteria associated with maize (Zea mays L.). Biol Fertil Soils 51:391-402.

59. Romero FM, Marina M, Pieckenstain FL. (2014). The communities of tomato (Solanum lycopersicum L.) leaf endophytic bacteria, analyzed by 16S-ribosomal RNA gene pyrosequencing. FEMS Microbiol Lett 351:187-194.

60. Rosenblueth M, Martinez-Romero E. (2006). Bacterial endophytes and their interactions with hosts. Mol Plant Microbe Interact 19:827-837.

61. Ryan RP, Germaine K, Franks A, Ryan DJ, Dowling DN. (2008). Bacterial endophytes: recent developments and applications. FEMS Microbiol Lett 278:1-9.

62. Seghers D, Wittebolle L, Top EM, Verstraete W, Siciliano SD. (2004). Impact of agricultural practices on the Zea mays L. endophytic community. Appl Environ Microbiol 70:1475-1482.

63. Senthilkumar M, Anandham R, Madhaiyan M, Venkateswaran V, Sa T. (2011). Endophytic Bacteria: perspectives and applications in agricultural crop production. In: 


\section{BACTERIAL ENDOPHYTES IN IMPORTANT GRASS SPECIES}

Maheshwari DK (ed). Bacteria in Agrobiology: Crop Ecosystems. Springer: Berlin Heidelberg, pp 61-96.

64. Sessitsch A, Hardoim P, Döring J, Weilharter A, Krause A, Woyke T, et al. (2012). Functional characteristics of an endophyte community colonizing rice roots as revealed by metagenomic analysis. Mol Plant Microbe Interact 25:28-36.

65. Sessitsch A, Reiter B, Pfeifer U, Wilhelm E. (2002). Cultivation-independent population analysis of bacterial endophytes in three potato varieties based on eubacterial and Actinomycetes-specific PCR of 16S rRNA genes. FEMS Microbiol Ecol 39:23-32.

66. Shannon P, Markiel A, Ozier O, Baliga NS, Wang JT, Ramage D, et al. (2003). Cytoscape: a software environment for integrated models of biomolecular interaction networks. Genome Res 13:2498-2504.

67. Stoltzfus JR, So R, Malarvithi PP, Ladha JK, De Bruijn FJ. (1997). Isolation of endophytic bacteria from rice and assessment of their potential for supplying rice with biologically fixed nitrogen. Plant Soil 194:25-36.

68. Sturz AV, Christie BR, Matheson BG, Arsenault WJ, Buchanan NA. (1999). Endophytic bacterial communities in the periderm of potato tubers and their potential to improve resistance to soil-borne plant pathogens. Plant Pathol 48:360-369.

69. Sturz AV, Christie BR, Nowak J. (2000). Bacterial Endophytes: potential role in developing sustainable systems of crop production. Crc Rev Plant Sci 19:1-30.

70. Sun ZB, Zhang H, Yuan XF, Wang YX, Feng DM, Wang YH, et al. (2012). Luteimonas cucumeris sp. nov., isolated a from cucumber leaf. Int J Syst Evol Microbiol 62:2916-2920.

71. Tan Z, Hurek T, Reinhold-Hurek B. (2003). Effect of N-fertilization, plant genotype and environmental conditions on nifH gene pools in roots of rice. Environ Microbiol 5:1009-1015.

72. R Development Core Team. (2013). R: A Language and Environment for Statistical Computing. R Foundation for Statistical Computing: Vienna.

73. Weinert N, Meincke R, Gottwald C, Radl V, Dong X, Schloter M, et al. (2010). Effects of genetically modified potatoes with increased zeaxanthin content on the abundance and diversity of rhizobacteria with in vitro antagonistic activity do not exceed natural variability among cultivars. Plant Soil 326:437-452.

74. Wemheuer B, Wemheuer F, Hollensteiner J, Meyer F-D, Voget S, Daniel R. (2015). The green impact: bacterioplankton response towards a phytoplankton spring bloom in 


\section{BACTERIAL ENDOPHYTES IN IMPORTANT GRASS SPECIES}

the southern North Sea assessed by comparative metagenomic and metatranscriptomic approaches. Front Microbiol 6:805.

75. Wemheuer F, Wemheuer B, Kretzschmar D, Pfeiffer B, Herzog S, Daniel R, et al. (2016). Impact of grassland management regimes on bacterial endophyte diversity differs with grass species. Lett Appl Microbiol 62:323-329.

76. Wietz M, Wemheuer B, Simon H, Giebel H-A, Seibt MA, Daniel R, et al. (2015). Bacterial community dynamics during polysaccharide degradation at contrasting sites in the Southern and Atlantic Oceans. Environ Microbiol 17:3288-3831.

77. Zhang YQ, Li WJ, Zhang KY, Tian XP, Jiang Y, Xu LH, et al. (2006). Massilia dura sp. nov., Massilia albidiflava sp. nov., Massilia plicata sp. nov. and Massilia lutea sp. nov., isolated from soils in China. Int J Syst Evol Microbiol 56:459-463.

78. Zhou Z-X, Jiang H, Yang C, Yang M-Z, Zhang H-B. (2010). Microbial community on healthy and diseased leaves of an invasive plant Eupatorium adenophorum in Southwest China. J Microbio 48:139-145.

79. Zinniel DK, Lambrecht P, Harris NB, Feng Z, Kuczmarski D, Higley P, et al. (2002). Isolation and characterization of endophytic colonizing bacteria from agronomic crops and prairie plants. Appl Environ Microbiol 68:2198-2208.

\section{SUPPLEMENTARY INFORMATION}

Supplementary figures and tables are provided along with the electronic version of this thesis (on DVD), under the following paths:

Figure S1:

Table S1:

Table S2:

Table S3:

Table S4:

Table S5:
Supplementary Information/Chapter III.6/Figure S1.docx Supplementary Information/Chapter III.5/ Table S1 - Sampling Data.xlsx Supplementary Information/Chapter III.5/ Table S2 - OUT Table.xlsx Supplementary Information/Chapter III.5/ Table S3 - AlphaDiversity.xlsx Supplementary Information/Chapter III.5/ Table S4 - FunctionalProfile.xlsx Supplementary Information/Chapter III.5/ Table S5 - Statistics Richness.docx 
Chapter III.7.

SoIl ARCHAEAl COMMUNities UNDER DifFERENT CROPPING REGIMES 
III.7.

Changes of soil archaeal community structure and diversity in response to intercropping of wheat (Triticum aestivum L.) and faba bean (Vicia faba L.)

Running title: Soil Archaeal Communities under Different Cropping Regimes

Sandra Granzow ${ }^{1}$, Kristin Kaiser ${ }^{2}$, Rolf Daniel $^{2}$, Stefan Vidal ${ }^{1}$, Franziska Wemheuer ${ }^{1, *}$

${ }^{1}$ Section of Agricultural Entomology, Department of Crop Sciences, Georg-AugustUniversity Göttingen, Grisebachstr.6, D-37077 Göttingen, Germany.

${ }^{2}$ Department of Genomic and Applied Microbiology, Institute of Microbiology and Genetics, Georg-August-University Göttingen, Grisebachstr. 8, D-37077 Göttingen, Germany

Author contributions:

Study design: SV, FK, RD

Experiments: SG

Data analysis: SG, KK, FW

Wrote the manuscript: SG, KK, FW 
SOIL ARCHAEAL COMMUNITIES UNDER DIFFERENT CROPPING REGIMES

\section{Abstract}

Multiple cropping systems provide many economic and ecological advantages including increased plant productivity. Although being important for nutrient cycling, the response of soil archaeal communities towards these cropping systems has been rarely studied. Here we investigated the effect of crop species and cropping system on soil archaeal communities in a greenhouse experiment. For this purpose, faba bean and wheat plants were grown under four different cropping regimes (monoculture wheat, monoculture bean, row or mixed intercropping of bean and wheat). Soil archaeal community structure and diversity were assessed by sequencing of $16 \mathrm{~S}$ rRNA gene amplicons. The highest archaeal diversity was observed in soil samples of row intercropping. Archaeal community structures between monocultures and intercropping regimes exhibited their own distinct community patterns which were attributed to community structures under row intercropping. In addition, we identified several indicator species being highly associated with crop species or cropping regimes and thus most likely responsible for the observed differences in community structure. For example, one species affiliated to the Marine Group II belonging to the Thermoplasmatales was associated with row intercropping. Obtained data underline the importance of soil archaea in agriculture and identify the complex interactions between cropping systems, archaeal communities and crop species.

\section{Introduction}

Archaea are found in a wide range of habitats including grassland, rainforest or agricultural soils (Etto et al.,. 2012; Gattinger et al., 2007; Chroňáková et al., 2015; Schneider et al., 2015). As these microorganisms play a key role in biogeochemical cycling on earth (reviewed in Offre et al., 2013), it is important to identify the main drivers forming archaeal communities in soil ecosystems. Previous studies showed that archaeal communities are affected by various factors such as plant species (Mao et al., 2011; Mao et al., 2013; Zhang et al., 2015a) or landscapes (Schneider et al., 2015). Moreover, fertilizer application influenced soil archaeal communities (Gattinger et al., 2007; Dorr de Quadros et al., 2012; Schneider et al., 2015).

Intensive agricultural systems including monocultures have clearly negative environmental impacts such as the loss of biodiversity (Matson et al., 1997). Conversely, multiple (or mixed) cropping systems provide enhanced ecological and economical services 


\section{SOIL ARCHAEAL COMMUNITIES UNDER DIFFERENT CROPPING REGIMES}

including a better control of diseases, pests and weeds (Francis, 1989; Paulsen et al., 2006; Winter et al., 2014). Moreover, these cropping systems enhance plant productivity by improving efficient use of light, nutrients and water (Francis, 1989; Malézieux et al., 2009), most probably through (positive) interspecific interaction in the rhizosphere (Li et al., 1999; Zhang et al., 2004; Inal et al., 2007). Multiple cropping systems are very diverse and defined as the growing of two or more crops on the same field in one year (Francis, 1986). Crop plants in these cropping systems do not compete for the same ecological niches as they ideally differ in uptake and utilization of nutrients and in the time of their major demands on the environmental resources (Willey, 1979; Jensen, 1996; Malézieux et al., 2009).

Previous studies reported that the diversity and community composition of soil archaea was influenced by multiple cropping systems such as intercropping or crop rotation (Breidenbach et al., 2015; Liu et al., 2015; Zhang et al., 2015a). In a study of the methanogenic archaeal community in a paddy field soil, differences in abundance and composition of this community in response to a rice-soybean crop rotation were observed (Liu et al., 2015). This is consistent with a study of Breidenbach et al. (2015) analysing the effect of crop rotation between rice and maize by 454 pyrosequencing of archaeal $16 \mathrm{~S}$ rRNA gene and $16 \mathrm{~S}$ rRNA. They found the community composition to be altered in the rotational fields. For example, the abundance of aerobic Thaumarchaeota increased, whereas the abundance of anaerobic methanogenic lineages decreased. In contrast to these results, crop rotation had only a minor effect on archaeal communities under field conditions (Watanabe et al., 2006; Scavino et al., 2013). However, our knowledge on structural changes of the entire archaeal community in response to multiple cropping systems and crop species is still rather limited, as most previous research focused only on ammonia-oxidizing or (Mao et al., 2011; Wang et al., 2012; Mao et al., 2013) or methanogenic archaea (Watanabe et al., 2006; Gattinger et al., 2007; Liu et al., 2015).

The aim of the present study was to investigate the response of soil archaeal community diversity and composition to different cropping systems as part of the IMPAC ${ }^{3}$ project ("Novel genotypes for mixed cropping allow for improved sustainable land use across arable land, grassland and woodland"). To assess structural changes of the soil archaeal community, the two agricultural important crop species common wheat (Triticum aestivum L.) and faba bean (Vicia faba L.) were grown in monoculture or as mixture. The two component crops were grown simultaneously in rows (row intercropping) or with no distinct row arrangement (mixed intercropping) as defined by Andrews and Kassam (1976). The entire archaeal community was examined by sequencing of $16 \mathrm{~S}$ rRNA genes and subsequent analysis of 
obtained sequencing data. We hypothesized (1) that intercropping of bean and wheat results in an increased wheat biomass and in turn to a decreased bean biomass. In addition, we expected (2) crop species and cropping regimes affect community structure and diversity of soil archaea. We further hypothesized (3) that that species richness and diversity are higher in multiple cropping systems compared to monocultures.

\section{Materials and Methods}

\section{Experimental design}

To investigate the effect of cropping system and crop species on the entire archaeal community, a greenhouse experiment was conducted in summer 2015. Faba bean (genotype: Hiverna) and wheat (genotype: Hybery) were cultured in monoculture or as mixture in polypropylene containers (Semadeni, Eurobehälter, LogiLine ® SGL Boden, 600 x 400 x 212 $\mathrm{mm}$ ), containing 75\% sterile commercial plant substrate (Fruhstorfer Erde Typ T25; N: 200$300 \mathrm{mg} \mathrm{L}^{-1}, \mathrm{P}_{2} \mathrm{O}_{5}$ : 200-300 mg L ${ }^{-1}$; Hawita Gruppe GmbH Vechta, Germany) and 25\% sand. This plant substrate is a peaty soil with a $\mathrm{pH}\left(\mathrm{CaCl}_{2}\right)$ of 5.5 to 6.5. For monocropping systems, twenty faba bean (FBM) or eighty wheat (WM) plants per container were grown in rows, respectively (Figure 1). In multiple cropping systems, approximately forty wheat and ten faba bean plants per container were grown in rows (row intercropping; RI) or with no distinct row arrangement (mixed intercropping; MI). The four different cropping regimes (monoculture wheat, monoculture bean, row or mixed intercropping of bean and wheat) were replicated five times in a randomized design. All plants were daily irrigated. To increase nutrient-limitation as well as intra- and interspecies interactions between the plants, no fertilization regime was applied.

\section{Sampling and edaphic parameters}

Soil samples were collected after a growing period of four weeks. We sampled the bulk soil, defined as root-free soil around the crops, and the rhizosphere soil, defined as soil tightly adhering to the roots. In the two intercropping regimes, bulk and rhizosphere soil samples of the two crop species were pooled for each container. All samples were frozen and stored at $-20^{\circ} \mathrm{C}$. For determination of soil properties, subsamples were dried at $60^{\circ} \mathrm{C}$ for two days and sieved to $<2 \mathrm{~mm}$. Soil organic carbon (C) and total nitrogen (N) concentrations from all dried subsamples were determined using a LECO TruSpec CN analyzer (Leco Copr., St. Joseph, MI). The gravimetric soil water content (\%) of all soil samples was calculated from 
oven-dried subsamples. Soil $\mathrm{pH}$ values were measured as follows: $2 \mathrm{~g}$ soil of each container and crop species were mixed with $5 \mathrm{~mL}$ PCR grade water. After incubation for 24 hours, $\mathrm{pH}_{\text {Water }}$ was measured in the supernatant with a glass electrode. Subsequently, $0.37 \mathrm{~g} \mathrm{KCl}$ was added and $\mathrm{pH}_{\mathrm{KCl}}$ was measured. Detailed information on soil characteristics is given in the supplemental material (Table S1).

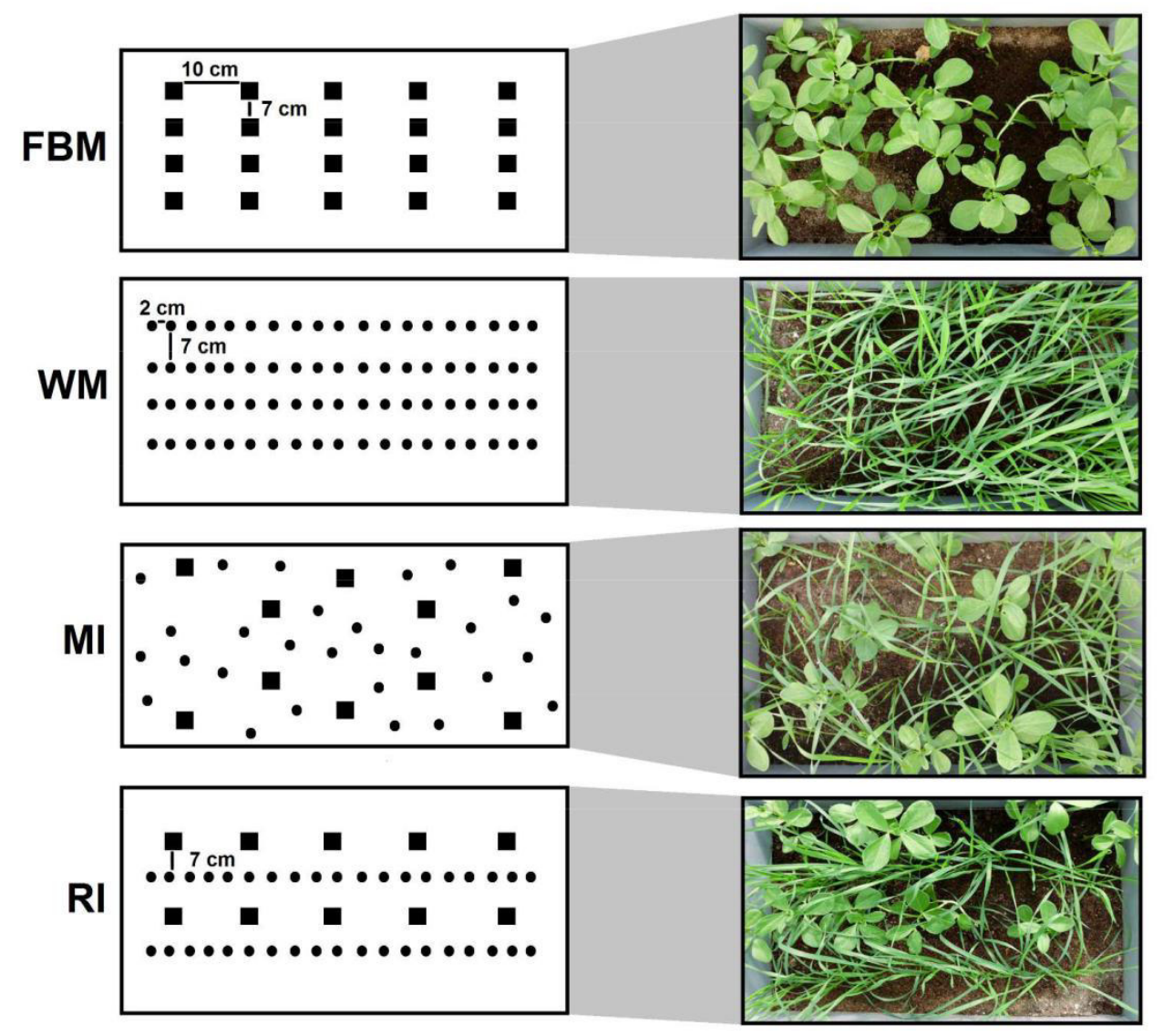

Figure 1. Study design. The 4 different cropping systems are shown (from top to bottom): faba bean in monoculture (FBM), wheat in monoculture (WM), mixed intercropping (MI) and row intercropping (RI) of faba bean and wheat.

\section{Crop biomass and height}

Aboveground as well as below-ground plant material of the two crop species were harvested separately for each container. Aboveground (shoots, leaves) and root biomass for each crop species and each container were measured. In addition, the heights of approximately 10 faba bean and 20 wheat plants in intercropping regimes and approximately 20 plants of monocropped faba bean and wheat plants were measured. Ten wheat and five bean plants which did not show any obvious disease symptoms were randomly selected from 
each container for molecular analysis. For determination of water content, ten wheat and five faba bean plants per container were weighted and subsequently oven-dried at $60^{\circ} \mathrm{C}$ for $48 \mathrm{~h}$ and re-weighted.

\section{Extraction of environmental DNA and amplification of archaeal 16S rRNA genes}

DNA was extracted from $0.125 \mathrm{~g}$ bulk or rhizosphere soil using the PowerSoil@ DNA Isolation Kit (MoBio Laboratories, Inc., USA) according to the manufacture's protocol. DNA concentrations were quantified using a NanoDrop ND-1000 UV-Vis Spectrophotometer (NanoDrop Technologies, USA) according to the manufacturer's protocol.

To assess archaeal community structures, the V4-V5 region of the 16S rRNA was amplified by PCR. The PCR reaction $(25 \mu \mathrm{L})$ contained: $5 \mu \mathrm{L}$ of five-fold Phusion GC buffer (Thermo Scientific, Waltham, MA, USA), $200 \mu \mathrm{M}$ of each of the four deoxynucleoside triphosphates, $4 \mu \mathrm{M}$ of each primer, $1.5 \mathrm{mM} \mathrm{MgCl}_{2}, 2.5 \% \mathrm{DMSO}, 1 \mathrm{U}$ of Phusion High Fidelity Hot Start DNA polymerase (Thermo Scientific) and approximately $10 \mathrm{ng}$ of DNA. The following thermal cycling scheme was used: initial denaturation at $98^{\circ} \mathrm{C}$ for $30 \mathrm{~s}$ and 30 cycles of $10 \mathrm{~s}$ at $98^{\circ} \mathrm{C}, 30 \mathrm{~s}$ at $63^{\circ} \mathrm{C}$ and $15 \mathrm{~s}$ at $72^{\circ} \mathrm{C}$. The final extension was carried out at $72^{\circ} \mathrm{C}$ for $2 \mathrm{~min}$. The initial annealing temperature of $63^{\circ} \mathrm{C}$ was reduced $1^{\circ} \mathrm{C}$ per cycle for the next 10 cycles and maintained at the final annealing temperature of $53^{\circ} \mathrm{C}$ for the remaining 20 cycles. Negative controls were performed by incubating the reaction mixture without template. The V4-V5 region was amplified with the following set of primers containing MiSeq adaptor (underlined): (Miseq_Arch_for5'TCGTCGGCAGCGTCAGATGTGTATAAGAGACAG-GGTGBCAGCCGCCGCGGTAA 3' and Miseq_Arch_rev 5'- GTCTCGTGGGCTCGGAGATGTGTATAAGAGACAGCCCGCCAATTYCTTTAAG -3'). Primer were designed de novo using all aligned archaeal sequences from the most recent, non-redundant SILVA (SSURef 123) database (Quast et al., 2013). After removal of all vertical gaps, Shannon values were determined in a sliding window of $20 \mathrm{bp}$ in $1 \mathrm{bp}$-steps along the sequence to identify highly conserved regions (low Shannon values). Subsequently, primers targeting these regions were designed using the proportional distribution of each nucleotide at each position.

Two independent PCR reactions were performed for rhizosphere as well as for bulk soil samples of each container. Obtained PCR products were purified using the peqGOLD Gel Extraction kit (Peqlab) and subsequently quantified using the Quant-iT dsDNA HS assay kit and a Qubit fluorometer (Invitrogen) as recommended by the manufacturer. The four purified PCR products per container were subsequently pooled in equal amounts. The Göttingen 


\section{SOIL ARCHAEAL COMMUNITIES UNDER DIFFERENT CROPPING REGIMES}

Genomics Laboratory determined the sequences of the partial 16S rRNA genes employing the MiSeq Sequencing platform and the MiSeq Reagent Kit v3 as recommended by the manufacturer (Illumina, San Diego, USA).

\section{Processing and analysis of datasets}

Generated 16S rRNA gene and rRNA datasets were processed with Usearch version 8.0.1623 (Edgar, 2010): Paired-end reads were merged and quality-filtered. Filtering included the removal of reads shorter than $350 \mathrm{bp}$. Processed sequences of all samples were joined and clustered in operational taxonomic units (OTUs) at 3\% genetic divergence using the UPARSE algorithm implemented in USEARCH. A de novo chimera removal was included in the clustering step. Afterwards, putative chimeric sequences were removed using UCHIME in reference mode with the most recent SILVA database (Silva SSURef $123 \mathrm{NR}$ ) as reference data set (Camacho et al., 2009). Subsequently, processed sequences were remapped on OTU sequences to calculate the distribution of each OTU in every sample. In addition, OTU sequence were taxonomically classified by BLAST alignment against the most recent SILVA database (see above) using QIIME (Caporaso et al., 2010). All non-archaeal OTUs were removed (Supplementary Table S1). Alpha diversity indices (Supplementary Table S2) and rarefaction curves (Supplementary Figure S1) were calculated with QIIME version 1.9 as described previously (Wemheuer et al., 2014).

\section{Statistical analysis}

All statistical analyses were conducted employing $\mathrm{R}$ (version 3.1.2; R Development Core Team, 2014). Differences were considered as statistically significant with $\mathrm{P} \leq 0.05$. Environmental parameters were tested for normality using the Shapiro test and for variance homogeneity using the Levene test within the car package. Correlation between cropping types and soil $\mathrm{pH}$ as well as aboveground and root biomass were subsequently tested by ANOVA and Kruskal-Wallis test, respectively. Ordination plots (NMDS; non-metric multidimensional scaling) were calculated using the metaMDS function within the vegan package (Oksanen et al., 2013) based on Bray-Curtis dissimilarities. The impact of cropping system on archaeal community structure was tested using the envfit function as described previously (Wietz et al., 2015). Indicator species were identified using the multipatt function within the IndicSpecies package (De Cáceres and Legendre, 2009). 
SOIL ARCHAEAL COMMUNITIES UNDER DIFFERENT CROPPING REGIMES

\section{Sequence data deposition}

Sequence data were deposited in the Sequence Read Archive (SRA) of the National Center for Biotechnology Information (NCBI) under the accession number SRA347195.

\section{Results and Discussion}

\section{Soil properties}

In this study, the influence of cropping system and regime on archaeal communities in soil was assessed. Therefore, bulk and rhizosphere soil samples from four different cropping regimes (monoculture wheat, monoculture bean, row or mixed cropping of bean and wheat) were collected. Several soil properties from soil samples including total $\mathrm{N}$ and C content, C:N ratio, water content, as well as soil $\mathrm{pH}$ were determined (Table 1, Table $\mathrm{S} 1$ in the Supplements). The C:N ratios ranged between 43.5 and 53.2 with the highest C:N ratio in rhizosphere soil samples of wheat in cropping regime MI (Table S1 in the Supplements). The lowest and highest $\mathrm{C}: \mathrm{N}$ ratios in bulk soil samples were observed in cropping regimes WM and MI, respectively (Table 1). As the C:N ratio explains the ability to use soil carbon and nitrogen for microbial processes such as the decomposition of soil organic matter (Wardle, 1992), it is an indicator of soil microbial activity (He et al., 1997). Statistical analysis revealed that $\mathrm{C}: \mathrm{N}$ ratios in bulk as well as in rhizosphere soil samples did not differ significantly among the four cropping regimes with one exception: the $\mathrm{C}: \mathrm{N}$ ratio in bulk soil samples of the cropping regime MI were significantly higher compared to the other cropping regimes (Table $1)$.

The soil $\mathrm{pH}$ values were relatively constant among all soil samples $\left(\mathrm{pH}_{\mathrm{water}}=\right.$ $\left.6.82 \pm 0.13 ; \mathrm{pH}_{\mathrm{KCl}}=6.55 \pm 0.09\right)$ with no significant differences between the four cropping regimes (data not shown). Water content varied between 61.6 and $86.3 \%$ with the lowest and the highest water content in bulk as well as rhizosphere soil samples of WM and FBM, respectively (Table 1, Table S1 in the Supplements). In addition, the water content in rhizosphere soil samples of WM was significantly lower compared to the other three cropping regimes (Table 1). We tested further if one of the edaphic parameters influenced the richness or the diversity of soil archaeal communities. No influence of water content, C:N ratio and soil $\mathrm{pH}$ on diversity and richness was detected (data not shown). 


\section{SOIL ARCHAEAL COMMUNITIES UNDER DIFFERENT CROPPING REGIMES}

\section{Plant growth and biomass}

To analyse the effect of cropping system and regime on plant growth and yield, aboveground as well as belowground biomass were recorded. Although not been statically significant, a higher aboveground biomass of wheat plants was observed in intercropping systems compared to the monocultures (Figure 2). This is in line with recent studies in legume-cereal intercropping systems (e.g., Li et al., 1999; Li et al., 2001; Zhang et al,. 2004; Zhang et al,. 2015b). Zhang et al. (2004) found an increased maize yield in a maize/faba bean intercropping system due to an interspecific facilitation in phosphorus and nitrogen $(\mathrm{N})$ uptake. In a study of Inal et al. (2007), the shoot yield of intercropped maize and intercropped peanut was lower compared to monoculture plants. The authors suggested that this effect mainly results from root development shortage by associated maize or competition between the plants. In mixtures combining a cereal and a legume, cereals are more competitive than legumes in taking up $\mathrm{N}$ from the soil due to faster root development and demand (CorreHellou et al., 2006) which could explain the findings in the present study. However, Inal et al. (2007) observed a better nutrition of intercropped maize and peanut with several micronutrients. Recently, it was concluded that th beneficial effects of intercropping crop yields and/or nutrient supply resulted mainly from (positive) interspecific interactions in the rhizosphere (Li et al., 1999; Li et al., 2001; Zhang et al., 2004; Inal et al., 2007).

Interestingly, intercropped plants had a higher average root biomass when grown in rows (RI) compared to those grown with no distinct row arrangement (MI) or in monocultures (Figure 2). In addition, shoot/root ratio for faba bean decreased from monoculture over mixed intercropping to row intercropping becoming significant between FBM and RI (data not shown). This indicates a higher root biomass for faba bean in RI which in turn correspondsto increased environmental stress (Eghball and Maranville, 1993). 


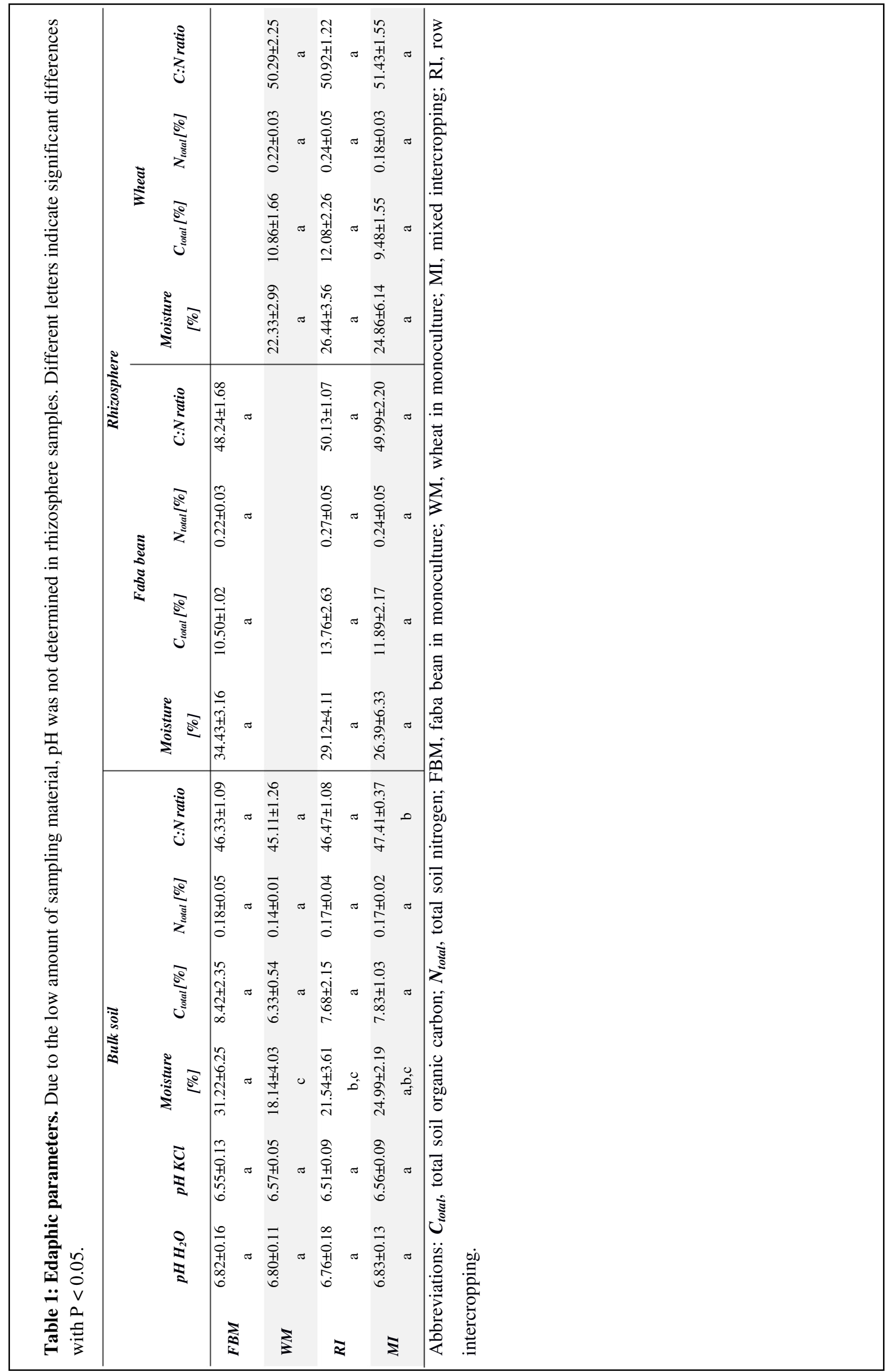



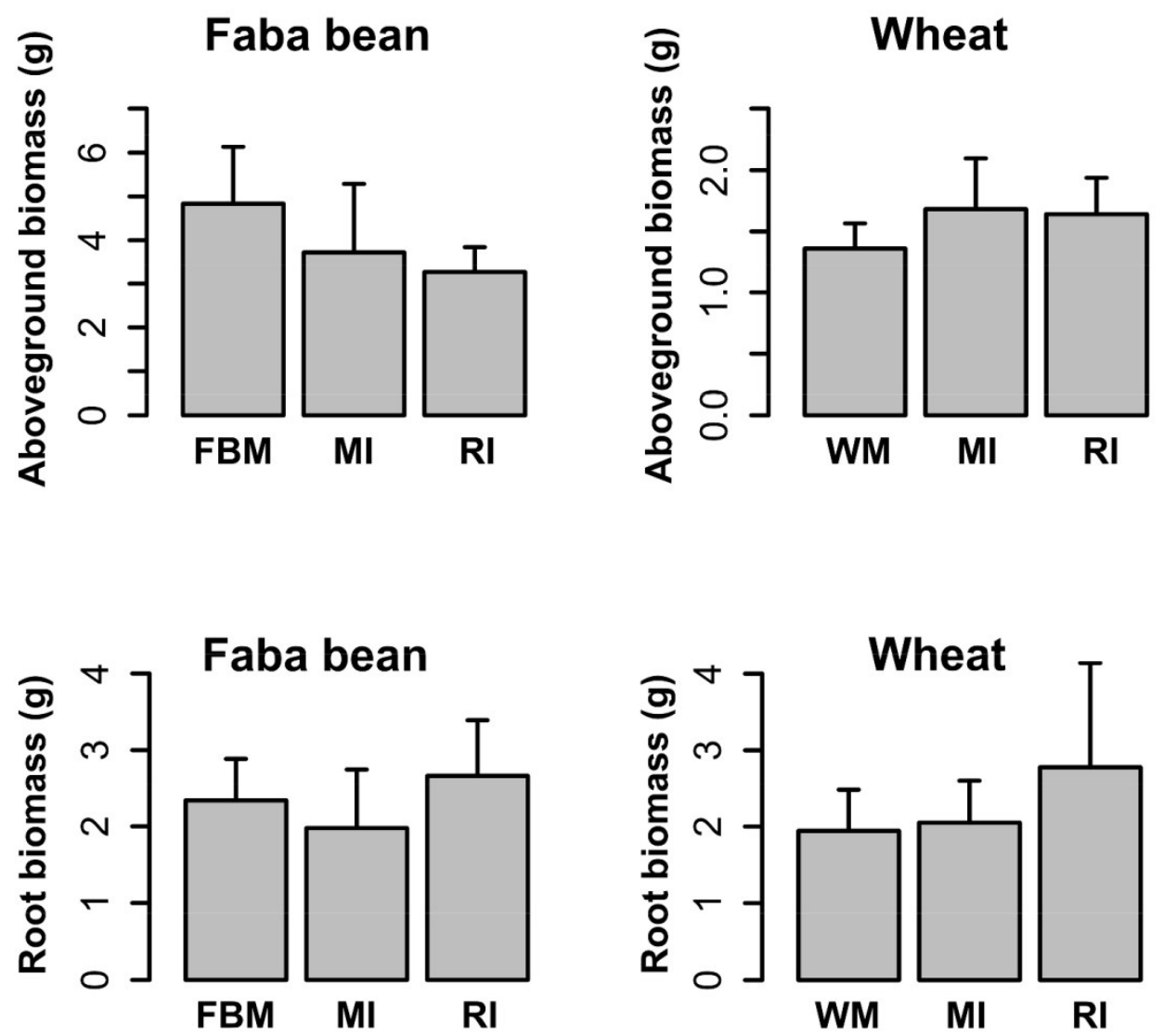

Figure 2. Average aboveground and root biomass per plant of faba bean (FBM) and wheat (WM) in monocultures as well as in mixed (MI) and row intercropping (RI).

Our results might be related to interspecific competition and facilitation that act on the crop plants in intercropping systems simultaneously (Li et al., 1999; Eghball and Maranville, 1993; Zhang and Li, 2003; Ghosh et al., 2006). Ghosh et al. (2006) showed that biological activities as well as several above- and belowground growth components were improved in intercropped sorghum but reduced in intercropped soybean indicating interspecies competition between the crops. In a study on low-input legume-cereal intercropping systems, the interaction between aboveground and belowground competition varied among species from negative to positive synergy and additivity (Mariotti et al., 2009). The authors concluded that the sowing time of the components and/or the design of the intercropping system should be modified to reduce the competition and to enhance facilitation effects.

\section{General characteristics of archaeal community structure}

To analyse and compare community structure and diversity of the soil archaeal communities, DNA was extracted from soil samples of faba bean and wheat plants grown in monoculture or in mixture. Subsequently, archaeal community composition and diversity were assessed by 
amplicon-based sequencing of the V4-V5 region of the 16S rRNA gene. Following quality filtering, denoising, and removal of potential chimeras and non-archaeal sequences, 47,998 high quality sequences with an average read length of 396 bp were used for analyzing archaeal community structures and diversity. Obtained sequences were clustered into 164 OTUs. Calculated rarefaction curves at 3\% genetic divergence (species level) revealed that the majority of the archaeal community was covered by the surveying effort (Figure 3). In addition, calculated coverage was 78.3\% (Supplementary Table S3).

\section{Bean monoculture}

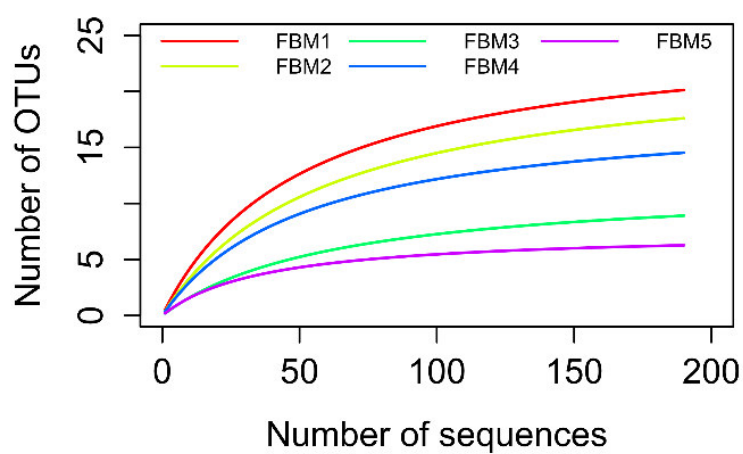

Mixed intercropping

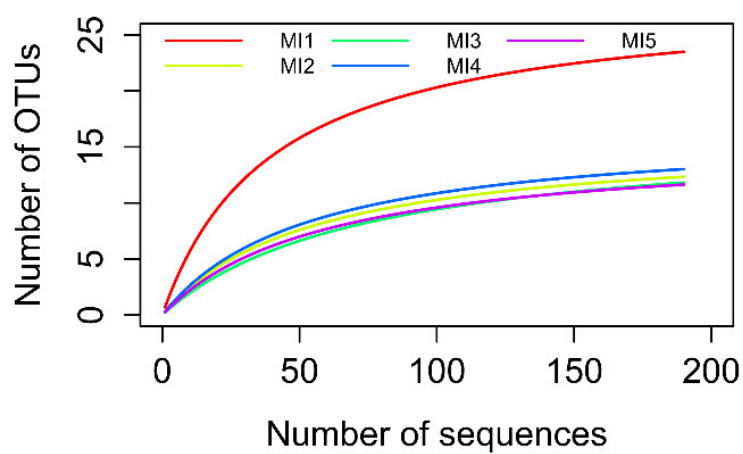

Wheat monoculture

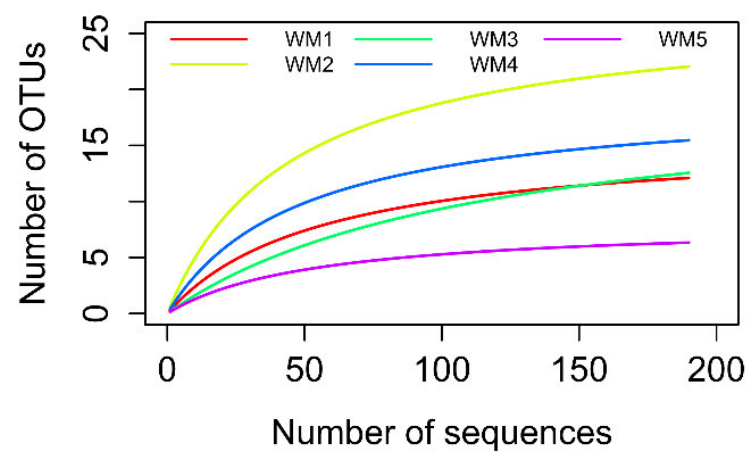

Row intercropping

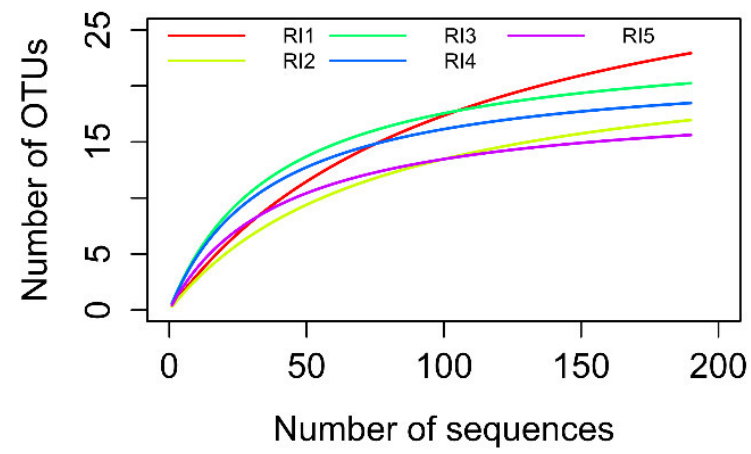

Figure 3: Rarefaction curves for five samples per cropping regime. Faba bean in monoculture (FBM1-5), wheat in monoculture (WM1-5) as well as faba bean and wheat in mixed (MI1-5) or row intercropping (RI1-5) are depicted.

Thaumarchaeota were identified as the dominant archaeal phylum across all samples (55.7\%) followed by Woesearchaeota (DHVEG-6) (26.7\%), Euryarchaeota (15.8\%) and the Miscellaneous Crenarchaeotic Group (1.7\%) (Figure 4). Thaumarchaeota were dominated by members of the Soil Crenarchaeotic Group and the terrestrial group. Within the Euryarchaeota, Methanobacteria were predominant, followed by Thermoplasmata and Methanomicrobia. These results were roughly in agreement with previous studies showing that Thaumarchaeota, the Miscellaneous Crenarchaeotic Group, and Euryarchaeota are common in a variety of different soils such as grassland, rainforest or agricultural soils (Etto 
et al., 2012; Chroňáková et al., 2015; Schneider et al., 2015). In a previous study on the influence of outdoor cattle husbandry on archaeal communities in four different grassland soils, Thaumarchaeota, Euryarchaeota as well as the Miscellaneous Crenarchaeotic Group were detected (Chroňáková et al., 2015). This is in line with the results of Schneider et al. (2015) who analysed the impact of rainforest transformation to intensively managed crop systems on prokaryotes. They found that the archaeal community was mainly represented by Thaumarchaeota as well as Euryarchaeota and in lower abundance by the Miscellaneous Crenarchaeotic Group.

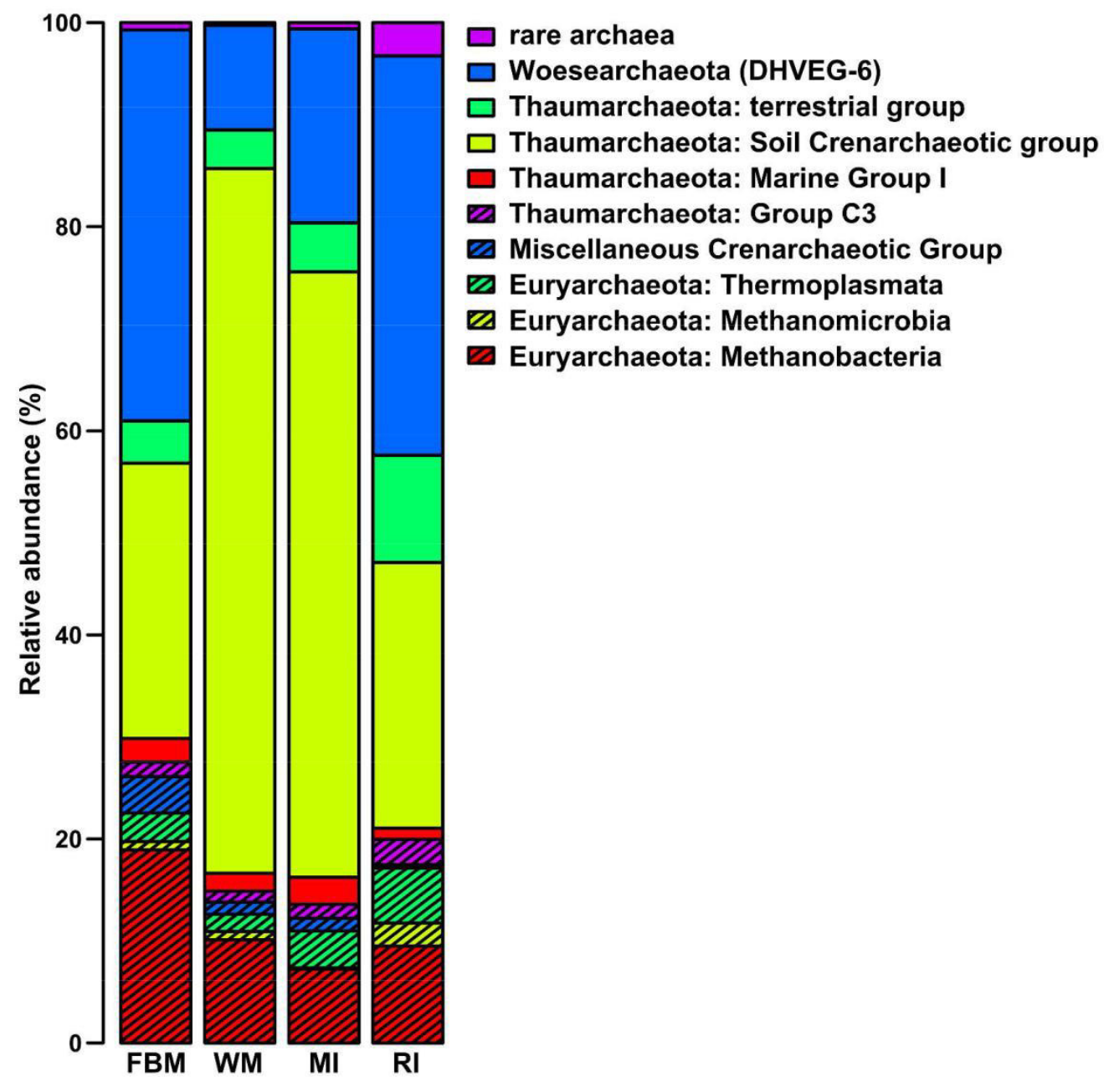

Figure 4. Average composition of the archeal community under the four cropping regimes faba bean monoculture (FBM), wheat monoculture (WM) as well as mixed (MI) and row intercropping (RI).

The occurrence of Woesearchaeota in soil samples of the present study is interesting, as members of this phylum dominated the surface waters of oligotrophic lakes (Ortiz-Alvarez and Casamayor, 2015) as well as the surface layer $(0-3 \mathrm{~cm})$ sediment of Lake Taihu (Fan and Xing, 2016). So far, most known archaeal genomes of this phylum are sediment- or groundwater-associated (Castelle et al., 2015). As Woesearchaeota are a relatively young 
phylum, knowledge about ecology and distribution of this phylum in other ecosystems such as soil is still rather limited.

\section{Diversity of archaeal community is altered by cropping system but not by crop species}

The diversity and richness of the archaeal communities did not differ between individually cropped wheat and faba bean plants (Supplementary Table S3). In contrast, Dorr de Quadros et al. (2012) investigated the archaeal and bacterial community in three legumes-cereal crop rotation systems in a subtropical Acrisol and found that the microbial diversity was higher in soil samples which were cultivated with cereals only. In two recent studies, the cultivation of different bioenergy crops significantly changed the abundance and diversity of ammoniaoxidizing, N-fixing and denitrifying organisms in soils (Mao, et al., 2011; 2013). The contrasting findings could be explained by the longer growth period of plants on experimental field sites, whereas a four-week greenhouse experiment was conducted in this study.

The archaeal richness in soil samples of the RI regime was higher than in soil samples derived from the other cropping regimes (Table S3 in the Supplements). However, statistical analysis revealed that the richness of soil archaeal communities was not affected by the different cropping regimes (data not shown). This finding might be related to the growth period of the plant in the present study which is supported by a previous study of Hargreaves et al. (2012). The authors observed that the cropping system influenced the diversity of bacteria and archaea only in July when plants are fully grown. Previous studies showed that a better growth of intercropped plants could improve the quantity and quality of root exudates and the turnover of root biomass, which benefits the growth of microorganisms in the rhizosphere (Chu et al., 2007; Yang et al., 2007). Compared to RI, plants in MI and in monoculture were grown in closer vicinity to other plants of the same and/or the other crop species, resulting in higher intra- and intraspecific competition, respectively. This could have influenced the nutrient availability and thus the archaeal diversity in soil. However, still little is known about the effect of multiple cropping systems and crop species on archaeal diversity as most previous studies focused only on ammonia-acidizing archaea (e.g., Mao et al., 2011; 2013).

\section{Crop species and cropping system altered the structure of soil archaeal communities}

Crop species as well as cropping regime influenced the archaeal community structure as well as the abundance of archaeal phyla and taxa (Figure 4). For example, the Miscellaneous 


\section{SOIL ARCHAEAL COMMUNITIES UNDER DIFFERENT CROPPING REGIMES}

Crenarchaeotic Group was more abundant in FBM than in the other cropping regimes. Legumes such as faba bean are well-known for their symbiosis with rhizobia which can improve soil fertility such as $\mathrm{N}$ content (Zahran, 1999). Thus, we suggest that members of this group favour nutrient rich soils. This is supported by the results of Chroňáková et al. (2015) who observed high abundances of the Miscellaneous Crenarchaeotic group in a nutrient rich, cattle-influenced grassland soil. In contrast to this, the Miscellaneous Crenarchaeotic Group was more abundant in managed soils with lower $\mathrm{C}: \mathrm{N}$ ratios than in soils of the other land-use systems such as rainforests (Schneider et al., 2015). Members of the Miscellaneous Crenarchaeotic Group have been found in a variety of different marine and continental habitats including subsurface ecosystems, soils or hydrothermal vents (as reviewed in Kubo et al., 2012). However, the ecological role of the Miscellaneous Crenarchaeotic Group is almost unknown.

Thaumarchaeota was the most abundant archaeal phylum in soil samples of cropping regimes WM and MI (75.8 and $68.6 \%$, respectively). Members of the Thaumarchaeota are widely distributed in moderate environments including soil (Nicol et al., 2003; Chroňáková et al., 2015; Schneider et al., 2015) and marine waters (Wemheuer et al., 2012), but are also found in extreme environments such as hot springs (Wemheuer et al., 2013) or hypersaline lakes (Schneider et al., 2013). In the last years, the phylum Thaumarchaeota gained more attention as it comprises all known ammonia-oxidizing archaea. Thus, this phylum plays an important role in the global $\mathrm{N}$ and $\mathrm{C}$ cycles (Pester et al., 2011). As only a few members of the Thaumarchaeota have been cultivated (Stahl and De la Torre, 2012), our knowledge of their ecological role in soil ecosystems is limited. However, all cultivated Thaumarchaeota are adapted to low concentrations of substrates, i.e. ammonia (Stieglmeier et al., 2014). This could explain the predominance of this phylum in the cropping regimes WM and MI due to the higher demand of wheat for $\mathrm{N}$ resulting in lower $\mathrm{N}$ concentrations. This is in agreement with the study of Chan et al. (2013). Here, the abundance of ammonia-oxidizing archaea was higher in maize than in alfalfa cultivation. The authors suggested that this is probably related to the high affinity of ammonia-oxidizing archaea for ammonia because the $\mathrm{N}$ availability was limited in maize cultivation due to the high $\mathrm{N}$ demand of maize. As we applied no fertilizer during the experiment, this fact could have also play a role for the archaeal community changes observed in this study.

Members of the Euryarchaeota were detected in higher abundances in soil of cropping regimes FBM and RI than in WM and MI. A comparison of this phylum at class level revealed that the relative abundance of Methanobacteria was higher in FMB, whereas 
Thermoplasmata and Methanomicrobia increased in soil of RI. Members of the euryarchaeotal classes Methanomicrobia and Methanobacteria are known as methanogens (Garrity et al., 2001) and are involved in sulfate reduction and the carbon cycle through methanogenesis in anoxic marine sediments (Lyimo et al., 2009). Thermoplasmata have been found in a wide range of environments such as soils and marine sediments (reviewed in Paul et al., 2012). Recently, members of this class have been detected as methylotrophic methanogens in bovine rumen with methylamines as their major energy and carbon sources, indicating their high potential as target in future strategies to mitigate methane emissions from ruminant livestock (Poulsen et al., 2013). Moreover, several species of the phylum Thermoplasmata play an important role in iron and sulphur cycling (Edwards et al., 2000). Thus, they may substantially improve the nutrient status of plants in RI which, in turns, resulted in a higher diversity of archaea as observed in the present study.

Interestingly, Woesearchaeota were the most abundant archaeal group in soil samples of FBM and RI. As mentioned above, genomes of this phylum are sediment- or groundwaterassociated (Castelle et al., 2015). The AR20 genome is the first complete genome of this phylum. Metabolic reconstruction indicates that most of the core biosynthetic pathways are partial or absent, such as glycolysis. However, the AR20 genome encodes genes for the synthesis of several traits indicating a symbiotic or parasitic lifestyle. It is possible that members of this phylum form close mutualistic relationships with faba bean as it is known for symbiotic bacteria (rhizobia).

Ordination analysis revealed that the cropping system (monoculture versus multiple cropping) affected the archaeal community composition as plants grown in monoculture regimes displayed a significant different community pattern compared to those grown under intercropping regimes (Figure 5A). We suggest that these changes are mainly attributed to the archaeal communities in RI regimes, which are different to community structures observed in monocultures and MI (Figure 5B). Similar results were observed in two previous studies (Wang et al., 2012; Breidenbach et al., 2015). Wang et al. (2012) analysed the effect of different cropping systems (monocultures vs. mixed cultures), crop species and soil type on the microbial community structure in three different soils by denaturing gradient gel electrophoresis. They found that ammonia-oxidizing-archaea and $\mathrm{N}_{2}$-fixer community composition were strongly influenced by crop species and cropping system indicating that these groups are quite sensitive to environmental conditions. Recently, Breidenbach et al. (2015) observed that crop rotation affected the archaeal community composition. In contrast, Chan et al. (2013) found only minor cropping effects on soil archaeal gene population 
dynamics. This is in accordance with a recent study showing that crop rotation influenced archaeal communities only slightly (Scavino et al., 2013; Watanabe et al., 2006).
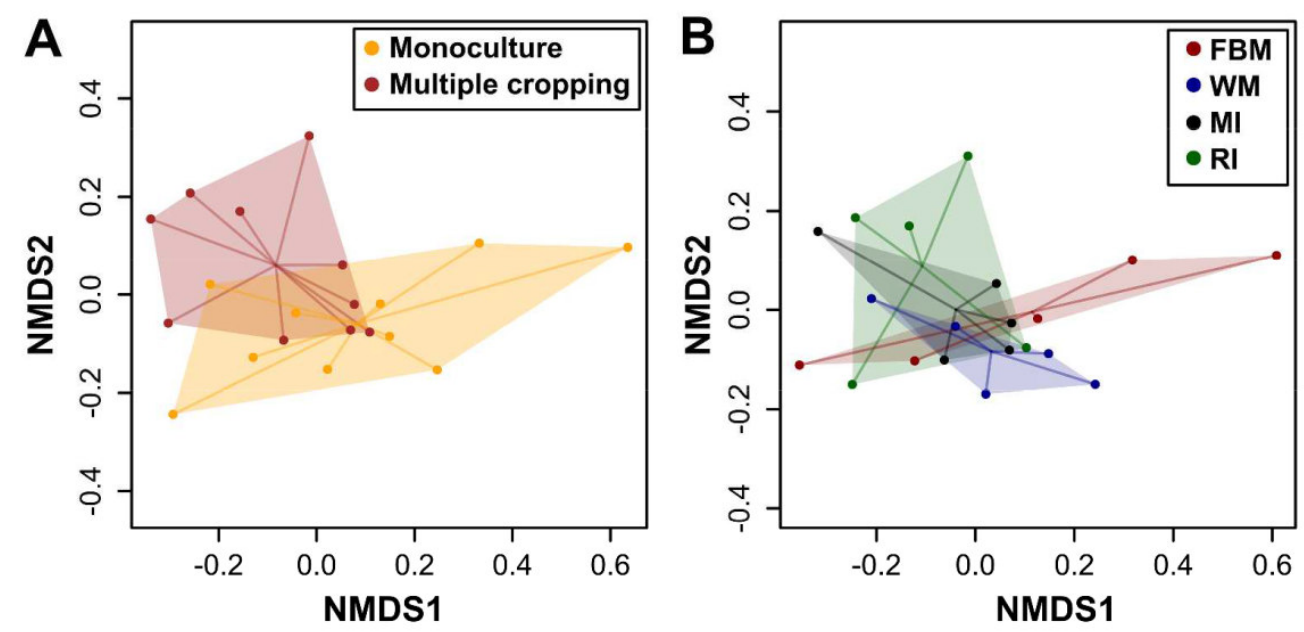

Figure 5. Effect of cropping system (A) and cropping regime (B) on archeal community structures.

Ordination analysis further revealed that there were no significant differences between archaeal community compositions of faba bean and wheat growing in monoculture (Figure 5B). This might be related to the short growing period. Zhang et al. (2015) found that growth stages of plants shaped the community compositions as well as in the abundance of ammoniaoxidizing archaea in the rhizospheres of faba bean and maize plants. Moreover, the authors detected an effect of plant species on these archaea. In contrast to this, Fan et al. (2011) showed that plant species did not significantly change the community structure of ammoniaoxidizing archaea. In another study, the ammonia-oxidizing archaeal communities were not affected by three different bioenergy crop species (Mao et al., 2013). Plant species effects on archaeal communities were detected in previous studies on two wetland plants (Llirós et al., 2014) and two contrasting vascular plants (Cadillo-Quiroz et al., 2010). Mao et al. (2011) showed that the planting of bioenergy crop species altered the archaeal community as well as $\mathrm{N}$-cycling genes in soil.

Although we could not detect any statistical influence of crop species growing in monoculture on archaeal community structure, several taxa differed in their abundance. We suggest two possible explanations for these effects. First, as plant species release specific root exudates and thereby select a specific community, the simultaneous growing of two or more plant species will result in a higher number and variety of root exudates. This was shown in two previous studies (Wu et al., 2009; Lamb et al., 2011). Wu et al. (2009) found that the composition of the archaeal community in a paddy field was affected by different rice cultivars, which varied in their quantity of organic root exudates. Lamb et al. (2011) observed 


\section{SOIL ARCHAEAL COMMUNITIES UNDER DIFFERENT CROPPING REGIMES}

that plant species richness had direct positive effects on archaeal amoA abundance. They suggested that with increasing complexity of the plant community more and different root exudates are distributed, which results in higher numbers of microbial niches in soil.

Secondly, the influence of plant species on archaeal communities can be related to differences in plant-specific traits, including rooting depth as well as litter quantity and quality (Gregory, 2006). Other reasons are secondary effects of plant species on soil $\mathrm{pH}$ and nutrient levels (Wardle, 1992; Lynch and Whipps, 1991), which might result in archaeal community compositional changes. Inal et al. (2007) found that the rhizosphere was modified by the roots of intercropped maize and peanut plants, which improved the availability of phosphorus (P) and iron $(\mathrm{Fe})$. Consequently, crops growing in multiple cropping systems interact with each other and the environment in an information feedback loop: the environment affects the plants, and the plants affect the environment (Malézieux et al., 2009). This is supported by the results of the present study as plants of faba bean and wheat under different cropping regimes interact with each other and their environment including soil archaeal communities in diverse ways.

To identify potential indicators for the two crop species faba bean or wheat, cropping system (monoculture versus multiple cropping) and the four cropping regimes (FBM, WM, RI or MI), multipattern analysis was applied. Several OTUs had significant indicator potential and were therefore strongly associated with a certain cropping regime (Table 2). Interestingly, no OTU was significantly associated with monoculture wheat plants, while several OTUs including Methanobacterium sp. and Methanomassilicoccus sp. were associated with monoculture faba bean (Table 2). Methanobacterium sp. and Methanomassiliicoccus sp. are known as anaerobic methanogenic archaea. Methanobacterium was isolated from sewage sludge and is also capably of autotrophy/ autotrophic growth (Zeikus and Wolee, 1972), whereas Methanomassiliicoccus luminyensis (order Methanomassiliicoccales) was first isolated from human faeces (Dridi et al., 2012). Interestingly, members of the Methanomassiliicoccales have an energy metabolism distinct from other methanogens (Söllinger et al., 2015). However, two uncultured archaeal OTUs were even better indicators for faba bean and could be found in each soil in which only faba bean was grown ( $\mathrm{B}=1$ in both cases). They belonged to the Woesearcheota and the Miscellaneous Crenarchaeotic Group. Furthermore, a member of the Thermoplasmatales Marine Group II could be identified as a good indicator for multiple cropping systems, and was additionally present in all RI soils. 
Table 2. Results of the indicator species analysis showing potential indicative archaeal OTUs for the different crop species, cropping systems and cropping regimes. Statistical values: A - species only occurs in sites of this group, B - all sites of this group harbour this species.

\begin{tabular}{llll}
\hline Indicator group & archeal $\boldsymbol{O T U}$ & $\boldsymbol{A}$ & $\boldsymbol{B}$ \\
\hline Crop species & & & \\
& uncultured Woesearcheota archeon & 0.9632 & 1 \\
& uncultured crenarcheote (misc. crenarcheaotic group) & 0.8754 & 1 \\
FBM & uncultured thaumarcheaon & 0.7826 & 0.8 \\
& Methanomassiliicoccus sp. & 0.9787 & 0.6 \\
& Methanobacterium sp. & 0.8333 & 0.6 \\
Multiple & uncultured Thaumarcheota terrestrial group & 0.9083 & 0.9333 \\
cropping & crenarcheaote & &
\end{tabular}

Cropping system (Mono vs. Multiple)

$\begin{array}{llll}\text { Multiple } & \text { Thermoplasmatales Marine Group II archeaon } & 0.9153 & 0.7 \\ \text { cropping } & & & \end{array}$

\section{Cropping regime (FBM, WM, MI and $R I)$}

\begin{tabular}{|c|c|c|c|}
\hline \multirow{3}{*}{ FBM } & uncultured Woesearcheota archeon & 0.9325 & 1 \\
\hline & uncultured crenarcheote (misc. crenarcheaotic group) & 0.8075 & 1 \\
\hline & Methanomassiliicoccus sp. & 0.9583 & 0.6 \\
\hline \multirow{2}{*}{ RI } & Thermoplasmatales Marine Group II archeaon & 0.7119 & 1 \\
\hline & uncultured Thermoplasmatales archeaon & 0.9444 & 0.6 \\
\hline $\begin{array}{l}\text { FBM, MI and } \\
\text { RI }\end{array}$ & $\begin{array}{l}\text { uncultured Thaumarcheota terrestrial group } \\
\text { crenarcheaote }\end{array}$ & 0.9228 & 0.9333 \\
\hline
\end{tabular}




\section{Conclusion}

Due to the prevalent role of archaea in biogeochemical cycling and thus in agriculture, it is important to assess structural responses of these communities to crop species and cropping systems. In this study, the archaeal community in soil of wheat and bean grown in monoculture or as multiple cropping system were investigated. In addition, aboveground and root biomass were measured. The biomass of the two crop species did not significantly vary between the four different cropping regimes, although the root biomass of monoculture wheat plants tended to be higher than that of intercropped wheat plants. This is in contrast to our hypothesis (1) that intercropping would result in higher biomass of wheat plants and in turn to a decreased bean biomass. According to our hypothesis (2), crop species as well as cropping regimes influenced the archaeal community structure and/or the abundance of several taxa. Moreover, we found a clear separation of soil archaeal communities by monoculture and multiple cropping system. Contrary to our hypothesis (2), diversity and richness of the archaeal communities did not differ between individually cropped wheat and faba bean plants. In contrast to this, we observed a higher diversity in row intercropping systems than in monoculture or mixed intercropping which is partly in line with our hypothesis (3). We suggest that this is the result of the intra- and interspecific interactions between plants, edaphic parameters, and archaeal communities. In the near future, we will analyse the response of soil archaea to cropping systems under field conditions. This will enable us to better understand the ecology and functions of soil archaea in intercropping systems. 


\section{Acknowledgements}

We thank Prof. Dr. Wolfgang Link from the Working Group "Breeding Research Faba Bean" (Division of Plant Breeding at the University of Göttingen) for providing the seed material and Dr. Bernd Wemheuer for designing the archaeal primers. This study is part of the project IMPAC $^{3}$ and was funded by the Federal Ministry of Education and Research (FKZ 031A351A). 


\section{References}

1. Andrews D, Kassam A. (1976). The importance of multiple cropping in increasing world food supplies. American Society of Agronomy.

3. Breidenbach B, Blaser MB, Klose M, Conrad R. (2015) Crop rotation of flooded rice with upland maize impacts the resident and active methanogenic microbial community. Environ Microbiol doi:10.1111/1462-2920.13041.

4. Cadillo-Quiroz H, Yavitt JB, Zinder SH, Thies JE. (2010). Diversity and community structure of archaea inhabiting the rhizoplane of two contrasting plants from an acidic bog. Microbial Ecol 59:757-767.

5. Camacho C, Coulouris G, Avagyan V, Ma N, Papadopoulos J, Bealer K, et al. (2009). BLAST+: architecture and applications. BMC Bioinformatics 10:1-9.

6. Caporaso JG, Kuczynski J, Stombaugh J, Bittinger K, Bushman FD, Costello EK, et al. (2010) QIIME allows analysis of high-throughput community sequencing data. Nat Methods 7:335-6.

7. Castelle CJ, Wrighton KC, Thomas BC, Hug LA, Brown CT, Wilkins MJ, et al. (2015) Genomic expansion of domain archaea highlights roles for organisms from new phyla in anaerobic carbon cycling. Curr Biol 25:690-701.

8. Chan Y-K, McCormick WA, Ma BL. (2013) Effects of inorganic fertilizer and manure on soil archaeal abundance at two experimental farms during three consecutive rotationcropping seasons. Appl Soil Ecol 68:26-35.

9. Chroňáková A, Schloter-Hai B, Radl V, Endesfelder D, Quince C, et al. (2015) Response of archaeal and bacterial soil communities to changes associated with outdoor cattle overwintering. PLoS ONE 10:e0135627.

10. Chu H, Lin X, Fujii T, Morimoto S, Yagi K, Hu J, et al. (2007). Soil microbial biomass, dehydrogenase activity, bacterial community structure in response to long-term fertilizer management. Soil Biol Biochem 39:2971-6.

11. Corre-Hellou G, Fustec J, Crozat Y. (2006). Interspecific competition for soil N and its interaction with $\mathrm{N} 2$ fixation, leaf expansion and crop growth in pea-barley intercrops. Plant Soil 282:195-208.

12. de Cáceres MD, Legendre P. (2009). Associations between species and groups of sites: indices and statistical inference. Ecology 90:3566-3574. 
13. Dorr de Quadros P, Zhalnina K, Davis-Richardson A, Drew J, Bayer C, Camargo FAO et al. (2012). The effect of tillage system and crop rotation on soil microbial diversity and composition in a subtropical Acrisol. Diversity 4:375-95.

14. Dridi B, Fardeau M-L, Ollivier B, Raoult D, Drancourt M. (2012). Methanomassiliicoccus luminyensis gen. nov., sp. nov., a methanogenic archaeon isolated from human faeces. Int J Syst Evol Micr 62:1902-7.

15. Edgar RC. (2010). Search and clustering orders of magnitude faster than BLAST. Bioinformatics 26:2460-2461.

16. Edwards KJ, Bond PL, Gihring TM, Banfield JF. (2000). An archaeal iron-oxidizing extreme acidophile important in acid mine drainage. Science 287:1796-1799.

17. Eghball B, Maranville JW. (1993). Root development and nitrogen influx of corn genotypes grown under combined drought and nitrogen stresses. Agron J 85:147-152.

18. Etto RM, Cruz LM, Jesus EC, Galvão CW, Galvão F, Souza EM, et al. (2012). Prokaryotic communities of acidic peatlands from the southern Brazilian Atlantic Forest. Braz J Microbiol 43:661-74.

19. Fan F, Zhang F, Lu Y. (2011). Linking plant identity and interspecific competition to soil nitrogen cycling through ammonia oxidizer communities. Soil Biol Biochem 43:46-54.

20. Fan X, Xing P. (2016) The vertical distribution of sediment archaeal community in the "black bloom” disturbing Zhushan Bay of Lake Taihu. Archaea 8232135.

21. Francis CA. (1986). Multiple cropping systems. Macmillan Publishing Company: New York.

22. Francis CA. (1989). Biological efficiencies in multiple-cropping systems. Adv Agron 42:1-42.

23. Garrity GM, Holt JG, Whitman WB, Keswani J, Boone DR, Koga Y, et al. (2001) Phylum All. Euryarchaeota phy. nov. In: Boone DR, Castenholz RW, Garrity GM (eds.). Bergey’s Manual ${ }^{\circledR}$ of Systematic Bacteriology. Springer: New York, 211-355.

24. Gattinger A, Hofle MG, Schloter M, Embacher A, Böhme F, Munch JC, et al. (2007). Traditional cattle manure application determines abundance, diversity and activity of methanogenic Archaea in arable European soil. Environ Microbiol 9:612-624.

25. Ghosh PK, Manna MC, Bandyopadhyay KK, Ajay, Tripathi AK, Wanjari RH, et al. (2006). Interspecific interaction and nutrient use in soybean/sorghum intercropping system. Agron J 98:1097-1108.

26. Gregory P. (2006). Roots, rhizosphere and soil: the route to a better understanding of soil science? Eur J Soil Sci 57:2-12. 


\section{SOIL ARCHAEAL COMMUNITIES UNDER DIFFERENT CROPPING REGIMES}

26. Hargreaves SK, Williams RJ, Hofmockel KS. (2015). Environmental filtering of microbial communities in Agricultural Soil Shifts with Crop Growth. PLoS ONE 10:e0134345.

27. He Z, Wu J, O’Donnell A, Syers J. (1997). Seasonal responses in microbial biomass carbon, phosphorus and sulphur in soils under pasture. Biol Fert Soils 24:421-428.

28. Inal A, Gunes A, Zhang F, Cakmak I. (2007). Peanut/maize intercropping induced changes in rhizosphere and nutrient concentrations in shoots. Plant Physio Bioch 45:350356.

29. Jensen ES. (1996). Grain yield, symbiotic $\mathrm{N}_{2}$ fixation and interspecific competition for inorganic $\mathrm{N}$ in pea-barley intercrops. Plant Soil 182:25-38.

30. Kubo K, Lloyd KG, Biddle JF, Amann R, Teske A, Knittel K. (2012). Archaea of the Miscellaneous Crenarchaeotal Group are abundant, diverse and widespread in marine sediments. ISME J 6:1949-1965.

31. Lamb EG, Kennedy N, Siciliano SD. (2011). Effects of plant species richness and evenness on soil microbial community diversity and function. Plant Soil 338:483-95.

32. Li L, Yang S, Li X, Zhang F, Christie P. (1999). Interspecific complementary and competitive interactions between intercropped maize and faba bean. Plant Soil 212:105114.

33. Li L, Sun J, Zhang F, Li X, Yang S, Rengel Z. (2001). Wheat/maize or wheat/soybean strip intercropping: I. Yield advantage and interspecific interactions on nutrients. Field Crops Res 1:123-37.

34. Liu D, Ishikawa H, Nishida M, Tsuchiya K, Takahashi T, Kimura M, et al. (2015). Effect of paddy-upland rotation on methanogenic archaeal community structure in paddy field soil. Microb Ecol 69:160-168.

35. Llirós M, Trias R, Borrego C, Bañeras L. (2014). Specific archaeal communities are selected on the root surfaces of Ruppia spp. and Phragmites australis. Wetlands 34:40311.

36. Lyimo TJ, Pol A, Jetten MS, Op den Camp HJM. (2009). Diversity of methanogenic archaea in a mangrove sediment and isolation of a new Methanococcoides strain. FEMS Microbiol Ecol 291:247-53.

37. Lynch JM, Whipps JM. (1990). Substrate flow in the rhizosphere. Plant Soil 129:1-10.

38. Malézieux E, Crozat Y, Dupraz C, Laurans M, Makowski D, Ozier-Lafontaine H, et al. (2009). Mixing plant species in cropping systems: concepts, tools and models: a review. Agron Sustain 29:43-62. 
39. Mao Y, Yannarell AC, Mackie RI. (2011). Changes in N-transforming archaea and bacteria in soil during the establishment of bioenergy crops. PLoS ONE 6:e24750.

40. Mao Y, Yannarell AC, Davis SC, Mackie RI. (2013). Impact of different bioenergy crops on N-cycling bacterial and archaeal communities in soil. Environ Microbiol 15:928-942.

41. Mariotti M, Masoni A, Ercoli L, Arduini I. (2009). Above- and below-ground competition between barley, wheat, lupin and vetch in a cereal and legume intercropping system. Grass Forage Sci 64:401-12.

42. Matson PA, Parton WJ, Power AG, Swift MJ. (1997). Agricultural intensification and ecosystem properties. Science 277:504-509.

43. Nicol GW, Glover LA, Prosser JI. (2003). The impact of grassland management on archaeal community structure in upland. Environ Microbiol 5:152-162.

44. Offre P, Spang A, Schleper C. (2013). Archaea in biogeochemical cycles. Ann Review Microbiol 67:437-457.

45. Oksanen J, Blanchet FG, Kindt R, Legendre P. Michin PR, O'Hara RB, et al. (2013). Vegan: community ecology package. R package version 2.0-10.

46. Ortiz-Alvarez R, Casamayor EO. (2015). High occurrence of Pacearchaeota and Woesearchaeota (Archaea superphylum DPANN) in the surface waters of oligotrophic high-altitude lakes. Environ Microbiol Rep 8:210-217.

47. Paul K, Nonoh JO, Mikulski L et al. "Methanoplasmatales," Thermoplasmatales-related archaea in termite guts and other environments, are the seventh order of methanogens. Appl Environ Microbiol 78:8245-8253.

48. Paulsen HM, Schochow M, Ulber B, Kühne S, Rahmann G. (2006). Mixed cropping systems for biological control of weeds and pests in organic oilseed crops. Aps Appl Biol 79:215-220.

49. Pester M, Schleper C, Wagner M. (2011). The Thaumarchaeota: an emerging view of their phylogeny and ecophysiology. Curr Opin Microbiol 14:300-306.

50. Poulsen M, Schwab C, Jensen BB, Engberg RM, Spang A, Canibe N, et al. (2013). Methylotrophic methanogenic Thermoplasmata implicated in reduced methane emissions from bovine rumen. Nature Commun 4:1428.

51. Quast C, Pruesse E, Yilmaz P, Gerken J, Schweer T, Yarza P, et al. (2013). The SILVA ribosomal RNA gene database project: improved data processing and web-based tools. Nucleic Acids Res 41:D590-6.

52. R Core Team. (2014). R: A Language and Environment for Statistical Computing. R Foundation for Statistical Computing, Vienna. 
53. Scavino AF, Ji Y, Pump J, Klose M, Claus P, Conrad R. (2013). Structure and function of the methanogenic microbial communities in Uruguayan soils shifted between pasture and irrigated rice fields. Environ microbiol 15:2588-2602.

52. Schneider D, Arp G, Reimer A, Reitner J, Daniel R. (2013). Phylogenetic analysis of a microbialite-forming microbial mat from a hypersaline lake of the Kiritimati Atoll, Central Pacific. PLoS ONE 8: e66662.

53. Schneider D, Engelhaupt M, Allen K, Kurniawan S, Krashevska V, et al. (2015) Impact of lowland rainforest transformation on diversity and composition of soil prokaryotic communities in Sumatra (Indonesia). Front Microbiol 6:1339.

54. Stahl DA, de la Torre JR. (2012) Physiology and diversity of ammonia-oxidizing archaea. Annu Rev Microbiol 66:83-101.

55. Söllinger A, Schwab C, Weinmaier T, Loy A, Tveit AT, Schleper C, et al. (2016). Phylogenetic and genomic analysis of Methanomassiliicoccales in wetlands and animal intestinal tracts reveals clade-specific habitat preferences. FEMS Microbiol Ecol 92:fiv149.

56. Stieglmeier M, Alves RJ, Schleper C. (2014). The Phylum Thaumarchaeota. In: Rosenberg E, DeLong EF, Lory S, Stackebrandt E, Thompson F (eds.). The Prokaryotes. Springer: Berlin Heidelberg, 347-362.

57. Wang Y, Marschner P, Zhang F. (2012). Phosphorus pools and other soil properties in the rhizosphere of wheat and legumes growing in three soils in monoculture or as a mixture of wheat and legume. Plant Soil 354:283-298.

58. Wardle D. (1992). A comparative assessment of factors which influence microbial biomass carbon and nitrogen levels in soil. Biol Rev 67:321-58.

59. Watanabe T, Kimura M, Asakawa S. (2006). Community structure of methanogenic archaea in paddy field soil under double cropping (rice-wheat). Soil Biol Biochem 38:1264-1274.

60. Wemheuer B, Wemheuer F, Daniel R. (2012). RNA-based assessment of diversity and composition of active archaeal communities in the German Bight. Archaea 695826.

61. Wemheuer B, Taube R, Akyol P, Wemheuer F, Daniel R. (2013). Microbial diversity and biochemical potential encoded by thermal spring metagenomes derived from the Kamchatka Peninsula. Archaea 136714.

62. Wemheuer B, Güllert S, Billerbeck S, Giebel H-A, Voget S, Simon M, et al. (2014). Impact of a phytoplankton bloom on the diversity of the active bacterial community in 
the southern North Sea as revealed by metatranscriptomic approaches. FEMS Microbiol Ecol 87:378-389.

63. Wietz M, Wemheuer B, Simon H, Giebel H-A, Seibt MA, Daniel R, et al. (2015). Bacterial community dynamics during polysaccharide degradation at contrasting sites in the Southern and Atlantic Oceans. Environ Microbiol 17:3822-3831.

64. Willey RW. (1979). Intercropping - its importance and research needs. Part 1, Competition and yield advantages. Field Crop Abst 12:1-10.

65. Winter M, de Mol F, von Tiedemann A. (2014). Cropping systems with maize and oilseed rape for energy production may reduce the risk of stem base diseases in wheat. Field Crops Res 156:249-257.

66. Wu L, Ma K, Li Q, Ke X, Lu Y. (2009). Composition of Archaeal Community in a Paddy Field as Affected by Rice Cultivar and N Fertilizer. Microb Ecol 58:819-826.

67. Yang R, Tang J, Chen X, Hu S. (2007). Effects of coexisting plant species on soil microbes and soil enzymes in metal lead contaminated soils. Appl Soil Ecol 37:240-246.

68. Zahran HH. (1999). Rhizobium-legume symbiosis and nitrogen fixation under severe conditions and in an arid climate. Microbiol Mol Biol Rev 63:968-989.

69. Zeikus JG, Wolee RS. (1972). Methanobacterium thermoautotrophicus sp. n., an anaerobic, autotrophic, extreme thermophile. J Bacteriol 109:707-713.

70. Zhang F, Li L. (2003). Using competitive and facilitative interactions in intercropping systems enhances crop productivity and nutrient-use efficiency. Plant Soil 248:305-312.

71. Zhang F, Shen J, Li L, Liu X. (2004). An overview of rhizosphere processes related with plant nutrition in major cropping systems in China. Plant Soil 260:89-99.

72. Zhang NN, Sun YM, Wang ET, Yand JS, Yuan HL, Scow KM. (2015a). Effects of intercropping and rhizobial inoculation on the ammonia-oxidizing microorganisms in rhizospheres of maize and faba bean plants. Appl Soil Ecol 85:76-85.

73. Zhang Y, Liu J, Zhang J, Liu H, Liu S, Zhai L, Wang H, et al. (2015b). Row ratios of intercropping maize and soybean can affect agronomic efficiency of the system and subsequent wheat. PLoS One 10:e0129245. 
SOIL ARCHAEAL COMMUNITIES UNDER DIFFERENT CROPPING REGIMES

\section{SUPPLEMENTARY INFORMATION}

Supplementary figures and tables are provided along with the electronic version of this thesis (on DVD), under the following paths:

Table S1:

Table S2:

Table S3:
Supplementary Information/Chapter III.7/ Table S1.docx Supplementary Information/Chapter III.7/ Table S2.docx

Supplementary Information/Chapter III.7/ Table S3.doc 


\section{CHAPTER III.8.}

MicRobial COMMUNitiES UNDER CROPPING REGIMES 
III.8.

For submission to Frontiers in Microbiology (Specialty Section: Plant Biotic Interactions)

\section{Differences between soil and endophytic microbial diversity of wheat (Triticum aestivum L.) and faba bean (Vicia faba L.) in monoculture and intercropping}

Running title: Microbial communities under cropping regimes

Sandra Granzow ${ }^{1, \dagger}$, Kristin Kaiser ${ }^{2, \dagger}$, Bernd Wemheuer ${ }^{2}$, Birgit Pfeiffer $^{3}$, Rolf Daniel ${ }^{2}$, Stefan Vidal $^{1}$, Franziska Wemheuer ${ }^{1, *}$

${ }^{1}$ Section of Agricultural Entomology, Department of Crop Sciences, Georg-August-University Göttingen, Grisebachstr.6, D-37077 Göttingen, Germany.

${ }^{2}$ Department of Genomic and Applied Microbiology, Institute of Microbiology and Genetics, Georg-August-University Göttingen, Grisebachstr. 8, D-37077 Göttingen, Germany.

${ }^{3}$ Plant Nutrition and Crop Physiology, Department of Crop Sciences, Georg-August-University Göttingen, Carl-Sprengel-Weg 1, D-37075 Göttingen, Germany

Author contributions:

${ }^{\dagger}$ These authors contributed equally to this work.

Study design: SV, FW

Data acquisition and analysis: SG, KK, BW, BP, FW

Wrote the manuscript: SG, KK, BW, FW, BP

All authors were involved in interpreting results and revision of the manuscript. 


\section{MICROBIAL COMMUNITIES UNDER CROPPING REGIMES}

\section{Abstract}

Multiple cropping systems provide many economic and ecological advantages. They have been shown to enhance plant productivity and offer great potential in sustainable intensification of agriculture. Thus, it is of crucial importance to understand the response of microbial communities towards these cropping systems. Bacterial and fungal soil communities are known to be influenced by cropping system or by crop plant, but little is known about the effects of multiple cropping systems on endophytic communities and the interactions between these communities. Here, we studied bacterial and fungal communities in bulk and rhizosphere soils as well as in the roots and leaves of wheat and faba bean plants growing in monoculture and in two multiple cropping regimes. Cropping regime and crop plant did not affect microbial community composition, but microbial communities were different between the different sampling locations investigated. This effect was more pronounced for bacteria than fungi, probably due to the active mode of colonization employed by fungi. Multipattern analyses revealed that differences in bacterial community composition between plant compartments are most likely caused by proteobacterial endophytes strongly associated with either leaves or roots. Co-occurrence networks analysis showed strong negative interactions between fungal OTUs, indicating strong competition and probably niche adaptation by specialized fungal taxa. In addition, differences in the richness and diversity between the crop plants were recorded. To our knowledge, this is one of the first studies investigating the bacterial and fungal community in rhizosphere, soil and endosphere with regard to multiple cropping by using high-throughput next generation sequencing.

\section{Introduction}

In the last decades, multiple (or mixed) cropping systems have come into the focus of interest due to their potential for a sustainable intensification of agriculture (Vandermeer, 1992). They provide enhanced ecological and economical services such as a reduction of pest damages and herbivore density (Francis, 1986; Letourneau et al., 2011; Winter et al., 2014). In addition, multiple cropping systems enhance plant productivity by improving a more efficient use of available resources (Hauggaard-Nielsen and Jensen, 2005; Aziz et al., 2015). Recently, it was suggested that an enhanced yield may also be the result of (positive) interspecific interactions in the rhizosphere (Li et al., 1999; Inal et al., 2007) or of changes in microbial and chemical properties in the soil (Song et al., 2007b).

Microorganisms including bacteria and fungi play essential roles in biogeochemical cycling and thus, ecosystem functioning (Ellouze et al., 2014; van der Heijden and Hartmann, 2016). They 


\section{MICROBIAL COMMUNITIES UNDER CROPPING REGIMES}

have been found in almost every environment such as the plant microbiome (Lugtenberg and Kamilova, 2009; Turner et al., 2013a; Berg et al., 2014; van der Heijden and Hartmann, 2016). Many bacteria and fungi in the plant's rhizosphere and endosphere are beneficial to plant nutrition acquisition, health and growth (Kent and Triplett, 2002; Lugtenberg and Kamilova, 2009; Philippot et al., 2013). These microorganisms may also alleviate abiotic stress conditions of their host plants (Malinowski and Belesky, 2000; De Zelicourt et al., 2013; Timmusk et al., 2014). In addition, they can enhance resistance of the host plant against biotic stressors such as herbivores or pathogens (Siddiqui and Shaukat, 2003; Dematheis et al., 2013; Vidal and Jaber, 2015). Therefore, these microorganisms play an important role in agricultural production.

In the last years, the number of studies investigating the effect of agricultural practices such as cropping systems on the plant microbiome in endo- and rhizosphere has increased (e.g. Wang et al., 2012; Murugan and Kumar, 2013; Nettles et al., 2016; Taheri et al., 2016). Song et al. (2007a) analyzed ammonia-oxidizing bacteria in the rhizosphere of intercropped wheat, maize and faba bean using denaturing gradient gel electrophoresis (DGGE). They found that the community composition of these bacteria differed between intercropping systems and monocultures. However, most previous research focused only on microorganism in the rhizosphere and/ or on ammoniaoxidizing bacteria (Song et al., 2007a; Zhang et al., 2015; Li et al., 2016). So far, the interactions between fungal and bacterial communities in soil, rhizosphere and endosphere in the agricultural important crop species under different cropping systems have not been studied simultaneously using high-throughput next generation sequencing.

Hence, the aim of the present study was to investigate structural and functional responses of fungal and bacterial communities in soil, rhizosphere and endosphere towards different cropping systems. This experiment is part of the IMPAC ${ }^{3}$ project ("Novel genotypes for mixed cropping allow for improved sustainable land use across arable land, grassland and woodland"). To assess structural changes of the fungal and bacterial communities, the two agricultural important crop species common wheat (Triticum aestivum L.) and faba bean (Vicia faba L.) were grown in monoculture or in two intercropping regimes as defined by Andrews and Kassam (1976): without any arrangement (mixed intercropping) or in distinct rows (row intercropping).

Bacterial and fungal communities in bulk and rhizosphere soil as well as in aerial and root endosphere were examined using Illumina (MiSeq) sequencing targeting the bacterial 16S rRNA gene and the fungal internal transcribed spacer (ITS), respectively. In addition, we used this unique dataset to calculate functional profiles with Tax4Fun (Aßhauer et al., 2015). Additionally, fungal OTUs were parsed into ecological guilds using FUNGuild (Nguyen et al., 2016). We hypothesized (1) that crop species as well as cropping regime affect microbial community and diversity. In addition, we expected (2) that microbial communities in bulk and rhizosphere soil as well as in the 


\section{MICROBIAL COMMUNITIES UNDER CROPPING REGIMES}

endosphere exhibit distinct microbial patterns. We further hypothesized (3) that factors altering the community composition in soil and endosphere will also affect microbial functioning. However, we assumed (4) that these effects would be more pronounced in endophyte communities in roots compared to those in aerial plant parts as well as in microbial communities in rhizosphere soil compared to bulk soil.

\section{Material and Methods}

\section{Experimental design}

To examine the influence of different cropping systems on the entire fungal and bacterial community in soil and endosphere, a semi-open greenhouse experiment with plants growing under normal diel illumination conditions was conducted in summer 2015. The two crop species faba bean (genotype: Hiverna) and wheat (genotype: Hybery) were cultured in monoculture or as mixture in polypropylene containers (Semadeni, Eurobehälter, LogiLine ${ }^{\circledR}$ SGL Boden, 600 x 400 x 212 mm), containing 75\% sterile commercial plant substrate (Fruhstorfer Erde Typ T25; N: 200-300 mg L ${ }^{-1}$, $\mathrm{P}_{2} \mathrm{O}_{5}$ : 200-300 $\mathrm{mg} \mathrm{L}^{-1}$; Hawita Gruppe GmbH Vechta, Germany) and 25\% sand. This plant substrate is a peaty soil with a $\mathrm{pH}\left(\mathrm{CaCl}_{2}\right)$ of 5.5 to 6.5 . For monocropping systems, twenty faba bean (FBM) or eighty wheat (WM) plants per container were grown in rows. In multiple cropping systems, forty wheat and ten faba bean plants per container were grown either in distinct rows (row intercropping; RI) or without any arrangement (mixed intercropping; MI). The four different cropping regimes were replicated five times in a randomized design. All plants were irrigated daily. To increase nutrient-limitation as well as intra- and interspecies interactions between the plants, no fertilization was applied.

\section{Soil sampling and edaphic parameters}

Soil samples were collected after a growing period of four weeks. We sampled the rhizosphere soil, defined as soil tightly adhering to the roots, and the bulk soil, defined as root-free soil around the crops. In the two intercropping treatments, bulk soil samples of the two crop species were pooled for each container. All soil samples were frozen and stored at $-20^{\circ} \mathrm{C}$. For determination of soil properties, subsamples were dried at $60^{\circ} \mathrm{C}$ for two days and sieved to $<2 \mathrm{~mm}$. Soil organic carbon (C) and total nitrogen $(\mathrm{N})$ concentrations from all dried subsamples were determined using a LECO TruSpec CN analyzer (Leco Copr., St. Joseph, MI). The gravimetric soil water content (\%) of all soil samples was calculated from oven-dried subsamples. Soil $\mathrm{pH}$ values were measured as follows: $2 \mathrm{~g}$ soil of each container and crop species were mixed with $5 \mathrm{~mL}$ PCR grade water. After 
MICROBIAL COMMUNITIES UNDER CROPPING REGIMES

incubation for 24 hours, $\mathrm{pH}_{\text {Water }}$ was measured in the supernatant with a glass electrode. Subsequently, $0.37 \mathrm{~g} \mathrm{KCl}$ was added and $\mathrm{pH}_{\mathrm{KCl}}$ was measured. Detailed information on soil characteristics is given in the Supplementary Table S1.

\section{Sampling and surface sterilization of plant material}

Above- as well as belowground plant material of the two crop species were harvested separately for each container. Aboveground (shoots, leaves) and root biomass for each crop species and each container were measured. In addition, the heights of approximately 10 faba bean and 20 wheat plants in intercropping regimes and approximately 20 plants of monocropped faba bean and wheat plants were measured. For determination of water content in aerial plant parts, ten wheat and five faba bean plants without roots per container were weighted and subsequently oven-dried at $60^{\circ} \mathrm{C}$ for $48 \mathrm{~h}$ and re-weighted. For detailed information see Supplementary Table S2. Ten wheat and five bean plants which did not show any obvious disease symptoms such as leaf spots were randomly selected from each container for molecular analysis. Plant material derived from the same container and plant species was pooled prior to surface sterilization.

Aerial plant parts (shoots and leaves) were surface-sterilized by serial washing in $70 \%$ ethanol for $1 \mathrm{~min}, 2 \%$ sodium hypochlorite for $30 \mathrm{sec}$ and $70 \%$ ethanol for $1 \mathrm{~min}$, followed by two times immersion in sterile, distilled water for $30 \mathrm{sec}$ and once in sterile, Diethylpyrocarbonate (DEPC)treated water. Surface sterilization of roots were performed according to Sun et al. (2008) with slight modifications. In this study, $2 \%$ sodium hypochlorite (2\%) and sterile, DEPC-treated water was used. To control the success of the applied disinfection process, aliquots of the water used in the final wash step were plated on common laboratory media plates, i.e., Luria-Bertani-Agar and potato dextrose agar, respectively. The plates were incubated in the dark at $25^{\circ} \mathrm{C}$ for at least one week. No growth of microorganisms was observed. In addition, water from the same aliquots was subjected to PCR targeting the bacterial 16S rRNA gene and ITS region of fungal rDNA. No amplification of 16S rRNA gene or ITS region was detected (data not shown). Thus, these results confirmed that the surface sterilization was successful in eliminating cultivable as well as noncultivable epiphytic bacteria and fungi as well as potential DNA traces from the plant surfaces. Surface-sterilized plant material was ground to a fine powder in liquid nitrogen using an autoclaved mortar and pestle. Aliquots of the obtained powder were stored at $-20^{\circ} \mathrm{C}$ until DNA extraction.

\section{Extraction of total community DNA}

Total endophytic microbial community DNA of aerial plant parts (referred to as leaves or leaf samples, for simplification) as well as roots was extracted employing the peqGOLD Plant DNA Mini Kit (Peqlab, Erlangen, Germany) according to the manufacturer's instructions with two 


\section{MICROBIAL COMMUNITIES UNDER CROPPING REGIMES}

modifications as described previously (Wemheuer et al., 2016). Total environmantal DNA of rhizosphere as well as bulk soil samples was extracted employing the PowerSoil@ DNA Isolation Kit (MoBio Laboratories, Inc., USA) according to the manufacture's protocol. The concentration of DNA extracts was quantified using a NanoDrop ND-1000 spectrophotometer (NanoDrop Technologies, Wilmington, DE, USA).

\section{Amplification of the 16S rRNA gene}

Bacterial endophyte and soil communities were assessed by a nested PCR approach targeting the $16 \mathrm{~S}$ rRNA gene. For details of the first PCR reaction mixture and the thermal cycling scheme see (Wemheuer et al., 2016). In brief, the primers 799f (5'-AACMGGATTAGATACCCKG-3') (Chelius and Triplett, 2001) and 1492R (5'-GCYTACCTTGTTACGACTT-3') (Lane, 1991) were used in the first PCR to suppress co-amplification of chloroplast-derived 16S rRNA genes (Chelius and Triplett, 2001). PCR amplification resulted in two PCR products: a bacterial product of approximately $735 \mathrm{bp}$ and a mitochondrial product with approximately $1.1 \mathrm{kbp}$. Genomic DNA of Bacillus licheniformis DSM13 was used as template in the positive control to select for the bacterial product. Obtained PCR products were subjected to nested PCR.

The V6-V8 region of the 16S rRNA gene was amplified with the primers 968F and 1401R (Nübel et al., 1996) containing MiSeq adaptors (underlined) (MiSeq-968F 5'TCGTCGGCAGCGTCAGATGTGTATAAGAGACAGAACGCGAAGAACCTTAC-3'; $\quad$ MiSeq1401R 5'-GTCTCGTGGGCTCGGAGATGTGTATAAGAGACAGCGGTGTGTACAAGACCC$\left.3^{\prime}\right)$. The PCR reaction $(25 \mu \mathrm{l})$ contained $5 \mu \mathrm{l}$ of five-fold Phusion HF buffer, $200 \mu \mathrm{M}$ of each of the four deoxynucleoside triphosphates, $4 \mu \mathrm{M}$ of each primer, $1 \mathrm{U}$ of Phusion high fidelity DNA polymerase (Thermo Scientific, Waltham, MA, USA) and approximately $50 \mathrm{ng}$ of the PCR product as template. Negative controls were performed by using the reaction mixture without template. The following thermal cycling scheme was used: initial denaturation at $98^{\circ} \mathrm{C}$ for $30 \mathrm{~s}, 30$ cycles of denaturation at $98^{\circ} \mathrm{C}$ for $15 \mathrm{~s}$, annealing at $53^{\circ} \mathrm{C}$ for $30 \mathrm{~s}$, followed by extension at $72^{\circ} \mathrm{C}$ for $30 \mathrm{~s}$. The final extension was carried out at $72^{\circ} \mathrm{C}$ for $2 \mathrm{~min}$. Three independent PCRs were performed per sample. Obtained PCR products per sample were controlled for appropriate size, pooled in equal amounts, and purified using the peqGOLD Gel Extraction Kit (Peqlab). Quantification of the PCR products was performed using the Quant-iT dsDNA HS assay kit and a Qubit fluorometer (Thermo Scientific) as recommended by the manufacturer.

\section{Amplification of the ITS region}

The fungal communities in soil and endosphere were assessed by a nested PCR approach targeting the ITS region. In the first PCR, the primers ITS1-F_KYO2 (5'- 
MICROBIAL COMMUNITIES UNDER CROPPING REGIMES

TAGAGGAAGTAAAAGTCGTAA-3') (Toju et al., 2012) and ITS4 (5'TCCTCCGCTTATTGATATGC-3') (White et al., 1990) were used. The PCR reaction mixture (25 $\mu$ l) contained: $5 \mu \mathrm{l}$ of five-fold Phusion GC buffer, $200 \mu \mathrm{M}$ of each of the four deoxynucleoside triphosphates, $4 \mu \mathrm{M}$ of each primer, 5\% DMSO, $25 \mathrm{mM} \mathrm{MgCl}_{2}$, $0.5 \mathrm{U}$ of Phusion High Fidelity Hot Start DNA polymerase (Thermo Scientific) and approximately $10 \mathrm{ng}$ DNA sample as template. Negative controls were performed by using the reaction mixture without template. The following thermal cycle scheme was utilized: initial denaturation at $98^{\circ} \mathrm{C}$ for 30 seconds followed by 6 cycles of denaturation at $98^{\circ} \mathrm{C}$ for $15 \mathrm{~s}$, annealing at $53^{\circ} \mathrm{C}$ for $30 \mathrm{~s}$ decreasing $0.5^{\circ} \mathrm{C}$ in each cycle, followed by extension at $72^{\circ} \mathrm{C}$ for $30 \mathrm{~s}$ and 29 cycles of denaturation at $98^{\circ} \mathrm{C}$ for $15 \mathrm{~s}$, annealing at $50^{\circ} \mathrm{C}$ for $30 \mathrm{~s}$, followed by extension at $72^{\circ} \mathrm{C}$ for $30 \mathrm{~s}$. The final extension was carried out at $72^{\circ} \mathrm{C}$ for 2 min. Obtained PCR products were subjected to nested PCR.

The ITS2 region was amplified with the primers ITS3_KYO2 (Toju et al., 2012) and ITS4 (White et al., 1990) containing the MiSeq adaptors (underlined) were used: MiSeq-ITS3_KYO2 (5'TCGTCGGCAGCGTCAGATGTGTATAAGAGACAGGATGAAGAACGYAGYRAA-3') and MiSeq-ITS4 $\left(5^{\prime}-\right.$ GTCTCGTGGGCTCGGAGATGTGTATAAGAGACAGTCCTCCGCTTATTGATATGC $\quad$-3’'). Purification and quantification were performed as described for bacterial PCR products. Three independent PCRs were performed per sample and obtained PCR products were pooled in equal amounts.

\section{Processing and analysis of bacterial and fungal datasets}

Generated datasets was processed with Usearch version 8.0.1623 (Edgar, 2010). Paired-end reads were merged and quality-filtered. Filtering included the removal of reads shorter than $300 \mathrm{bp}$. Processed sequences of all samples were joined and clustered in operational taxonomic units (OTUs) at 3\% genetic divergence using the UPARSE algorithm implemented in USEARCH. A de novo chimera removal was included in the clustering step. Afterwards, putative chimeric sequences were removed using UCHIME in reference mode with the most recent RDP training set (version 15) as reference data set (Cole et al., 2009) for bacteria and the most recent uchime reference data (version 7) obtained from the UNITE database for fungi, respectively. Afterwards, OTU sequences were taxonomically classified using QIIME (Caporaso et al., 2010) by BLAST alignment against the most recent SILVA database (SILVA SSURef $123 \mathrm{NR}$ ) and the latest QIIME release of the UNITE database (version 7), respectively. All non-bacterial or non-fungal OTUs were removed from the respective datasets. Subsequently, processed sequences were mapped on OTU sequences to calculate the distribution and abundance of each OTU in every sample. Alpha diversity indices 


\section{MICROBIAL COMMUNITIES UNDER CROPPING REGIMES}

(Supplementary Tables S3 and S4) and rarefaction curves were calculated in R (version 3.2.3) (R Development Core Team, 2013) using the vegan package (Oksanen et al., 2013).

\section{Statistical analysis}

All statistical analyses were conducted in R, with the exception of the statistics on fungal thriophic guilds, which was carried out in SigmaPlot (version 11.0, Systat Software GmbH, Erkrath, Germany). Differences were considered as statistically significant with $\mathrm{P} \leq 0.05$. Non-metric multidimensional scaling plots (NMDS) were calculated using the metaMDS function within the vegan package based on Bray-Curtis dissimilarities to visualize differences in community composition separately for bacteria and fungi. The impact of cropping system on bacterial and fungal community structure was tested using the envfit function as described previously (Wietz et al., 2015).

To analyze possible effects of sampling location on richness and diversity, ANOVA with error (Crawley, 2007) were conducted. A pairwise t-test with Bonferroni correction was applied to test for differences between the cropping systems. Differences in richness and diversity with regard to cropping regime were tested by ANOVA and Kruskal-Wallis test, respectively. Prior to analysis, alpha diversity indices were tested for normality using the Shapiro test and for variance homogeneity using the Levene test within the car package. Differences between single treatments were tested either by pairwise $\mathrm{t}$ test or Wilcoxon test using Bonferroni corrected $\mathrm{p}$ values. Correlation between cropping types and soil $\mathrm{pH}$ as well as aboveground and root biomass were tested by ANOVA and Kruskal-Wallis test, respectively. Prior to analysis, environmental parameters as well as alpha diversity indices were tested for normality using the Shapiro test and for variance homogeneity using the Levene test within the car package. Differences between single treatments were tested either by pairwise $\mathrm{t}$ test or Wilcoxon test using Bonferroni corrected $\mathrm{p}$ values. Functional profiles for bacterial communities were predicted from obtained 16S rRNA gene data using Tax4Fun (Aßhauer et al., 2015). In addition, we used this unique dataset to parse fungal genera into ecological guilds using FUNGuild according to Nguyen et al. (2016).

To identify potential indicators for each cropping regime and associations with the sampling locations, multipattern analyses were applied at genus level. Therefore, all fungal and bacterial genera (178 and 881, respectively) which were found with more than $0.5 \%$ abundance in the respective sampling locations were used. Therefore, multipatt from the IndicSpecies (De Cáceres and Legendre, 2009) package was applied. The resulting indicator values for a particular cropping system, as well as the associations strengths (that is, point biserial coefficients $R$ ) with a particular compartment were corrected for unequal sample size using the function IndVal.g and r.g, respectively (Tichy and Chytry, 2006). As a single taxon can occupy a certain niche in several 
MICROBIAL COMMUNITIES UNDER CROPPING REGIMES

cropping systems, and be present in more than just one of the compartments in the endosphere and soil, it is necessary to consider all possible combinations to detect these associations (De Cáceres et al., 2010).

Correlation-based co-occurrence networks were additionally constructed for each of the sampling locations to gain a more detailed insight into the possible interactions between fungi and bacteria in the soil and endosphere. Therefore, bacterial and fungal OTU tables were combined (bulk soil, $n=20$; rhizosphere, $n=27$; root, $n=15$; leaf, $n=18$ ). To enhance reliability of the cooccurrence patterns, only taxa present in $>50 \%$ of the samples were taken into analysis. Pairwise correlation coefficients were calculated using cor in R. Positive correlation coefficients ( $\mathrm{r}>0.6$ for bulk soil, rhizosphere and roots, $\mathrm{r}>0.3$ for leaves) were considered as two taxa co-occurring, or cooperation between the two taxa. Negative correlation coefficients $(\mathrm{r}<-0.6$ for bulk soil, rhizosphere and roots, $\mathrm{r}<-0.3$ for leaves) were considered as two taxa avoiding each other, or competition between the two taxa. Network visualization was performed in Cytoscape version 3.2.0 (Shannon et al., 2003). The Spring Embedded Edge-Weighed Layout was employed for both bipartite and co-occurrence networks.

\section{Results and Discussion}

\section{Soil characteristics and growth of faba bean and wheat plants}

Several soil (Table 1, Supplementary Table S1) and plant properties (Table 2, Supplementary Table $\mathrm{S} 2)$ were determined. Soil $\mathrm{pH}$ values were constant among all soil samples $\left(\mathrm{pH}_{\text {water }}=6.82 \pm 0.13\right.$; $\mathrm{pH}_{\mathrm{KCl}}=6.55 \pm 0.09$ ) with no significant differences between the four cropping regimes. Water content varied between 61.6 and $86.3 \%$. Statistical analysis revealed that the water content in rhizosphere soil samples of WM was significantly lower compared to the other three cropping regimes. Moreover, soil $\mathrm{C}$ and $\mathrm{N}$ content in bulk as well as in rhizosphere soil samples did not differ significantly among the four cropping regimes. However, the $\mathrm{C}: \mathrm{N}$ ratio in bulk soil samples of the cropping regime MI were significantly higher compared to the other cropping regimes. The C:N ratio explains the ability to use soil carbon and nitrogen for microbial processes such as the decomposition of soil organic matter (Wardle, 1992). As consequence, it is an indicator of soil microbial activity (He et al., 1997). The results of the present study indicate that the soil microbial activity in all soil samples with exception of bulk soil sample MI did not differ significantly among the four cropping regimes. 


\section{MICROBIAL COMMUNITIES UNDER CROPPING REGIMES}

Table 1: Edaphic parameters for bulk soil and rhizopshere, respectively. Different letters indicate significant differences with $\mathrm{P}<0.05$.

\begin{tabular}{lcccc}
\hline & Moisture (\%) & $C_{\text {total }}(\%)$ & $N_{\text {total }}(\%)$ & C:N ratio \\
\hline FBM & $31.22 \pm 6.25 \mathrm{a}$ & $8.42 \pm 2.35 \mathrm{a}$ & $0.18 \pm 0.05 \mathrm{a}$ & $46.33 \pm 1.09 \mathrm{a}$ \\
WM & $18.14 \pm 4.03 \mathrm{c}$ & $6.33 \pm 0.54 \mathrm{a}$ & $0.14 \pm 0.01 \mathrm{a}$ & $45.11 \pm 1.26 \mathrm{a}$ \\
RI & $21.54 \pm 3.61 \mathrm{~b}, \mathrm{c}$ & $7.68 \pm 2.15 \mathrm{a}$ & $0.17 \pm 0.04 \mathrm{a}$ & $46.47 \pm 1.08 \mathrm{a}$ \\
MI & $24.99 \pm 2.19 \mathrm{a}, \mathrm{b}, \mathrm{c}$ & $7.83 \pm 1.03 \mathrm{a}$ & $0.17 \pm 0.02 \mathrm{a}$ & $47.41 \pm 0.37 \mathrm{~b}$
\end{tabular}

Faba bean rhizosphere

$\begin{array}{lllll}\text { FBM } & 34.43 \pm 3.16 \mathrm{a} & 10.50 \pm 1.02 \mathrm{a} & 0.22 \pm 0.03 \mathrm{a} & 48.24 \pm 1.68 \mathrm{a} \\ \text { RI } & 29.12 \pm 4.11 \mathrm{a} & 13.76 \pm 2.63 \mathrm{a} & 0.27 \pm 0.05 \mathrm{a} & 50.13 \pm 1.07 \mathrm{a} \\ \text { MI } & 26.39 \pm 6.33 \mathrm{a} & 11.89 \pm 2.17 \mathrm{a} & 0.24 \pm 0.05 \mathrm{a} & 49.99 \pm 2.20 \mathrm{a}\end{array}$

\section{Wheat rhizosphere}

$\begin{array}{lllll}\text { FBM } & 22.33 \pm 2.99 \mathrm{a} & 10.86 \pm 1.66 \mathrm{a} & 0.22 \pm 0.03 \mathrm{a} & 50.29 \pm 2.25 \mathrm{a} \\ \text { RI } & 26.44 \pm 3.56 \mathrm{a} & 12.08 \pm 2.26 \mathrm{a} & 0.24 \pm 0.05 \mathrm{a} & 50.92 \pm 1.22 \mathrm{a} \\ \text { MI } & 24.86 \pm 6.14 \mathrm{a} & 9.48 \pm 1.55 \mathrm{a} & 0.18 \pm 0.03 \mathrm{a} & 51.43 \pm 1.55 \mathrm{a}\end{array}$

Abbreviations: $\boldsymbol{C}_{\text {total }}$, total soil organic carbon; $\boldsymbol{N}_{\text {total }}$, total soil nitrogen; FBM, faba bean in monoculture; WM, wheat in monoculture; MI, mixed intercropping; RI, row intercropping.

To analyze the effect of cropping system and regime on plant growth and yield, aboveground as well as root biomass were recorded. The heights of the two crop species did not differ between the different cropping regimes (Table 2, Supplementary Table S2). Nonetheless, we found a higher aboveground biomass of wheat plants in intercropping systems, whereas the aboveground biomass of bean plants growing in the two intercropping regimes was lower compared to the monocultures. However, this was not statistically significant which might be related to the short growing period of the plants. Similar results for increased yields of the cereal crop were observed in a maize/faba bean intercropping system. The authors suggest that these results are caused by interspecific facilitation in phosphorus and nitrogen uptake. This is in line with other studies concluding that the beneficial effects of intercropping crop yields and/or nutrient supply resulted mainly from (positive) interspecific interactions in the rhizosphere (Vandermeer, 1992; Li et al., 1999). 


\section{MICROBIAL COMMUNITIES UNDER CROPPING REGIMES}

Table 2. Plant growth characteristics. Different letters indicate statistically significant differences with $\mathrm{P}<0.05$ between groups. The above- and belowground biomass per plant (g) is shown. For height, approximately 10 faba bean and 20 wheat plants in intercropping regimes and approximately 20 plants of monocropped faba bean and wheat plants were measured.

\begin{tabular}{|c|c|c|c|c|c|}
\hline & Height $(\mathrm{cm})$ & $\begin{array}{l}\text { Aboveground } \\
\text { biomass (g) }\end{array}$ & $\begin{array}{l}\text { Water content } \\
(\%)\end{array}$ & Root biomass (g) & shoot/root ratio \\
\hline \multicolumn{6}{|c|}{ Faba bean } \\
\hline FBM & $21.40 \pm 1.84 \mathrm{a}$ & $4.83 \pm 1.16 \mathrm{a}$ & $90.47 \pm 0.55 a$ & $2.34 \pm 0.49 \mathrm{a}$ & $2.11 \pm 0.52 \mathrm{a}$ \\
\hline RI & $18.80 \pm 1.69 \mathrm{a}$ & $3.27 \pm 0.52 \mathrm{a}$ & $87.92 \pm 1.66 b$ & $2.66 \pm 0.65 b$ & $1.29 \pm 0.32 b$ \\
\hline MI & $19.26 \pm 2.68 \mathrm{a}$ & $3.72 \pm 1.40 \mathrm{a}$ & $87.10 \pm 2.49 \mathrm{~b}$ & $1.98 \pm 0.69 a$ & $1.92 \pm 0.43 \mathrm{ab}$ \\
\hline \multicolumn{6}{|l|}{ Wheat } \\
\hline WM & $38.78 \pm 1.12 \mathrm{a}$ & $1.36 \pm 0.18 \mathrm{a}$ & $84.58 \pm 4.01 \mathrm{a}$ & $1.94 \pm 0.48 \mathrm{a}$ & $0.76 \pm 0.25 a$ \\
\hline $\mathbf{R I}$ & $40.30 \pm 3.00 \mathrm{a}$ & $1.64 \pm 0.27 \mathrm{a}$ & $82.4 \pm 2.02 \mathrm{a}$ & $2.78 \pm 1.22 b$ & $0.71 \pm 0.29 a$ \\
\hline MI & $39.76 \pm 1.40 \mathrm{a}$ & $1.68 \pm 0.37 \mathrm{a}$ & $84.72 \pm 1.12 \mathrm{a}$ & $2.05 \pm 0.49 \mathrm{a}$ & $0.86 \pm 0.22 a$ \\
\hline
\end{tabular}

Abbreviations: FBM, faba bean in monoculture; WM, wheat in monoculture; MI, mixed intercropping; RI, row intercropping.

A higher average root biomass was observed for intercropped plants grown in rows (RI) compared to those grown in monocultures or with no distinct row arrangement (MI) (Table 2). The shoot/root ratio for faba bean decreased from monoculture over intercropping regime MI to RI. Further analysis revealed that the differences observed for faba bean in cropping regimes FBM and RI were statistically significant (data not shown). According to Eghball and Maranville (1993), environmental stresses increase the relative weight of roots compared to shoots. The results of the present study indicate that wheat had a higher competetive availibitly than faba bean growing in cropping regime RI. This finding is in line with previous studies showing that interspecific competition and facilitation act on the crop plants simultaneously in intercropping systems (Li et al., 1999; Zhang and Li, 2003; Ghosh et al., 2006). In mixtures of cereal and legume crops, cereals are more competitive than legumes in taking up $\mathrm{N}$ from the soil due to their faster root development and a higher $\mathrm{N}$ demand (Corre-Hellou et al.; Hauggaard-Nielsen et al., 2001). Recently, it was concluded that the time of sowing or planting of the component crops and/or the design of the intercropping system should be modified to reduce the competition and to enhance facilitation effects (Mariotti et al., 2009; Aziz et al., 2015).

\section{Bacterial and fungal communities are dominated by a few phyla}

Sequencing of bacterial 16S rRNA and fungal ITS gene amplicons from soil and endosphere samples resulted in 815.423 and 146.660 high-quality reads for bacteria and fungi, respectively. These sequences grouped into 3.994 bacterial and 567 fungal OTUs. Calculated rarefaction curves at $3 \%$ genetic distance (species level) revealed that the majority of fungal and bacterial community 


\section{MICROBIAL COMMUNITIES UNDER CROPPING REGIMES}

was recovered by the surveying effort (data not shown). Richness (number of observed OTUs) and diversity (Shannon indices) for bacterial communities ranged from to 5.8 to 258.1 and 0.36 to 4.37 , respectively (Supplementary Table S3). For fungal communities, richness and Shannon indices varied between 3.2 and 23.4 and between 0.52 and 2.83 (Supplementary Table S4). The high deviance observed for bacterial and fungal richness derived from the different sampling locations analyzed. The lowest and highest bacterial richness was observed for endophytes in aerial parts of monoculture wheat plants and in bulk soil of MI, respectively (Table 3). In addition, the lowest and highest fungal richness was found in roots and aerial parts of monoculture faba bean, respectively (Table 3).

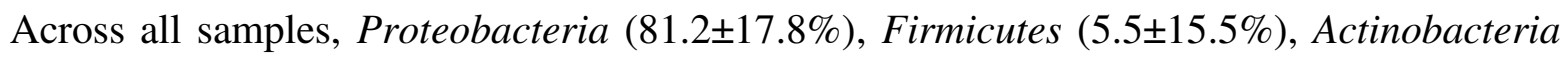
$(5.2 \pm 6.7 \%)$, Bacteroidetes $(3.0 \pm 3.3 \%)$ and Acidobacteria $(1.3 \pm 1.7 \%)$ were the most abundant bacterial phyla (Figure 1). This is in line with previous studies investigating bacterial communities in bulk soil, rhizosphere and roots of barley (Bulgarelli et al., 2013) as well as in root and leaves of wheat (Robinson et al., 2015). Similar results were obtained for bacterial communities in soil and rhizosphere samples of different cereal crops and legumes (Turner et al., 2013b) and in soil of winter wheat-rice as well as winter wheat-maize cropping systems (Zhao et al., 2014). In the present study, the bacterial orders Xanthomonadales and Burkholderiales dominated the bulk/rhizosphere soil and endophytic samples, respectively. At genus level, Rhodanobacter (Xanthomonadales) dominated bulk soil and rhizosphere samples (61\% and 59\%, respectively). Ralstonia was the most abundant member of the Burkolderiales in leaf and root samples (15\% and $24 \%$, respectively). One member of this genus, $R$. solanacearum, was previously described as pathogen involved in eggplant wilt by colonization of the vascular vessels (Vasse et al., 1995). 


\section{MICROBIAL COMMUNITIES UNDER CROPPING REGIMES}

Table 3. Bacterial and fungal richness and diversity. Diversity is expressed as Shannon values and richness as the number of observed OTUs. Different letters indicate statistically significant differences between groups.

\begin{tabular}{|c|c|c|c|c|}
\hline & \multicolumn{2}{|c|}{ Bacteria } & \multicolumn{2}{|c|}{ Fungi } \\
\hline & Richness & Diversity & Richness & Diversity \\
\hline \multicolumn{5}{|c|}{ Bulk soil } \\
\hline FBM & $95.00 \pm 25.01 \mathrm{a}$ & $1.90 \pm 0.54 \mathrm{a}$ & $14.76 \pm 2.25 \mathrm{ab}$ & $2.18 \pm 0.25 \mathrm{a}$ \\
\hline WM & $67.60 \pm 55.80 \mathrm{a}$ & $1.58 \pm 0.80 \mathrm{ab}$ & $18.42 \pm 1.34 \mathrm{ac}$ & $2.50 \pm 0.07 \mathrm{a}$ \\
\hline RI & $103.60 \pm 27.26 \mathrm{a}$ & $1.95 \pm 0.49 \mathrm{a}$ & $16.20 \pm 1.30 \mathrm{abc}$ & $2.31 \pm 0.13 \mathrm{a}$ \\
\hline MI & $111.20 \pm 71.33 \mathrm{a}$ & $2.00 \pm 1.04 b$ & $16.82 \pm 1.18 \mathrm{abc}$ & $2.41 \pm 0.10 \mathrm{a}$ \\
\hline \multicolumn{5}{|c|}{ Faba bean rhizosphere } \\
\hline FBM & $225.90 \pm 46.40 \mathrm{a}$ & $4.20 \pm 0.85 a$ & $18.40 \pm 1.95 \mathrm{a}$ & $2.52 \pm 0.14 \mathrm{a}$ \\
\hline RI & $94.20 \pm 55.43 \mathrm{a}$ & $2.31 \pm 0.85 a$ & $18.68 \pm 3.87 \mathrm{a}$ & $2.52 \pm 0.32 \mathrm{a}$ \\
\hline MI & $131.20 \pm 19.56 a$ & $2.11 \pm 0.40 \mathrm{a}$ & $16.80 \pm 2.10 \mathrm{a}$ & $2.32 \pm 0.17 \mathrm{a}$ \\
\hline \multicolumn{5}{|c|}{ Wheat rhizosphere } \\
\hline $\mathbf{W M}$ & $70.60 \pm 30.07 a$ & $1.46 \pm 0.59 \mathrm{a}$ & $18.54 \pm 2.91 \mathrm{ab}$ & $2.52 \pm 0.24 \mathrm{a}$ \\
\hline $\mathbf{R I}$ & $103.00 \pm 36.43 \mathrm{ab}$ & $1.88 \pm 0.57 \mathrm{a}$ & $14.78 \pm 0.71 \mathrm{ab}$ & $2.14 \pm 0.13 b$ \\
\hline MI & $172.80 \pm 21.05 b$ & $3.45 \pm 0.54 \mathrm{a}$ & $21.13 \pm 0.67 \mathrm{ac}$ & $2.66 \pm 0.02 \mathrm{a}$ \\
\hline \multicolumn{5}{|c|}{ Faba bean roots } \\
\hline FBM & $122.60 \pm 0 \mathrm{a}$ & $3.24 \pm 0 \mathrm{a}$ & $13.77 \pm 4.52 \mathrm{a}$ & $2.08 \pm 0.53 \mathrm{a}$ \\
\hline $\mathbf{R I}$ & $53.20 \pm 28.93 a$ & $1.26 \pm 0.56 \mathrm{a}$ & $18.50 \pm 0 \mathrm{a}$ & $2.28 \pm 0 \mathrm{a}$ \\
\hline MI & $14.00 \pm 34.36 \mathrm{a}$ & $0.36 \pm 1.11 \mathrm{a}$ & $18.20 \pm 0.80 \mathrm{a}$ & $2.47 \pm 0.08 \mathrm{a}$ \\
\hline \multicolumn{5}{|c|}{ Wheat roots } \\
\hline WM & $82.20 \pm 16.78 \mathrm{a}$ & $2.09 \pm 0.34 \mathrm{a}$ & $15.10 \pm 7.46 \mathrm{a}$ & $2.03 \pm 0.89 \mathrm{a}$ \\
\hline $\mathbf{R I}$ & $126.50 \pm 30.36 a$ & $2.89 \pm 0.49 a$ & $18.50 \pm 1.09 \mathrm{a}$ & $2.37 \pm 0.03 \mathrm{a}$ \\
\hline MI & $80.80 \pm 28.87 a$ & $1.47 \pm 0.73 \mathrm{a}$ & $18.24 \pm 2.66 \mathrm{a}$ & $2.32 \pm 0.26 \mathrm{a}$ \\
\hline \multicolumn{5}{|c|}{ Faba bean aerial parts } \\
\hline FBM & $19.40 \pm 5.67 \mathrm{a}$ & $0.68 \pm 0.58 \mathrm{a}$ & $22.00 \pm 0 \mathrm{a}$ & $2.74 \pm 0 \mathrm{a}$ \\
\hline $\mathbf{R I}$ & $37.90 \pm 7.95 \mathrm{a}$ & $2.13 \pm 0.46 \mathrm{a}$ & $15.83 \pm 2.70 \mathrm{a}$ & $2.03 \pm 0.29 \mathrm{a}$ \\
\hline MI & $23.80 \pm 0 \mathrm{a}$ & $1.32 \pm 0 \mathrm{a}$ & $12.90 \pm 0 \mathrm{a}$ & $2.00 \pm 0 \mathrm{a}$ \\
\hline \multicolumn{5}{|c|}{ Wheat aerial parts } \\
\hline $\mathbf{W M}$ & $5.80 \pm 8.93 \mathrm{a}$ & $1.09 \pm 0.62 \mathrm{a}$ & $16.04 \pm 1.17 \mathrm{a}$ & $2.34 \pm 0.09 \mathrm{a}$ \\
\hline $\mathbf{R I}$ & $12.70 \pm 2.44 \mathrm{a}$ & $1.77 \pm 0.32 \mathrm{a}$ & $15.96 \pm 3.42 \mathrm{a}$ & $2.34 \pm 0.31 \mathrm{a}$ \\
\hline MI & $34.30 \pm 9.00 \mathrm{a}$ & $2.39 \pm 0.31 \mathrm{a}$ & $16.73 \pm 2.49 \mathrm{a}$ & $2.35 \pm 0.24 \mathrm{a}$ \\
\hline
\end{tabular}

\footnotetext{
Abbreviations: FBM, faba bean in monoculture; WM, wheat in monoculture; MI, mixed intercropping; RI, row intercropping.
} 


\section{MICROBIAL COMMUNITIES UNDER CROPPING REGIMES}

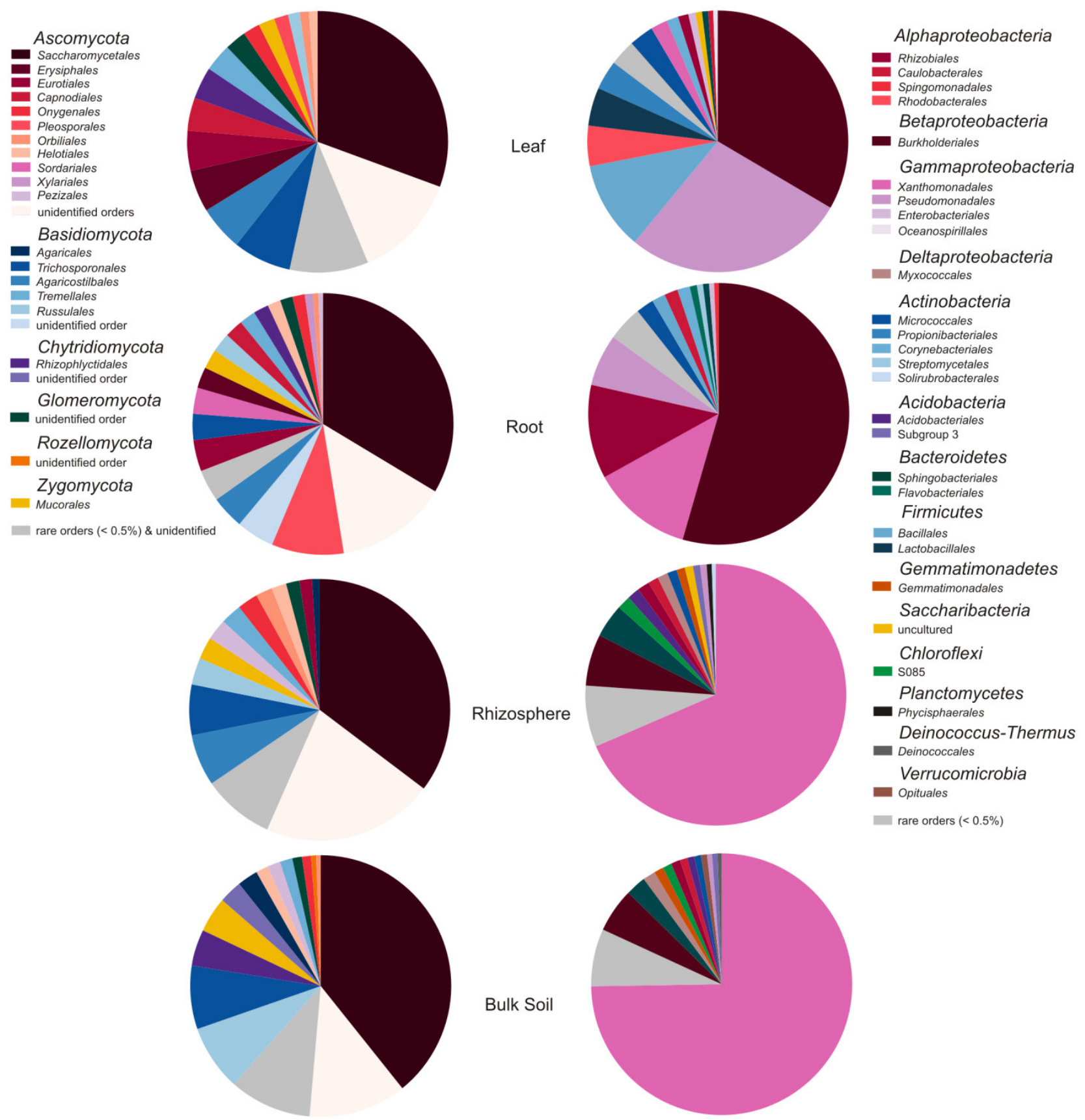

Figure 1. Relative abundances of bacterial and fungal orders, derived from the different sampling locations. All order representing more than $0.5 \%$ oft he total community per location are shown. All orders $>0.5 \%$ were considered rare.

Fungi were represented by the abundant phyla Ascomycota (66.0 $12.1 \%)$, Basidiomycota

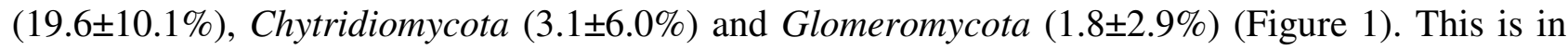
accordance with previous studies (Shakya et al., 2013; Penton et al., 2014; Chen et al., 2015). Penton et al. (2014) analyzed fungal communities in soils of agricultural fields under continuous wheat cropping and found that Ascomycota, Basidiomycota, and Chytridiomycota dominated the fungal communities. In the present study, the Saccharomycetales (Ascomycota) dominated all soil and endosphere samples. In contrast to this, the endophytic fungal community in rice sprouts and roots were dominated by the order Eurotiales and Hypocreales, respectively (Wang et al., 2016). 
MICROBIAL COMMUNITIES UNDER CROPPING REGIMES

\section{Diversity and richness of fungal and bacterial communities are driven in a different way}

We analyzed the effect of cropping regimes on diversity and richness of fungal and bacterial communities in all sampling locations (endosphere and soil samples) separately to avoid pseudoreplication. Statistical analysis revealed that the richness and diversity of bacterial communities in bulk soil as well as the richness in rhizosphere soil of wheat plants were significantly affected by the applied cropping regimes (Table 3). This is in accordance with a study of Yang et al. (2016). They investigated the bacterial community in rhizosphere soil of ten common spring crops in North China under different cropping systems and found that the bacterial diversity was influenced by crop species as well as cropping system. In contrast to this, different crop rotations had only a minor influence on bacterial diversity. The authors suggest that this is related to the previous fallow period (Silva et al., 2013).

In addition, the richness and diversity of fungi in rhizosphere samples of wheat as well as the richness of fungi in bulk soil samples was significantly affected by cropping regimes. This is in line with previous studies (e.g., Chen et al., 2015; LeBlanc et al., 2015). In a study about the impact of cropping systems on fungal communities in soil, fungal richness and diversity of these communities was increased by crop rotation (Chen et al., 2015). This is in line with a study of Manici and Caputo (2009). Here, a higher fungal diversity in fields with crop rotation compared to fields intensively cultivated with potatoes for many years. Similar results were found by Xiong et al. (2016) investigating effects of long-term vanilla monocropping of fungal communities in bulk and rhizosphere soils.

\section{Composition of fungal and bacterial communities is not affected by crop species and cropping regime but by sampling location}

To identify the influence of the different cropping systems on microbial community composition, NMDS analyses were performed separately for the bacterial and fungal communities (Figure 2 A and B). Neither bacterial nor fungal communities showed a clustering with respect to the different cropping regimes. In contrast to this, the bacterial endophytes in roots of intercropped soybean and maize plants were significantly affected by intercropping (Zhang et al., 2011). Similar results were observed for fungal communities in the endosphere of durum wheat roots (Taheri et al., 2016). 


\section{MICROBIAL COMMUNITIES UNDER CROPPING REGIMES}

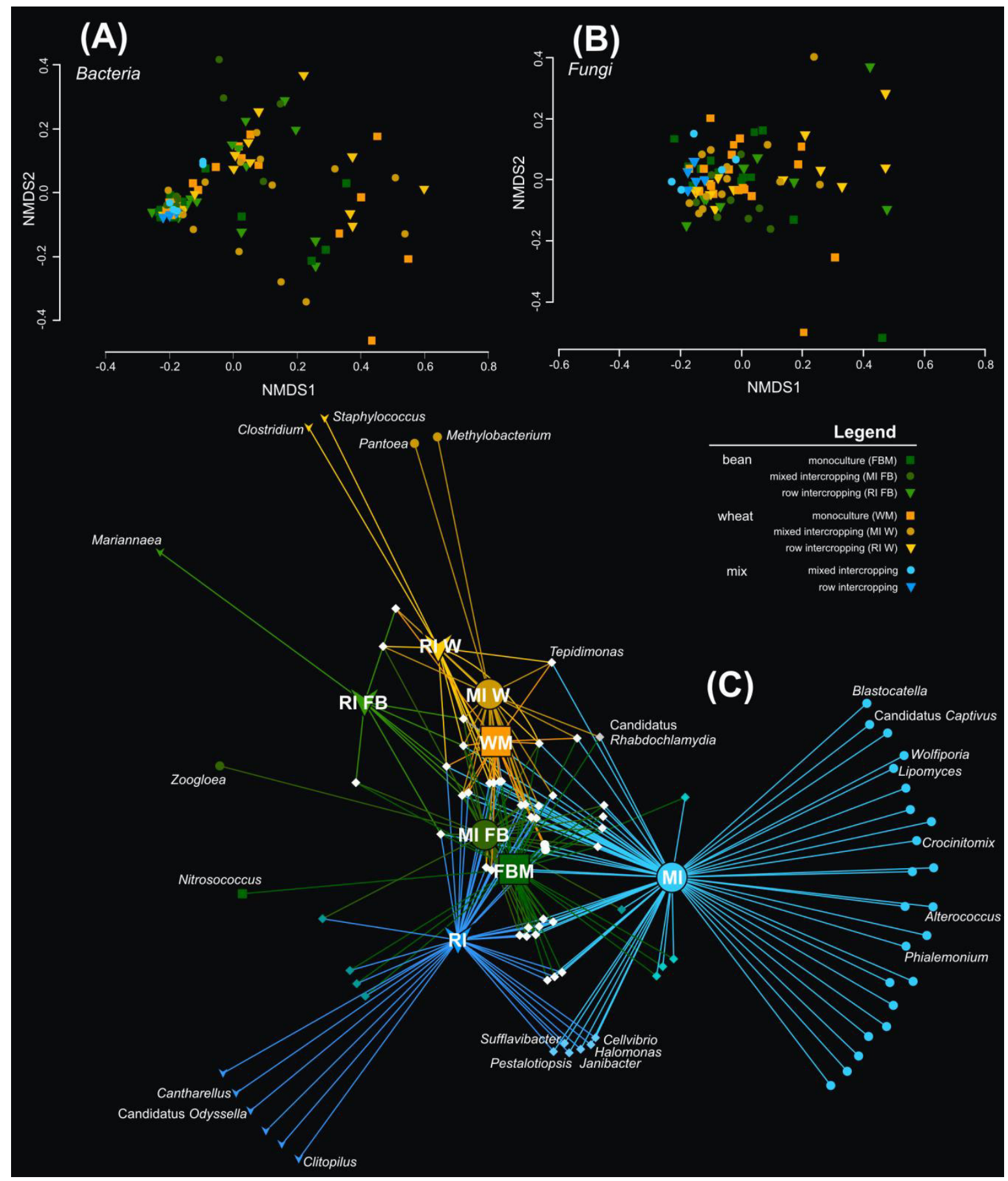

Figure 2. Microbial community response toward the cropping systems. NMDS ordination of bacterial (A) and fungal (B) communities color coded by the respective cropping regime. Ordination is based on Bray-Burtis dissimilarities between samples. The bipartite network based on indicator values (C) of the 92 significantly associated OTUs is also color coded by cropping regime. Cropping regimes and OTUs associated with only one cropping regime are color coded with respect to A and B. The edge-weighed spring-embedded algorithm pulled together OTUs with similar associations and cropping regimes with similar structure. White nodes represent multi-regime crosscombinations. OTUs that could be assigned to a genus and that are associated with only one or two cropping regimes are indicated. FBM: all samples derived from faba bean monoculture; WM: all samples derived from wheat monoculture; MI FB: faba bean endospheric samples from mixed intercropping; RI FB: faba bean endopheric samples from row intercropping; MI W: wheat endospheric samples from mixed intercropping; RI W: wheat endospheric samples from row intercropping; MI: soil and rhizosphere samples from mixed intercropping; RI: soil and rhizosphere samples from row intercropping. 


\section{MICROBIAL COMMUNITIES UNDER CROPPING REGIMES}

Contrasting results for effects of cropping systems on soil and rhizosphere microbial communities were observed in previous studies. Navarro-Noya et al. (2013) found that wheat-maize rotation and monoculture had no effect on the bacterial community composition in soil. In contrast, fungal and bacterial communities in paddy soils (Jiang et al., 2016) or in bulk soil samples (Suzuki et al., 2012) were altered by crop rotation systems. In the last mentioned study, however, the effect was strong only for fungal communities, while the bacterial communities were mainly affected by soil properties. In a previous study about the effect of soil type and cropping system on fungal and bacterial communities in the rhizosphere of legumes and wheat, cropping system had only little effect on these communities (Wang et al., 2012). Similar findings were obtained in a study on soil bacterial communities in winter wheat-rice (WR) and winter wheat-maize (WM) cropping systems derived from five locations (Zhao et al., 2014). Here, the effect of crop rotation was only low, but significant. Other studies showed that different cropping practices changed microbial communities in roots and/or soil (Manici and Caputo, 2009; Zhang et al., 2011; Yang et al., 2016). Yang et al. (2016) found that the rhizosphere bacterial community composition was influenced by cropping system as well as crop species.

In the present study, crop species did not affect bacterial and fungal community composition in soil and endosphere. This is not in accordance with recent studies showing that different plant species harbor distinct endophytic communities (Gange et al., 2007; Gaiero et al., 2013; Bonito et al., 2014; Wemheuer et al., 2016) as well as rhizosphere and/or bulk soil microbial communities (Kent and Triplett, 2002; Berg and Smalla, 2009; Turner et al., 2013b; Pii et al., 2016). In a study investigating the effect of different plant species such as bean or clover and soil type on microbial communities, plant species had the strongest effect in soil as well as in plant-associated habitats rhizosphere and rhizoplane (Wieland et al., 2001). Mouhamadou et al. (2013) showed that fungal communities in bulk and rhizosphere soil of two perennial grass species were affected by the grass species investigated. However, in a previous study investigating the leaf endophytic fungal communities of different trees, no distinct communities were identified for individual tree species (Cannon and Simmons, 2002).

We suggest that the missing effects of intercropping and crop species on bacterial and fungal communities are most likely attributed to the short growth period. It is possible that effects of both intercropping and plant species will only become evident after a longer growth period. This finding is in accordance with a study on rhizosphere ammonia-oxidizing bacteria under different intercropping systems analyzed by DGGE. Here, intercropping had a strong effect on these bacteria at anthesis, but was less pronounced at the seedling stage of the two crops (Song et al., 2007a). Wang et al. (2012) observed distinct DGGE-patterns for fungal communities in the rhizosphere of 


\section{MICROBIAL COMMUNITIES UNDER CROPPING REGIMES}

intercropped wheat and faba bean plants collected during the flowering period. This might have favored the shifts in microbial community composition observed in their study.

Since the cropping regime did not seem to have an influence on microbial community composition, we next distinguished between the different sampling locations (bulk/rhizosphere soil and leaf/root endosphere). Bacterial samples derived from the soil samples clustered closely and therefore contained very similar structured communities (Figure $3 \mathrm{~A}$ ). There was no difference between bulk soil and rhizosphere bacterial communities, which is in contrast to previous findings (Costa et al., 2006; Jin et al., 2014; Mendes et al., 2014; Sugiyama et al., 2014). In the present study, the endosphere samples derived from roots and aerial plant parts (leaves/shoots) formed two additional clusters, indicating distinct community patterns in the respective plant compartments. This is consistent with previous observations for several plant species such as wheat (Robinson et al., 2015), cacti (Fonseca-García et al., 2016), or rice (Edwards et al., 2015).

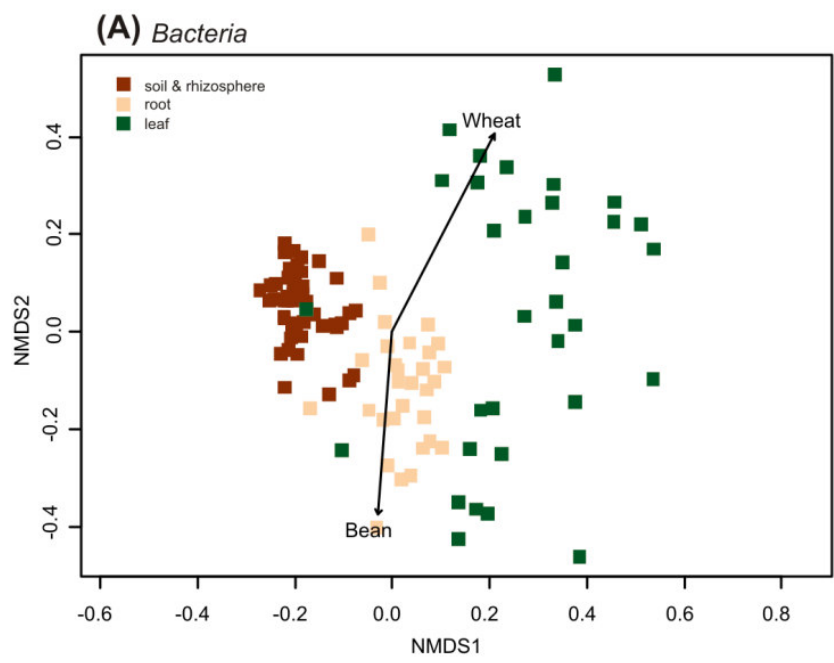

(B) Fungi

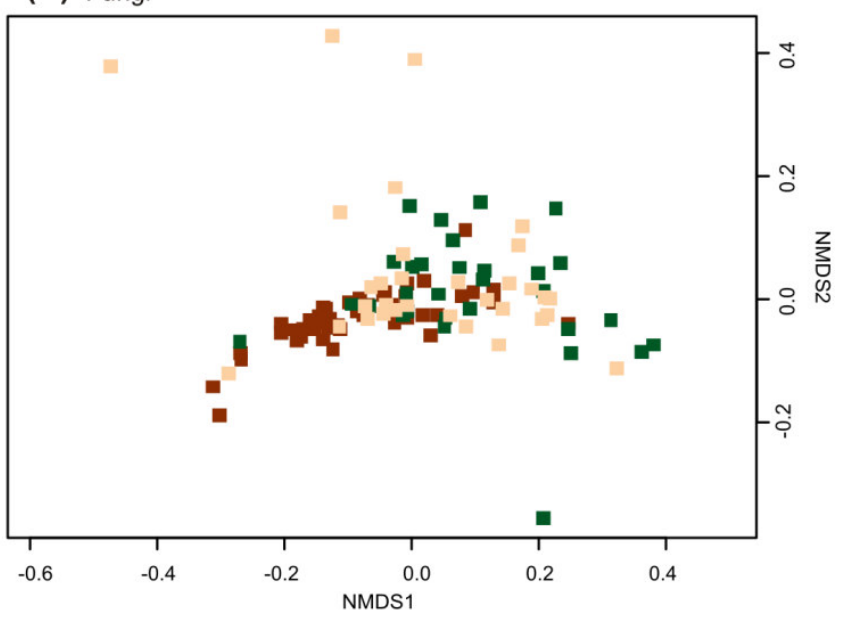

Figure 3. NMDS ordination of bacterial (A) and fungal (B) communities. This figure represents Figure 2 A and B, but color-coded by the respective sampling locations.

Fungal community structure, however, does not seem to be influenced by sampling location and did not cluster with respect to endosphere or soil (Figure $3 \mathrm{~B}$ ). The findings in the present study are not in line with a previous study showing that plant compartment was the principal driver of fungal community composition in endosphere, phyllosphere and soil (Fonseca-García et al., 2016). Mouhamadou et al. (2013) found that fungal communities in soil differed between bulk and rhizosphere soil samples of the two investigated grass species. In another study of fungal communities in roots and shoots of perennial forbs, a high degree of plant organ specificity was detected (Wearn et al., 2012). In contrast to the studies mentioned above, Coleman-Derr et al. (2016) observed that composition of prokaryotic communities of different Agave species was primarily determined by the plant compartment, while the composition of fungal communities was mainly influenced by the biogeography of the host species. 


\section{MICROBIAL COMMUNITIES UNDER CROPPING REGIMES}

\section{Indicator analysis revealed differences in soil communities between the cropping regimes}

A bipartite network was used to visualize the indicative potential of taxa (on genus level) for one or a combination of cropping systems (Figure $2 \mathrm{C}$ ). The bipartite network differed from the NMDS ordinations (Figure $2 \mathrm{~A}$ and B). The most striking difference is the distinct spacing of the MI and RI soil and rhizosphere samples (given in blue). While the bacterial and fungal community composition between both systems is very similar, there are a number of indicators uniquely associated with cropping regimes RI or MI. This suggests that the cropping regime might not substantially alter the community composition in general, but is represented by a number of uniquely associated taxa. On the contrary, endophytic samples derived from both intercropping regimes do not seem to select for such specialists. However, this might results from the fact that endophytic communities are not as homogenous as soil and rhizosphere communities. The samples of cropping regimes MI and RI have the highest number of associated taxa, while no taxon is exclusively associated with wheat monoculture, and only one taxon (Nitrosococcus) is exclusively associated with faba bean monoculture. This is interesting as the oxidation of ammonia to nitrite is carried out only a few bacteria such as Nitrosococcus (Purkhold et al., 2000). Legumes including faba bean form symbiotic relationships with rhizobia allowing them to fix atmospheric nitrogen (Zahran, 1999).

\section{Influence of sampling location on the microbial community interactions}

A second bipartite association network was constructed to visualize the association of taxa with different sampling locations. This time, the bipartite network strongly resembled the NMDS ordination plots, by recovering the two major discriminants which is the sampling location and the endosphere versus soil (Figure 4). Endosphere and bulk soil shared a high number of associated taxa which are mainly bacteria. This finding is reflected by a very similar bacterial community structure in the soil samples in general. Additionally, 278 of significantly associated taxa are bacteria and only 31 belong to the fungi, suggesting that fungi are more competitive to each other than bacteria. However, three fungal taxa were associated with the aboveground endosphere: the basidiomycete Cuniculitrema, an unidentified Glomeromycete, and Penicillium. Members of this genus are known as ubiquitous soil fungi and important in the food industry where they are used to produce enzymes and other macromolecules (Rodriguez Couto and Sanroman, 2006) and are also able to produce antibiotics (Yang et al., 2008). Malassezia (Basidiomycota) and the two ascomycetes Alternaria and Monographella are the only fungal taxa significantly associated with roots that could be assigned to a genus. While Malassezia is a saprotroph (Findley, et al. 2013), both Alternaria and Monographella are described as pathothrophs (Tedersoo et al. 2014). 


\section{Bacteria \\ - Acidobacteria \\ - Actinobacteria \\ - Bacteroidetes \\ - Chloroflexi \\ - Gemmatimonadetes \\ - Saccharibacteria \\ - Proteobacteria \\ - Firmicutes \\ - rare phyla}

\section{Fungi}

Ascomycota

Basidiomycota

Chytridiomycota

$\checkmark$ Glomeromycota

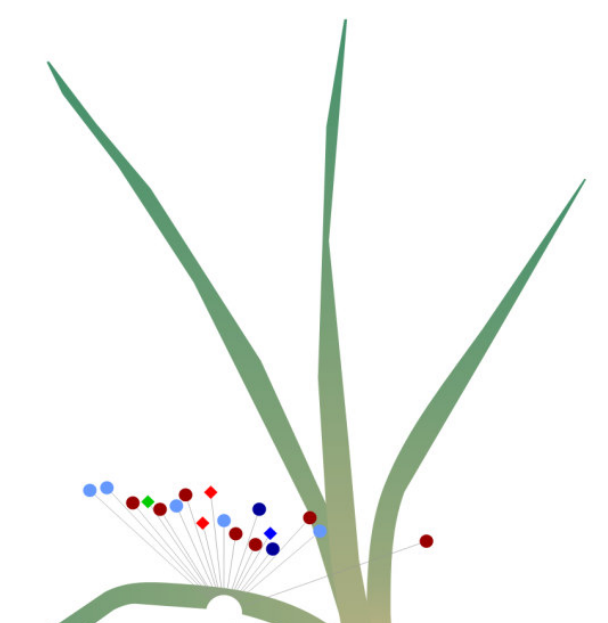

\section{LEAF}

ABOVEGROUND

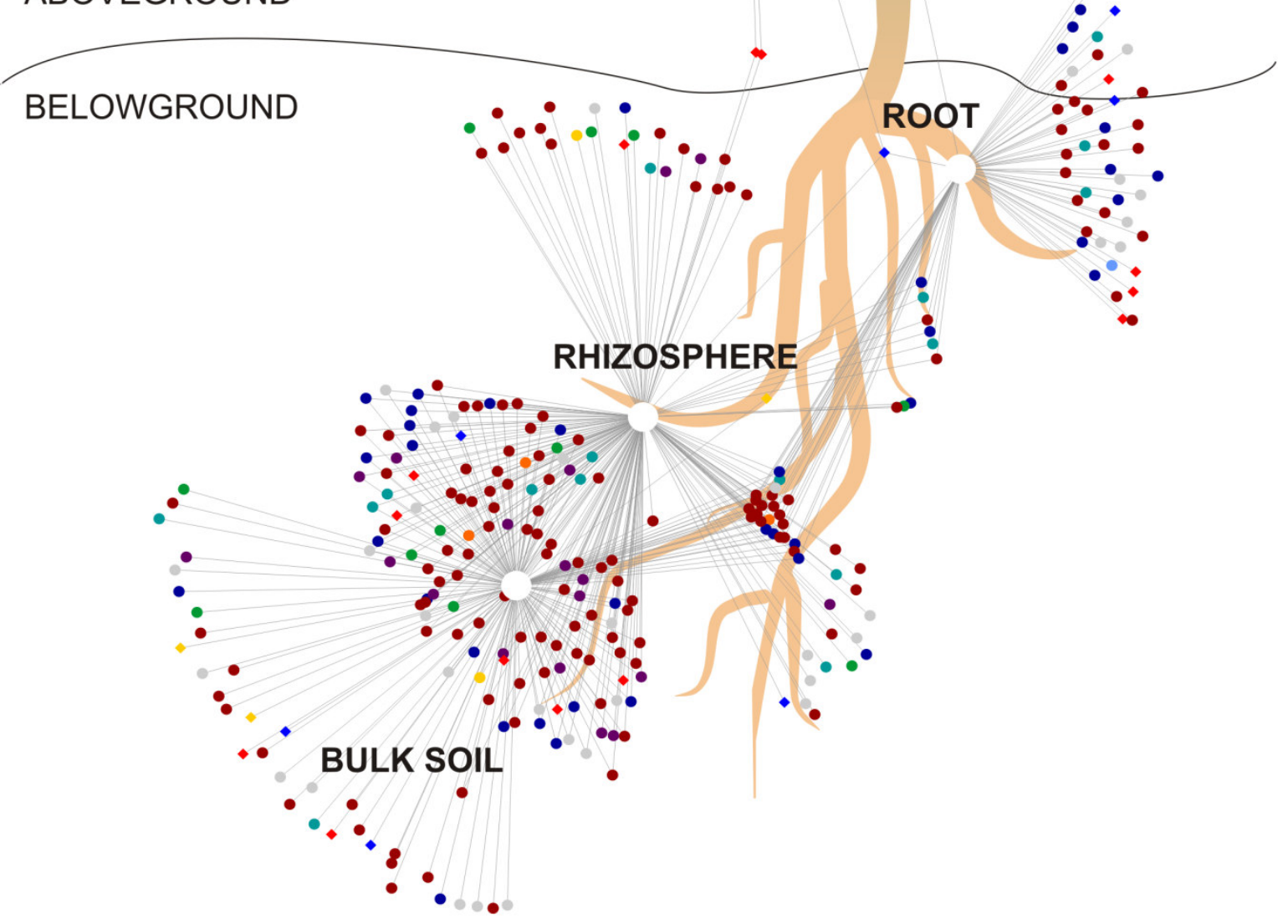

Figure 4: Bipartite association network. Positive associations between leaf, root, rhizosphere and bulk soil and 305 significantly associated OTUs are shown. The edge-weighed spring embedded algorithm pulled together OTUs with similar associations and compartments with similar structure. 
MICROBIAL COMMUNITIES UNDER CROPPING REGIMES

We further analyzed the response of taxonomic groups to the different sampling locations, employing co-correlation networks. These networks can identify how uniformly a group responds to a specific influence. Among the most populated phyla, the network density for Acidobacteria, Actinobacteria, Bacteroidetes and Basidiomycota was the highest while it was more dispersed for Proteobacteria, Chloroflexi, Verrucomicrobia and Ascomycetes (Figure 5). Interestingly, the proteobacterial network was highly reflecting the influence of soil and endosphere, respectively. Additionally, Proteobacteria seem to contribute most to the separation of leaves from roots. This is in line with other studies that found Proteobacteria to constitute the main part of endophytic communities (Bulgarelli et al., 2013; Romero et al., 2014; Hardoim et al., 2015; Robinson et al., 2015). Bacteroidetes and Actinobacteria in contrast, separate the roots, while Chloroflexi seem to contribute most to the separation of the rhizospheric samples. Ascomycota and Basidiomycota are the only taxonomic groups where OTUs does negatively influence each other, which resulted in further separation between leaf and roots. 


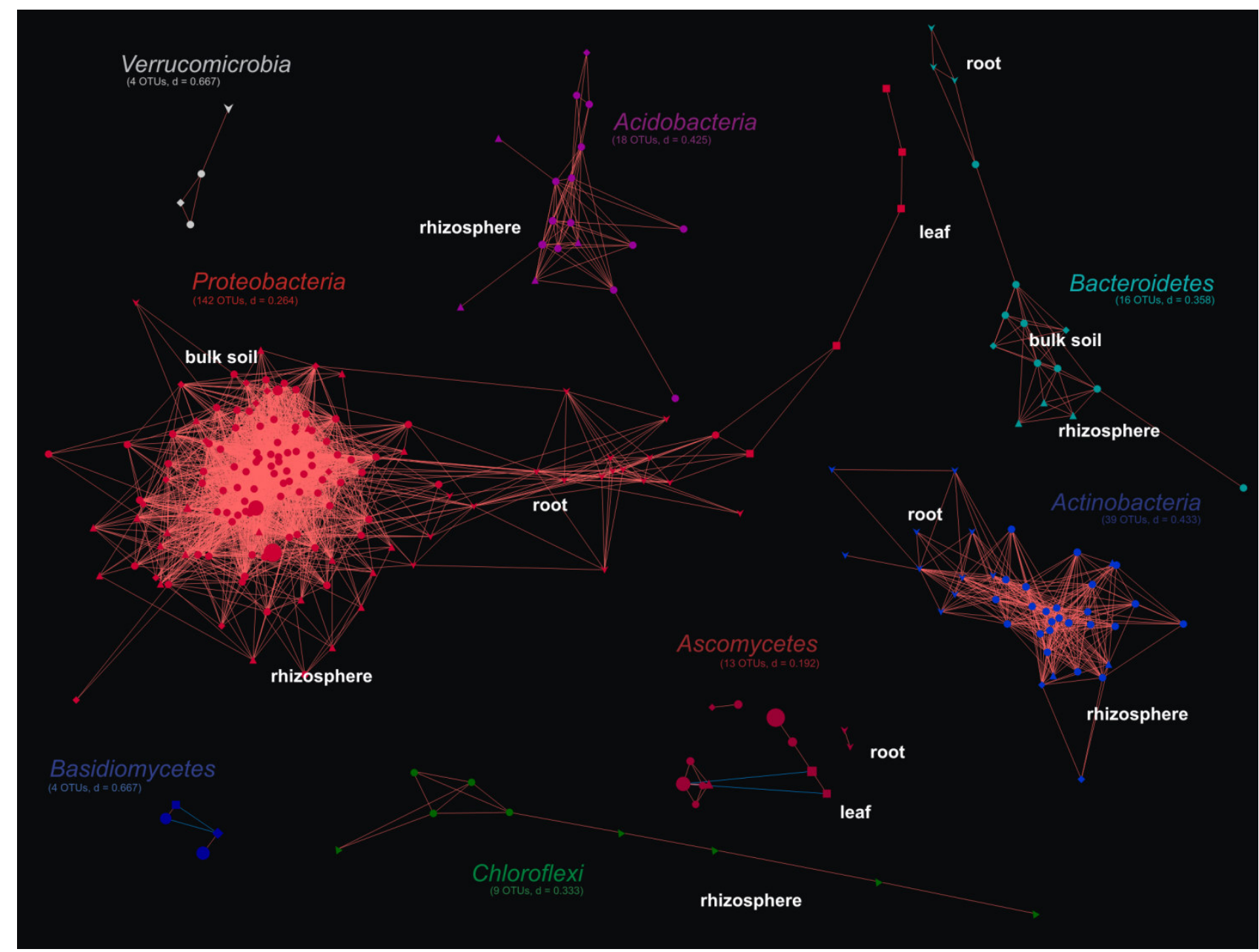

Figure 5. Co-correlation networks calculated for the significantly $(P<0.05)$ associated OTUs of the most populated phyla. Nodes correspond to OTUs and their size to the average abundance of each OTU across the dataset. Edges represent positive (red) or negative (blue) correlations between pairs of OTUs ( $\mathrm{R}>0.3$ or $\mathrm{R}<-0.3$ for positive and negative correlations, respectively). Again, the edge-weighed spring embedded algorithm pulled together strongly correlated OTUs. Strong clustering of OTUs indicated that most OTUs of this cluster showed a similar response (in most cases a positive correlation). Network density (d) calculated for each network represents the number of significant co-correlations divided by all possible co-correlations, that is, higher density represents more uniform response. Symbol coding indicates association to one specific compartments (squares = eaves; $\mathrm{V}=$ roots; triagles = rhizosphere; diamonds = bulk soil). OTUs associated with more than one compartments are circular and clusters are labeled with the approximate compartment association.

\section{Bacterial and fungal co-occurrence along the growth axis}

Bacterial communities differed with respect to the sampling location, and whether they stem from the endosphere or the soil. Fungal communities did not follow this pattern. However, it is important not only to consider the differing environmental parameters, such as the cropping regime or plant species, or even the different compartments. Bacteria and fungi co-occur in microbial communities and could be found in the endosphere as well as in the soil samples. We further elucidated, how the co-occurrence patterns of bacteria and fungi change along the growth axis of a plant. Co-occurrence can always be a hint at cooperation, while a negative relationship between OTUs can hint at avoidance or competition. The correlation-based co-occurrence networks constructed for each 


\section{MICROBIAL COMMUNITIES UNDER CROPPING REGIMES}

compartment were very different (Figure 6 for endosphere, Figure 7 for soil and rhizosphere). They not only differed with respect to the number of nodes and edges (which to some degree reflected the diversity of each compartment), they also varied with respect to type of interactions.

\section{Endophyte co-occurence networks}

Leaf

(A)

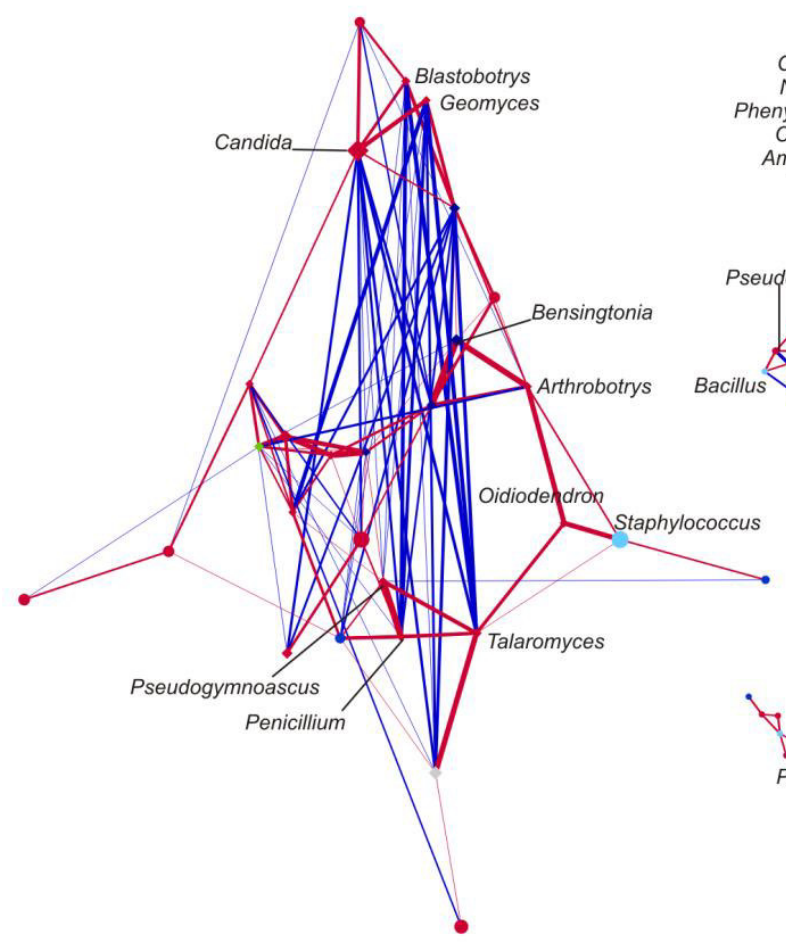

Root

\section{(B)}

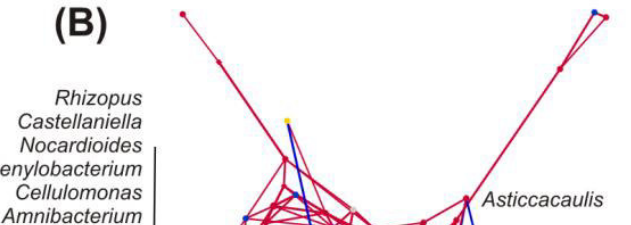

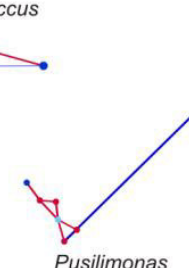

usilimonas

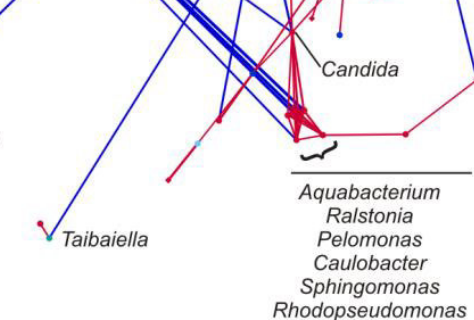

Figure 6. Co-occurrence networks of fungal and bacterial OTUs in the endosphere. Node color indicates respective phylum per OTU as provided in Figure x. Node size is scaled to the mean relative abundance of each node per compartment. Edges indicate co-occurrence or cooperation relationships in red, avoidance or competition relationships are in blue. Edge width is scaled to the correlation coefficient of each pair of OTUs. Bacterial OTUs are given as circular nodes, fungal nodes are diamond shaped.

A striking feature of the leaf network (Figure $6 \mathrm{~A}$ ) is the number of negative correlation, which occurred almost exclusively between fungal OTUs, which would suggest a strong intraphylum competition. Possibly, they occupy different niches within the leaves. Candida is the most abundant fungal OTU in leaves, Streptococcus the most abundant bacterial OTU. They seem to be better adapted to the leaf habitat. Furthermore, the strong negative relation of Rhodobacter, and to a lesser extent Xanthomonas, in both bulk soil and rhizosphere are interesting (Figure 7 A). Rhodanobacter is also by far the most abundant phylotype in the soil samples, which might be reflected by the negative interactions. Possibly, Rhodanobacter is enriched in the potting soil that is used. Therefore, the negatively related clusters might reflect the soil and rhizosphere communities that are starting to establish themselves. To our knowledge, this study provides the first analysis of 


\section{MICROBIAL COMMUNITIES UNDER CROPPING REGIMES}

fungal and bacterial co-occurrence patterns in different sampling locations and plant compartments. Therefore, knowledge on the interactions is still very limited.

Soil-microorganism co-occurence networks

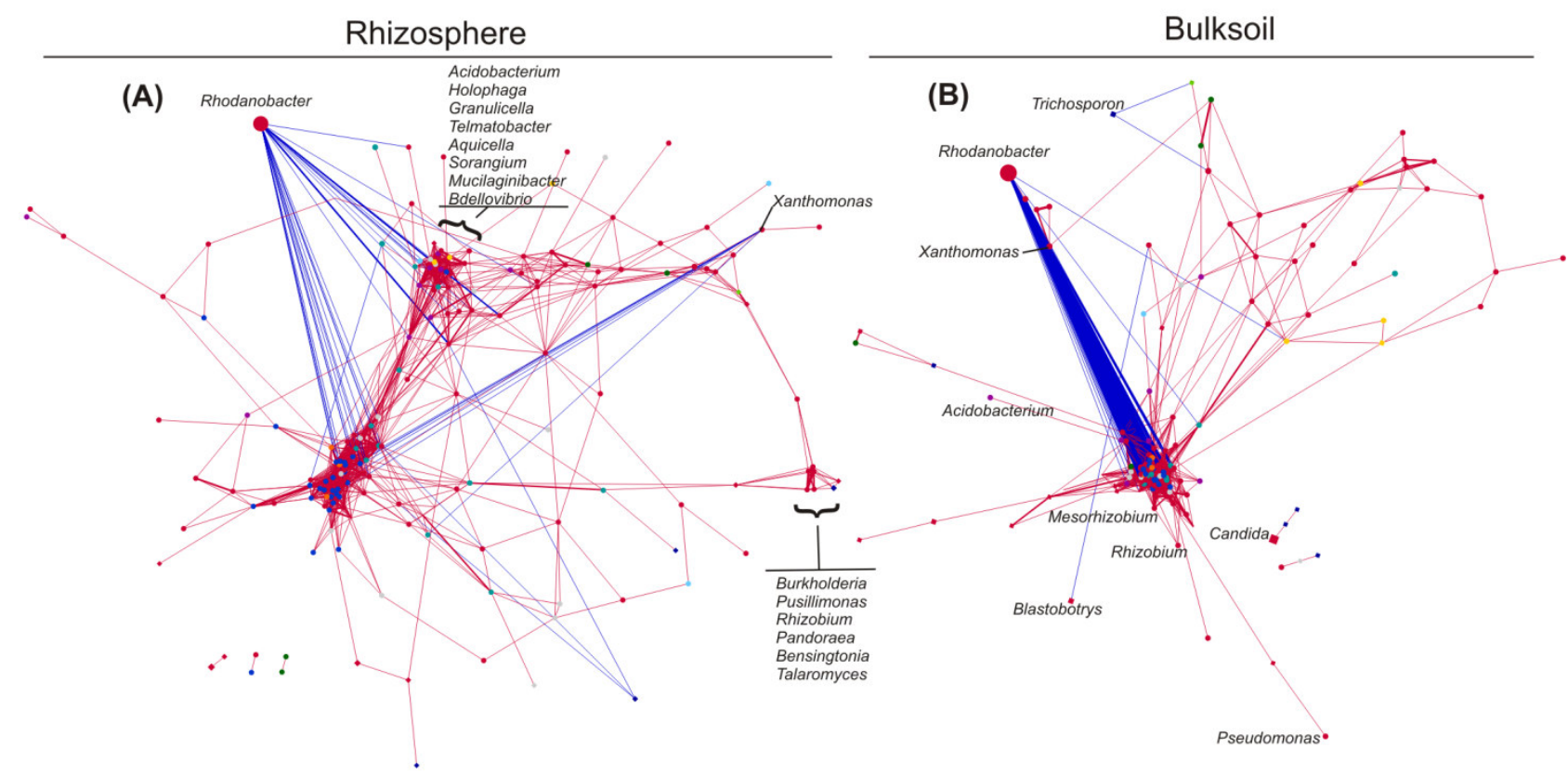

Figure 7. Co-occurrence networks of fungal and bacterial OTUs in the soil. Color-coding, node sizes and edgeweighting according to Figure 6.

Cropping regime, crop species, and sampling location influenced the functioning of bacterial and fungal communities

To gain a closer look into the ecological roles of fungal community members, we used FUNGuild to classify fungal species by their trophic modes to gain an insight into their lifestyle (Nguyen $e t$ al., 2016)e. While 80 OTUs went unmatched, 158 were parsed into an ecological guild. The community composition based on the trophic modes was compared between the different treatments (Table 4). The abundances between the different cropping systems and plants did not vary significantly, except for pathothroph-saprotrophic fungi. They showed a higher abundance in WMand, accordingly, wheat-derived samples. 
Table 4. Relative abundances of fungal trophic guilds (mean \pm SD). The abundances are shown for the different cropping regimes, sampling locations and the two crop specoes. Letters indicate significant differences with $\mathrm{P}<0.05$ between the treatment groups as revealed by Dunn's and Man-Whitney test.

\begin{tabular}{|c|c|c|c|c|}
\hline Treatment & $n$ & Pathotrophs (\%) & Saptrotrophs (\%) & Symbiotrophs (\%) \\
\hline \multicolumn{5}{|c|}{ Cropping regime } \\
\hline FBM & 19 & $6 \pm 13$ & $14 \pm 20$ & $1 \pm 2$ \\
\hline WM & 20 & $7 \pm 20$ & $13 \pm 10$ & $2 \pm 2$ \\
\hline RI & 35 & $7 \pm 16$ & $16 \pm 16$ & $2 \pm 4$ \\
\hline MI & 34 & $5 \pm 11$ & $16 \pm 14$ & $3 \pm 4$ \\
\hline \multicolumn{5}{|c|}{ Sampling location } \\
\hline Bulk soil & 20 & $0.3 \pm 0.5^{\mathrm{abc}}$ & $5.7 \pm 3.8^{\mathrm{a}}$ & $1.3 \pm 1.3$ \\
\hline Rhizosphere soil & 29 & $0.5 \pm 1.7^{\mathrm{a}}$ & $19.4 \pm 16.3^{\mathrm{b}}$ & $1.7 \pm 2.7$ \\
\hline Root & 29 & $10.8 \pm 19.1^{b}$ & $15.3 \pm 16.9^{\mathrm{abc}}$ & $1.9 \pm 3.5$ \\
\hline Aerial parts & 30 & $10.4 \pm 19.1^{\mathrm{bc}}$ & $17.1 \pm 13.9^{\mathrm{bc}}$ & $2.8 \pm 0.8$ \\
\hline \multicolumn{5}{|c|}{ Crop species } \\
\hline Faba bean & 49 & $4.8 \pm 11.0$ & $18.1 \pm 18.3$ & $2.1 \pm 3.6$ \\
\hline Wheat & 49 & $8.3 \pm 18.9$ & $14.1 \pm 11.3$ & $1.9 \pm 3.1$ \\
\hline
\end{tabular}

Abbreviations: FBM, faba bean in monoculture; WM, wheat in monoculture; MI, mixed intercropping; RI, row intercropping.

Between the different plant parts as well as rhizosphere and bulk soil, the community composition varied more strongly. Firstly, endophytic fungal communities contained significantly more pathogens than rhizosphere samples. This is not surprising, as pathogens co-evolve with their hosts and are specialized in host colonization by secreting effector molecules. Thereby, they interfere with plant hormone synthesis or plant defense (Lo Presti et al., 2015). Secondly, the pathotroph-saprotroph-symbiotrophic group showed significant differences in abundance, especially between rhizosphere and roots. In general, this group was more abundant in bulk soil and rhizosphere samples than in endosphere samples. Lastly, saprotrophic fungi dominated the fungal community in all samples. They were significantly more abundant in rhizosphere compared to bulk soil samples. Additionally, they were also highly abundant in endosphere samples. This might be explained by the fact that saprotrophic fungi are generally defined to receive nutrients by break down of dead host cells (Nguyen et al., 2016). Saprotrophic fungi have already been described to dominate the endophytic fungal community of potato roots derived from rotational fields (Manici and Caputo, 2009). Our results show that the recruitment of different trophic guilds of fungi is influenced by the sampling location and, consequently, explains the differences found for the community profiles (NMDS). 


\section{MICROBIAL COMMUNITIES UNDER CROPPING REGIMES}

In addition, functional profiles were predicted for bacterial communities and the abundances of key enzymes of the nitrogen metabolism were compared (Figure 8) because nitrogen is a major driver of bacterial communities in the endosphere (Rodríguez-Blanco et al., 2015; Wemheuer et al., 2016) as well as soil (Herzog et al., 2015; Li et al., 2016). In general, the abundances of these key enzymes differed between the sampling locations endosphere vs. soil and between the cropping regimes monocultures (FBM and WM) vs. intercropping. More precisely, the highest abundances of almost all key enzymes were observed in FBM samples. Nitrogenase, the enzyme catalyzing the nitrogenfixing step, was found in highest abundance in the faba bean monoculture samples, being slightly more abundant in the soil samples. Legumes such as faba bean are well-known for their symbiosis with rhizobia. Biological nitrogen fixation can improve nitrogen content in soils (Peoples et al., 1995; Zahran, 1999) which might result in higher abundances of key enzymes including the nitrogenase. However, for wheat monoculture and samples from intercropping, the nitrogenase gene was more abundant in the endosphere compared to the soil communities. Biological nitrogen fixation by endophytic bacteria were observed in leaves of several plants such as crop species (James, 2000; Burbano et al., 2011; Carvalho et al., 2014) or trees including Pinus flexilis (Moyes et al., 2016). The findings observed in this study indicates that nitrogen fixation plays a greater role in the endosphere as expected.

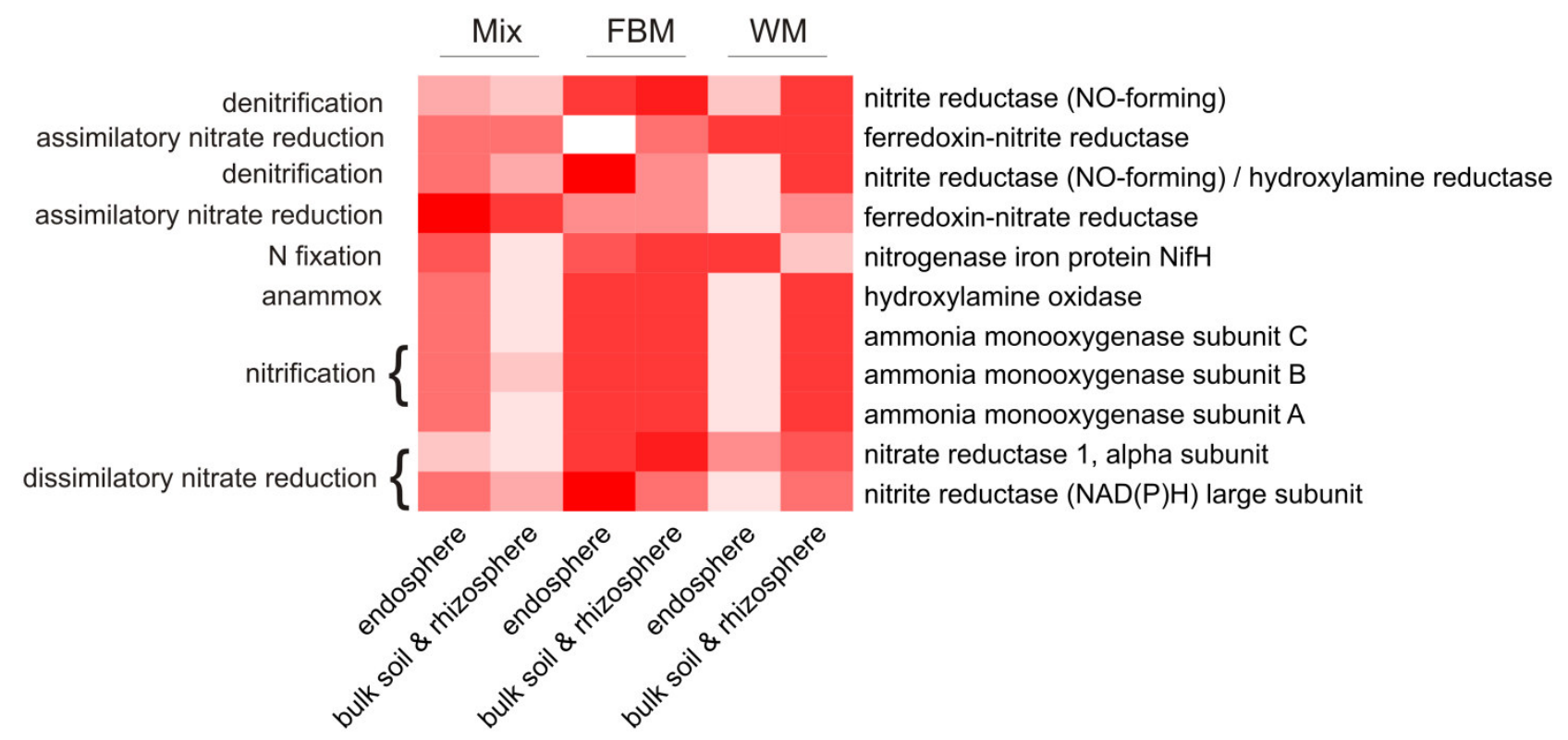

Figure 8. Key-enzyme encoding genes involved in nitrogen cycling. For each subpathway one or more key-enzyme encoding gene(s) is giving for samples derived from intercropping (mix), faba bean monoculture (FBM) and wheat monoculture (WM). Samples were distinguished between endosphere and bulk soil and rhizosphere. Genes are colorcoded by abundance along a gradient of red to white, representing highly and lowly abundant genes, respectively.

In addition, most enzymes were more abundant in wheat samples derived from soil, when compared to the wheat endosphere samples. In the samples derived from intercropping, however, this trend was reversed: all key enzyme were more (or equally) abundant in the endosphere compared to the 
MICROBIAL COMMUNITIES UNDER CROPPING REGIMES

soil samples. This indicates an effect of cropping regime and crop species on $\mathrm{N}$ cycling bacteria although the composition of bacterial communities was not affected by these factors. However, more studies are required to analyze not only changes of microbial community diversity and composition, but also the functioning of these communities with regard to cropping regime, sampling location as well as crop species.

\section{Conclusion}

Although multiple cropping systems provide many economic and ecological advantages, our knowledge about the impact of these systems on microbial communities is still rather limited. Nonetheless, it is of crucial importance to understand this impact as multiple cropping offers a great potential in the sustainable intensification of agriculture. The present study provides first insights into the complex response of bacterial and fungal communities in soil and endosphere of wheat and faba bean plants towards the different cropping regimes by using high-throughput next generation sequencing. Crop species did not affect bacterial and fungal community composition in soil and endosphere, while differences in the richness and diversity between the two crop plants were recorded. In addition, cropping regimes influenced the microbial diversity and richness in soil and rhizosphere, but had no effect on community composition. This is only partly in line with our hypothesis (1) that crop species as well as cropping regime affect microbial community and diversity. We observed differences between soil and endophytic communities in roots and aerial parts which is in line with our hypothesis (2). However, this observation was more pronounced for bacteria than fungi. The differences in bacterial community composition between plant compartments are most likely caused by proteobacterial endophytes strongly associated with either aerial parts or roots. Functional classification of fungal taxa revealed differences between soil and endosphere which supports the hypothesis (3). Moreover, strong negative interactions between fungal OTUs were detected indicating strong competition and probably niche adaptation by specialized fungal taxa. Contrary to our hypothesis (4), the effects of crop species and cropping regime on diversity, composition, and functioning were similar in the soil communities as well as in the two endophytic communities. Obtained data generated the basis for further research on the complex interaction of management practices and their impact on soil and plant-associated microbial communities and their functioning. 


\section{MICROBIAL COMMUNITIES UNDER CROPPING REGIMES}

Acknowlegements

This study is part of the project IMPAC ${ }^{3}$ and was funded by the Federal Ministry of Education and Research (FKZ 031A351A). The authors thank Prof. Dr. Wolfgang Link from the Working Group "Breeding Research Faba Bean" (Division of Plant Breeding at the University of Göttingen) for providing the seed material and Dr. Jürgen Grotheer (Department of Physical Geography at the University of Göttingen), for the C:N analysis of the soil samples. 


\section{References}

1. Andrews D, Kassam A. (1976). The importance of multiple cropping in increasing world food supplies. American Society of Agronomy.

2. Aziz M, Mahmood A, Asif M, Ali A. (2015). Wheat-based intercropping: a review. J Anim Plant Sci 25:896-904.

3. Aßhauer KP, Wemheuer B, Daniel R, Meinicke P. (2015). Tax4Fun: predicting functional profiles from metagenomic 16S rRNA data. Bioinformatics 13:2882-2884.

4. Berg G, Grube M, Schloter M, Smalla K. (2014). Unraveling the plant microbiome: looking back and future perspectives. Front Microbiol 5:148.

5. Berg G, Smalla K. (2009). Plant species and soil type cooperatively shape the structure and function of microbial communities in the rhizosphere. FEMS Microbiol Ecol 68:1-13.

6. Bonito G, Reynolds H, Robeson MS, Nelson J, Hodkinson BP, Tuskan G, et al. (2014). Plant host and soil origin influence fungal and bacterial assemblages in the roots of woody plants. Mol Ecol 23:3356-3370.

7. Bulgarelli D, Schlaeppi K, Spaepen S, Ver Loren Van Themaat E, Schulze-Lefert P. (2013). Structure and functions of the bacterial microbiota of plants. Annu Rev Plant Biol 64:807-838.

8. Burbano CS, Liu Y, Rösner KL, Reis VM, Caballero-Mellado J, Reinhold-Hurek B, et al. (2011). Predominant nifH transcript phylotypes related to Rhizobium rosettiformans in field-grown sugarcane plants and in Norway spruce. Env Microbiol Rep 3:383-389.

9. Cannon PF, Simmons CM. (2002). Diversity and host preference of leaf endophytic fungi in the Iwokrama Forest Reserve, Guyana. Mycologia 94:210-220.

10. Caporaso JG, Kuczynski J, Stombaugh J, Bittinger K, Bushman FD, Costello EK, et al. (2010). QIIME allows analysis of high-throughput community sequencing data. Nat Methods 7:335-336.

11. Carvalho T, Balsemão-Pires E, Saraiva R, Ferreira P, Hemerly A. (2014). Nitrogen signalling in plant interactions with associative and endophytic diazotrophic bacteria. $\mathbf{J}$ Exp Bot eru319.

12. Chelius MK, Triplett EW. (2001). The diversity of Archaea and Bacteria in association with the roots of Zea mays L. Microbial Ecol 41:252-263. 


\section{MICROBIAL COMMUNITIES UNDER CROPPING REGIMES}

13. Chen D, Chen X, Liang Y, Huo X, Zhang C, Duan Y, et al. (2015). Influence of cropping system on enzyme activities and fungal communities in soil. Acta Pratacultuae Sinica 24:77-84.

14. Cole JR, Wang Q, Cardenas E, Fish J, Chai B, Farris RJ, et al. (2009). The Ribosomal Database Project: improved alignments and new tools for rRNA analysis. Nucleic Acids Res 37:D141-D145.

15. Coleman-Derr D, Desgarennes D, Fonseca-Garcia C, Gross S, Clingenpeel S, Woyke T, et al. (2016). Plant compartment and biogeography affect microbiome composition in cultivated and native Agave species. New Phytol 209:798-811.

16. Corre-Hellou G, Fustec J, Crozat Y. (2006). Interspecific competition for soil N and its interaction with $\mathrm{N}_{2}$ fixation, leaf expansion and crop growth in pea-barley intercrops. Plant Soil 282:195-208.

17. Costa R, Gotz M, Mrotzek N, Lottmann J, Berg G, Smalla K. (2006). Effects of site and plant species on rhizosphere community structure as revealed by molecular analysis of microbial guilds. FEMS Microbiol Ecol 56:236-249.

18. Crawley M.J. (2007). The R Book. Wiley Publishing: Hoboken.

19. De Cáceres MD, Legendre P. (2009). Associations between species and groups of sites: indices and statistical inference. Ecology 90:3566-3574.

20. De Cáceres MD, Legendre P, Moretti M. (2010). Improving indicator species analysis by combining groups of sites. Oikos 119:1674-1684.

21. De Zelicourt A, Al-Yousif M, Hirt H. (2013). Rhizosphere microbes as essential partners for plant stress tolerance. Mol Plant 6:242-245.

22. Dematheis F, Kurtz B, Vidal S, Smalla K. (2013). Multitrophic interactions among Western corn rootworm, Glomus intraradices and microbial communities in the rhizosphere and endorhiza of maize. Front Microbiol 4:357.

23. Edgar RC. (2010). Search and clustering orders of magnitude faster than BLAST. Bioinformatics 26:2460-2461.

24. Edwards J, Johnson C, Santos-Medellín C, Lurie E, Podishetty NK, Bhatnagar S, et al. (2015). Structure, variation, and assembly of the root-associated microbiomes of rice. PNAS 112:E911-E920.

25. Eghball B, Maranville JW. (1993). Root development and nitrogen influx of corn genotypes grown under combined drought and nitrogen stresses. Agron J 85:147-152. 
26. Ellouze W, Esmaeili Taheri A, Bainard LD, Yang C, Bazghaleh N, Navarro-Borrell A, et al. (2014). Soil fungal resources in annual cropping systems and their potential for management. BioMed Res Int 531824.

27. Fonseca-García C, Coleman-Derr D, Garrido E, Visel A, Tringe SG, Partida-Martínez LP. (2016). The Cacti Microbiome: Interplay between habitat-filtering and hostspecificity. Front Microbiol 7:150.

28. Francis CA. (1986). Multiple cropping systems. Macmillan Publishing Company: New York.

29. Gaiero JR, Mccall CA, Thompson KA, Day NJ, Best AS, Dunfield KE. (2013). Inside the root microbiome: bacterial root endophytes and plant growth promotion. Am J Bot 100:1738-1750.

30. Gange AC, Soma D, Amanda FC, Sutton BC. (2007). Site- and species-specific differences in endophyte occurrence in two herbaceous plants. J Ecol 95:614-622.

31. Ghosh PK, Manna MC, Bandyopadhyay KK, Tripathi AK, Wanjari RH, Hati KM, et al. (2006). Interspecific interaction and nutrient use in soybean/sorghum intercropping system. Agron J 98:1097-1108.

32. Hardoim PR, Van Overbeek LS, Berg G, Pirttila AM, Compant S, Campisano A, et al. (2015). The hidden world within plants: ecological and evolutionary considerations for defining functioning of microbial endophytes. Microbiol Mol Biol Rev 79:293-320.

33. Hauggaard-Nielsen H, Ambus P, Jensen ES. (2001). Temporal and spatial distribution of roots and competition for nitrogen in pea-barley intercrops - a field study employing 32P technique. Plant Soil 236:63-74.

34. Hauggaard-Nielsen H, Jensen ES. (2005). Facilitative root interactions in intercrops. Plant Soil 274:237-250.

35. He LZ, Wu J, O`Donnell GA, Syers KJ. (1997). Seasonal responses in microbial biomass carbon, phosphorus and sulphur in soils under pasture. Biol Fertil Soils 24:421-428.

36. Herzog S, Wemheuer F, Wemheuer B, Daniel R. (2015). Effects of fertilization and sampling time on compasition and diversity of entire and active bacterial communities in german grassland soils. PloS ONE doi: 0.1371/journal.pone.0145575.

37. Inal A, Gunes A, Zhang F, Cakmak I. (2007). Peanut/maize intercropping induced changes in rhizosphere and nutrient concentrations in shoots. Plant Physiol Biochem 45:350-356. 


\section{MICROBIAL COMMUNITIES UNDER CROPPING REGIMES}

38. James E. (2000). Nitrogen fixation in endophytic and associative symbiosis. Field Crop Res 65:197-209.

39. Jiang Y, Liang Y, Li C, Wang F, Sui Y, Suvannang N, et al. (2016). Crop rotations alter bacterial and fungal diversity in paddy soils across East Asia. Soil Biol Biochem 95:250-261.

40. Jin H, Yang X-Y, Yan Z-Q, Liu Q, Li X-Z, Chen J-X, et al. (2014). Characterization of rhizosphere and endophytic bacterial communities from leaves, stems and roots of medicinal Stellera chamaejasme L. Syst Appl Microbiol 37:376-385.

41. Kent AD, Triplett EW. (2002). Microbial communities and their interactions in soil and rhizosphere ecosystems. Annu Rev Microbiol 56:211-236.

42. Lane DJ. (1991). 16S/23S rRNA sequencing. International Society for Microbial Ecology.

43. Leblanc N, Kinkel LL, Kistler HC. (2015). Soil fungal communities respond to grassland plant community richness and soil edaphics. Microbial Ecol 70:188-195.

44. Letourneau DK, Armbrecht I, Rivera BS, Lerma JM, Carmona EJ, Daza MC, et al. (2011). Does plant diversity benefit agroecosystems? A synthetic review. Ecol Appl 21:9-21.

45. Li L, Yang S, Li X, Zhang F, Christie P. (1999). Interspecific complementary and competitive interactions between intercropped maize and faba bean. Plant Soil 212:105-114.

46. Li Q-S, Wu L-K, Chen J, Khan MA, Luo X-M, Lin W-X. (2016). Biochemical and microbial properties of rhizospheres under maize/peanut intercropping. J Integr Agric 15:101-110.

47. Lo Presti L, Lanver D, Schweizer G, Tanaka S, Liang L, Tollot M, et al. (2015). Fungal effectors and plant susceptibility. Annu Rev PLant Biol 66:513-545.

48. Lugtenberg B, Kamilova F. (2009). Plant-growth-promoting rhizobacteria. Annu Rev Microbiol 63:541-556.

49. Malinowski DP, Belesky DP. (2000). Adaptations of endophyte-infected cool-season grasses to environmental stresses: mechanisms of drought and mineral stress tolerance. Crop Sci 40:923-940.

50. Manici LM, Caputo F. (2009). Fungal community diversity and soil health in intensive potato cropping systems of the east Po valley, northern Italy. Ann Appl Biol 155:245258. 
51. Mariotti M, Masoni A, Ercoli L, Arduini I. (2009). Above- and below-ground competition between barley, wheat, lupin and vetch in a cereal and legume intercropping system. Grass Forage Sci 64:401-412.

52. Mendes LW, Kuramae EE, Navarrete AA, Van Veen JA, Tsai SM. (2014). Taxonomical and functional microbial community selection in soybean rhizosphere. ISME J 8:1577-1587.

53. Mouhamadou B, Puissant J, Personeni E, Desclos-Theveniau M, Kastl EM, Schloter M, et al. (2013). Effects of two grass species on the composition of soil fungal communities. Biol Fertil Soils 49:1131-1139.

54. Moyes AB, Kueppers LM, Pett-Ridge J, Carper DL, Vandehey N, O'Neil J, et al. (2016). Evidence for foliar endophytic nitrogen fixation in a widely distributed subalpine conifer. New Phytol 210:657-668.

55. Murugan R, Kumar S. (2013). Influence of long-term fertilisation and crop rotation on changes in fungal and bacterial residues in a tropical rice-field soil. Biol Fertil Soils 49:847-856.

56. Navarro-Noya YE, Gómez-Acata S, Montoya-Ciriaco N, Rojas-Valdez A, SuárezArriaga MC, Valenzuela-Encinas C, et al. (2013). Relative impacts of tillage, residue management and crop-rotation on soil bacterial communities in a semi-arid agroecosystem. Soil Biolo Biochem 65:86-95.

57. Nettles R, Watkins J, Ricks K, Boyer M, Licht M, Atwood LW, et al. (2016). Influence of pesticide seed treatments on rhizosphere fungal and bacterial communities and leaf fungal endophyte communities in maize and soybean. Appl Soil Ecol 102:61-69.

58. Nguyen NH, Song Z, Bates ST, Branco S, Tedersoo L, Menke J, et al. (2016). FUNGuild: An open annotation tool for parsing fungal community datasets by ecological guild. Fungal Ecol 20:241-248.

59. Nübel U, Engelen B, Felske A, Snaidr J, Wieshuber A, Amann RI, et al. (1996). Sequence heterogeneities of genes encoding 16S rRNAs in Paenibacillus polymyxa detected by temperature gradient gel electrophoresis. J Bacteriol 178:5636-5643.

60. Oksanen J, Blanchet FG, Kindt R, Legendre P, Minchin PR, O'Hara RB, et al. (2013). Vegan: community ecology package. R package version 2.0-10.

61. Penton CR, Gupta VVSR, Tiedje JM, Neate SM, Ophel-Keller K, Gillings M, et al. (2014). Fungal community structure in disease suppressive soils assessed by 28S LSU gene sequencing. PLoS ONE 9:e93893. 


\section{MICROBIAL COMMUNITIES UNDER CROPPING REGIMES}

62. Peoples MB, Herridge DF, Ladha JK. (1995). Biological nitrogen fixation: An efficient source of nitrogen for sustainable agricultural production? Plant Soil 174:328.

63. Philippot L, Raaijmakers JM, Lemanceau P, Van Der Putten WH. (2013). Going back to the roots: the microbial ecology of the rhizosphere. Nat Rev Micro 11:789-799.

64. Pii Y, Borruso L, Brusetti L, Crecchio C, Cesco S, Mimmo T. (2016). The interaction between iron nutrition, plant species and soil type shapes the rhizosphere microbiome. Plant Physiol Biochem 99:39-48.

65. Purkhold U, Pommerening-Röser A, Juretschko S, Schmid MC, Koops H-P, Wagner M. (2000). Phylogeny of all recognized species of ammonia oxidizers based on comparative 16S rRNA and amoA sequence analysis: implications for molecular diversity surveys. Appl Environ Microbiol 66:5368-5382.

66. R Core Team (2013). R: A Language and Environment for Statistical Computing. R Foundation for Statistical Computing: Vienna.

67. Robinson RJ, Fraaije BA, Clark IM, Jackson RW, Hirsch PR, Mauchline TH. (2015). Endophytic bacterial community composition in wheat (Triticum aestivum) is determined by plant tissue type, developmental stage and soil nutrient availability. Plant Soil doi:10.1007/s11104-015-2495-4.

68. Rodriguez Couto S, Sanroman M. (2006). Application of solid-state fermentation to food industry--a review. J Food Eng 76:291-302.

69. Romero FM, Marina M, Pieckenstain FL. (2014). The communities of tomato (Solanum lycopersicum L.) leaf endophytic bacteria, analyzed by 16S-ribosomal RNA gene pyrosequencing. FEMS Microbiol Lett 351:187-194.

70. Shakya M, Gottel N, Castro H, Yang ZK, Gunter L, Labbé J, et al. (2013). A multifactor analysis of fungal and bacterial community structure in the root microbiome of mature Populus deltoides trees. PLoS ONE 8:e76382.

71. Shannon P, Markiel A, Ozier O, Baliga NS, Wang JT, Ramage D, et al. (2003). Cytoscape: a software environment for integrated models of biomolecular interaction networks. Genome Res 13:2498-2504.

72. Siddiqui I, Shaukat S. (2003). Endophytic bacteria. Prospects and opportunities for the biological control of plant parasitic nematodes. Nematol Mediterr 31:111-120.

73. Silva A, Babujia L, Matsumoto L, Guimarães M, Hungria M. (2013). Bacterial diversity under different tillage and crop rotation systems in an Oxisol of southern Brazil. Open Agric J 7:40-47. 
74. Song Y, Marschner P, Li L, Bao X, Sun J, Zhang F. (2007a). Community composition of ammonia-oxidizing bacteria in the rhizosphere of intercropped wheat (Triticum aestivum L.), maize (Zea mays L.), and faba bean (Vicia faba L.). Biol Fertil Soils 44:307-314.

75. Song Y, Zhang F, Marschner P, Fan F, Gao H, Bao X, et al. (2007b). Effect of intercropping on crop yield and chemical and microbiological properties in rhizosphere of wheat (Triticum aestivum L.), maize (Zea mays L.), and faba bean (Vicia faba L.). Biol Fertil Soils 43:565-574.

76. Sugiyama A, Ueda Y, Zushi T, Takase H, Yazaki K. (2014). Changes in the bacterial community of soybean rhizospheres during growth in the field. PLoS ONE 9:e100709.

77. Sun L, Qiu F, Zhang X, Dai X, Dong X, Song W. (2008). Endophytic bacterial diversity in rice (Oryza sativa L.) roots estimated by $16 \mathrm{~S}$ rDNA sequence analysis. Microb Ecol 55:415-424.

78. Suzuki C, Takenaka M, Oka N, Nagaoka K, Karasawa T. (2012). A DGGE analysis shows that crop rotation systems influence the bacterial and fungal communities in soils. Soil Sci Plant Nutr 58:288-296.

79. Taheri AE, Hamel C, Gan Y. (2016). Cropping practices impact fungal endophytes and pathogens in durum wheat roots. Appl Soil Ecol 100:104-111.

80. Tichy L, Chytry M. (2006). Statistical determination of diagnostic species for site groups of unequal size. J Veg Sci 17:809-818.

81. Timmusk S, Abd El-Daim IA, Copolovici L, Tanilas T, Kännaste A, Behers L, et al. (2014). Drought-tolerance of wheat improved by rhizosphere bacteria from harsh environments: enhanced biomass production and reduced emissions of stress volatiles. PLoS ONE 9:e96086.

82. Toju H, Tanabe AS, Yamamoto S, Sato H. (2012). High-coverage ITS primers for the DNA-based identification of Ascomycetes and Basidiomycetes in environmental samples. PLoS ONE 7:e40863.

83. Turner TR, James EK, Poole PS. (2013a). The plant microbiome. Genome Biol 14:10.1186.

84. Turner TR, Ramakrishnan K, Walshaw J, Heavens D, Alston M, Swarbreck D, et al. (2013b). Comparative metatranscriptomics reveals kingdom level changes in the rhizosphere microbiome of plants. ISME J 7:2248-2258.

85. Van Der Heijden MGA, Hartmann M. (2016). Networking in the plant microbiome. PLoS Biol 14:e1002378. 


\section{MICROBIAL COMMUNITIES UNDER CROPPING REGIMES}

86. Vandermeer JH. (1992). The ecology of intercropping. Cambridge University Press: Cambridge.

87. Vasse J, Frey P, Trigalet A. (1995). Microscopic studies of intercellular infection and protoxylem invasion of tomato roots by Pseudomonas solanacearum. Mol Plant Microb Interact.

88. Vidal S, Jaber LR. (2015). Entomopathogenic fungi as endophytes: plant-endophyteherbivore interactions and prospects for use in biological control. Curr Sci 108:1.

89. Wang W, Zhai Y, Cao L, Tan H, Zhang R. (2016). Endophytic bacterial and fungal microbiota in sprouts, roots and stems of rice (Oryza sativa L.). Microbiol Res 188189:1-8.

90. Wang Y, Marschner P, Zhang F. (2012). Phosphorus pools and other soil properties in the rhizosphere of wheat and legumes growing in three soils in monoculture or as a mixture of wheat and legume. Plant Soil 354:283-298.

91. Wardle D. (1992). A comparative assessment of factors which influence microbial biomass carbon and nitrogen levels in soil. Biol Rev 67:321-358.

92. Wearn JA, Sutton BC, Morley NJ, Gange AC. (2012). Species and organ specificity of fungal endophytes in herbaceous grassland plants. J Ecol 100:1085-1092.

93. Wemheuer F, Wemheuer B, Kretzschmar D, Pfeiffer B, Herzog S, Daniel R, et al. (2016). Impact of grassland management regimes on bacterial endophyte diversity differs with grass species. Lett Appl Microbiol 62:323-329.

94. White TJ, Bruns T, Lee S, Taylor J. (1990). Amplification and direct sequencing of fungal ribosomal RNA genes for phylogenetics. PCR protocols: a guide to methods and applications 18:315-322.

95. Wieland G, Neumann R, Backhaus H. (2001). Variation of microbial communities in soil, rhizosphere, and rhizoplane in response to crop species, soil type, and crop development. Appl Environ Microbiol 67:5849-5854.

96. Wietz M, Wemheuer B, Simon H, Giebel H-A, Seibt MA, Daniel R, et al. (2015). Bacterial community dynamics during polysaccharide degradation at contrasting sites in the Southern and Atlantic Oceans. Environ Microbiol 17:3822-3831.

97. Winter M, De Mol F, Von Tiedemann A. (2014). Cropping systems with maize and oilseed rape for energy production may reduce the risk of stem base diseases in wheat. Field Crop Res 156:249-257. 
98. Xiong W, Zhao Q, Xue C, Xun W, Zhao J, Wu H, et al. (2016). Comparison of fungal community in Black Pepper-Vanilla and Vanilla monoculture systems associated with Vanilla Fusarium Wilt Disease. Front Microbiol 7:117.

99. Yang L, Xie J, Jiang D, Fu Y, Li G, Lin F. (2008). Antifungal substances produced by Penicillium oxalicum strain PY-1-potential antibiotics against plant pathogenic fungi. World J Microbiol Biotechnol 24:909-915.

100. Yang Z, Yang W, Li S, Hao J, Su Z, Sun M, et al. (2016). Variation of bacterial community diversity in rhizosphere soil of sole-cropped versus intercropped wheat field after harvest. PLoS ONE 11:e0150618.

101. Zahran HH. (1999). Rhizobium-legume symbiosis and nitrogen fixation under severe conditions and in an arid climate. Microbiol Mol Biol Rev 63:968-989.

102. Zhang F, Li L. (2003). Using competitive and facilitative interactions in intercropping systems enhances crop productivity and nutrient-use efficiency. Plant Soil 248:305312.

103. Zhang NN, Sun YM, Wang ET, Yang JS, Yuan HL, Scow KM. (2015). Effects of intercropping and rhizobial inoculation on the ammonia-oxidizing microorganisms in rhizospheres of maize and faba bean plants. Appl Soil Ecol 85:76-85.

104. Zhang YZ, Wang ET, Li M, Li QQ, Zhang YM, Zhao SJ, et al. (2011). Effects of rhizobial inoculation, cropping systems and growth stages on endophytic bacterial community of soybean roots. Plant Soil 347:147-161.

105. Zhao J, Zhang R, Xue C, Xun W, Sun L, Xu Y, et al. (2014). Pyrosequencing reveals contrasting soil bacterial diversity and community structure of two main winter wheat cropping systems in China. Microb Ecol 67:443-453. 
MICROBIAL COMMUNITIES UNDER CROPPING REGIMES

\section{SUPPLEMENTARY INFORMATION}

Supplementary figures and tables are provided along with the electronic version of this thesis (on DVD), under the following paths:

Table S1:

Table S2:

Supplementary Information/Chapter III.8/ Table S1.xlsx

Table S3:

Supplementary Information/Chapter III.8/ Table S2.xslx

Table S4:

Supplementary Information/Chapter III.8/ Table S3.xlsx

Supplementary Information/Chapter III.8/ Table S3.xlsx 


\section{CHAPTER IV}

\section{GENERAL DISCUSSION}


'Education is what remains after you have forgotten everything you learned in school.' Albert Einstein 


\section{GENERAL DISCUSSION}

Microorganisms are the most abundant and diverse group of organisms. Especially Bacteria and Archaea can be found in every environment investigated so far, even in those that are completely life-threatening from an anthropogenic view. They thrive in hot springs and deep sea vents, volcanic sites and the perpetual ice of Antarctica (Mientus et al., 2013; Montross et al., 2014; Urich et al., 2014; Wemheuer et al., 2013). Microorganisms are major drivers of biogeochemical cycles (Lengeler et al., 1999; Martinko and Madigan, 2005) and important players in ecosystem structuring (Azam and Malfatti, 2007). The sampling and classification of microorganisms is, however, challenging due to their small size. Additionally, only a very small amount of the actual diversity of prokaryotic microorganisms can be cultivated by using standard cultivation approaches.

The mechanisms that shape microbial community structure, influence their functioning and act upon the environment are still not fully understood. Microbial community analyses are mostly based on taxonomic marker gene analysis, e.g. 16S rRNA genes sequences, which are used to classify the organisms present in a sample. Therefore, the environmental DNA (or RNA) needs to be extracted. This is challenging, especially with soil samples (Lombard et al., 2011). Varying effects of soil pH (Sagova-Mareckova et al., 2008), clay (Novinscak et al., 2011) and organic carbon content can compromise extraction, as compounds such as humic acids are known to inhibit DNA polymerase and reverse transcriptase that are often employed in downstream analyses (Tebbe and Vahjen, 1993). Consequently, generation of datasets comprising a wide variety of different soil types raise the necessity of an extraction protocol that (1) produces high purity nucleic acids from different soil types, (2) yields long nucleic acid fragments (3) is representative for the microbial diversity in a sample. The application of the same extraction method is crucial and a prerequisite for comparative analyses between samples within a study. Therefore, the first part of this thesis focused on comparing various DNA and RNA extraction methods (Chapter III.1). The MoBio Power Soil DNA isolation kit perform equally well over the range of tested soils (Wüst et al., 2016). It produced similar amounts of DNA and 16S rRNA gene copies for each soil and did not overestimate any of the abundant phyla detected.

The main focus of this thesis was the analysis of diversity and ecology of terrestrial microbial assemblages in different environments. The focus was on the response of the microbial communities towards anthropogenic factors such as land use type and intensification. In particular, the effects of land use intensity on soil bacterial community 


\section{GENERAL DISCUSSION}

diversity, structure and function in soils of grasslands and forests in Germany (Chapter III.2, III.4 and III.5) and in the endosphere of grasses (Chapter III.6) were investigated. In addition, the response of soil microbial communities toward different tree species (Chapter III.3) was analyzed. Finally, soil and endophytic microbial communities in an intercropping experiment with faba bean and wheat (Chapter III.7 and Chapter III.8) were investigated.

\section{IV.1. TERRESTRIAL MICROBES}

\section{IV.1.1.Soil bacterial communities and their response to land use intensity}

The main study of this thesis (Chapter III.2) focused on investigating the effect of land use type and intensity on soil bacterial communities in forests and grasslands. In forests, land use intensification occurs through different factors. First, there are different management regimes. These management regimes are unmanaged forests, age class forests (clear cutting at regular intervals) and selection forests (single tree removal). Age class and selection forests are different in the strength of disturbances (soil compaction), mostly due to differing harvesting intervals. Unmanaged forests are natural, undisturbed forests from which neither dead wood nor other organic matter is removed. Furthermore, forests differ in the dominant tree species and stand age. Replacing natural beech stands by the faster growing species spruce indicates land use intensification by selection of tree species. Furthermore, tree species selection and stand age affect the susceptibility of a stand to disturbances such as wind throw and pathogens. This results in the need of a higher management intensity to reduce the risk of stand loss. In 2013 (Schall and Ammer, 2013) implemented a silvicultural management index (SMI), to integrate all these components and facilitate the investigation of land use intensification in forests.

In grasslands, there are also different factors contributing to land use intensification. The management regimes are meadow, pasture and mown pasture. They already integrate mowing and grazing, two of the intensification factors. Additionally, plots of each management are either fertilized or unfertilized. Blüthgen and colleagues (Blüthgen et al., 2012) introduced the land-use intensity index (LUI) to assess land use intensity in grasslands. It weights each of the three factors equally taking into account the amount of nitrogen applied by fertilization ( $\mathrm{kg}$ nitrogen $\mathrm{ha}^{-1} \mathrm{y}^{-1}$ ), the mowing frequency (cuts per year) and the grazing intensity (livestock units days of grazing $\mathrm{ha}^{-1} \mathrm{y}^{-1}$ ).

Bacterial diversity and community composition were generally unaffected by increasing land use intensity in both systems. However, a significant correlation of the SMI 
with forest soil bacterial communities in the Schorfheide-Chorin could be found. The SMI did not affect the bacterial community structure in forest soil in the Hainich-Dün or Schwäbische Alb. This could be attributed to the high variance of SMI within the pine stands in the Schorfheide-Chorin, where also the tree species-effect is most pronounced. No differences between the management regimes could be detected. Strikingly, the tree species was an important driver of bacterial community structure in forests. The effect of tree species clearly distinguished between soil bacterial communities from coniferous or broadleaved forest soils. Several studies focused on the effects of land use intensification through manipulation of tree species, soil compaction or harvesting and organic matter removal on soil microbial communities (Table 1). In all studies taking the effect of tree species into account, an effect on the microbial community could be found. Again, this separation was mainly between coniferous and broadleaved tree species, although distinct microbial communities under different types of broadleaved trees are reported (Urbanová et al., 2015). The effect of tree species is most likely an indirect one, as coniferous trees are known to acidify their surrounding soils significantly (Hornung, 1985). A detailed analysis of the tree species-related effects on microbial communities (Chapter III.3) showed the presence of distinct microbial communities in soil of beech and spruce dominated forests. The diversity of bacteria was higher in beech forest soils compared to spruce forest. The opposite was detected for fungal diversity. Additionally, the results indicated that community composition was affected by the distance from spruce tree trunks. This effect was not detected in beech dominated forest soils and is likely due to the very different root systems. While spruce trees are typically shallow rooted, beech trees develop a deep reaching root system and can acquire nutrients over a range of soil horizons. Spruce roots would therefore more strongly influence the upper soil layers around the tree than compared to beech. Upper soil layers favored saprotrophic bacterial and fungal taxa, which are usually connected with organic matter breakdown (Edwards and Zak, 2010; Lindahl et al., 2007; Pankratov et al., 2007; Stursová et al., 2012). Furthermore, microbial community was impacted by season, an effect that was significant in beech forests, but not in spruce forests. Seasonality in soil microbial communities has been reported previously for bacteria in oak dominated forests (López-Mondéjar et al., 2015), and fungi in beech forest soils (Buée et al., 2005). Interestingly, this study also provided evidence for distinct microbial community profiles under single trees, which has been previously reported for fungi in Pinus muricata forest soils (Branco et al., 2013).

Although the studied gradient of land use intensification ranged from unmanaged forests to age class forests and selection forests an impact of management on soil bacterial 


\section{GENERAL DISCUSSION}

community structure and diversity was not detected. Furthermore, gamma diversity of 15 taxonomic groups in even-aged and uneven-aged forests was not significantly impacted by the two forest systems (Chapter III.5). The management regimes differ in their rates of soil disturbance by compaction through harvesting and organic matter removal. Both factors influence microbial communities (Hartmann et al., 2012; Hartmann et al., 2014), but the effect on soil bacterial communities was not as pronounced as on soil mycorrhiza.

Table x: Studies on land use intensification in grasslands and forests. Studies contained within this thesis are given in bold.

\begin{tabular}{|c|c|c|c|c|c|}
\hline Reference & Method & $\begin{array}{l}\text { Type of land use } \\
\text { intensification }\end{array}$ & Samples & Effect on & Effect? \\
\hline \multicolumn{6}{|l|}{ FOREST } \\
\hline $\begin{array}{l}\text { Lejon et al., } \\
2005\end{array}$ & ARISA & tree species & 16 & $\begin{array}{l}\text { community } \\
\text { composition }\end{array}$ & yes \\
\hline $\begin{array}{l}\mathrm{He} \text { et al., } \\
2006\end{array}$ & $\begin{array}{c}\text { 16S RNA clone } \\
\text { libraries }\end{array}$ & $\begin{array}{l}\text { dead wood removal } \\
\text { / management }\end{array}$ & 12 & $\begin{array}{l}\text { community } \\
\text { composition / } \\
\text { diversity }\end{array}$ & no \\
\hline $\begin{array}{l}\text { Axelrood et } \\
\text { al., } 2002\end{array}$ & $\begin{array}{l}\text { 16S RNA clone } \\
\text { libraries }\end{array}$ & soil compaction & 6 & $\begin{array}{l}\text { bacterial } \\
\text { community } \\
\text { composition }\end{array}$ & yes \\
\hline $\begin{array}{l}\text { Lin et al., } \\
2011 \mathrm{a}\end{array}$ & $\begin{array}{c}\text { 16S RNA clone } \\
\text { libraries }\end{array}$ & $\begin{array}{l}\text { native forest / } \\
\text { plantation; tree } \\
\text { species }\end{array}$ & 9 & $\begin{array}{l}\text { community } \\
\text { composition / } \\
\text { diversity }\end{array}$ & yes \\
\hline $\begin{array}{l}\text { Lin et al., } \\
2011 \mathrm{~b}\end{array}$ & $\begin{array}{c}\text { 16S RNA clone } \\
\text { libraries }\end{array}$ & $\begin{array}{c}\text { disturbance } \\
\text { (native/plantation) }\end{array}$ & & $\begin{array}{l}\text { community } \\
\text { composition / } \\
\text { diversity }\end{array}$ & yes \\
\hline $\begin{array}{l}\text { Selvam et } \\
\text { al., } 2010\end{array}$ & $\begin{array}{c}\text { 16S RNA clone } \\
\text { libraries }\end{array}$ & tree species & & diversity & yes \\
\hline $\begin{array}{l}\text { Upchurch et } \\
\text { al., } 2008\end{array}$ & 16S RNA libraries & forest age & 9 & diversity & yes \\
\hline $\begin{array}{l}\text { Hackl et al., } \\
2004\end{array}$ & $\begin{array}{l}\text { TRFLP / 16S } \\
\text { sequencing }\end{array}$ & $\begin{array}{l}\text { tree species / mixed } \\
\text { stands }\end{array}$ & 60 & $\begin{array}{l}\text { bacterial } \\
\text { community } \\
\text { composition }\end{array}$ & yes \\
\hline $\begin{array}{l}\text { Felsmann et } \\
\text { al., } 2015\end{array}$ & $\begin{array}{l}\text { TRFLP / 16S } \\
\text { sequencing }\end{array}$ & tree species & 9 & $\begin{array}{l}\text { community } \\
\text { composition / } \\
\text { diversity }\end{array}$ & yes \\
\hline $\begin{array}{l}\text { Myers et } \\
\text { al., 2001 }\end{array}$ & PLFA & tree species & & $\begin{array}{l}\text { community } \\
\text { composition }\end{array}$ & yes \\
\hline $\begin{array}{l}\text { Thoms et } \\
\text { al., } 2010\end{array}$ & PLFA & $\begin{array}{l}\text { tree species } \\
\text { diversity } \\
\text { compaction }\end{array}$ & 27 & $\begin{array}{l}\text { community } \\
\text { composition }\end{array}$ & yes \\
\hline $\begin{array}{l}\text { Busse et al., } \\
2006\end{array}$ & PLFA & $\begin{array}{l}\text { organic matter } \\
\text { removal / weed } \\
\text { control }\end{array}$ & & $\begin{array}{l}\text { community } \\
\text { composition }\end{array}$ & yes \\
\hline $\begin{array}{l}\text { Siira- } \\
\text { Pietikäinen } \\
\text { et al., } 2001\end{array}$ & PLFA & harvesting & & $\begin{array}{l}\text { community } \\
\text { composition }\end{array}$ & $\begin{array}{l}\text { yes (clear } \\
\text { felling) }\end{array}$ \\
\hline $\begin{array}{l}\text { Chatterjee } \\
\text { et al., } 2008\end{array}$ & PLFA & harvesting & 162 & $\begin{array}{l}\text { community } \\
\text { composition }\end{array}$ & yes \\
\hline $\begin{array}{l}\text { Brockett et } \\
\text { al., } 2012\end{array}$ & PLFA & tree species & 63 & $\begin{array}{l}\text { community } \\
\text { composition / } \\
\text { enzyme activities }\end{array}$ & some \\
\hline $\begin{array}{l}\text { Hackl et al., } \\
2005\end{array}$ & PLFA & $\begin{array}{l}\text { tree species /mixed } \\
\text { stands }\end{array}$ & 240 & $\begin{array}{l}\text { community } \\
\text { composition }\end{array}$ & yes \\
\hline
\end{tabular}


Urbanová et al., 2015

pyrosequencing

Hartmann

et al., 2012

pyrosequencing

Nacke et al., 2011

pyrosequening

Hartmann

et al., 2014

pyrosequencing

pyrosequencing

Nacke et al.

Chapter

III.3

Kaiser et

al. Chapter

III. 2

pyrosequencing

\section{GRASSLAND}

Kennedy et

al., 2005b

McCaig et

al., 2001

16S RNA clone

Kuramae et DGGE / microchip

al., 2012

/real time PCR

Clegg et al., 2003

Jangid et

al., 2010

Steenwerth

et al., 2002

Yeates et

al., 1997

Grayston et

al., 2001

Ingram et

al., 2008

Patra et al., 2008

Herold et

al., 2014

Kennedy et

al., 2005a

Sayer et al.,

2013

Thomson et al., 2015

Will et al., 2010

Hartmann

et al., 2015

pyrosequencing

pyrosequencing libraries /DGGE

$$
\begin{aligned}
& \text { tree species } \\
& \text { organic matter } \\
& \text { removal / } \\
& \text { compaction }
\end{aligned}
$$

tree species

compaction

tree species

128

tree species /

organic matter

removal /

compaction

42

81

9

9

150 unimproved/semiimproved

unimproved/semi improved

/improved grassland natural

grassland/arable

field, pasture;

deciduous vs. Pine forest

$\mathrm{N}$ fertilized/soil

drainage

grassland

restoration at

different timepoints agriculture/

annual/perennial grassland

conventional/organi

c grassland

management

unimproved/semi-

improved/improved grassland

no grazing/heavy grazing

intensive/extensive management fertilization / mowing / grazing unimproved/semiimproved

unimproved/improv ed/restored

unimproved/improv ed; short-term/longterm abandoned fertilization / mowing / grazing

conventional / organic farming community

composition

yes

community

composition

yes

community

composition/diversi yes

ty

community

composition /

diversity

yes

community

composition

yes

community

composition /

diversity

yes

community
composition

diversity /

community

composition

yes

community

composition

no

community

composition

yes

community

composition

yes

community

composition

yes

community

composition

no

community

composition/microb yes

ial biomass

community

composition

community

composition

community

composition

community

composition

community

composition

西

yes

yes

no

yes

yes

community

composition

yes

diversity

yes

community

composition /

diversity yes 


\section{GENERAL DISCUSSION}

\begin{tabular}{|c|c|c|c|c|c|}
\hline $\begin{array}{l}\text { Nacke } \\
\text { al., } 2011\end{array}$ & pyrosequening & $\begin{array}{c}\text { fertilization / } \\
\text { mowing / grazing }\end{array}$ & 9 & $\begin{array}{c}\text { community } \\
\text { composition/diversi } \\
\text { ty }\end{array}$ & no \\
\hline $\begin{array}{l}\text { Tardy et al., } \\
2015\end{array}$ & pyrosequencing & $\begin{array}{l}\text { low / medium / high } \\
\text { land use intesity }\end{array}$ & 162 & diversity & yes \\
\hline $\begin{array}{l}\text { Carey et al., } \\
2015\end{array}$ & MiSeq & $\begin{array}{l}\text { fertilization / } \\
\text { mowing }\end{array}$ & 40 & $\begin{array}{l}\text { community } \\
\text { composition / } \\
\text { diversity }\end{array}$ & no \\
\hline $\begin{array}{l}\text { Kaiser et } \\
\text { al. Chapter } \\
\text { III.2 }\end{array}$ & pyrosequencing & $\begin{array}{c}\text { fertilization / } \\
\text { mowing / grazing }\end{array}$ & 150 & $\begin{array}{c}\text { community } \\
\text { composition / } \\
\text { diversity }\end{array}$ & no \\
\hline
\end{tabular}

In the grassland systems investigated within this thesis, a small land use intensification effect on soil microbial communities was recorded. The land use intensity index (LUI, Blüthgen et al. 2012) was significantly correlated with the microbial community structure in grasslands in the Schwäbische Alb, but not in the Hainich-Dün or Schorfheide-Chorin. The effect most likely results from stronger organic fertilization in the Schwäbische Alb. Grasslands in the Hainich-Dün and Schorfheide-Chorin predominantly receive inorganic fertilizers. A recent study by Hartmann and colleagues (2015) described distinct microbial communities for conventional and organic farming systems. None of the other factors (grazing or mowing) resulted in an effect on bacterial community composition or diversity. Several studies investigated the influence of grassland management on soil microbial communities and showed that management altered bacterial community composition (Table 1). However, previous studies carried out within the Biodiversity Exploratories also could not verify an effect of land use intensity in grasslands (Herold et al., 2014; Nacke et al., 2011), except for Will et al. (2010) who showed the highest bacterial diversity in non-fertilized meadows. Additionally, a recent study focused on species-abundance distributions of 10 above- and belowground taxonomic groups (Chapter III.4). Belowground microorganisms (represented by bacteria and arbuscular mycorrhizal fungi) were not affected by land use intensification, or mowing, grazing, and fertilization. Generally, species richness was largely unaltered by land use intensity (Chapter III.4). Tardy et al. (2015) encountered that bacterial diversity was highest in moderately managed soils. They investigated the effects along a gradient of management intensity in three different regions. It was suggested that this is a result of the stress response of the bacterial communities. In highly stressed environments diversity decreases due to the dominance of competitive species and competitive exclusion whereas in unstressed environments diversity decreases due to the dominance of adapted species through selection. In conclusion, land use intensification has no general effect on soil microbial community composition or diversity within the Biodiversity Exploratory 
framework. However, it is very difficult to compare the results of this thesis with studies that have not been carried out within the Biodiversity Exploratories. This is due to the fact that land use and management per se are not standardized definition. Thus, the definitions of land use and management vary considerably between studies. As far as it could be inferred from the publications summarized in Table 1, land use intensification was analyzed within a similar range as covered by the Biodiversity Exploratories. Additionally, it has to be noted that most of these studies applied different community profiling techniques such as TRFLP (Liu et al., 1997) or DGGE (Muyzer et al., 1993), or PLFA. None of these techniques provides such a high level of taxonomic resolution as NGS-based sequencing and analysis of 16S rRNA gene amplicons (Prosser et al., 2010).

\section{IV.1.2. Soil bacterial communities in response to environmental parameters}

While land use intensification had no significant effect on microbial community composition and diversity, both differed between the two land use types grassland and forest and the corresponding sampling regions (Chapter III.2). Soil pH was identified as the strongest driver of bacterial communities in grasslands and forests (Chapter III.2). It also exhibited a strong impact on bacterial and fungal communities in beech and spruce forests (Chapter III.3). This $\mathrm{pH}$ effect reflects the separation of community composition between grasslands and forests and the effect of tree species (coniferous vs. broadleaved). Forest soil samples were generally more acidic compared to grassland soil samples, while samples from coniferous forests were more acidic than samples derived from broadleaved forests. Soil $\mathrm{pH}$ further explains the higher bacterial diversity in grassland soils compared to forest soils. Soil $\mathrm{pH}$ was previously described as a strong driver of microbial community composition at the continental scale (Fierer and Jackson, 2006). Additionally, factors such as the $\mathrm{C}: \mathrm{N}$ ratio and the gravimetric water content were shown to drive community composition to some extent, which is also in line with previous studies (Brockett et al., 2012; Cederlund et al., 2014).

This study went beyond the scope of previous studies by not only identifying drivers of bacterial communities but also by testing the response of the most abundant bacterial groups toward $\mathrm{pH}$. The responses differed between groups; some showed preference for very acidic conditions (high abundance at low $\mathrm{pH}$ ), whereas others were almost unaffected by $\mathrm{pH}$ (relatively stable abundance over the studied $\mathrm{pH}$ range). Effects on certain bacterial groups have previously been investigated by correlation analysis (Nacke et al., 2011; Naether et al., 2012). However, relations between organisms and environmental gradients more likely result 


\section{GENERAL DISCUSSION}

in unimodal or skewed unimodal response curves restricted by growth limiting conditions and competition (Austin and Smith, 1990). Furthermore, the results provided insights into the acid tolerance (ATR) or adaptation to acidic conditions of bacteria in soils (Chapter III.2). An important system obviously employed by soil bacteria are proton pumps, which enable an active control of intracellular $\mathrm{pH}$ values. Enzymes involved in the arginine metabolism (especially arginine deiminase) also seem to be more abundant in low $\mathrm{pH}$ soils, indicating a role of alkali production in soil bacterial ATR. This system has been described for several soil-dwelling bacteria (Pseudomonas, Bacillus, Mycoplasma) as well as oral bacteria (Cunin et al., 1986). A possible mechanism is that arginine is actively transported into the cell (e.g. by arginine:ornithine antiporters) where alkaline compounds (such as $\mathrm{NH}_{3}$ ) are produced (e.g. by arginine deiminase) that might help stabilize intracellular $\mathrm{pH}$. Levansucrase, an enzyme, which is involved in exopolysaccharide formation, was highly abundant in low $\mathrm{pH}$ soil samples. Bacteria therefore might also employ biofilm formation to protect themselves from stressful acidic conditions, as has previously been shown for Lysteria monocytogenes (Oh and Marshall, 1996).

In conclusion, a major factor driving microbial communities is the soil $\mathrm{pH}$. Bacteria respond strongly toward $\mathrm{pH}$ and several groups seem to occupy certain ' $\mathrm{pH}$ niches', where they reach highest abundances. Lastly, the here reported study (Chapter III.2) presents evidence for a genomic adaptation of soil bacteria against acidic conditions.

\section{IV.1.3. Bacterial functioning in grasslands and forests}

As grassland and forest differ in their soil microbial community compositions, the functions carried out by bacteria and fungi might also differ between these ecosystems. Metagenomic approaches to unravel the functional potential of soils have been carried out before (e.g. Delmont et al., 2012; Fierer et al., 2012a; Fierer et al., 2012b; Pan et al., 2014). These studies unravel bacterial functions to the level of metabolic subsystems from the SEED database (Overbeek et al., 2014). Other studies focused only on specialized enzymes such as carbohydrate-active enzymes (CAZymes) (Cardenas et al., 2015), or directly targeted enzymes of interest (Baldrian et al., 2012). Both approaches cannot unravel the whole potential of bacterial contribution to nutrient cycling. The application of metagenomic shotgun sequencing of soil DNA samples has several drawbacks. Soils are enormously diverse and therefore have a very high genomic diversity. This makes it almost impossible to capture the whole genomic information of a sample. Further, lots of information from shotgun 
metagenomic sequencing cannot be annotated (Fierer et al., 2012b). Within this study, a bioinformatic approach was applied and functional profiles predicted on the basis of $16 \mathrm{~S}$ rRNA genes with a newly developed tool called Tax4Fun (Aßhauer et al., 2015). This approach is much more time- and cost-effective, and Tax4Fun has been shown to predict highly accurate functional profiles from 16S rRNA data for a range of samples including soils. It further provides detailed information on the level of KEGG pathway or KO genes. Genes encoding key enzymes for important metabolic pathways involved in nutrient (nitrogen, phosphate, carbon and sulfur) cycling were either more abundant in grassland or forest. It has been suggested, that methanotrophic bacteria in forest soils are the largest sink of atmospheric methane (Kolb, 2009). The results within this study suggest that the functional potential for aerobic methane oxidation and nitrous-oxide reduction is indeed higher in forest soils. This suggests that forest soils play an important role in the regulation and removal of atmospheric greenhouse gases such as methane and nitrous oxide. The functional potential for acid phosphatases is higher in more acidic forest soils, while alkaline phosphatases are potentially more abundant in grasslands. The genes encoding urease were 1.2-fold more abundant in the grassland profile. The availability of urea was higher in the grassland samples, as these are partly fertilized with manure or dung or were grazed by animals. Chitinase genes also showed a 1.2-fold higher abundance in grasslands compared to forest soils. This might result from the higher abundance of Actinobacteria in grassland soils as this group is known to harbor a high number of chitinase genes (Bai et al., 2014). Genes involved in polyaromatic hydrocarbon (PAH) degradation are more abundant in grasslands. Possibly, this degradation is carried out by bacteria in grassland systems, while in forest systems this process is taken over by ligninolytic fungi (Hammel, 1995), which were not analyzed within this study.

To date, this is the first approach to distinguish multiple functions from different ecosystems based on single genes. The results of this thesis suggested distinct functional traits for grassland and forest systems and further indicate a certain functional 'adaptation' to the respective environment. As the grasslands and forests within the present study are long-term established systems, it would be interesting to evaluate if a similar 'adaptation' on the genetic level is also present in younger systems. The results further are based on a predictive metagenome and not an actual one. Therefore, metagenomic approaches targeting the respective key genes, or metagenomic shotgun sequencing will be necessary to verify these findings. 


\section{GENERAL DISCUSSION}

In conclusion, bacterial communities in German grasslands and forests form distinct patterns and are driven by edaphic parameters. Land use intensification does not significantly alter community composition or diversity. This could be attributed to a general resistance or resilience of soil bacterial communities toward anthropogenic influences. However, it is also important to keep in mind the range of factors, which are investigated for their effects. As suggested by (Brockett et al., 2012), 'the range of (...) values (...) may not have been as great (...) relative to the range of other site factors (...), to display the expected relationships.' Optimally, the factors causing a certain effect that should be investigated should be the only factors allowed to range, while all other factors should be held constant. Naturally, it is hard to control for stable or similar conditions in the field or in natural systems in general. Therefore, the presence or absence of effects should always be seen in relation to the range of factors causing them.

\section{IV.2. PLANT-ASSOCIATED MICROBIAL COMMUNITIES}

Soil-inhabiting microorganisms are often also associated with plants. This is especially true for the rhizosphere, the part of the soil immediately influenced by plant roots. Bacterial nitrogen fixers are often associated with or live in symbiosis with roots of several plants. Also fungi form close associations or symbioses with plants. Arbuscular mycorrhizal fungi actively penetrate their host plants cells, while ectomycorrhizal fungi form a non-invasive symbiosis with their host plants. Despite root-associated, rhizospheric microorganisms, also epiphytes (living in the phyllosphere; Vorholt, 2012) and endophytes (living inside the plant without causing disease; Hallmann et al., 1997) are closely associated with plants. These organisms are thought to be beneficial to their host plants by providing various functions such as productions of antimicrobial compounds and biological pest control (Bulgarelli et al., 2013).

Within this thesis, three studies focused on plant-associated microbial communities. The first study focused on bacterial endophytes in three agricultural important grasses: (1) Lolium perenne L., (2) Festuca rubra L. and (3) Dactylis glomerata L. In the design of this study, impact of fertilization and mowing frequency was analyzed with regard to plant species-specific endophytic communities in 2010 and 2011. Bacterial community composition was significantly shaped by the respective host plant, and diversity was higher in $D$. glomerata. The impact of fertilization and mowing on community composition and diversity varied between the sampling times without a clear trend. Diversity and community composition were influenced by fertilization only in 2010 whereas no effect of mowing frequency was recorded in either year. It is possible that fertilization and mowing exhibit indirect effects on the endophytic communities by changing the physiological status of plants. 
Fuentes-Ramírez and colleagues (1999) observed reduced colonization of sugarcane by Gluconacetobacter diazotrophicus after nitrogen-fertilization. They concluded that fertilization altered the plant physiological state, which interfered with the interactions between plant and endophyte. A similar hypothesis was raised by (Hallmann et al., 1999), who observed an impact of organic amendments on endophytic communities in crops. However, the effects of fertilization and mowing on endophytic communities analyzed in Chapter III.6 are not consistent at both sampling times. Possibly, other factors such annual mean temperature or precipitation might interfere and additionally alter the physiological states of the plants, as these factors cannot be controlled in a field study.

The last two studies within this thesis analyzed soil and plant-associated microbial communities in an intercropping experiment with faba bean (Vicia faba L.) and wheat (Triticum aestivum L.). The impact of plant monocultures and mixed cultures on soil archaeal communities (Chapter III.7) and on bacterial and fungal communities in soil, rhizosphere and endosphere (Chapter III.8) was investigated. Intercropping has previously been shown to produce beneficial effects for the mixing partners, as long as the intercropping partners do not occupy identical ecological niches (Ofori and Stern, 1987). In Chapter III.6, three different grass species significantly affected bacterial community composition. In the intercropping experiment however, plant species did only affect bacterial endophytic communities, but not the community composition of the rhizospheric or soil microbial communities. Plant speciesspecific endophytic communities have been indicated by previous studies (Berg and Smalla, 2009). There is also evidence that bacterial and fungal communities in the rhizophere are influenced by intercropping of faba bean and wheat (Song et al., 2007; Wang et al., 2012). These experiments however were carried out over a growing period of up to three years. The 4 weeks growth period in the presented experiment might have been too short for specific bacterial and fungal communities to establish. This additionally suggests that endophytic communities are mainly shaped by recruitment through the host plant. It has been suggested that endophytic communities are partly inherited from the parent generation (Ralphs et al. 2011, Uchitel et al. 2011). However, this inherited part of the endophytic community did not seem to play a strong role in shaping the community composition in wheat and faba bean, especially with respect to the fungal endophytes. Possibly, the effect will only become apparent after longer host-microbe adaptation periods. Nevertheless, soil archaeal community composition was affected by plant species and cropping regime (Chapter III.7). Bacterial and fungal communities were not altered by cropping regime, regardless if they derived from bulk 


\section{GENERAL DISCUSSION}

soil, rhizosphere or endosphere (Chapter III.8). Only microbial diversity and richness of bulk soil and rhizosphere samples was affected by the cropping regimes. Previous studies showed that ammonia-oxidizing archaea were affected by crop species (wheat, faba bean, white lupin) and cropping regime (Wang et al. 2012) and that crop rotation also affected archaeal community composition (Breidenbach et al. 2015). This in contrast to other studies suggesting that cropping effects and crop rotation have only minor effects on archaeal communities (Chan et al. 2013, Scavino et al. 2013).

It is unclear, why soil archaeal communities are influenced by cropping regime in the present experiment but bacteria and fungi are not. This might be due to the low diversity of soil-inhabiting archaea. However, little is known about the ecological roles of archaea in soils, and it is possible that they have faster adaptation systems or are more susceptible to changing environmental conditions.

While cropping regime did not influence bacterial and fungal communities in this experiment, the origin of the samples (leaf, root, rhizosphere or bulk soil) was the major driver of microbial community composition. This effect was more pronounced for bacteria but also detectable for fungi. Bulk soil and rhizospheric communities were very similar but endophytic communities differed. Bacterial endophyte communities varied more strongly in their composition between root and leaf samples, while this effect was only weakly detected for fungi. Fungi can actively colonize their plants host tissue, but bacteria are more restricted to passive dispersal inside the plant. This might contribute to the similar fungal endophytic communities.

In conclusion, it could be shown that anthropogenic influences alter plant-associated microbial communities and result in plant species-specific patterns of endophytic communities. Furthermore, the results suggest that endophytic communities are no result of inheritance but rely more on recruitment of microbes by the host plants. Additionally, archaeal communities in soils were shown to be more susceptible to changes in cropping regime than bacterial or fungal communities.

\section{IV.3. Concluding remarks and outlook}

The majority of studies within this thesis investigated the diversity, structure and function of microbial communities under changing environmental conditions. Our knowledge about the response of microbial communities towards changing conditions such as altered soil properties or land use intensification, are still limited. 
In summary, drivers of microbial community structure and diversity subsequently affect microbial functioning (Figure 4). Soil microbial communities are primarily shaped by edaphic properties ( $\mathrm{pH}$, soil texture, nutrients, moisture; Chapter III.2 and III.3). They are additionally affected by plants, e.g. the dominant tree species in forests (Chapter III.2 and III.3) or crop species (faba bean vs. wheat; Chapter III.7). Plant-associated microbial communities living in the rhizosphere and endosphere are also affected by their corresponding host plants (Chapter III.6), or the sampled plant compartments (Chapter III.8). Land use intensification only exhibited minor effects on microbial community structure in grassland and forest soils (Chapter III.2, III.4, III.5). Similarly, endophytic bacterial communities only responded weakly to fertilization and mowing (Chapter III.6). In grassland and forest soils, bacterial functioning followed the same drivers as bacterial community structure and diversity (Chapter III.2) and functioning of endophytic bacterial communities differed between different grasses (Chapter III.6). Furthermore, grassland and forest soils selects for certain bacterial traits (e.g. greenhouse gas regulation in forest soils, urease and alkaline phosphatase in grassland soils; Figure 4). 


\section{GENERAL DISCUSSION}

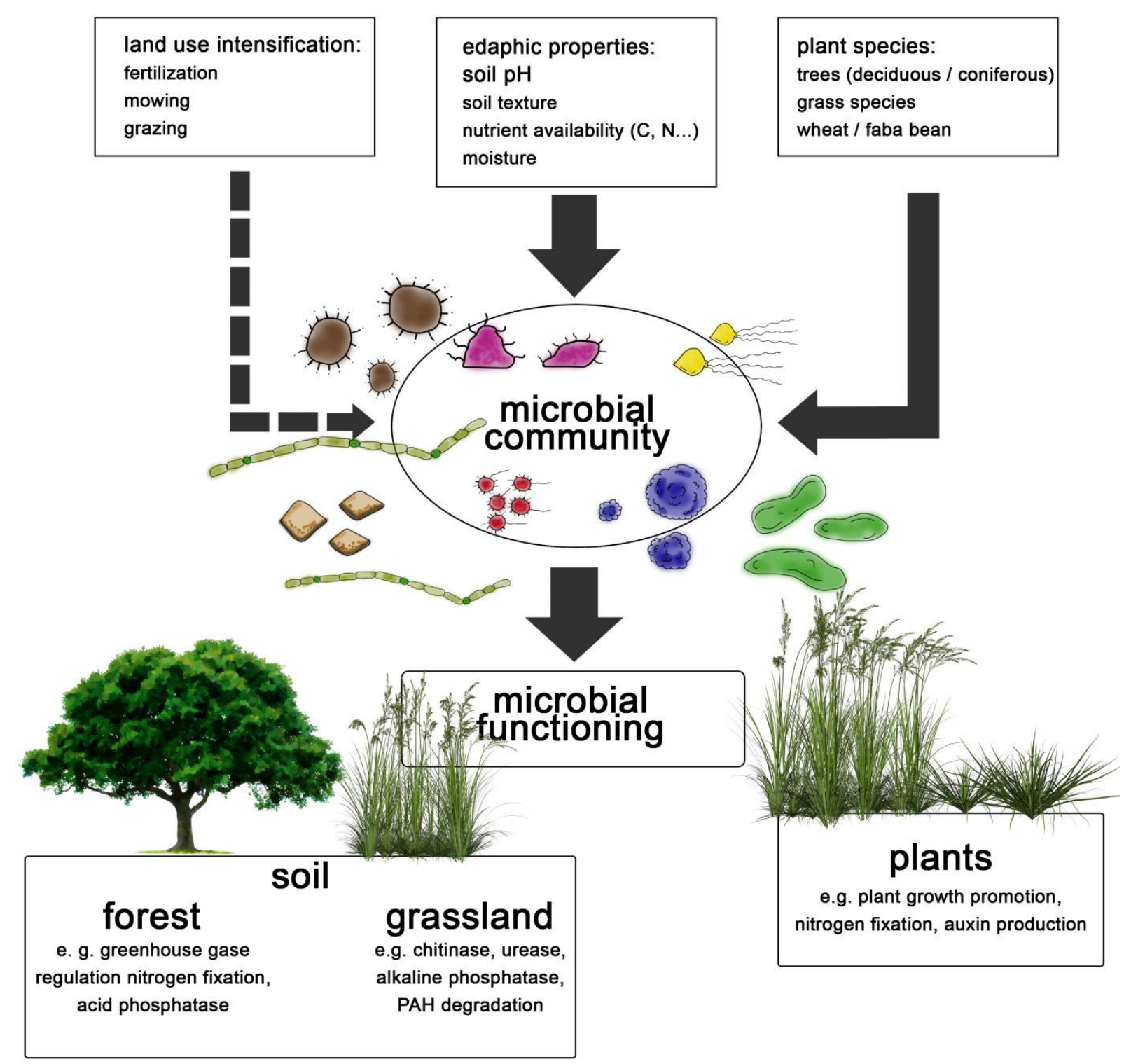

Figure 4. Drivers of microbial communities and microbial functioning as identified within this thesis. Drivers of soil and plant-associated microbial community structure and diversity subsequently drive microbial functioning in forest and grassland soils (Chapter III.2) and endophyte functioning within different grasses (Chapter III.6).

In summary, it was found that soil microbial communities are driven primarily by edaphic properties, while plant-associated microbial communities are primarily driven by their respective host plants. Land use intensification, as the anthropogenic factor under analysis, had minor effects on the communities. However, this effect was not consistently recovered for all studies, or samples under analysis. This suggests that land use intensification will only affect microbial communities if it significantly alters edaphic factors such as nutrient concentrations and availability or the plants physiological status (e.g. by extensive fertilization), which was not the case in any of the studies presented within this thesis. 
Therefore, microbial communities are well adapted to their respective environments and resistant to land use intensification practiced in temperate grassland and forest systems.

The results provided within this thesis contribute to our understanding of drivers and ecological roles of microbial community structures in soils and in association with plants. The results also suggest that the application of novel statistical and bioinformatic tools has the potential to broaden our knowledge on microbial communities, by providing new insights into the relationships between microbes and their environments. However, it will be necessary to investigate not only the total microbial communities, which was the aim of this thesis, but also the active fraction (RNA-based analyses) to fully unravel reasons for structural changes of microbial communities. Metagenomic and metatranscriptomic approaches as well as enzymatic assays will aid in drawing a comprehensive picture of the ecological roles that bacteria, fungi and archaea play in soils, the rhizosphere and in association with plants. 


\section{CHAPTER V}

GENERAL REFERENCES 


\section{GENERAL REFERENCES}

1. Allan E, Manning P, Alt F, Binkenstein J, Blaser S, Blüthgen N, et al. (2015). Land use intensification alters ecosystem multifunctionality via loss of biodiversity and changes to functional composition. Ecol Lett 18:834-843.

2. Aßhauer KP, Wemheuer B, Daniel R, Meinicke P. (2015). Tax4Fun: predicting functional profiles from metagenomic 16S rRNA data. Bioinformatics 31:2882-2884.

3. Austin MP, Smith TM (1990). A new model for the continuum concept. In: Grabherr G, Mucina L, Dale MB, Ter Braak CJF, (eds). Progress in theoretical vegetation science. Springer: Netherlands, pp 35-47.

4. Axelrood PE, Chow ML, Radomski CC, McDermott JM, Davies J. (2002). Molecular characterization of bacterial diversity from British Columbia forest soils subjected to disturbance. Can J Microbiol 48:655-674.

5. Azam F, Malfatti F. (2007). Microbial structuring of marine ecosystems. Nat Rev Microbiol 5:782-791.

6. Bai Y, Eijsink VG, Kielak AM, van Veen JA, de Boer W. (2014). Genomic comparison of chitinolytic enzyme systems from terrestrial and aquatic bacteria. Environ Microbiol 18:38-49.

7. Baldrian P, Kolařík M, Stursová M, Kopecký J, Valášková V, Větrovský $\mathrm{T}$, et al. (2012). Active and total microbial communities in forest soil are largely different and highly stratified during decomposition. ISME J 6:248-258.

8. Berg G, Smalla K. (2009). Plant species and soil type cooperatively shape the structure and function of microbial communities in the rhizosphere. FEMS Microbiol Ecol 68:113.

9. Blüthgen N, Dormann CF, Prati D, Klaus VH, Kleinebecker T, Hölzel N, et al. (2012). A quantitative index of land-use intensity in grasslands: Integrating mowing, grazing and fertilization. Basic Appl Ecol 13:207-220.

10. Bodelier PL, Meima-Franke M, Hordijk CA, Steenbergh AK, Hefting MM, Bodrossy L, et al. (2013). Microbial minorities modulate methane consumption through niche partitioning. ISME J 7:2214-2228.

11. Branco S, Bruns TD, Singleton I. (2013). Fungi at a small scale: spatial zonation of fungal assemblages around single trees. Plos One 8:e78295. 


\section{GENERAL REFERENCES}

12. Breidenbach B, Blaser MB, Klose M, Conrad R. (2015) Crop rotation of flooded rice with upland maize impacts the resident and active methanogenic microbial community. Environ Microbiol doi:10.1111/1462-2920.13041.

13. Brockett BFT, Prescott CE, Grayston SJ. (2012). Soil moisture is the major factor influencing microbial community structure and enzyme activities across seven biogeoclimatic zones in western Canada. Soil Biol Biochem 44:9-20.

14. Buée M, Vairelles D, Garbaye J. (2005). Year-round monitoring of diversity and potential metabolic activity of the ectomycorrhizal community in a beech (Fagus sylvatica) forest subjected to two thinning regimes. Mycorrhiza 15:235-245.

15. Bulgarelli D, Schlaeppi K, Spaepen S, Ver Loren van Themaat E, Schulze-Lefert P. (2013). Structure and functions of the bacterial microbiota of plants. Annu Rev Plant Biol 64:807-838.

16. Busse MD, Beattie SE, Powers RF, Sanchez FG, Tiarks AE. (2006). Microbial community responses in forest mineral soil to compaction, organic matter removal, and vegetation control. Can J For Res 36; 577-588.

17. Cardenas E, Kranabetter JM, Hope G, Maas KR, Hallam S, Mohn WW. (2015). Forest harvesting reduces the soil metagenomic potential for biomass decomposition. ISME $\mathbf{J}$ 9:2465-2476.

18. Cardinale BJ, Duffy JE, Gonzalez A, Hooper DU, Perrings C, Venail P, et al. (2012). Biodiversity loss and its impact on humanity. Nature 486:59-67.

19. Carey CJ, Beman JM, Eviner VT, Malmstrom CM, Hart SC. (2015). Soil microbial community structure is unaltered by plant invasion, vegetation clipping, and nitrogen fertilization in experimental semi-arid grasslands. Front Microbiol 6:466.

19. Cederlund H, Wessén E, Enwall K, Jones CM, Juhanson J, Pell M, et al. (2014). Soil carbon quality and nitrogen fertilization structure bacterial communities with predictable responses of major bacterial phyla. Appl Soil Ecol 84:62-68.

20. Chan Y-K, McCormick WA, Ma BL. (2013) Effects of inorganic fertilizer and manure on soil archaeal abundance at two experimental farms during three consecutive rotation-cropping seasons. Appl Soil Ecol 68:26-35.

21. Chatterjee A, Vance GF, Pendall E, Stahl PD. (2008). Timber harvesting alters soil carbon mineralization and microbial community structure in coniferous forests. Soil Biol Biochem 40:1901-1907. 
22. Clegg CD, Lovell RD, Hobbs PJ. (2003). The impact of grassland management regime on the community structure of selected bacterial groups in soils. FEMS Microbiol Ecol 43:263-270.

23. Corlett RT. (2015). The Anthropocene concept in ecology and conservation. Trends Ecol Evol 30:36-41.

24. Cotter PD, Hill C. (2003). Surviving the acid test: responses of gram-positive bacteria to low pH. Microbiol Mol Biol Rev 67:429-453.

25. Cruz-Martinez K, Suttle KB, Brodie EL, Power ME, Andersen GL, Banfield JF. (2009). Despite strong seasonal responses, soil microbial consortia are more resilient to long-term changes in rainfall than overlying grassland. ISME J 3:738-744.

26. Cunin R, Glansdorff N, Pierard A, Stalon V. (1986). Biosynthesis and metabolism of arginine in bacteria. Microbiol rev 50:314.

27. Daniel R. (2005). The metagenomics of soil. Nat Rev Microbiol 3:470-478.

28. Delmont TO, Prestat E, Keegan KP, Faubladier M, Robe P, Clark IM, et al. (2012). Structure, fluctuation and magnitude of a natural grassland soil metagenome. ISME J 6:1677-1687.

29. De Vries FT, Manning P, Tallowin JR, Mortimer SR, Pilgrim ES, Harrison KA, et al. (2012). Abiotic drivers and plant traits explain landscape-scale patterns in soil microbial communities. Ecol Lett 15:1230-1239.

30. Dilworth MJ, Howieson JG, Reeve WG, Tiwari RP, Glenn AR. (2001). Acid tolerance in legume root nodule bacteria and selecting for it. Aust J Exp Agric 41:435-446.

31. Dominati E, Patterson M, Mackay A. (2010). A framework for classifying and quantifying the natural capital and ecosystem services of soils. Ecol Econ 69:18581868.

32. Edwards IP, Zak DR. (2010). Phylogenetic similarity and structure of Agaricomycotina communities across a forested landscape. Mol Ecol 19:1469-1482.

33. Felsmann K, Baudis M, Gimbel K, Kayler ZE, Ellerbrock R, Bruelheide H, et al. (2015). Soil bacterial community structure responses to precipitation reduction and forest management in forest ecosystems across Germany. Plos One 10:e0122539.

34. Fierer N, Jackson RB. (2006). The diversity and biogeography of soil bacterial communities. Proc Natl Acad Sci USA 103:626-631.

35. Fierer N, Lauber CL, Ramirez KS, Zaneveld J, Bradford MA, Knight R. (2012a). Comparative metagenomic, phylogenetic and physiological analyses of soil microbial communities across nitrogen gradients. ISME J 6:1007-1017. 


\section{GENERAL REFERENCES}

36. Fierer N, Leff JW, Adams BJ, Nielsen UN, Bates ST, Lauber CL, et al. (2012b). Cross-biome metagenomic analyses of soil microbial communities and their functional attributes. Proc Natl Acad Sci USA 109:21390-21395.

37. Fischer M, Bossdorf O, Gockel S, Hänsel F, Hemp A, Hessenmöller D, et al. (2010). Implementing large-scale and long-term functional biodiversity research: The Biodiversity Exploratories. Basic Appl Ecol 11:473-485.

38. Fuentes-Ramírez LE, Caballero-Mellado J, Sepúlveda J, Martínez-Romero E. (1999). Colonization of sugarcane by Acetobacter diazotrophicus is inhibited by high Nfertilization FEMS Microbiol Ecol 29:117-128.

39. Gamalero E, Lingua G, Giusy Caprì F, Fusconi A, Berta G, Lemanceau P. (2004). Colonization pattern of primary tomato roots by Pseudomonas fluorescens A6RI characterized by dilution plating, flow cytometry, fluorescence, confocal and scanning electron microscopy. FEMS Microbiol Ecol 48:79-87.

40. Gans J, Wolinsky M, Dunbar J. (2005). Computational improvements reveal great bacterial diversity and high metal toxicity in soil. Science 309:1387-1390.

41. Goldmann K, Schöning I, Buscot F, Wubet T. (2015). Forest management type influences diversity and community composition of soil fungi across temperate forest ecosystems. Front Microbiol 6, 1300.

42. Grayston SJ, Griffith GS, Mawdsley JL, Campbell CD, Bardgett RD. (2001). Accounting for variability in soil microbial communities of temperate upland grassland ecosystems. Soil Biol Biochem 33:533-551.

43. Hackl E, Zechmeister-Boltenstern S, Bodrossy L, Sessitsch A. (2004). Comparison of diversities and compositions of bacterial populations inhabiting natural forest soils. Appl Environ Microbiol 70:5057-5065.

44. Hackl E, Pfeffer M, Donat C, Bachmann G, Zechmeister-Boltenstern S. (2005). Composition of the microbial communities in the mineral soil under different types of natural forest. Soil Biol Biochem 37:661-671.

45. Hallmann J, Quadt-Hallmann A, Mahaffee WF, Kloepper JW. (1997). Bacterial endophytes in agricultural crops. Can J Microbiol 43:895-914.

46. Hallmann J, Rodríguez-Kábana R, Kloepper, JW. (1999). Chitin-mediated changes in bacterial communities of the soil, rhizosphere and within roots of cotton in relation to nematode control. Soil Biol Biochem 31:551-560.

47. Hammel KE. (1995). Mechanisms for polycyclic aromatic hydrocarbon degradation by ligninolytic fungi. Environ Health Perspect 103:41-43. 
48. Hartmann M, Howes CG, VanInsberghe D, Yu H, Bachar D, Christen R, et al. (2012). Significant and persistent impact of timber harvesting on soil microbial communities in Northern coniferous forests. ISME J 6:2199-2218.

49. Hartmann M, Niklaus PA, Zimmermann S, Schmutz S, Kremer J, Abarenkov K, et al. (2014). Resistance and resilience of the forest soil microbiome to logging-associated compaction. ISME J 8:226-244.

50. Hartmann M, Frey B, Mayer J, Mäder P, Widmer F. (2015). Distinct soil microbial diversity under long-term organic and conventional farming. ISME J 9:1177-1194.

51. He J, Xu Z, Hughes J. (2006). Molecular bacterial diversity of a forest soil under residue management regimes in subtropical Australia. FEMS Microbiol Ecol 55:38-47.

52. He Z, Xiong J, Kent AD, Deng Y, Xue K, Wang G, et al. (2014). Distinct responses of soil microbial communities to elevated $\mathrm{CO} 2$ and $\mathrm{O} 3$ in a soybean agro-ecosystem. ISME J 8:714-726.

53. Heimann M, Reichstein M. (2008). Terrestrial ecosystem carbon dynamics and climate feedbacks. Nature 451:289-292.

54. Herold N, Schöning I, Gutknecht J, Alt F, Boch S, Müller J, et al. (2014). Soil property and management effects on grassland microbial communities across a latitudinal gradient in Germany. Appl Soil Ecol 73:41-50.

55. Herzog S, Wemheuer F, Wemheuer B, Daniel R. (2015). Effects of fertilization and sampling time on composition and diversity of entire and active bacterial communities in German grassland soils. Plos One 10:e0145575.

56. Hiltner L. (1904). Über neuere Erfahrungen und Probleme auf dem Gebiete der Bodenbakteriologie unter besonderer Berücksichtigung der Gründüngung und Brache. Arb DLG 98:59-78.

57. Hof C, Rauber R. (2003). Anbau von Gemengen im ökologischen Landbau. Geschäftsstelle Bundesprogramm Ökologischer Landbau.

58. Hornung M. (1985). Acidification of soils by trees and forests. Soil Use Manage 1:2427.

59. Ingram LJ, Stahl PD, Schuman GE, Buyer JS, Vance GF, Ganjegunte GK, et al. (2008). Grazing Impacts on Soil Carbon and Microbial Communities in a Mixed-Grass Ecosystem. Soil Sci Am J 72:939-948.

60. Jangid K, Williams MA, Franzluebbers AJ, Blair JM, Coleman DC, Whitman WB. (2010). Development of soil microbial communities during tallgrass prairie restoration. Soil Biol Biochem 42:302-312. 


\section{GENERAL REFERENCES}

61. Karhu K, Auffret MD, Dungait JA, Hopkins DW, Prosser JI, Singh BK, et al. (2014). Temperature sensitivity of soil respiration rates enhanced by microbial community response. Nature 513:81-84.

62. Kennedy N, Edwards S, Clipson N. (2005a). Soil Bacterial and Fungal Community Structure Across a Range of Unimproved and Semi-Improved Upland Grasslands. Microb Ecol 50:463-473.

63. Kennedy NM, Gleeson DE, Connolly J, Clipson NJ. (2005b). Seasonal and management influences on bacterial community structure in an upland grassland soil. FEMS Microbiol Ecol 53:329-337.

64. Keuter A, Hoeft I, Veldkamp E, Corre MD. (2013). Nitrogen response efficiency of a managed and phytodiverse temperate grassland. Plant Soil 364:193-206.

65. Kolb S. (2009). The quest for atmospheric methane oxidizers in forest soils. Environ Microbiol Rep 1:336-346.

66. Kowalchuk GA, Yergeau E, Leveau JH, Sessitsch A, Bailey M. (2010). Plantassociated microbial communities. In: Liu, W-T, Jansson JK (eds). Environmental Molecular Microbiology. Caister Academic Press: Norfolk, 131-148.

67. Kuramae EE, Yergeau E, Wong LC, Pijl AS, van Veen JA, Kowalchuk GA. (2012). Soil characteristics more strongly influence soil bacterial communities than land-use type. FEMS Microbiol Ecol 79:12-24.

68. Lauber CL, Hamad, M, Knight R, Fierer N. (2009). Pyrosequencing-based assessment of soil $\mathrm{pH}$ as a predictor of soil bacterial community structure at the continental scale. Appl Environ Microbiol 75:5111-5120.

69. Lejon DP, Chaussod R, Ranger J, Ranjard L. (2005). Microbial community structure and density under different tree species in an acid forest soil (Morvan, France). Microb Ecol 50:614-625.

70. Lengeler JW, Drews G, Schlegel HG. (1999). Biology of the Prokaryotes. Georg Thieme Verlag, Stuttgart.

71. Lin Y-T, Jangid K, Whitman WB, Coleman DC, Chiu C-Y. (2011a). Soil bacterial communities in native and regenerated perhumid montane forests. Appl Soil Ecol 47:111-118.

72. Lin YT, Jangid K, Whitman WB, Coleman DC, Chiu CY. (2011b). Change in bacterial community structure in response to disturbance of natural hardwood and secondary coniferous forest soils in central taiwan. Microb Ecol 61:429-437. 
73. Lindahl BD, Ihrmark K, Boberg J, Trumbore SE, Högberg P, Stenlid J, et al. (2007). Spatial separation of litter decomposition and mycorrhizal nitrogen uptake in a boreal forest. New Phytol 173:611-620.

74. Lindow SE, Brandl MT. (2003). Microbiology of the phyllosphere. Appl Environ Microbiol 69:1875-1883.

75. Liu WT, Marsh TL, Cheng H, Forney LJ. (1997). Characterization of microbial diversity by determining terminal restriction fragment length polymorphisms of genes encoding 16S rRNA. Appl Environ Microbiol 63:4516-4522.

76. Lombard N, Prestat E, van Elsas JD and Simonet P. (2011). Soil-specific limitations for access and analysis of soil microbial communities by metagenomics. FEMS Microbiol Ecol 78:31-49.

77. López-Mondéjar R, Voř́šková J, Větrovský T, Baldrian P. (2015). The bacterial community inhabiting temperate deciduous forests is vertically stratified and undergoes seasonal dynamics. Soil Biol Biochem 87:43-50.

78. Manning P, Gossner MM, Bossdorf O, Allan E, Zhang Y-Y, Prati D, et al. (2015). Grassland management intensification weakens the associations among the diversities of multiple plant and animal taxa. Ecology 96:1492-1501.

79. Marilley L, Vogt G, Blanc M, Aragno M. (1998). Bacterial diversity in the bulk soil and rhizosphere fractions of Lolium perenne and Trifolium repens as revealed by PCR restriction analysis of 16S rDNA. Plant Soil 198:219-224.

80. Martinko JM, Madigan M. (2005). Brock biology of microorganisms. Prentice Hall, Upper Saddle River.

81. Marupakula S, Mahmood S, Finlay RD. (2016). Analysis of single root tip microbiomes suggests that distinctive bacterial communities are selected by Pinus sylvestris roots colonized by different ectomycorrhizal fungi. Environ Microbiol 18:1470-1483.

82. McCaig AE, Glover LA, Prosser JI. (2001). Numerical analysis of grassland bacterial community structure under different land management regimens by using $16 \mathrm{~S}$ ribosomal DNA sequence data and denaturing gradient gel electrophoresis banding patterns. Appl Environ Microbiol 67:4554-4559.

83. McNear Jr D. (2013). The rhizosphere-roots, soil and everything in between. Nature Education Knowledge 4:1. 


\section{GENERAL REFERENCES}

84. Mientus M, Brady S, Angelov A, Zimmermann P, Wemheuer B, Schuldes J, et al. (2013). Thermostable xylanase and $\beta$-glucanase derived from the metagenome of the Avachinsky crater in Kamchatka (Russia). Curr Biotechnol 2:284-293.

85. Montross S, Skidmore M, Christner B, Samyn D, Tison J-L, Lorrain R, et al. (2014). Debris-Rich basal ice as a microbial habitat, Taylor Glacier, Antarctica. Geomicrobiol J 31:76-81.

86. Muyzer G, de Waal EC, Uitterlinden AG. (1993). Profiling of complex microbial populations by denaturing gradient gel electrophoresis analysis of polymerase chain reaction-amplified genes coding for 16S rRNA. Appl Environ Microbiol 59:695-700.

87. Myers RT, Zak DR, White DC, Peacock A. (2001). Landscape-Level Patterns of Microbial Community Composition and Substrate Use in Upland Forest Ecosystems. Soil Sci Am J 65:359-367.

88. Nacke H, Thürmer A, Wollherr A, Will C, Hodac L, Herold N, et al. (2011). Pyrosequencing-based assessment of bacterial community structure along different management types in German forest and grassland soils. Plos One 6:e17000.

89. Naether A, Foesel BU, Naegele V, Wüst PK, Weinert J, Bonkowski M, et al. (2012). Environmental factors affect Acidobacterial communities below the subgroup level in grassland and forest soils. Appl Environ Microbiol 78:7398-7406.

90. Nejad P, Johnson PA. (2000). Endophytic bacteria induce growth promotion and wilt disease suppression in oilseed rape and tomato. Biol Control 18:208-215.

91. Newbold T, Hudson LN, Hill SL, Contu S, Lysenko I, Senior RA, et al. (2015). Global effects of land use on local terrestrial biodiversity. Nature 520:45-50.

92. Novinscak A and Filion M. (2011). Effect of soil clay content on RNA isolation and on detection and quantification of bacterial gene transcripts in soil by quantitative reverse transcription-PCR. Appl Environ Microbiol 77:6249-6252.

93. Ofori F, Stern WR. (1987). Cereal-legume intercropping systems. Adv Agron 41:4190.

94. Oh DH, Marshall DL. (1996). Monolaurin and acetic acid inactivation of Listeria monocytogenes attached to stainless steel. J Food Prot 59:249-252.

95. Overbeek R, Olson R, Pusch GD, Olsen GJ, Davis JJ, Disz T, et al. (2014). The SEED and the Rapid Annotation of microbial genomes using Subsystems Technology (RAST). Nucleic Acids Res 42:D206-214.

96. Pan Y, Cassman N, de Hollander M, Mendes LW, Korevaa, H, Geerts RH, et al. (2014). Impact of long-term N, P, K, and NPK fertilization on the composition and 
potential functions of the bacterial community in grassland soil. FEMS Microbiol Ecol 90:195-205.

97. Pankratov TA, Tindall BJ, Liesack W, Dedysh SN. (2007). Mucilaginibacter paludis gen. nov., sp. nov. and Mucilaginibacter gracilis sp. nov., pectin-, xylan- and laminarin-degrading members of the family Sphingobacteriaceae from acidic Sphagnum peat bog. Int J Syst Evol Microbiol 57:2349-2354.

98. Patra AK, Le Roux X, Grayston SJ, Loiseau P, Louault F. (2008). Unraveling the effects of management regime and plant species on soil organic carbon and microbial phospholipid fatty acid profiles in grassland soils. Bioresour Technol 99:3545-3551.

99. Paul EA. (2014). Soil microbiology, ecology and biochemistry. Academic press: Oxford.

100. Petersen U, Wrage N, Köhler L, Leuschner C, Isselstein J. (2012). Manipulating the species composition of permanent grasslands - a new approach to biodiversity experiments. Basic Appl Ecol 13:1-9.

101. Prosser J, Jansson JK, Liu W-T. (2010). Nucleic-acid-based characterization of community structure and function. In: Liu W-T, Jannson JK (eds). Environmental Molecular Microbiology. Caister Academic Press: Norfolk, 63-86.

102. Quadt-Hallmann A, Kloepper J, Benhamou N. (1997). Bacterial endophytes in cotton: mechanisms of entering the plant. Can J Microbiol 43:577-582.

103. Ralphs MH, Cook D, Gardener DR, Grum DS. (2011). Transmission of locoweed endophyte to the next generation of plants. Fungal Ecol 4:251-255.

104. Ramirez KS, Craine JM, Fierer N. (2010). Nitrogen fertilization inhibits soil microbial respiration regardless of the form of nitrogen applied. Soil Biol Biochem 42:23362338 .

105. Ramirez KS, Craine JM, Fierer N. (2012). Consistent effects of nitrogen amendments on soil microbial communities and processes across biomes. Global Change Biol 18:1918-1927.

106. Rauber R, Schmidtke K, Kimpel-Freund H. (2000). Konkurrenz und Ertragsvorteile in Gemengen aus Erbsen (Pisum sativum L.) und Hafer (Avena sativa L.). J Agron Crop Sci 185:33-47.

107. Reinhold-Hurek B, Hurek T. (1998). Life in grasses: diazotrophic endophytes. Trends Microbiol 6:139-144. 


\section{GENERAL REFERENCES}

108. Röske I, Sabra W, Nacke H, Daniel R, Zeng A-P, Antranikian G, et al. (2014). Microbial community composition and dynamics in high-temperature biogas reactors using industrial bioethanol waste as substrate. Appl Microbiol Biot 98:9095-9106.

109. Sagova-Mareckova M, Cermak L, Novotna J, Plhackova K, Forstova J and Kopecky J. (2008). Innovative methods for soil DNA purification tested in soils with widely differing characteristics. Appl Environ Microbiol 74:2902-2907.

110. Sayer EJ, Wagner M, Oliver AE, Pywell RF, James P, Whiteley AS, et al. (2013). Grassland management influences spatial patterns of soil microbial communities. Soil Biol Biochem 61:61-68.

111. Scavino AF, Ji Y, Pump J, Klose M, Claus P, Conrad R. (2013). Structure and function of the methanogenic microbial communities in Uruguayan soils shifted between pasture and irrigated rice fields. Environ microbiol 15:2588-2602.

112. Schall P, Ammer C. (2013). How to quantify forest management intensity in Central European forests. Eur J For Res 132:379-396.

113. Schneider D, Arp G, Reimer A, Reitner J, Daniel R. (2013). Phylogenetic analysis of a microbialite-forming microbial mat from a hypersaline lake of the Kiritimati atoll, Central Pacific. Plos One 8:e66662.

114. Schneider D, Engelhaupt M, Allen K, Kurniawan S, Krashevska V, Heinemann M, et al. (2015). Impact of lowland rainforest transformation on diversity and composition of soil prokaryotic communities in Sumatra (Indonesia). Front Microbiol 6:1339.

115. Seghers D, Wittebolle L, Top EM, Verstraete W, Siciliano SD. (2004). Impact of agricultural practices on the Zea mays L. endophytic community. Appl Environ Microbiol 70:1475-1482.

116. Selvam A, Tsai SH, Liu CP, Chen IC, Chang CH, Yang SS. (2010). Microbial communities and bacterial diversity of spruce, hemlock and grassland soils of Tatachia Forest, Taiwan. J Environ Sci Health B 45:386-398.

117. Sessitsch A, Reiter B, Pfeifer U, Wilhelm E. (2002). Cultivation-independent population analysis of bacterial endophytes in three potato varieties based on eubacterial and Actinomycetes-specific PCR of 16S rRNA genes. FEMS Microbiol Ecol 39:23-32.

118. Siddiqui I, Shaukat S. (2003). Endophytic bacteria: prospects and opportunities for the biological control of plant-parasitic nematodes. Nematol Mediterr 31:111-120. 
119. Siira-Pietikäinen A, Pietikäinen J, Fritze H, Haimi J. (2001). Short-term responses of soil decomposer communities to forest management: clear felling versus alternative forest harvesting methods. Can J For Res 31:88-99.

120. Sikorski J. (2015). The prokaryotic biology of soil. Soil Org 87:1-28.

121. Simon C, Wiezer A, Strittmatter AW, Daniel R. (2009). Phylogenetic diversity and metabolic potential revealed in a glacier ice metagenome. Appl Environ Microbiol 75:7519-7526.

122. Somers E, Vanderleyden J, Srinivasan M. (2004). Rhizosphere bacterial signalling: a love parade beneath our feet. Crit Rev Microbiol 30:205-240.

123. Song Y, Marschner P, Li L, Bao X, Sun J, Zhang F. (2007a). Community composition of ammonia-oxidizing bacteria in the rhizosphere of intercropped wheat (Triticum aestivum L.), maize (Zea mays L.), and faba bean (Vicia faba L.). Biol Fertil Soils 44:307-314.

124. Steenwerth KL, Jackson LE, Calderón FJ, Stromberg MR, Scow KM. (2002). Soil microbial community composition and land use history in cultivated and grassland ecosystems of coastal California. Soil Biol Biochem 34:1599-1611.

125. Strickland MS, Lauber C, Fierer N, Bradford MA. (2009). Testing the functional significance of microbial community composition. Ecology 90:441-451.

126. Stursová M, Zifčáková L, Leigh MB, Burgess R, Baldrian P. (2012). Cellulose utilization in forest litter and soil: identification of bacterial and fungal decomposers. FEMS Microbiol Ecol 80:735-746.

127. Sturz A, Christie B, Matheson B, Nowak J. (1997). Biodiversity of endophytic bacteria which colonize red clover nodules, roots, stems and foliage and their influence on host growth. Biol Fertil Soils 25:13-19.

128. Tardy V, Spor A, Mathieu O, Lévèque J, Terrat S, Plassart P, et al. (2015). Shifts in microbial diversity through land use intensity as drivers of carbon mineralization in soil. Soil Biol Biochem 90:204-213.

129. Tebbe CC, Vahjen W. (1993). Interference of humic acids and DNA extracted directly from soil in detection and transformation of recombinant DNA from bacteria and a yeast. Appl Environ Microb 59:2657-2665.

130. Thoms C, Gattinger A, Jacob M, Thomas FM, Gleixner G. (2010). Direct and indirect effects of tree diversity drive soil microbial diversity in temperate deciduous forest. Soil Biol Biochem 42:1558-1565. 


\section{GENERAL REFERENCES}

131. Thomson BC, Tisserant E, Plassart P, Uroz S, Griffiths RI, Hannula SE, et al. (2015). Soil conditions and land use intensification effects on soil microbial communities across a range of European field sites. Soil Biol Biochem 88:403-413.

132. Tittensor DP, Walpole M, Hill SL, Boyce DG, Britten GL, Burgess ND, et al. (2014). A mid-term analysis of progress toward international biodiversity targets. Science 346:241-244.

133. Torsvik V, Goksøyr J, Daae FL. (1990). High diversity in DNA of soil bacteria. Appl Environ Microbiol 56:782-787.

134. Uchitel A, Omacini M, Chaneton EJ. (2011). Inherited fungal symbionts enhance establishment of an invasive annual grass across successional habitats. Oecologia 165:465-475.

135. Upchurch R, Chiu C-Y, Everett K, Dyszynski G, Coleman DC, Whitman WB. (2008). Differences in the composition and diversity of bacterial communities from agricultural and forest soils. Soil Biol Biochem 40:1294-1305.

136. Urbanová M, Šnajdr J, Baldrian P. (2015). Composition of fungal and bacterial communities in forest litter and soil is largely determined by dominant trees. Soil Biol Biochem 84:53-64.

137. Urich T, Lanzén A, Stokke R, Pedersen RB, Bayer C, Thorseth IH, et al. (2014). Microbial community structure and functioning in marine sediments associated with diffuse hydrothermal venting assessed by integrated meta-omics. Environ Microbiol 16:2699-2710.

138. Uroz S, Turpault MP, Delaruelle C, Mareschal L, Pierrat JC, Frey-Klett P. (2011). Minerals Affect the Specific Diversity of Forest Soil Bacterial Communities. Geomicrobiol J 29:88-98.

139. Vorholt JA. (2012). Microbial life in the phyllosphere. Nat Rev Microbiol 10:828-840. Walker TS, Bais HP, Grotewold E, Vivanco JM. (2003). Root exudation and rhizosphere biology. Plant Physiol 132:44-51.

140. Walker TS, Bais HP, Grotewold E, Vivanco JM. (2003). Root exudation and rhizosphere biology. Plant Physiol 132:44-51.

141. Wang Y, Marschner P, Zhang F. (2012). Phosphorus pools and other soil properties in the rhizosphere of wheat and legumes growing in three soils in monoculture or as a mixture of wheat and legume. Plant Soil 354:283-298. 
142. Watt M, Hugenholtz P, White R, Vinall K. (2006). Numbers and locations of native bacteria on field-grown wheat roots quantified by fluorescence in situ hybridization (FISH). Environ Microbiol 8:871-884.

143. Wemheuer B, Taube R, Akyol P, Wemheuer F, Daniel R. (2013). Microbial diversity and biochemical potential encoded by thermal spring metagenomes derived from the Kamchatka Peninsula. Archaea 2013:136714.

144. Wemheuer B, Güllert S, Billerbeck S, Giebel HA, Voget S, Simon M, et al. (2014). Impact of a phytoplankton bloom on the diversity of the active bacterial community in the southern North Sea as revealed by metatranscriptomic approaches. FEMS Microbiol Ecol 87:378-389.

145. Wemheuer F, Wemheuer B, Kretzschmar D, Pfeiffer B, Herzog S, Daniel R, et al. (2016). Impact of grassland management regimes on bacterial endophyte diversity differs with grass species. Lett Appl Microbiol 62:323-329.

146. Will C, Thürmer A, Wollherr A, Nacke H, Herold N, Schrumpf M, et al. (2010). Horizon-specific bacterial community composition of German grassland soils, as revealed by pyrosequencing-based analysis of $16 \mathrm{~S}$ rRNA genes. Appl Environ Microbiol 76:6751-6759.

147. Wüst PK, Nacke H, Kaiser K, Marhan S, Sikorski J, Kandeler E, et al. (2016). Estimates of soil bacterial ribosome content and diversity are significantly affected by the nucleic acid extraction method employed. Appl Environ Microbiol 82:2595-2607.

148. Yeates GW, Bardgett RD, Cook R, Hobbs PJ, Bowling PJ, Potter JF. (1997). Faunal and microbial diversity in three welsh grassland soils under conventional and organic management regimes. J Appl Ecol 34:453-470. 
CHAPTER VI

APPENDIX 


\section{APPENDIX}

\section{ACKNOWLEDGEMENTS}

This thesis would not have been possible without the faith, believe and support of a lot of people along the way.

First of all, thanks should go to Prof. Dr. Rolf Daniel. Thank you for providing me with the opportunity to write my $\mathrm{PhD}$ thesis under your supervision within this interesting, challenging field of research, and thank you for your continuous support and encouragement.

I am also very grateful to PD Dr Michael Hoppert, for accepting the co-reference for this thesis and the constructive discussions within my thesis committee meetings.

I would like to thank Prof. Dr. Stefan Scheu, who also accompanied my $\mathrm{PhD}$ as a valuable member of my thesis committee. Additional thanks go to the other members of my examination board, for their time and effort: Prof. Dr. Kai Heimel, Prof Dr. Stefan Vidal and Prof. Dr. Stefanie Pöggeler.

I am deeply thankful toward my two supervisors Heiko and Bernd. Heiko introduced me into the field of microbial ecology and was always amazingly patient and helpfull, especially when I first ventured into data analysis and was confronted with analyses I had no idea of. Thank you so much for your support in the beginning and throughout the time until the bitter end :-) Bernd, you told me mostly everything I know about bioinformatics, microbial ecology analyses and statistics - and R (my secret love). I know I wasn't an easy student - but I am sincerely grateful for all your time, help, all our discussions, all I was able to learn from you and that you continued to support me, no matter what. Thank you so very much.

I would like to thank Vera Korolkov, who wrote her master thesis under my supervision and contributed to the results of this thesis, for her motivated work. Additionally, I would like to thank my other students Carl Foest, who also finished his master thesis under my supervision, and Ines Friedrich, whose Bachelor thesis was also partly supervised by me. You've been such a pleasure to work with!

Further thanks should go to all co-authors of the manuscripts presented in this thesis, for corrections, thoughts and valuable discussion! I am especially grateful for Franzi's amazing support - in proof-reading manuscripts as well as providing me with the opportunity to work on some of her interesting projects. Thank you so much for everything!

My colleagues are the people I am most grateful for. We do not really have a 'working' atmosphere in our deparment, but rather a friendly one and I do not consider you my colleagues, but rather my friends, and I mean it. During my time in the lab and office, a lot of people came and went. I am very happy to have had the chance to meet and get to know every single one of you. Special thanks go to Dr. Silja Brady and Dr. Dominik Schneider, who 


\section{APPENDIX}

always had an open ear and offered their support whenever necessary and also to Dr. Robert Hertel. My fellow PhD students were amazing - Sarah, Amelié, Mingji, Genis, Randy, Richard and Simone - I can't believe what we've been through together, and that my PhD time is really over now. Thank you so much - I know that without your support and your friendship everything would have been so much harder! Thanks also go to Mechthild and Melanie, for keeping up order in the laboratories and preventing scientific anarchy from taking over ; ) Thanks to our amazing students - Dirk, Katha, Tobi, Katrina, Tim, Till, Lizzy, Inka, Karo, Karl, David, Caro, Jörn (to name just a few) and our visitors from abroad: Alejandra, Katia, Miguel, Monica - you made the department a happy and colorful place!

I would also like to thank all the other people of our AG (present as well as gone), because you all contributed to making the department a place I really enjoyed to work at. Thanks to Jaqueline, Florian, Marvin, Andreas, Anja, Sonja, Sonja, Jörg, Kathleen and especially Frauke and Andrea, who did the sequencing. Thanks also to the office ladies Petra and Daniela, for their help and patience. I am really grateful for the time within the AG and all the amazing trips and BBQs we shared.

Finally, I would like to thank those people, who were not directly involved with this thesis and whose support therefore means even more to me. First of all I would like to thank all of my friends because they had to endure the one or other talk I gave upon the topic of my $\mathrm{PhD}$, for listening to my hopes and fears and for somehow always being able to put me back on solid ground and keep me going. Special thanks to Sarah and Tobi - you know why.

I am very thankful that I had my dog Jax with me during the last month of this thesis. $\mathrm{He}$ definitely kept me from going insane at the one or other point. He also always reminded me that there is more to life than just work, and sometimes, you just have to be thankful and happy because of the little things in life.

Of course this thesis would not have been possible without the support of my family. Despite my 'professional' ups and downs, we had some personal ups and downs to conquer - and we did. Thank you for always being there for me and thank you so much for your unconditional believe in me, even when I had temporarily lost it. You have made me the person I am today, and I am so proud to be your daughter, granddaughter and sister.

Finally, I would like to thank you, Fabian. You are the most amazing person I ever met and I am so infinitely thankful that I did. You really are my sunshine, when days are greys. You keep me up when I'm feeling down - and this thesis is as much your success as it is mine, because I would never have pulled it through until the end without your support. So thank you for being there for me, always, in every circumstance, at any time, everywhere, unconditionally. Thank you for believing in me. I love you. 
'There is no formula for success except, perhaps, an unconditional acceptance of life and what it brings.'

- Arthur Rubinstein 


\section{CURRICULUM VITAE}

Name: $\quad$ Kristin Kaiser

Date of Birth: $\quad 2^{\text {nd }}$ March, 1987

Place of Birth: $\quad$ Melsungen, Germany

\section{Education}

Since 06/2012 Georg-August-University Göttingen, Germany

$\mathrm{PhD}$ thesis at the Department of Genomic and Applied Microbiology at the Institute of Microbiology and Genetics

Topic: Dependence of soil microbial community structure and function on land use types and management regimes. (as part of the German Biodiversity Exploratories)

10/2009 - 03/2012 Georg-August-University Göttingen, Germany

Master of Science program „Microbiology and Biochemistry“

Master thesis: Functional and phylogenetic analyses of soil microbial communities derived from the German Biodiversity Exploratory Hainich.

10/2006 - 09/2009 Georg-August-University Göttingen, Germany

Biology in the Bachelor of Science program

Bachelor thesis: The influence of transcription onto the reversion of the gudB-allele in Bacillus subtilis (Der Einfluss der Transkription auf die Reversion des gudB-Allels in Bacillus subtilis)

$2003-2006$

Secondary school, Geschwister-Scholl Schule in Melsungen, Germany Qualification: A levels

1999 - 2003 Secondary school, Gymnasium at the Gesamtschule in Melsungen, Germany

1997 - $1999 \quad$ Transition stage, Gesamtschule in Melsungen, Germany

1993 - $1997 \quad$ Primary school in Melsungen, Germany

Practical experiences 


\section{APPENDIX}

2010

2010

2011

$2012-2013$

2013
Supervision of Microbiology practical courses for bachelor students

Labrotation, Institute for Microbiology and Genetics, General Microbiology, Structural and functional analysis of microbial consortia

Labrotation, Institute for Microbiology and Genetics, General and Applied microbiology, Cloning and heterologous expression of putative cellulase genes

Supervision of Master Thesis 'Metagenomics of Deadwood' (by Carl Foest)

Supervision of Master Thesis 'Assessment and exploitation of bacterial and functional diversity in soils of the Biodiversity Exploratory Hainich` (by Vera Korolkov)

\section{Scientific Meetings and Method Courses}

$4^{\text {th }}$ International Congress of the European Soil Sciences Societies Eurosoil 2012, Bari, Italy

$10^{\text {th }}$ Annual Assembly of the German Biodiversity Exploratories, Mainz, Germany

2013

Annual Conference of the Association for General and Applied Microbiology (VAAM), Bremen, Germany $2^{\text {nd }}$ International Thünen Symposium on Soil Metagenomics, Workshop on Bioinformatic tools for soil microbiologists, Braunschweig, Germany

Workshop on SEM modeling, Agroecology department, University of Göttingen 


\section{APPENDIX}

\section{LIST OF PUBLICATIONS}

Wüst P, Nacke H, Kaiser K, Marhan S, Sikorski J, Kandeler E, et al. (2016). Estimates of the bacterial ribosome content and diversity in soils are significantly affected by different nucleic acid extraction methods. Appl Environ Microb 82:2595-2607.

Kaiser K, Wemheuer B Korolkov V, Wemheuer F, Nacke H, Schöning I, et al. (2016). Driving forces of soil bacterial community structure, diversity, and function in temperate grassland and forests. Sci Rep 6:33696; doi: 10.1038/srep33696. 


\section{THESIS DECLARATIONS}

\section{Declaration of plagiarism}

I hereby confirm that I have written this doctoral thesis independently. I have not used other sources or facilities others than the ones mentioned in the chapters. Moreover, I have not used unauthorized assistance and have not submitted this thesis previously in any form for another degree at any institution or university.

\section{Kristin Kaiser}

Göttingen, May 2016 